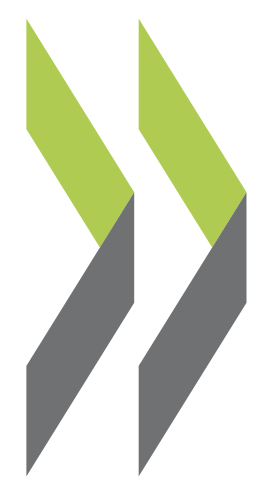

OECD Social, Employment and Migration Working Papers No. 75

\title{
Activation Policies in Ireland
}

\section{David Grubb,}

Shruti Singh,

Peter Tergeist

https://dx.doi.org/10.1787/227626803333 
Organisation de Coopération et de Développement Économiques

Organisation for Economic Co-operation and Development

08-Jan-2009

DIRECTORATE FOR EMPLOYMENT, LABOUR AND SOCIAL AFFAIRS

English text only

EMPLOYMENT, LABOUR AND SOCIAL AFFAIRS COMMITTEE

OECD SOCIAL, EMPLOYMENT AND MIGRATION WORKING PAPERS NO. 75

ACTIVATION POLICIES IN IRELAND

David Grubb, Shruti Singh and Peter Tergeist

JEL Classification: H53, H83, I38, J08, J63, J65, J68.

All Social, Employment and Migration Working Papers are now available through OECD's Internet website at http://www.oecd.org/els

JT03258009

Document complet disponible sur OLIS dans son format d'origine

Complete document available on OLIS in its original format 


\title{
DIRECTORATE FOR EMPLOYMENT, LABOUR AND SOCIAL AFFAIRS
}

\author{
http://www.oecd.org/els
}

\section{OECD SOCIAL, EMPLOYMENT AND MIGRATION WORKING PAPERS}

\author{
http://www.oecd.org/els/workingpapers
}

This series is designed to make available to a wider readership selected labour market, social policy and migration studies prepared for use within the OECD. Authorship is usually collective, but principal writers are named. The papers are generally available only in their original language - English or French - with a summary in the other.

Comment on the series is welcome, and should be sent to the Directorate for Employment, Labour and Social Affairs, 2, rue André-Pascal, 75775 PARIS CEDEX 16, France.

The opinions expressed and arguments employed here are the responsibility of the author(s) and do not necessarily reflect those of the OECD

\author{
Applications for permission to reproduce or translate \\ all or part of this material should be made to: \\ Head of Publications Service \\ OECD \\ 2, rue André-Pascal \\ 75775 Paris, CEDEX 16 \\ France
}

Copyright OECD 2009 


\section{ACKNOWLEDGEMENTS}

David Grubb and Peter Tergeist are economists in the Employment Analysis and Policies Division at the OECD Directorate for Employment, Labour and Social Affairs, and Shruti Singh is an economist on secondment to the OECD from the UK Department of Work and Pensions (DWP). They prepared this review under the supervision of the head of division, Stefano Scarpetta.

The authors met staff in a number of Irish institutions central to this study on a mission in November 2007. Comments on an earlier draft of the report were provided by the authorities in October 2008. The authors extend their thanks to many people particularly in FÁS who explained their work and provided information, to the DETE which supported this work and organised the mission visits, to the DSFA for advice given during meetings with the review team and subsequently and comments on the Summary and Recommendations, and to a number of others for their contributions to the content and preparation of the report. 

DELSA/ELSA/WD/SEM(2009)01

\section{SUMMARY}

The Irish economy doubled in size during the 1990s, and still achieved the fastest growth in the OECD area during the first half of the 2000s. Economic growth was accompanied by a major improvement in labour market conditions. Survey unemployment declined from over $16 \%$ of the labour force in the 1980 s to $4.5 \%$, below the OECD average, in 2007. The share of long-term unemployment in total unemployment declined from two-thirds in 1990 to $30 \%$ in 2007.

However, vacancies and employment expectations in the construction sector fell sharply throughout 2007. In 2008 the economic slowdown spread through the economy and by November the Live Register, Ireland's administrative register of unemployment benefit and credit claimants, was $107000(66 \%)$ above levels a year earlier. A critical issue for Ireland's social and economic future is whether the labour market enjoys a full cyclical recovery or returns to the persistently depressed conditions of the 1980s and early 1990s. Recession overburdens all parts of the labour market policy administration, and negatively affects programme outcomes, so it can be argued that this is not the right time to think of changing institutional arrangements or extend the target groups for activation measures. However, this report focuses mainly on structural and administrative factors which exert influence throughout the cycle. It contributes to policy debate, development and planning, which in any case sometimes take years before full roll-out in day-to-day operations, and are not less urgent now.

In Ireland the placement function of the Public Employment Service (PES) is primarily within FÁS, the Training and Employment Authority, which is supervised by the Department of Enterprise, Trade and Employment (DETE). But employment counselling services are also provided by the "Local Employment Service" (which has partly-separate funding and management arrangements); Facilitators within the Department of Social and Family Affairs (who implement an "Activation Programme", which however lacks participation requirements); and the "Services to the Unemployed" activity within the Local Development Social Inclusion Programme (which is managed through a third Department).

The number of staff in FÁS Employment Services and the Local Employment Service, relative to the number of wage and salary earners in the economy, appears to be relatively low, about half the average level of staffing of institutions responsible for the placement function in Australia and Northern and Western Europe (countries which also have high benefit coverage rates for unemployment). Funding for the PES as a whole including benefit administration, as a percentage of GDP, is also below the average for this group of countries although it is comparable to levels observed in some of them such as Norway or Switzerland. Such statistics should be interpreted with care, because in Ireland placement service staffing depends on which institutions are counted under this heading, and public expenditure is higher as a share of Gross National Income than it is as a share of GDP. Bearing this in caveat in mind, it is clear that the intensification of activation measures would require a refocusing of existing resources and possibly an increase in them.

Since the 1990s a wide range of assistance has been available to the unemployed in terms of labour market programmes (e.g. in-work benefits, job-creation programmes, and training). However, it was generally possible to receive unemployment benefits without registration for placement or any other contact with employment services, or participation in active programmes. A requirement to register with FÁS, the Training and Employment Authority, was introduced for long-term unemployed youths in 1996 and activation principles were extended with the introduction of the National Employment Action Plan 
(NEAP) in 1998. These initiatives, together with increased control activity by the Department of Social Welfare (now DSFA), helped to bring registered unemployment down particularly in the late 1990s. NEAP interviews continue to be almost the only form of quasi-compulsory face-to-face contact with an employment counsellor during a typical unemployment spell, but their frequency averaged across all registered unemployed remains very low, partly because clients are not referred to the NEAP process a second time even in cases of repeat unemployment. DSFA interviews reviewing benefit eligibility, which take place at the $7^{\text {th }}$ and $12^{\text {th }}$ or $15^{\text {th }}$ month of unemployment, appear to be more frequent. DSFA enforcement of availability-for-work requirements for unemployment payments remains only partly effective, because its procedures are not a substitute for regular employment counselling which, whenever possible, refers clients directly to job vacancies.

FÁS manages a range of activities, including training of employed and unemployed workers, jobcreation programmes and "local training initiatives". This range of responsibilities arguably gives FÁS as an organisation a particularly broad understanding of socio-economic issues, ranging from the skill needs of large and small businesses to the problems of drug rehabilitees, remote villages or inner-city housing estates. FÁS management of the training function seems sound: since FÁS also purchases training from outside providers, it is well placed to arbitrage between internal and external provision, although an external audit of this might be useful. FÁS' involvement in running direct job creation schemes, such as Community Employment (CE) and some other initiatives, is perhaps more problematic. Support for funding of this programme partly reflects its popularity with some participant groups and local appreciation of the services it provides, rather than its effectiveness in terms of enforcing mutual obligation principles for benefits or raising participants' rate of transition to unsubsidised employment.

Although the commonly-cited survey figure for unemployment in Ireland in the mid-2000s was below the international average, unemployment benefit recipiency levels have long been unusually high, as compared to the survey figure. From 2002 to 2007 the lowest social welfare rate was substantially increased, relative to average earnings, increasing the risk that the higher recipiency levels emerging in the current recession will take on a structural dimension. In the history of other (mainly European) countries, a political consensus for more intensive activation measures has often arisen only after long years of high unemployment, and Ireland should preferably avoid this scenario.

Owing to growth in recipiency of lone-parent benefits from the early 1980 s to 2000 and in recipiency of incapacity benefits after that, overall working-age benefit-recipiency rates in the mid-2000s were not much different from those in the mid-1980s, despite much lower unemployment. Several large groups lone parents, adult dependents of benefit recipients, and people with disabilities who have remaining work capacity - receive benefits without a formal requirement to be available for work, arrangements which are increasingly out of line with international practice. This is a political choice but caution may also be fostered by a tendency for the implementation of administrative reforms within DSFA to be slow and doubts about whether other institutions are able to adequately support these additional client groups into employment. 


\section{RÉSUMÉ}

L'Irlande a vu la taille de son économie doubler au cours des années 90 et, de tous les pays de l'OCDE, c'est encore elle qui a enregistré la croissance la plus rapide dans la première moitié des années 2000. Cette croissance économique s'est accompagnée d'une très nette amélioration de la situation du marché du travail. D'après les enquêtes, le chômage a reculé passant de plus de $16 \%$ de la population active dans les années 80 à $4.5 \%$ (pourcentage inférieur à la moyenne OCDE) en 2007. La part du chômage de longue durée dans le chômage total, qui était de deux-tiers en 1990, est tombée à 30 \% en 2007.

Toutefois, les offres et les perspectives d'emploi dans le secteur du bâtiment ont connu une baisse spectaculaire tout au long de l'année 2007. En 2008, le ralentissement s'est propagé à l'ensemble de l'économie à tel point qu'en novembre, on dénombrait 107000 inscrits de plus au Live Register (fichier administratif des personnes sollicitant une indemnité de chômage) par rapport à l'année précédente, soit une progression de $66 \%$. La question de savoir si le marché du travail va se redresser complètement, ou s'il est en train de retourner à un état d'atonie persistante des années 80 et début des années 90 est donc cruciale pour l'avenir économique et social de l'Irlande. Le ralentissement surcharge tous les acteurs de la politique du marché du travail et pèse sur les résultats des divers programmes. On peut donc faire valoir qu'il n'est pas opportun de penser à changer les dispositifs institutionnels ou à étendre les mesures d'activation à de nouveaux groupes cibles. Pourtant, ce rapport examine principalement les facteurs administratifs et structurels qui agissent au long de différentes phases de la conjoncture. Il contribue au débat, au développement et à la planification des politiques, qui de toute façon prennent parfois des années à se dérouler pleinement dans les opérations quotidiennes et qui restent urgents.

En Irlande, la fonction de placement du Service public de l'emploi (SPE) est l'apanage de la FÁS (Autorité de la formation et de l'emploi) qui est supervisée par le ministère des Entreprises, du Commerce et de l'Emploi (Department of Enterprise, Trade and Employment - DETE). Mais des prestations de conseil personnalisé en matière d'emploi sont également offertes par un réseau de «Services locaux de l'emploi » (jouissant d'une autonomie partielle sur le plan du financement et de la gestion), des «facilitateurs » au sein du ministère des Affaires sociales et familiales (Department of Social and Family Affairs - DSFA) qui met en œuvre un "programme d'activation» (qui, toutefois, ne comporte pas d'obligation de participer), et par le biais de l'activité dite de «services aux sans-emploi » dans le cadre du Programme d'inclusion sociale par le développement local, géré par un troisième ministère.

Rapporté au nombre de salariés que compte l'économie irlandaise, le nombre d'employés des services pour l'emploi de la FÁS et du réseau de Services locaux de l'emploi semble assez faible : en effet, il équivaut à la moitié environ des effectifs des institutions en charge de la fonction de placement en Australie et dans les pays d'Europe du Nord et de l'Ouest (pays qui affichent aussi des taux de couverture chômage élevés). En pourcentage du PIB, le financement du SPE dans son ensemble, administration des prestations comprise, est également inférieur à la moyenne pour ce groupe de pays, mais similaire aux nivaux observés dans certains comme la Norvège ou la Suisse. Cependant, il convient de se montrer prudent dans l'interprétation de ces statistiques parce qu'en Irlande, le niveau des effectifs des services de placement varie selon les institutions qui sont comptabilisées sous cette rubrique, et que les dépenses publiques sont plus élevées quand elles sont exprimées en part du Revenu national brut que quand elles le sont en part du PIB.

Dès les années 90, les chômeurs avaient à leur disposition une large palette d'aides sous forme de programmes du marché du travail (prestations liées à l'exercice d'un emploi, programme de création d'emplois et formation). Toutefois, il était généralement possible de percevoir des indemnités de chômage sans s'inscrire comme demandeur d'emploi ni avoir quelque contact que ce soit avec les services de l'emploi, 
ni même participer à des programmes actifs. L'obligation de s'enregistrer auprès de la FÁS a été mise en place en 1996 pour les jeunes chômeurs de longue durée, et les principes de l'activation ont été élargis avec l'adoption du Plan national d'action pour l'emploi (NEAP) en 1998. Conjuguée à une intensification des contrôles effectués par le ministère de la Protection sociale (Department of Social Welfare, devenu entretemps ministère des Affaires sociales et familiales - DSFA), ces initiatives ont contribué à faire baisser le chômage inscrit, en particulier à la fin des années 90. Encore aujourd'hui, les entretiens dans le cadre du NEAP sont pratiquement la seule forme de contact face-à-face et quasi-obligatoire avec un conseiller pour l'emploi au cours d'un épisode de chômage type, mais quand on fait la moyenne sur l'ensemble des chômeurs recensés, on voit que la fréquence de ces contacts reste très faible. Ce phénomène tient en partie au fait que les clients ne sont pas invités à s'orienter une deuxième fois vers le dispositif NEAP même dans les cas de chômage récurrent. Les entretiens imposés par le DSFA pour vérifier les droits à prestations, qui ont lieu au cours des $7^{\mathrm{e}}$ et $12^{\mathrm{e}}$ ou $15^{\mathrm{e}}$ mois de chômage, semblent plus fréquents. L'imposition par le DFSA de l'obligation d'être disponible pour le travail si l'on veut bénéficier des prestations de chômage n'est pas encore totalement effective car ses procédures ne remplacent pas les entretiens réguliers avec un conseiller pour l'emploi qui, chaque fois que possible, oriente directement les clients vers les postes vacants.

La FÁS gère un éventail d'activités dont la formation des chômeurs mais aussi des travailleurs pourvus d'un emploi, les programmes de création d'emplois et les « initiatives locales de formation ». Il n'est pas interdit de penser que la diversité de ces attributions permet à la FÁS, en tant qu'organisation, d'avoir une connaissance particulièrement vaste des questions socioéconomiques, depuis les besoins en compétences des grandes et des petites entreprises jusqu'aux problèmes des toxicomanes réadaptés, en passant par les besoins des résidents de villages isolés ou de quartiers d'habitation en centre-ville. La gestion par la FÁS de la fonction de formation paraît saine : comme l'Autorité achète aussi des prestations de formation à des fournisseurs externes, elle est bien placée pour arbitrer entre la fourniture en interne et la fourniture par des prestataires extérieurs bien que, sur ce point, un audit externe puisse apporter des informations utiles. La participation de la FÁS à l'administration de mécanismes de création directe d'emplois comme les emplois de proximité (Community Employment) est peut-être plus problématique. L'aide au financement de ce programme témoigne en partie de sa popularité auprès de certains groupes de participants et de l'appréciation des services fournis à l'échelon local, plutôt que son efficacité en termes d'application des principes d'obligations mutuelles ou de l'augmentation du taux de passage à l'emploi non subventionné parmi les participants.

S'il est vrai que le chiffre du chômage selon les enquêtes, couramment cité, en Irlande au milieu des années 2000 était inférieur à la moyenne internationale, cela fait longtemps que le niveau des effectifs de bénéficiaires d'indemnités de chômage est anormalement élevé par rapport à ce chiffre. Entre 2002 et 2007, le minimum social a été considérablement relevé par rapport aux rémunérations moyennes, augmentant le risque de voir la progression des effectifs d'allocataires qui se profile à l'occasion de la récession actuelle prendre une dimension structurelle. Dans les annales des autres pays (européens, principalement), on voit que, souvent, un consensus politique autour de mesures d'activation plus intensives ne s'est dégagé qu'après de longues périodes de taux de chômage élevé. Il serait préférable que l'Irlande évite cet écueil.

En raison de l'augmentation du nombre de bénéficiaires de l'allocation de parent isolé entre le début des années 80 et l'an 2000 et, par la suite, de l'accroissement du nombre de bénéficiaires de prestations d'invalidité, la proportion globale d'allocataires d'âge actif n'est guère différente de celle observée au milieu des années 80 alors que le chômage est beaucoup plus faible. Plusieurs groupes de taille importante (parents isolés, adultes à charge de bénéficiaires de prestations et personnes handicapées conservant une capacité de travail) perçoivent des prestations sans être obligés dans les règles d'être disponibles pour travailler. Or, ces modalités sont de moins en moins en harmonie avec les pratiques des autres pays. Il s'agit d'un choix politique mais il se peut aussi que les atermoiements soient encouragés par la lenteur de la mise en œuvre des réformes administratives au sein du DFSA et par des doutes quant à savoir si d'autres institutions sont à même d'aider correctement ces groupes de clients supplémentaires à retrouver le chemin de l'emploi. 


\section{TABLE OF CONTENTS}

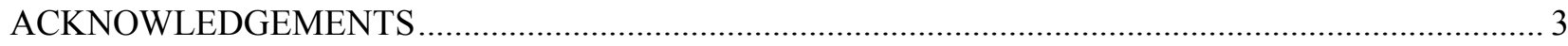

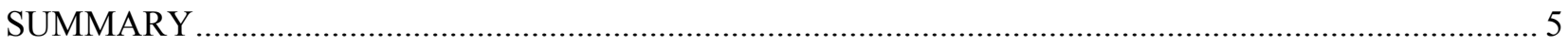

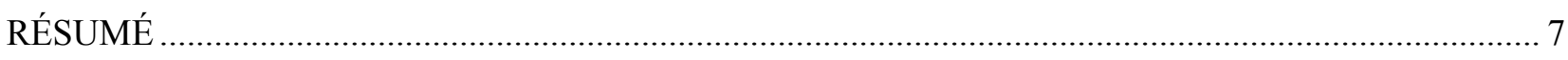

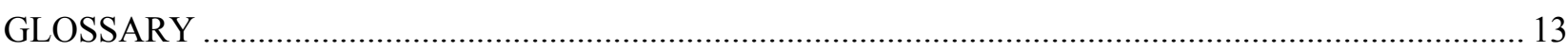

ACTIVATION POLICIES IN IRELAND

CHAPTER 1. THE BACKGROUND TO ACTIVE LABOUR MARKET POLICIES IN IRELAND .... 15

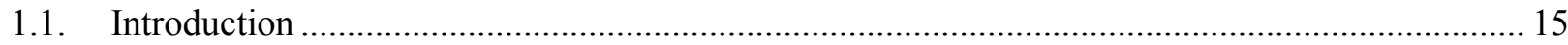

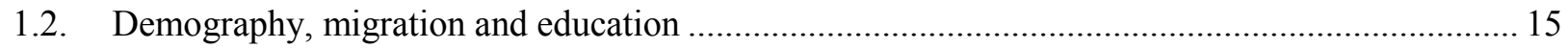

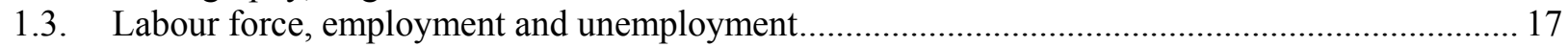

1.4. Government, partnership agreements and national planning ……............................................ 19

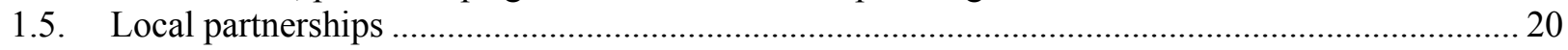

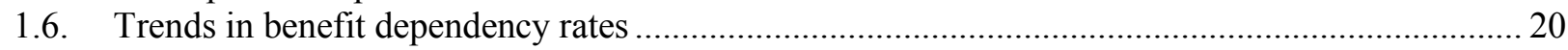

1.7. History of the PES and labour market programmes ............................................................... 22

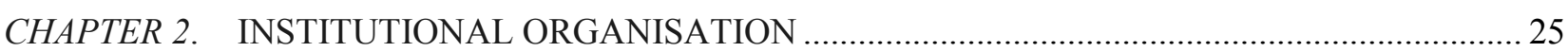

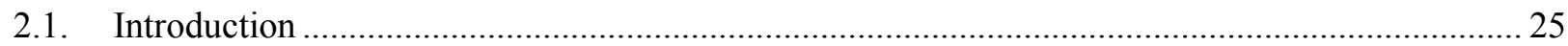

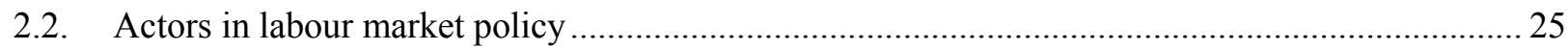

2.3. Main characteristics of the Irish Public Employment Service ….................................................. 30

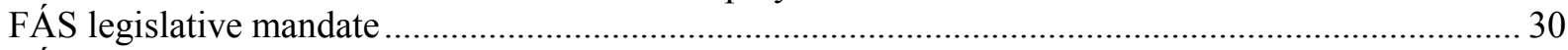

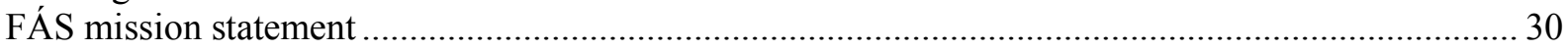

Board structure, social partnership and degree of autonomy.............................................................. 31

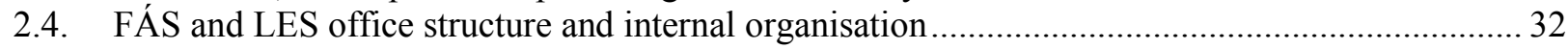

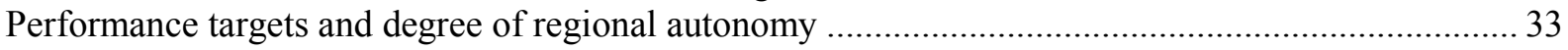

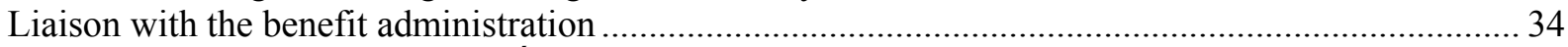

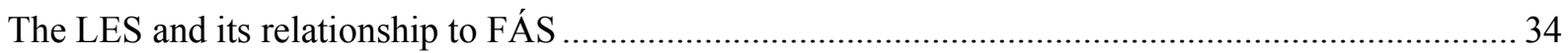

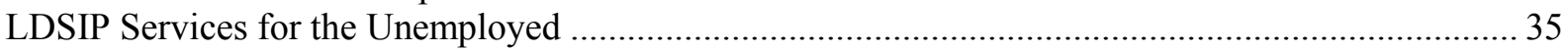

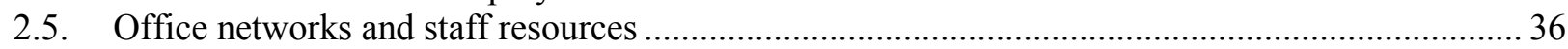

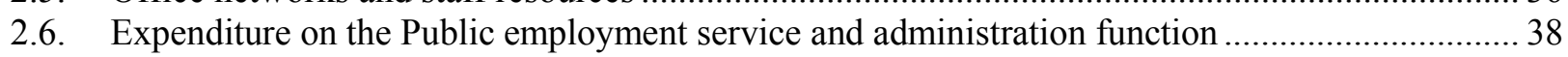

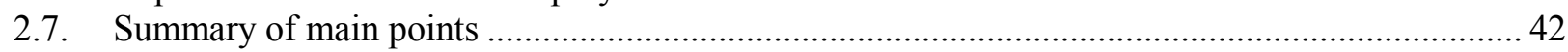

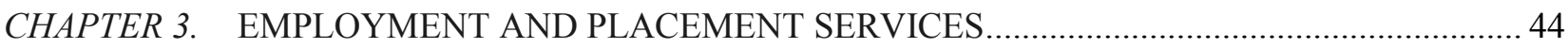

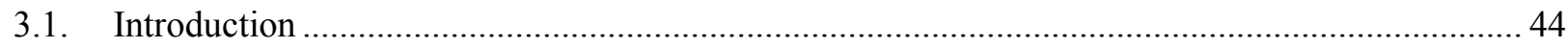

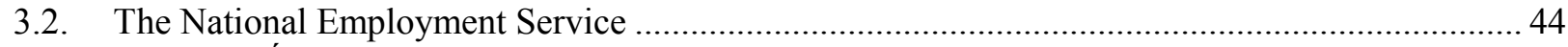

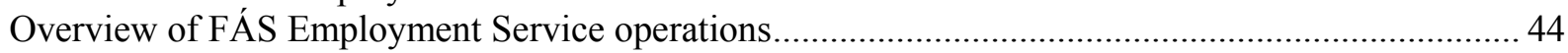

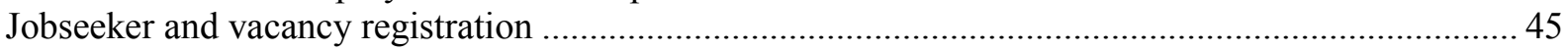

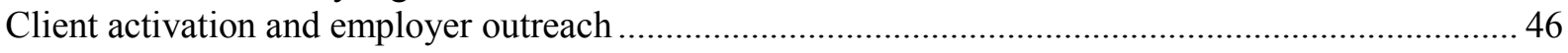

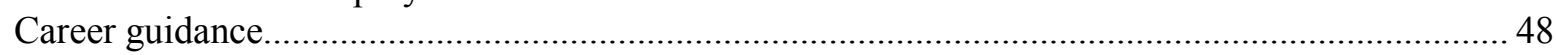

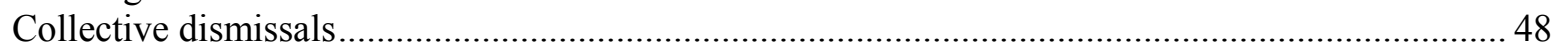

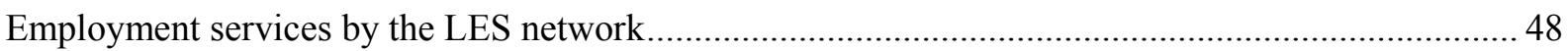

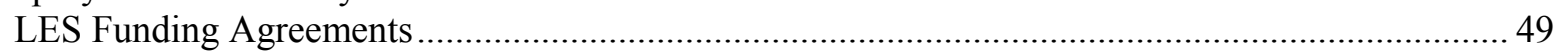

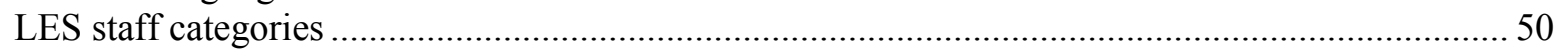

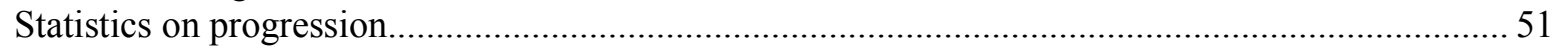




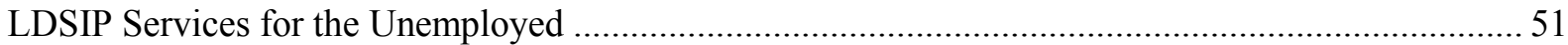

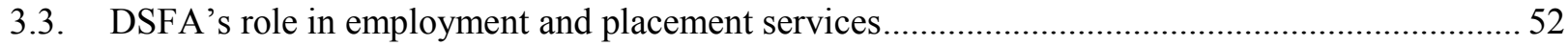

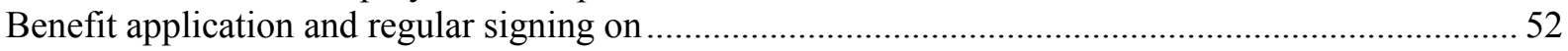

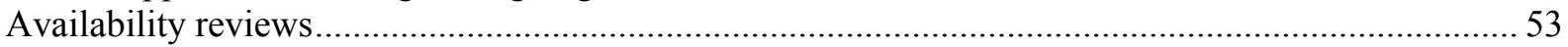

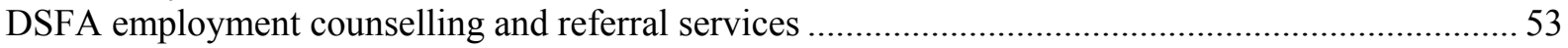

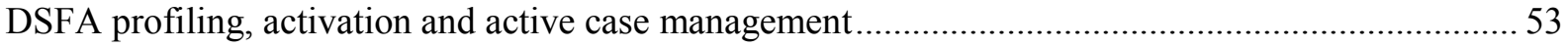

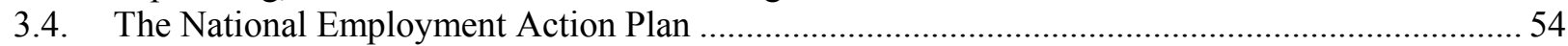

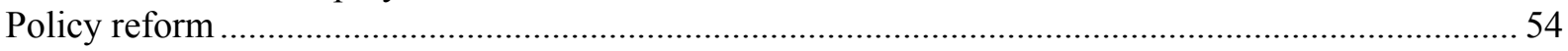

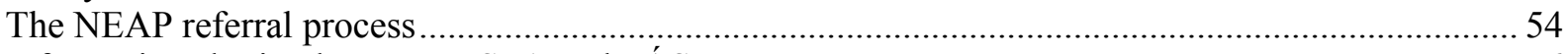

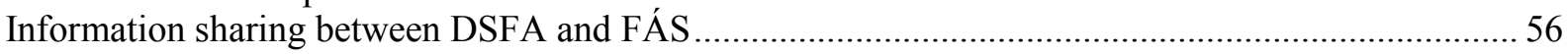

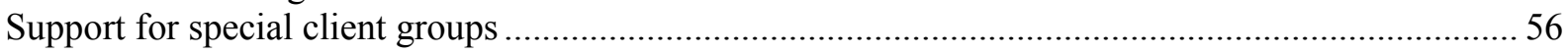

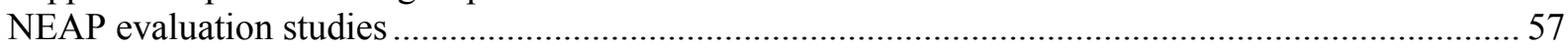

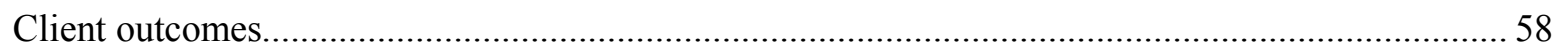

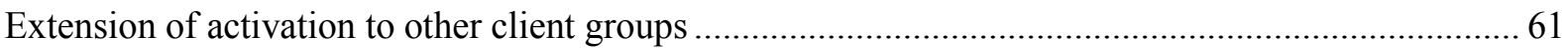

3.5. Quantitative indicators of job-broking activities and labour market penetration .......................... 61

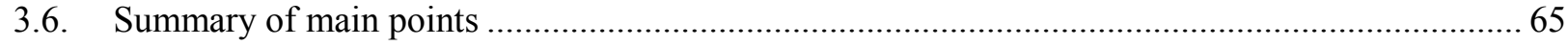

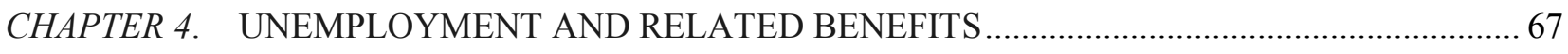

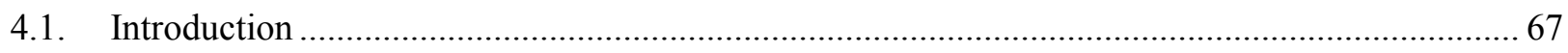

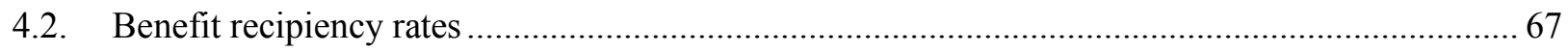

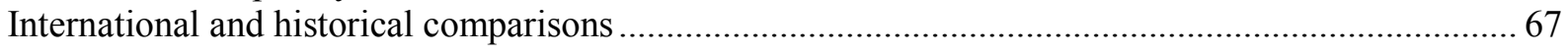

Unemployment benefit recipients and labour force survey unemployment ........................................ 71

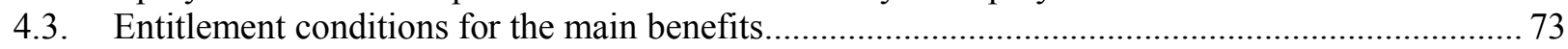

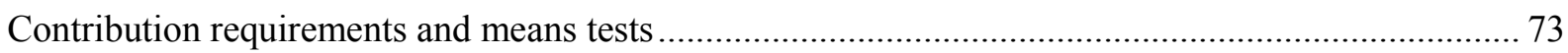

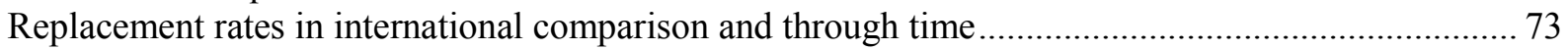

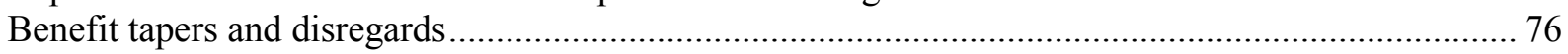

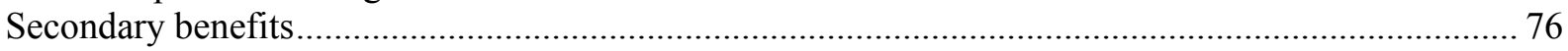

4.4. Unemployment benefit eligibility criteria and their administration ........................................... 77

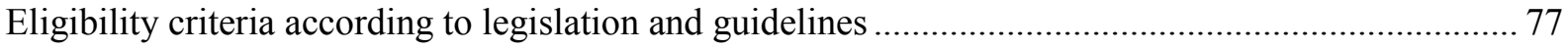

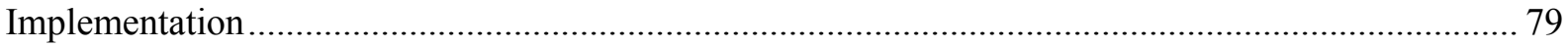

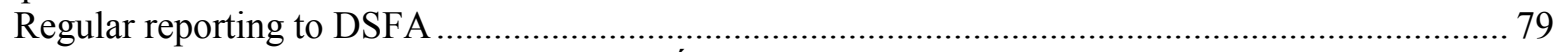

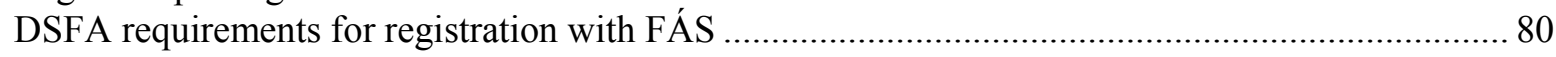

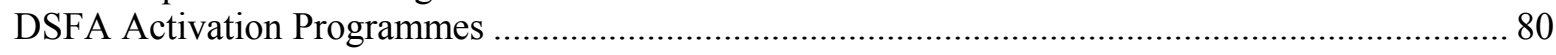

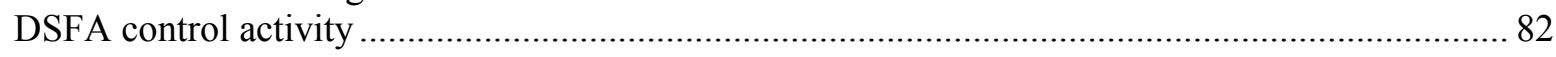

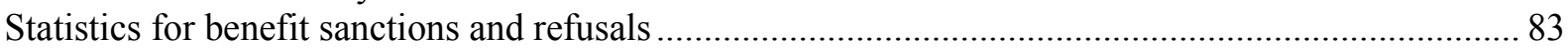

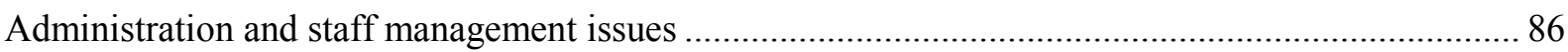

4.5. Reforms of lone-parent and disability payments and the Supplementary Welfare Allowance....... 86

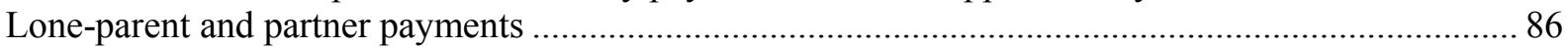

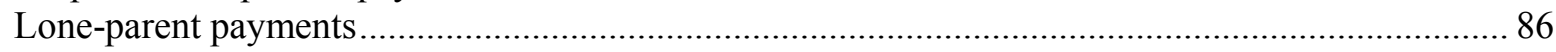

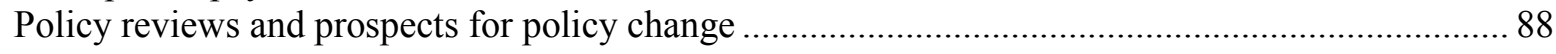

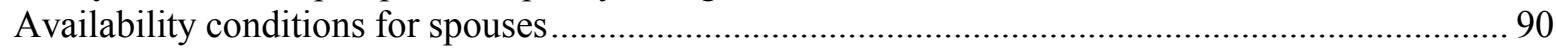

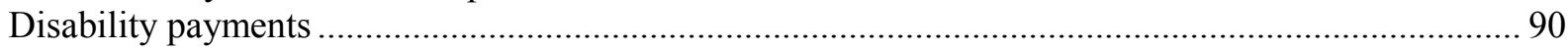

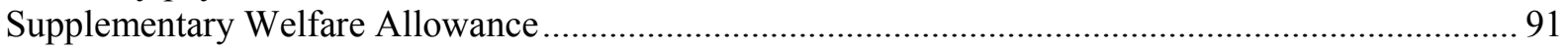

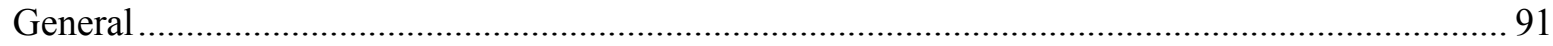

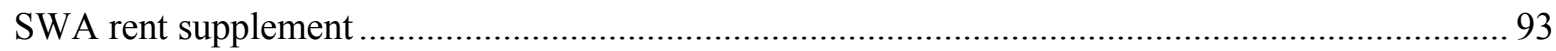

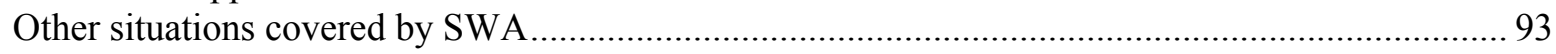

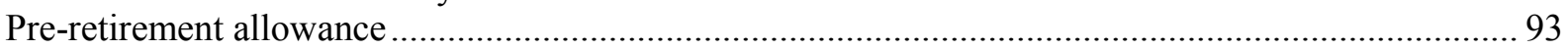

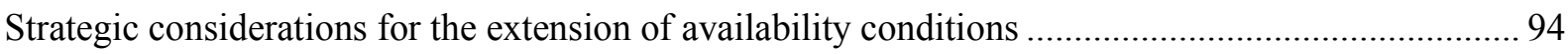

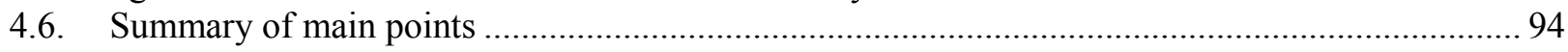


CHAPTER 5. ACTIVE LABOUR MARKET PROGRAMMES.......................................................... 96

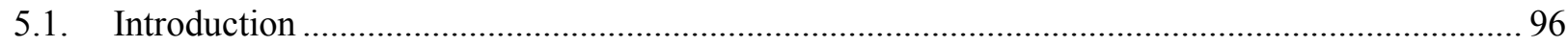

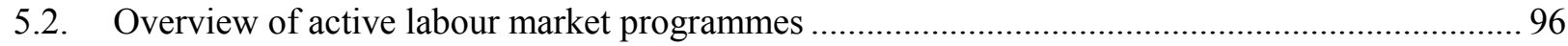

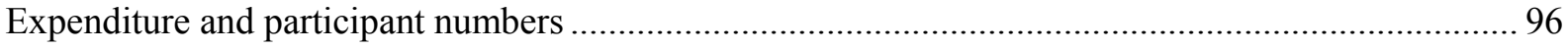

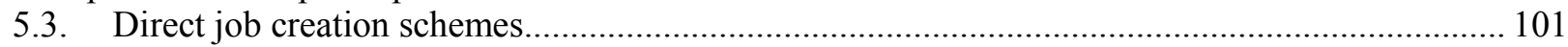

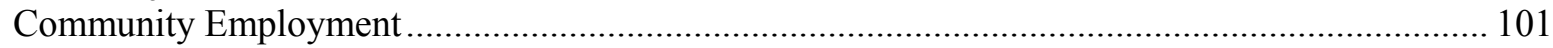

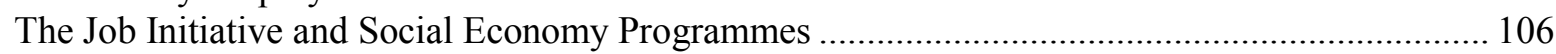

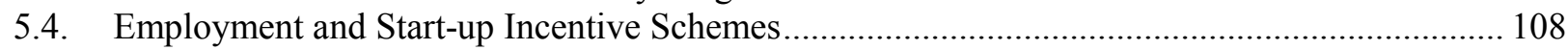

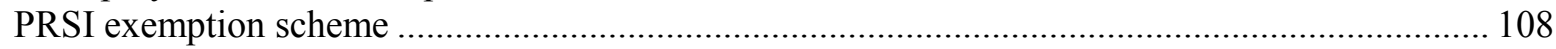

Back to Work Allowance and Back to Work Enterprise Allowance .............................................. 109

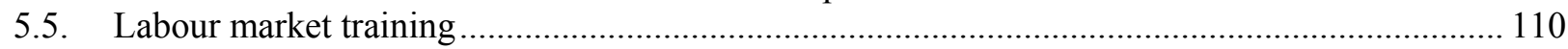

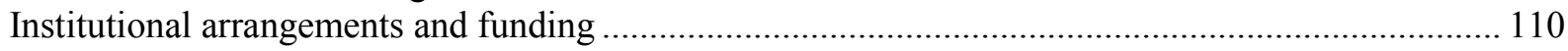

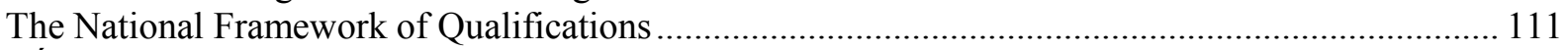

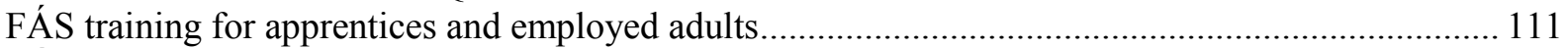

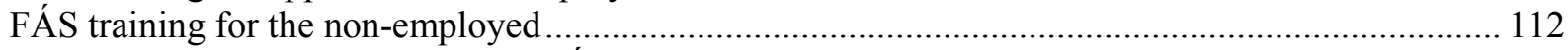

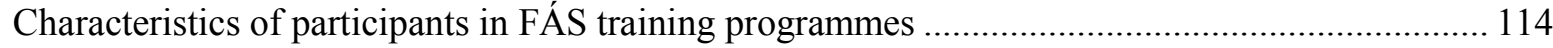

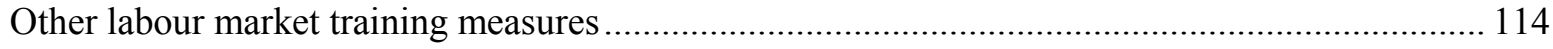

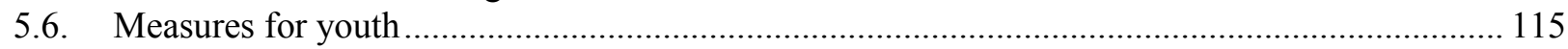

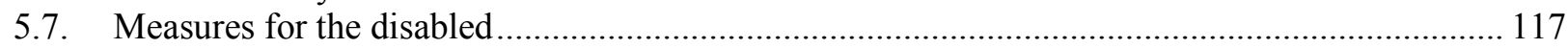

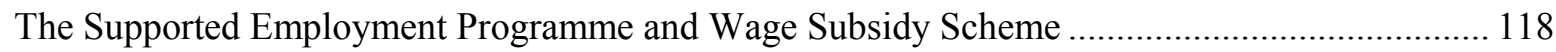

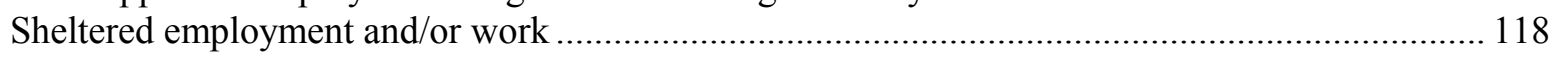

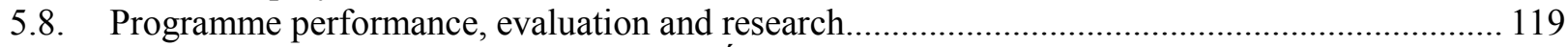

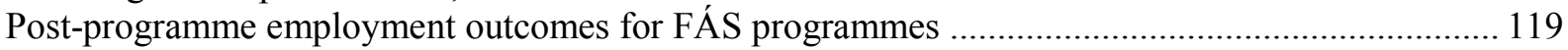

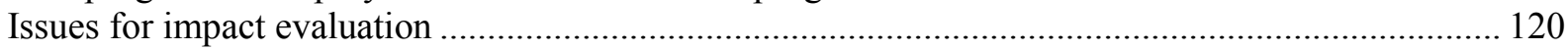

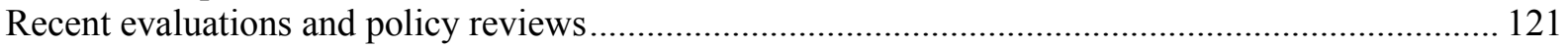

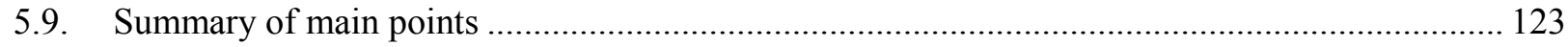

ANNEX 5.A. The cost per participant-year of labour market programmes .......................................... 125

CHAPTER 6. SUMMARY AND RECOMMENDATIONS ........................................................... 128

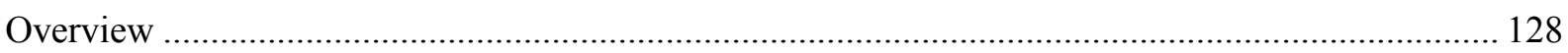

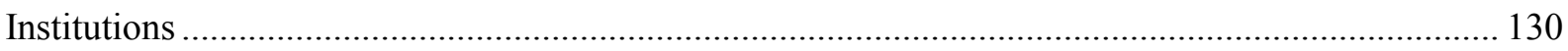

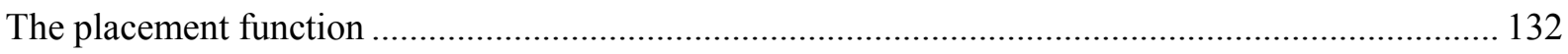

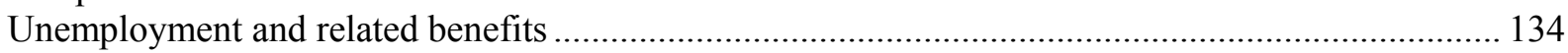

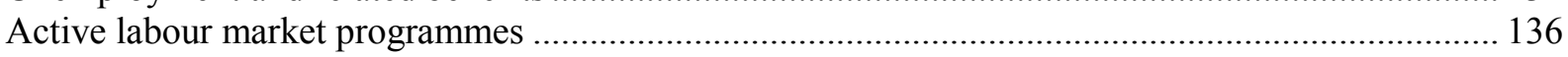

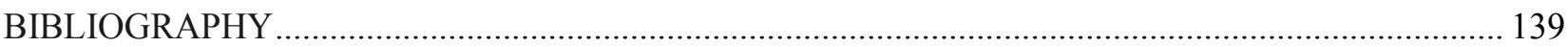

\section{List of Boxes}

Box 2.1. The Local Development Social Inclusion Programme.......................................................... 28

Box 3.1. Services to be provided by Northside Partnership LES ..................................................... 50

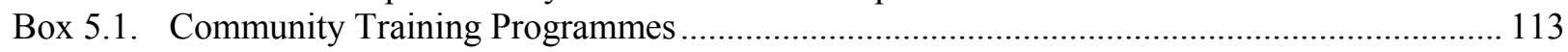

Box 5.2. Mainstreaming of disability services and the transfer of the National Rehabilitation Board.........117

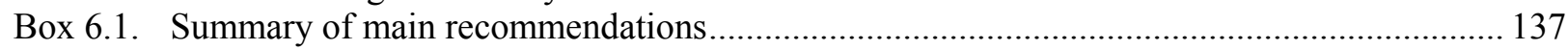




\section{List of Tables}

Table 1.1. Income-replacement benefit recipiency rates for the working-age population, Ireland, 1980-2004

Table 1.2. Spending on active labour market programmes, Ireland, Nordic countries and other OECD areas, 2006.

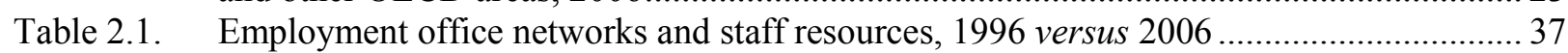

Table 2.2. Estimation of Category 1 Public employment services and administration in OECD data for public expenditure on labour market programmes, 1998-2006 ................................... 40

Table 3.1. Outcomes of NEAP referrals 2003-2007 …..................................................................... 59

Table 3.2. Outcomes for those who did not attend the NEAP interview, 2003-2007 .............................. 59

Table 3.3. Progressions of FÁS interviewees under the NEAP process, 2003-2007 ......................... 60

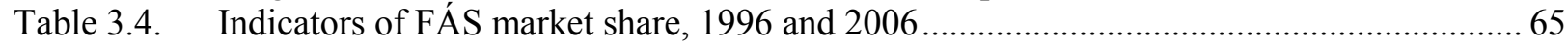

Table 4.1. Recipiency rates for incapacity, unemployment, lone-parent and safety net benefits, Ireland, Australia, New Zealand and United Kingdom, 2000-2007 …............................. 70

Table 4.2. Ratio of the number of unemployment benefit recipients to the number

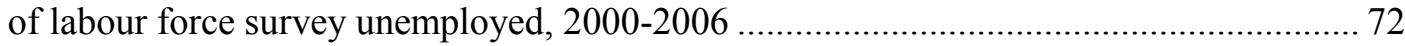

Table 4.3. Unemployment benefit refusals and sanctions, Ireland, 2004-06 ........................................ 84

Table 5.1. Public expenditure, participant stocks and expenditure per participant in labour market programmes, 1998-2006 ……............................................................. 98

Table 5.2. Participation in active programmes and in open unemployment compared, 1998-2005 .. 101

Table 5.3. Participant characteristics and post-programme outcomes for FÁS programmes ............ 119

Table 5.A.1. Expenditure per participant-year in labour market programmes, 1998-2006 .................. 126

\section{List of Figures}

Figure 1.1. GDP, population and GDP per capita, Ireland and OECD, 1983-2006 ......................... 16

Figure 1.2. Population aged 65 and over, OECD countries, 2005 ................................................. 16

Figure 1.3. Tertiary graduation rates, selected OECD countries, 2005 .......................................... 17

Figure 1.4. Employment and unemployment indicators, Ireland and OECD areas, 1983-2007 .......... 18

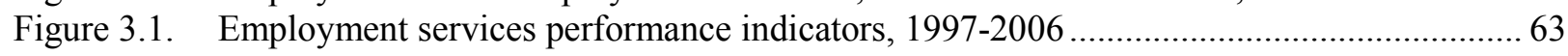

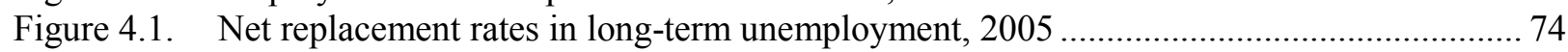

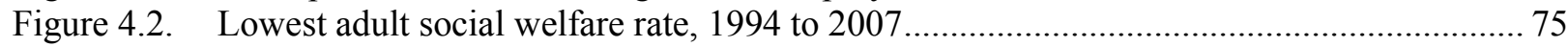




\section{GLOSSARY}

\begin{tabular}{|c|c|}
\hline $\mathrm{ABP}$ & Area-Based Partnership \\
\hline $\mathrm{ADM}$ & Area Development Management (predecessor to Pobal) \\
\hline ALMP & Active labour market programme \\
\hline BTEA & Back to Education Allowance \\
\hline BTWA & Back to Work Allowance \\
\hline BWEA & Back to Work Education Allowance \\
\hline $\mathrm{CE}$ & Community Employment \\
\hline CSF & Community Support Framework (EU) \\
\hline CTC & Community Training Centre \\
\hline CTF & Customised Training Fund \\
\hline CWO & Community Welfare Officer \\
\hline DCRGA & Department of Community, Rural and Gaeltacht Affairs \\
\hline DES & Department for Education and Science \\
\hline DETE & Department of Enterprise, Trade and Employment \\
\hline DSFA & Department of Social and Family Affairs \\
\hline DSW & Department of Social Welfare \\
\hline EHRDOP & Employment and Human Resources Development Operational Programme \\
\hline ERIN & DSFA computer database \\
\hline ESF & European Social Fund \\
\hline ESO & Employment Service Officer \\
\hline ESRI & Economic and Social Research Institute \\
\hline EURES & European employment service network, administered by the European Commission \\
\hline FÁS & Training and Employment Authority (Foras Áiseanna Saothair) \\
\hline FETAC & Further Education and Training Council \\
\hline Forfás & National policy advisory body for enterprise and science (an agency of DETE) \\
\hline GDP & Gross Domestic Product \\
\hline GNI & Gross National Income \\
\hline HETAC & Higher Education and Training Awards Council \\
\hline HSE & Health and Safety Executive \\
\hline HSP & High Supports Process \\
\hline ICTU & Irish Congress of Trade Unions \\
\hline ILO & International Labour Organisation / Office \\
\hline ILP & Individual Learner Plan \\
\hline INOU & Irish National Organisation of the Unemployed \\
\hline IT & Information technology \\
\hline JA & Jobseeker's Allowance \\
\hline JB & Jobseeker's Benefit \\
\hline JI & Job Initiative (employment programme) \\
\hline JSA & Jobseeker's Allowance (UK) \\
\hline LDSIP & Local Development Social Inclusion Programme \\
\hline LES & Local Employment Service \\
\hline LESN & Local Employment Services Network \\
\hline
\end{tabular}


LMP Labour market programme

LR Live Register

LTI Local Training Initiative

NCC National Contact Centre

NDP National Development Plan

NEAP National Employment Action Plan

NESC National Economic and Social Council

NESF National Economic and Social Forum

NQAI National Qualifications Authority of Ireland

NRB National Rehabilitation Board

NTF National Training Fund

OFP One-Parent Family Payment

OSI Office for Social Inclusion

PES Public employment service

PLANET Representative organisation of the thirty-eight Area-Based Partnership companies

Pobal National non-profit company which manages ABPs and other local programmes

PPS

PRETA

PRSI

SE

SST

STP

SWA

UA

Personal public service (number)

Pre-Retirement Allowance

Pay-Related Social Insurance

Social Economy (employment programme)

Specific Skills Training

Specialist Training Provider

UB

Supplementary Welfare Allowance

Unemployment Allowance

Unemployment Benefit

VEC

Vocational Education Committee

VTOS

Vocational Training Opportunities Scheme 
DELSA/ELSA/WD/SEM(2009)01

\title{
ACTIVATION POLICIES IN IRELAND
}

\author{
CHAPTER 1
}

\section{THE BACKGROUND TO ACTIVE LABOUR MARKET POLICIES IN IRELAND}

\subsection{Introduction}

1. The Irish labour market has been characterised by a dramatic turnaround in the mid and late 1990s. From 1993 to 2000, GDP grew at an average rate of $9 \%$ per year, by far the highest growth rate among OECD countries. Since 2000, GDP growth continued at about 5\% per year so that Ireland now has the third-highest level of GDP per capita in Europe, after Luxembourg and Norway (Figure 1.1). ${ }^{1}$ High economic growth was accompanied by increasing labour force participation and declines of unemployment to around the $4 \%$ level until late 2007 , when signs of recession began to appear. GDP growth fell away sharply in 2008 , and the unemployment rate rose to near $8 \%$ by the end of the year.

\subsection{Demography, migration and education}

2. Ireland's fertility rate remained high until the mid-1980s. ${ }^{2}$ However, during the years of high unemployment, due to high rates of out-migration the population grew only slowly, from 3.4 million in 1980 to 3.6 million in 1995. After 1995, despite the lower birth rate, the population has grown rapidly due to return migration by Irish citizens and, more recently, immigration. Ireland was one of the three existing EU Member States (along with Sweden and the United Kingdom, subject to certain restrictions) that as from May 2004 allowed citizens from eight of the ten new EU Member States to work without special authorisation. By 2005, Ireland's total population was 4.1 million, of which $11.8 \%$ were foreign-born, almost twice their share ten years earlier. In contrast to earlier experience, only a small proportion of the recent migration inflow has come from the United Kingdom (OECD, 2007b, Tables A.1.4 corrected, and B.1.1).

3. In 1960, as a result of high emigration by the population of working age, Ireland had close to the highest old-age dependency ratio in OECD Europe (OECD, 1998b). But now, reflecting the continuation of the baby-boom period into the 1980s as well as recent immigration, Ireland has a particularly low oldage share in its total population (Figure 1.2).

1. Note however that Gross National Income (GNI) is about $20 \%$ lower than GDP, due to the large role of multinational enterprises whose profits represent domestic output but not national income. Although GNI has also grown dramatically, in terms of GNI per head Ireland's international ranking is fairly close to the OECD average (www.oecdobserver.org/news/fullstory.php/aid/1507/GDP_and_GNI.html).

2. Above 2.5 per woman until 1985 (http://unstats.un.org/unsd/cdb/cdb_list_series.asp). 
Figure 1.1. GDP, population and GDP per capita, Ireland and OECD, 1983-2006
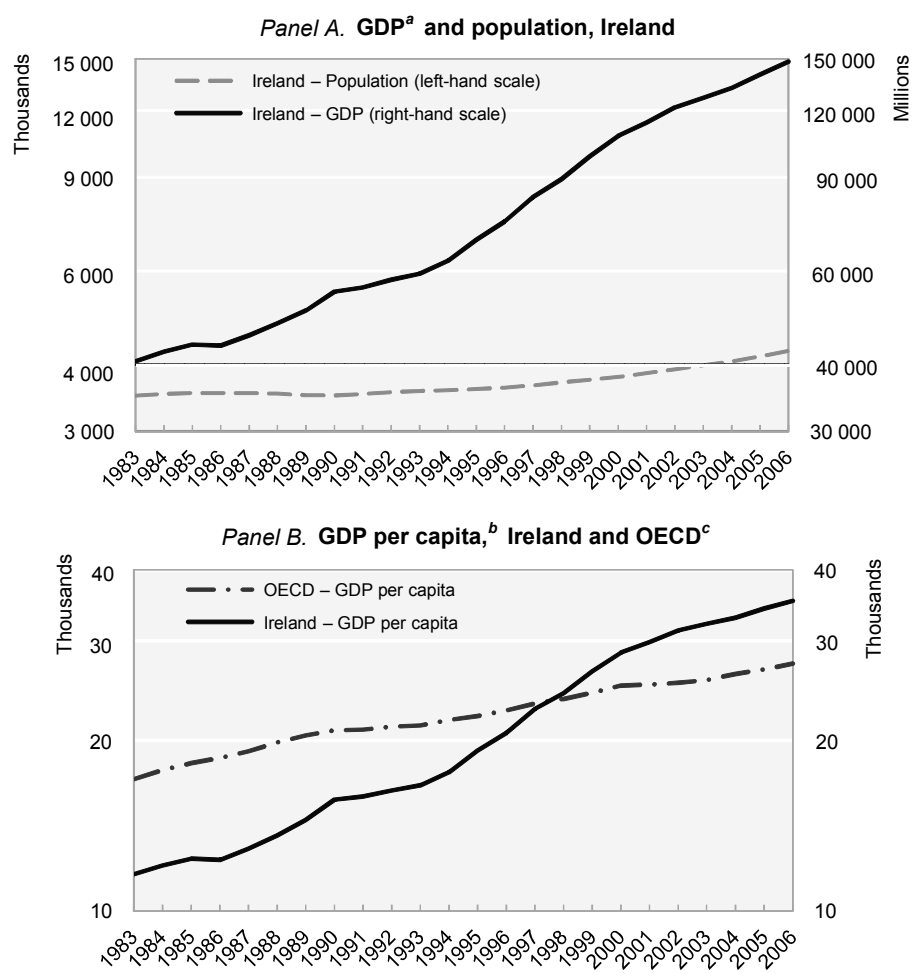

a) Millions of US dollars at price levels and Purchasing Power Parity of 2000 (Table B.3 of the source).

b) Thousands of US dollars at price levels and Purchasing Power Parity of 2000 (Table B.7 of the source).

c) OECD does not include the Czech Republic, Hungary, Poland and the Slovak Republic due to incomplete GDP data. Source: OECD (2008), National account of OECD countries, Volume I, Main aggregates 1995-2006.

Figure 1.2. Population aged 65 and over, OECD countries, 2005

Percentage of total population

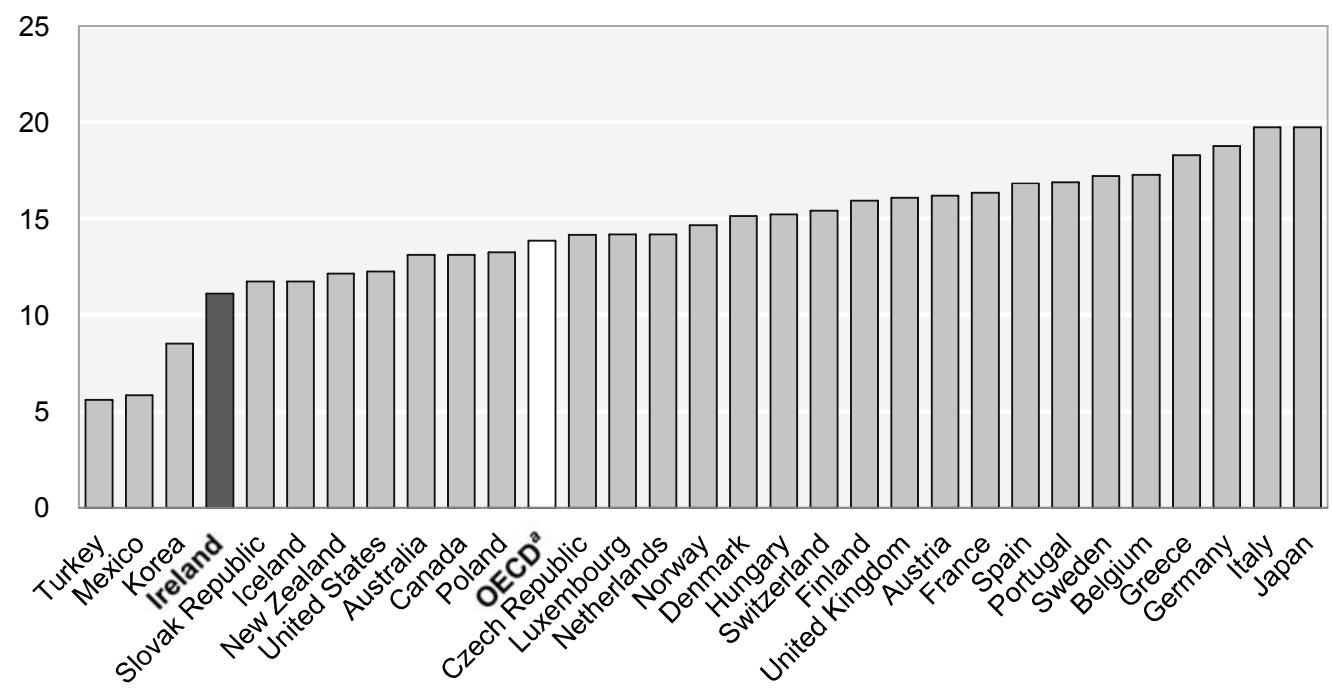

a) Weighted average of OECD countries.

Source: United Nations, World Population Prospects: The 2006 Revision. 
4. The large gains in labour productivity that have boosted Ireland's economic growth since the early 1990s were underpinned by a steep rise in average educational attainment of the working-age population. As late as $2005,35 \%$ of people aged 25 to 64 , and even $60 \%$ of those aged 55 to 64 had not completed secondary schooling; ${ }^{3}$ however, among the younger age groups, secondary educational attainment is now much higher (in 2005, it was at $81 \%$ in the age group 25-34, compared with an OECD average of 77\%; OECD, 2007e). Overall rates of graduation from tertiary education are also well above average, related to the high participation in relatively short, occupationally-oriented courses (Figure 1.3), so that Ireland can now claim to have a relatively well-educated workforce. ${ }^{4}$ By contrast, take-up of adult learning seems to be relatively low (OECD, 2006a, Figure 3.5). Finally, the pre-school attendance of young children remains relatively low, although Ireland is now giving this increased attention.

Figure 1.3. Tertiary graduation rates, ${ }^{a, b}$ selected OECD countries, 2005

\section{Sum of graduation rates for single years of age}

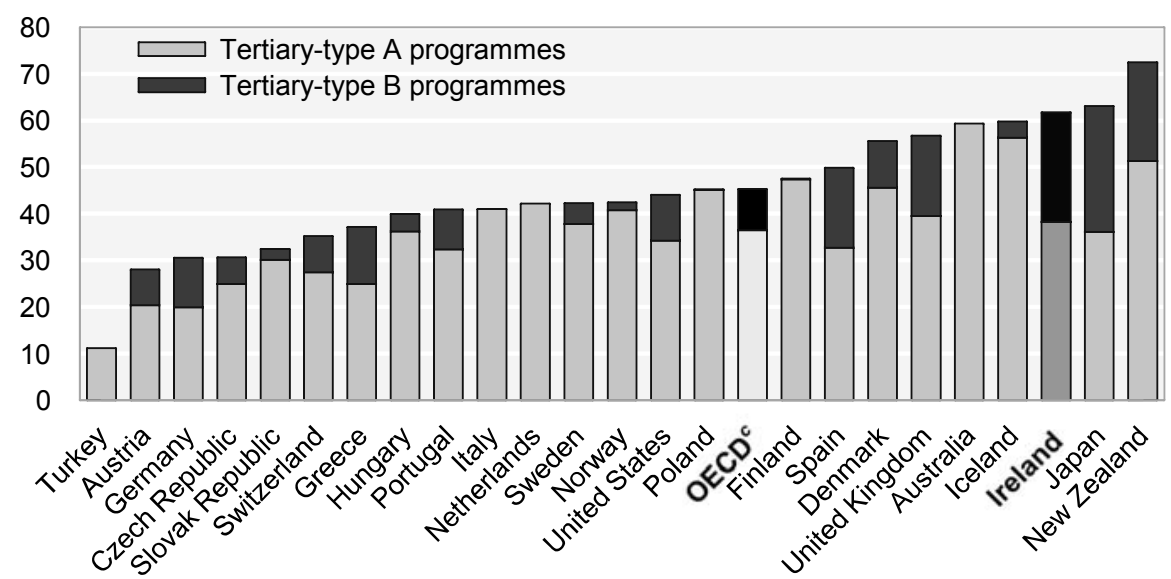

a) Tertiary-type A refers to university-level programmes. Tertiary-type B programmes (ISCED 5B) are typically shorter, but with a minimum two years full-time equivalent at the tertiary level; and vocational, with a focus on practical, technical or occupational any skills for direct entry into the labour market although some theoretical foundations may be covered.

b) People in a given cohort who obtain both a Type A and a Type B qualification will be counted twice in the totals shown.

c) Unweighted average of countries shown.

Source: OECD (2007), Education at a Glance 2007 - OECD Indicators, Paris.

\subsection{Labour force, employment and unemployment}

5. During the decade 1997-2006, employment grew by over 4\% per year on average and the labour force grew by $3.5 \%$ per year, which despite immigration was considerably faster than growth in the working-age population. As a result, the employment rate which had been relatively low caught up with the OECD average (Figure 1.4). Women accounted for more than $90 \%$ of the increase in labour force participation since 1990, and their employment rate grew by over $50 \%$ during the same period, albeit from a very low base. However, there is a striking and persistent difference in labour force participation between women with and without children.

3. In the International Adult Literacy Survey, 55\% of Irish adults scored in the bottom two literacy levels (Australia, New Zealand and the United Kingdom were close to median values, about $45 \%$ to $50 \%$ ) (OECD, 2000, Figure 2.2).

4. FÁS (2005) remarks "almost one in four of the population over the age of 15 has a third-level qualification, the $5^{\text {th }}$ highest in the EU". 
Figure 1.4. Employment and unemployment indicators, Ireland and OECD areas, 1983-2007

Percentage of the population aged 15 to 64
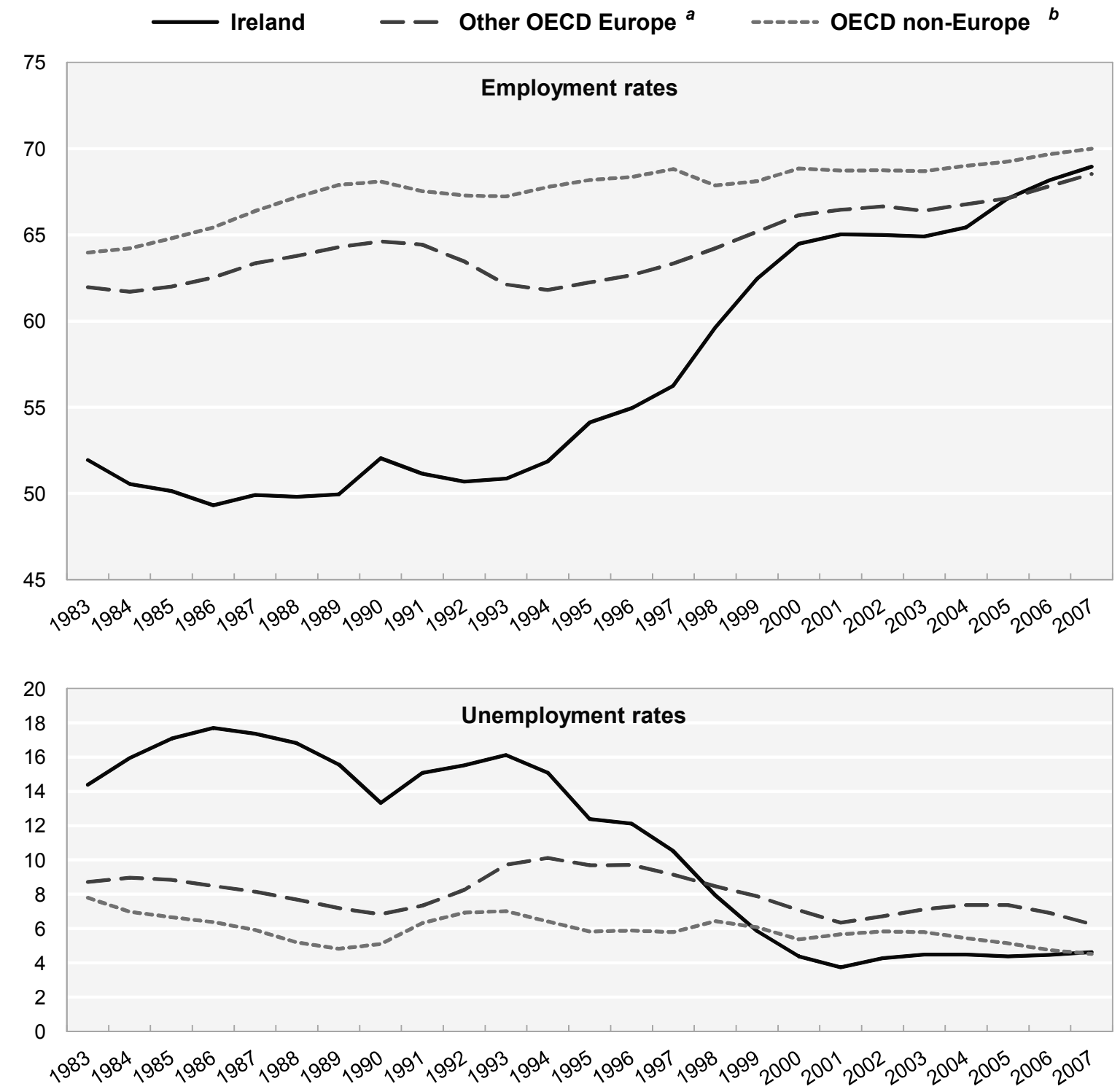

Averages include only countries with data series for 1983 onwards and the United Kingdom (1983 value estimated).

a) Other OECD Europe is an unweighted average Belgium, Denmark, Finland, France, Germany, Greece, Italy, Luxembourg, the Netherlands, Norway, Portugal, Spain, Sweden and the United Kingdom.

b) OECD non-Europe is an unweighted average of Australia, Canada, Japan, Korea, and the United States.

Source: OECD Labour Force Statistics database (www.oecd.org/els/employment/data).

6. Within a period of only six years, from 1994 to 2000, the Irish unemployment rate fell from 8 points above the OECD average to 2 points below. From 2000 to 2007, survey unemployment stayed low, between 4 and $5 \%$, although the number of persons on the Live Register (LR), composed mainly of recipients of Jobseeker's Benefit and Jobseeker's Allowance, remained considerably higher. 


\subsection{Government, partnership agreements and national planning}

7. Ideological differences between the main political parties in Ireland are not very marked. Since 1997, Fianna Fail has been the dominant partner in a coalition with the Progressive Democrats, a rightwing party. Since the 2007 election, the Green party also has two ministerial posts.

8. The government and social partners in Ireland have regularly concluded central partnership agreements (social pacts), starting with the Programme for National Recovery (1988-90) and continuing with new pacts every three years through to the Programme for Prosperity and Fairness (2000-3) and Sustaining Recovery (2003-5) (www.ictu.ie/html/publications/pubagr.html). Initially, the agreements were tripartite, involving government, unions and employers, but from 1997, farming organisation and voluntary and community groups were also represented in the negotiations. Usually, these agreements have coupled wage guidelines with government commitments for action on, for example, taxes and social welfare. They have been held by many commentators to have been an important factor in the strong growth of the economy, the rise in industrial competitiveness and the improvement in employment prospects (O'Donnell and O'Reardon, 2000).

9. The most recent agreement, Towards 2016 (Department of the Taoiseach, 2006) covers 10 years. Part I includes Sections on Education and Training, on Ireland's National Reform Programme (NRP) under the EU Lisbon Agenda, and on policies for the disabled and for People of Working Age. Part II includes Sections on Pay, Workplace Relations, Employment Rights and the Public Service. It includes an agreement with the Irish Congress of Trade Unions (ICTU) for a $10.4 \%$ increase in pay rates over the 27 months following the expiry of current agreements. Since the second programme, agreements have contained local bargaining provisions contingent, in the case of the public sector, on adherence to a change management (modernisation) process ${ }^{5}$ and, in the case of the private sector, on appropriate cost-offsetting measures and phasing arrangements (Kelly, 2001).

10. The National Economic and Social Council (NESC) and the National Economic and Social Forum (NESF) play an important role in policy analysis and formulating proposals in Ireland. The NESC, created in 1973, provides a forum for discussion of economic and social principles; it has 31 members representing trade unions, employer organisations, NGOs, farmers' organisations and key government departments. Its "strategy reports" have constituted the key input to the negotiation of the recurring national-level social partnership agreements. The NESF, created in 1993, has a remit to contribute to the formation of a wider national consensus on social and economic policy initiatives particularly in relation to unemployment, equality and social exclusion, again in the context of social partnership arrangements. Its activities include organising the Social Inclusion Forum (SIF) which is attended by many NGOs and generates a wide range of policy proposals. Its membership comprises members of Parliament, central and local government, trade unions and employers, and the voluntary and community sector. The two organisations have recently been combined under the roof of the National Economic and Social Development Office (NESDO). ${ }^{6}$

11. The social pacts have been accompanied since 1997 by a separate National Anti-Poverty Strategy (NAPS). The first NAPS was succeeded by the National Action Plan against Poverty and Social Exclusion 2001-3 and 2003-5, and the current National Action Plan for Social Inclusion which covers the ten-year period 2007-2016 (OSI, 2003; and 2006). The NAPS introduced in 1998 the concept of "poverty proofing"

5. As can be seen from www.cspvg.gov.ie/verification-docs the change management process is quite structured. In the case of DSFA, delays in implementing change (see Chapter 4) have led to recommendations for staff wage increases to be withheld.

6. This umbrella organisation also includes the National Centre for Partnership and Performance, established in 2001 to promote workplace change and innovation through social partnership. 
under which "memoranda for the Government involving significant policy proposals must indicate clearly the impact of the proposal on groups in poverty or at risk of falling into poverty" (www.welfare.ie/publications/naps/natantibgnote.html). In a 2002 review of the NAPS, the government made a commitment to raise the lowest rate of social welfare benefit to EUR 150 per week in 2002 terms an increase of more than $25 \%$ - by 2007.

12. Since 2000, the social pacts have been accompanied by the National Development Plan 2000-6 and its successor, the National Development Plan 2007-2013 (Government of Ireland, 1999; and 2006), which cover large-scale infrastructure investments, including investments in fields such as education, health services, social housing, childcare and rural and local development. Given the relatively stable political environment, proposed or planned policy reforms are described in a relatively consistent way not only in social pacts and development plans, but also in documents such as government submissions to the European Commission (such as Department of the Taoiseach, 2005), Departmental Green Papers (such as DSFA, 2006a), and the incoming Government's programme (Department of the Taoiseach, 2007).

\subsection{Local partnerships}

13. "Area-Based Partnerships" were created under the 1990-93 tripartite agreement. The partnerships shared a number of key features in terms of structure and administration: a formal institutional structure; administration by a Board (usually of some 15-20 members), membership of which was drawn from a diversity of public, private and voluntary interests; a commitment to a strategic and integrated approach to local development; local autonomy in agreeing priorities and allocating funds; and financial and policy support from both national government and the EU (Moseley et al., 2001). Although they were given a wide remit, their key responsibilities were: $i$ ) to help the long-term unemployed back into the job market; ii) to assist the development of local economic and employment projects, with a special emphasis on promoting entrepreneurs within low-income communities and establishing new businesses in the social economy; and iii) to support more traditional community development projects, particularly for vulnerable groups. Local partnerships have been seen as representing a new model of policy governance (OECD, 1996; 2001c; and Teague, 2006).

14. A national management body (Area Development Management, ADM) launched the first 12 partnerships in deprived areas in 1991, and developed a number of programmes to frame their activities. The number of Area-Based Partnerships was increased to 38 in 1994/5, using funding that was then available from the EU Community Support Framework (CSF). As from 2000, national authorities took over funding and 31 Community Partnerships were created in smaller areas of disadvantage. In 2005, the national management body was renamed Pobal (Gaelic for "People/Community"). In 2006, the funds managed by Pobal were provided $60 \%$ by the Department of Community, Rural and Gaeltacht Affairs (DCRGA) (about 1/6 of the DCRGA funding was for a programme called Services for the Unemployed), $29 \%$ by the Office of the Minister for Children, and 7\% by FÁS, the national employment service body, as funding for Local Employment Services (Pentony, 2005; Teague, 2006; Pobal, 2006a; and 2007).

\subsection{Trends in benefit dependency rates}

15. During most of the 1980s and 1990s, the percentage of the working-age population in Ireland receiving an income-replacement benefit was above the OECD average, due mainly to high unemployment and a high benefit coverage rate. It was, however, below the European average. In the 2000 s the overall working-age benefit-dependency rates fell slightly below the OECD average. Nevertheless, as compared 
with 1985 and 1990, most of the fall in recipiency of unemployment benefits had by 2004 been offset by an increase in recipiency rates for other working-age benefits (Table 1.1). ${ }^{7}$

Table 1.1. Income-replacement benefit recipiency rates for the working-age population, Ireland, 1980-2004

Percentage of the population aged 15 to 64

\begin{tabular}{|c|c|c|c|c|c|c|c|c|c|c|c|c|c|c|c|c|c|c|}
\hline & & Australia & Austria & Belgium & Canada & Denmark & Finland & France & Germany & Ireland & d Japan & $\begin{array}{l}\text { Nether- } \\
\text { lands }\end{array}$ & $\begin{array}{c}\text { New } \\
\text { Zealand }\end{array}$ & Spain & Sweden & $\begin{array}{c}\text { United } \\
\text { Kingdom }\end{array}$ & $\begin{array}{l}\text { United } \\
\text { States }\end{array}$ & OECD-16 \\
\hline \multirow{6}{*}{ Old age } & 1980 & 1.8 & 3.3 & 4.0 & 0.6 & 1.2 & 1.4 & 2.2 & 2.7 & 0.0 & 3.5 & - & 1.3 & 0.4 & 1.8 & 3.4 & 1.8 & 2.0 \\
\hline & 1985 & 1.6 & 4.3 & 7.2 & 0.6 & 2.0 & 1.4 & 6.0 & 2.8 & 0.0 & 5.0 & 0.7 & 1.3 & 0.7 & 1.3 & 3.5 & 2.0 & 2.5 \\
\hline & 1990 & 1.5 & 4.3 & 8.0 & 2.3 & 2.1 & 1.6 & 6.6 & 3.2 & 0.3 & 5.0 & 0.6 & 1.4 & 1.0 & 0.8 & 3.6 & 2.0 & 2.8 \\
\hline & 1995 & 2.2 & 5.5 & 7.0 & 3.2 & 3.2 & 1.9 & 7.2 & 3.7 & 0.6 & 5.1 & 0.8 & 1.5 & 1.3 & 0.7 & 3.2 & 1.8 & 3.1 \\
\hline & 2000 & 1.8 & 7.3 & 6.7 & 3.1 & 3.7 & 2.5 & 6.9 & 4.7 & 0.4 & 5.2 & 0.7 & 1.4 & 1.0 & 0.5 & 3.5 & 1.8 & 3.2 \\
\hline & 2004 & 1.6 & 6.0 & 4.9 & 3.4 & 2.3 & 2.7 & 6.4 & 4.0 & 0.4 & 6.0 & 0.6 & 0.6 & 0.9 & 0.4 & 3.7 & 1.8 & 2.9 \\
\hline \multirow{6}{*}{ Survivors } & 1980 & 0.8 & 3.0 & 1.6 & 1.3 & 0.5 & 2.0 & 0.5 & 1.6 & 1.5 & 0.8 & 1.8 & 0.8 & 1.6 & 1.5 & 1.6 & 1.3 & 1.4 \\
\hline & 1985 & 0.7 & 2.7 & 1.7 & 1.5 & - & 2.1 & 0.4 & 1.7 & 1.7 & 1.0 & 1.7 & 0.6 & 1.8 & 1.3 & 1.4 & 0.8 & 1.4 \\
\hline & 1990 & 0.6 & 2.6 & 1.5 & 1.9 & - & 1.9 & 0.4 & 1.7 & 1.6 & 1.1 & 1.8 & 0.6 & 1.8 & 1.1 & 1.2 & 0.7 & 1.4 \\
\hline & 1995 & 0.4 & 2.3 & 1.3 & 2.0 & - & 1.8 & 0.4 & 1.7 & 1.6 & 1.3 & 1.8 & 0.4 & 1.8 & 1.0 & 1.0 & 0.7 & 1.3 \\
\hline & 2000 & 0.2 & 2.1 & 1.1 & 1.7 & - & 1.6 & 0.4 & 1.6 & 1.4 & 1.6 & 1.0 & 0.4 & 1.8 & 0.3 & 0.8 & 0.6 & 1.1 \\
\hline & 2004 & 0.2 & 2.1 & 1.1 & 1.6 & - & 1.5 & 0.4 & 1.7 & 1.3 & 1.8 & 0.8 & 0.4 & 1.8 & 0.2 & 0.5 & 0.5 & 1.1 \\
\hline \multirow{6}{*}{$\begin{array}{l}\text { Incapacity } \\
\text { (sickness } \\
\text { and disability) }\end{array}$} & 1980 & 5.2 & 6.5 & 4.4 & 3.6 & 10.1 & 9.5 & 7.4 & 7.9 & 5.0 & 3.2 & 10.2 & 1.5 & 3.3 & 9.9 & 4.0 & 7.4 & 6.2 \\
\hline & 1985 & 5.6 & 5.8 & 4.4 & 4.5 & 9.6 & 9.0 & 6.6 & 7.4 & 6.0 & 3.0 & 9.8 & 1.9 & 4.1 & 9.9 & 4.5 & 7.1 & 6.2 \\
\hline & 1990 & 5.3 & 6.1 & 4.3 & 4.6 & 10.6 & 10.2 & 6.4 & 7.0 & 5.3 & 3.0 & 11.0 & 2.8 & 4.2 & 10.6 & 6.0 & 7.7 & 6.6 \\
\hline & 1995 & 5.5 & 5.9 & 4.4 & 5.8 & 11.1 & 10.0 & 6.4 & 7.1 & 5.0 & 2.9 & 10.0 & 3.9 & 4.2 & 11.0 & 7.9 & 8.6 & 6.9 \\
\hline & 2000 & 7.2 & 5.5 & 4.7 & 5.1 & 11.4 & 9.0 & 7.0 & 6.5 & 5.9 & 3.2 & 10.9 & 4.0 & 4.2 & 12.6 & 7.2 & 8.4 & 7.1 \\
\hline & 2004 & 8.1 & 5.8 & 5.0 & 4.8 & 11.3 & 8.9 & 6.8 & 5.8 & 6.2 & 3.1 & 10.7 & 4.8 & 3.8 & 14.7 & 7.5 & 9.3 & 7.3 \\
\hline \multirow{6}{*}{ Unemployment } & 1980 & 3.2 & 0.9 & 5.4 & 6.0 & 5.2 & - & 3.1 & 2.0 & 4.5 & 0.8 & 2.9 & 1.1 & 2.8 & 1.1 & 4.7 & 2.5 & 3.1 \\
\hline & 1985 & 5.4 & 2.2 & 8.4 & 8.8 & 7.0 & - & 4.3 & 4.1 & 9.8 & 0.7 & 6.2 & 1.8 & 4.1 & 2.0 & 7.7 & 1.8 & 5.0 \\
\hline & 1990 & 3.8 & 3.0 & 7.3 & 8.6 & 7.6 & 5.5 & 4.3 & 3.9 & 9.3 & 0.5 & 5.0 & 6.3 & 5.0 & 1.3 & 4.0 & 1.6 & 4.8 \\
\hline & 1995 & 6.7 & 3.9 & 8.8 & 8.1 & 8.0 & 10.1 & 5.2 & 6.7 & 11.2 & 0.8 & 6.3 & 5.8 & 5.5 & 6.0 & 5.3 & 1.6 & 6.3 \\
\hline & 2000 & 5.1 & 3.4 & 6.6 & 5.2 & 4.2 & 6.0 & 4.4 & 6.4 & 5.1 & 1.0 & 3.5 & 6.2 & 3.8 & 3.5 & 2.5 & 1.3 & 4.3 \\
\hline & 2004 & 4.1 & 3.9 & 7.5 & 5.5 & 4.6 & 6.1 & 5.3 & 7.7 & 5.2 & 0.8 & 5.8 & 3.0 & 4.2 & 3.2 & 1.9 & 1.8 & 4.4 \\
\hline \multirow{6}{*}{$\begin{array}{r}\text { Social assistance } \\
\text { and lone parents }\end{array}$} & 1980 & 2.0 & 0.6 & 1.5 & 1.7 & 2.5 & 0.5 & 0.2 & 0.9 & 1.0 & 0.5 & 1.2 & 1.9 & 0.0 & 0.2 & 1.0 & 3.4 & 1.2 \\
\hline & 1985 & 2.6 & 0.5 & 1.6 & 2.3 & 1.8 & 0.7 & 0.3 & 1.7 & 1.5 & 0.5 & 1.6 & 2.7 & 0.0 & 0.5 & 2.0 & 3.7 & 1.5 \\
\hline & 1990 & 2.5 & 0.6 & 2.0 & 2.2 & 1.8 & 0.8 & 1.5 & 2.1 & 2.2 & 0.3 & 1.5 & 4.3 & 0.2 & 0.5 & 2.9 & 3.6 & 1.8 \\
\hline & 1995 & 3.0 & 0.5 & 2.4 & 3.0 & 1.5 & 1.5 & 2.6 & 2.2 & 3.3 & 0.3 & 1.4 & 4.4 & 0.2 & 1.1 & 3.5 & 3.7 & 2.2 \\
\hline & 2000 & 3.2 & 0.9 & 2.1 & 1.7 & 1.7 & 1.2 & 2.9 & 2.1 & 4.4 & 0.3 & 1.1 & 4.4 & 0.2 & 1.0 & 2.6 & 1.6 & 2.0 \\
\hline & 2004 & 3.5 & 1.1 & 2.1 & 1.5 & 1.8 & 1.2 & 3.1 & 2.5 & 4.4 & 0.4 & 1.0 & 4.9 & 0.1 & 0.8 & 2.1 & 1.8 & 2.0 \\
\hline \multirow{6}{*}{ Maternity and care } & 1980 & 0.0 & 1.2 & 0.1 & 0.2 & 0.4 & 0.2 & 0.5 & 0.2 & 0.4 & 0.1 & 0.0 & 0.0 & 0.0 & 1.5 & 0.4 & 0.0 & 0.3 \\
\hline & 1985 & 0.0 & 1.3 & 0.1 & 0.2 & 0.8 & 1.3 & 0.5 & 0.2 & 0.3 & 0.1 & 0.0 & 0.0 & 0.0 & 2.0 & 0.3 & 0.0 & 0.4 \\
\hline & 1990 & 0.1 & 1.5 & 1.1 & 0.4 & 1.0 & 3.9 & 1.0 & 0.2 & 0.2 & 0.1 & 0.0 & 0.0 & 0.0 & 2.8 & 0.6 & 0.0 & 0.8 \\
\hline & 1995 & 0.2 & 3.0 & 1.0 & 0.4 & 2.5 & 4.0 & 1.3 & 0.2 & 0.5 & 0.1 & 0.0 & 0.0 & 0.0 & 2.8 & 1.2 & 0.0 & 1.1 \\
\hline & 2000 & 0.3 & 1.9 & 1.1 & 0.4 & 1.6 & 3.2 & 1.9 & 0.2 & 0.7 & 0.2 & 0.0 & 0.0 & 0.0 & 2.0 & 1.7 & 0.0 & 1.0 \\
\hline & 2004 & 0.3 & 4.1 & 1.1 & 0.8 & 2.4 & 3.0 & 1.6 & 0.2 & 0.9 & 0.2 & 0.0 & 0.0 & 0.0 & 2.3 & 2.9 & 0.0 & 1.2 \\
\hline \multirow{6}{*}{ Total } & 1980 & 13.0 & 15.5 & 17.0 & 13.4 & 19.9 & 13.5 & 13.8 & 15.2 & 12.4 & 8.8 & 16.1 & 6.5 & 8.1 & 16.1 & 15.0 & 16.5 & 13.8 \\
\hline & 1985 & 15.9 & 16.8 & 23.5 & 18.0 & 21.2 & 14.6 & 18.1 & 18.0 & 19.3 & 10.3 & 19.9 & 8.3 & 10.6 & 17.0 & 19.4 & 15.4 & 16.6 \\
\hline & 1990 & 13.6 & 18.0 & 24.3 & 19.9 & 23.2 & 23.9 & 20.1 & 18.2 & 18.9 & 10.0 & 20.0 & 15.3 & 12.1 & 17.0 & 18.3 & 15.6 & 18.0 \\
\hline & 1995 & 17.9 & 21.2 & 24.8 & 22.5 & 26.2 & 29.3 & 23.0 & 21.6 & 22.1 & 10.5 & 20.3 & 16.0 & 12.8 & 22.6 & 22.2 & 16.4 & 20.6 \\
\hline & 2000 & 17.8 & 21.2 & 22.3 & 17.3 & 22.5 & 23.6 & 23.4 & 21.6 & 17.9 & 11.5 & 17.2 & 16.3 & 11.1 & 19.9 & 18.3 & 13.8 & 18.5 \\
\hline & 2004 & 17.8 & 23.0 & 21.6 & 17.7 & 22.4 & 23.3 & 23.5 & 21.9 & 18.5 & 12.3 & 19.0 & 13.6 & 10.8 & 21.6 & 18.7 & 15.2 & 18.8 \\
\hline
\end{tabular}

Data not available.

See OECD (2003), Chapter 4 for a discussion of definition and coverage. Estimates for 1980 to 1999 presented there were extrapolated to 2004 using data for the main benefits in each category. Estimates for Finland are new. Estimates should be considered approximate.

Source: OECD (2003), Chapter 4, updated as described.

16. Since 1985, compared with the experience of the three OECD countries with similar and historically-related benefit systems (Australia, New Zealand and the United Kingdom), Ireland had until recently experienced less increase in recipiency rates for incapacity (invalidity and sickness) benefits. Maternity benefits (whose duration was increased to 14 weeks in 1997 and 18 weeks in 2001) and, more significantly, two other benefits have seen recipient numbers increase to two to three times their 1990 level. By 2004, there were about 30000 recipients of Supplementary Welfare Allowance basic payment (a last-resort minimum income benefit), 90000 recipients of One-Parent Family Payments, and

7. More complete conversion of the estimates for benefit recipients onto a full-time equivalent basis would somewhat reduce the rates reported for Ireland, since in recent years means tests have been eased to encourage the take-up of part-time work with a reduced rate of payment. 
over 180000 recipients of Illness Benefit, Invalidity Pension and Disability Allowance, which may be compared with 130000 on unemployment (Benefit and Allowance) payments that year. ${ }^{8}$

17. While in $2005 / 2006$ the female employment rate in Ireland had risen slightly above the OECD average, the lone-parent employment rate was the lowest in the OECD (OECD, 2007c, Table 1.1). This probably reflects payment of a benefit, the One-Parent Family Payment (OFP) without a requirement to be available for and seeking employment, until children are aged 18 (or 22 if in full-time education) which is the highest age limit in the OECD (op.cit., Table 4.6). The number of recipients of this benefit and its predecessors increased very rapidly during the 1980s and 1990s. Australia (as from 2006) and the United Kingdom (with the change introduced over the period 2008-2010, e.g. see http://news.bbc.co.uk/1/hi/uk politics/7143028.stm) now require, or will require, lone parents on benefit to be available for work when their youngest child reach age seven. A Green Paper (DSFA, 2006a) has suggested that OFP should be restricted to parents whose children are aged less than 7. If and when such a policy is implemented, the group targeted by activation measures will expand, and limitations in the effectiveness of the current measures and the resources devoted to them will be further underscored.

\subsection{History of the PES and labour market programmes}

18. In Ireland, the Department of Labour managed the function of paying unemployment benefits from 1966 to 1971, when a National Manpower Service (NMS) was created and the benefit payment function was transferred to the then Department of Social Welfare (DSW). In 1988, the NMS was merged with two other agencies, the Industrial Training Authority (AnCO) and the Youth Employment Agency (YEA) to form FÁS, the Training and Employment Authority. The new agency had, and still has, many more staff in training centres than in employment service offices.

19. In addition to relatively short training courses for employed people, apprentices and the unemployed, the first large programmes of subsidised hiring and job creation were put into place in the mid-1970s. The number of participants in the Work Experience Programme (WEP) for first-time jobseekers peaked at 6000 in 1983. The Social Employment Scheme (SES) for adult long-term unemployed was brought in in 1985 and had 10000 participants in 1986, which increased to 20000 by 1993 (OECD, 1998b). It was then replaced by Community Employment (CE) in 1994, whose participant numbers soon reached 40000 . This was over 3\% of total employment (about 1.3 million) at the time, and $\mathrm{CE}$ funding became a significant influence in the Irish labour market: it promoted an expansion of the community and voluntary sector, professionalizing some existing organisations and creating some new ones (Boyle, N., 2005).

20. In the 1990s, funding under the EU's Community Support Framework (CSF) was an important influence on the Irish economy. Total funding exceeded 3\% of GDP in 1992-1994 and remained close to 2.5\% of GDP until 1999 (Özenen, 2006). Spending then fell to 0.4\% of GDP under the 2000-2006 CSF. About $30 \%$ of the total funding - up to about $1 \%$ of GDP, in the early 1990 s - was devoted to investment in human resources, which was channelled mainly through the European Social Fund (ESF). The ESF funded training but not job-creation schemes such as CE. In 2000, a National Training Fund, based on employer contributions of $0.7 \%$ of reckonable earnings for most employees, was created to replace most of the CSF funding. Thus the broad pattern of labour market programme spending was not directly affected by the sharp fall in CSF funding that occurred after 2000.

21. Boyle, N. (2004; and 2005) argues that FÁS' role in training has been vital to Ireland's economic success: "the bulk of job growth has been in sectors that have drawn heavily on FÁS alumni", and the reformed (standards-based) FÁS apprenticeship system was "crucial in supplying the skilled labour that

8. The number of disability benefit recipients continues to increase rapidly, exceeding 200000 by 2006 . 
fuelled the most dynamic domestic sectors of the economy such as construction". Although spending on apprenticeship support was particularly high in international comparative terms as a percentage of GDP in the 1990s, ${ }^{9}$ public spending on training for the unemployed has been only about the OECD average, higher than in other English-speaking OECD countries but considerably lower than in Nordic countries or Austria, Germany and Switzerland (Table 1.2).

Table 1.2. Spending on active labour market programmes, Ireland, Nordic countries and other OECD areas, 2006

Percentage of GDP

\begin{tabular}{|c|c|c|c|c|}
\hline & Ireland & $\begin{array}{c}\text { Nordic } \\
\text { countries }^{a}\end{array}$ & $\begin{array}{c}\text { Other } \\
\text { OECD Europe }\end{array}$ & $\begin{array}{c}\text { OECD } \\
\text { non-Europe }^{c}\end{array}$ \\
\hline \multicolumn{5}{|l|}{ Programme category } \\
\hline $\begin{array}{l}\text { 1. Public employment service and administration } \\
\text { (includes benefit administration) }\end{array}$ & $0.10^{d}$ & 0.22 & 0.19 & 0.13 \\
\hline 2. Training & 0.24 & 0.37 & 0.18 & 0.07 \\
\hline 3. Employment Incentives ${ }^{e}$ & 0.03 & 0.30 & 0.10 & 0.01 \\
\hline 5. Supported employment and rehabilitation & 0.01 & 0.23 & 0.08 & 0.03 \\
\hline 6. Direct job creation & 0.21 & 0.04 & 0.09 & 0.02 \\
\hline 7. Start-up incentives & 0.00 & 0.01 & 0.02 & 0.01 \\
\hline 8. Out-of-work income maintenance and support & 0.80 & 1.17 & 0.91 & 0.39 \\
\hline 9. Early retirement & 0.06 & 0.28 & 0.12 & 0.00 \\
\hline Total & 1.46 & 2.62 & 1.69 & 0.64 \\
\hline Active measures (Categories 1 to 7 ) & 0.59 & 1.17 & 0.66 & 0.25 \\
\hline Passive measures (Categories 8 and 9$)^{f}$ & 0.86 & 1.45 & 1.02 & 0.39 \\
\hline
\end{tabular}

a) Denmark, Finland, Norway and Sweden. Data for Denmark refer to 2004.

b) Austria, Belgium, the Czech Republic, France, Germany, Hungary, Ireland, Italy, Luxembourg, the Netherlands, Poland, Portugal, Spain, Switzerland, and the United Kingdom.

c) Australia, Canada, Japan, Korea, New Zealand and the United States. c) Includes the employment service and programme administration functions of FÁS, but excludes training staff costs. Includes Local Employment Service and estimated DSFA benefit administration costs: see Table 2.3 for further details.

d) Includes the employment service and programme administration functions of FÁs, but excludes training staff costs. Includes Local Employment Service and estimated DSFA benefit administration costs: see Table 2.3 for further details.

e) Includes Category 3 Job rotation and sharing.

f) Includes Category 9 Early retirement for labour market reasons.

Source: OECD (2008), OECD Employment Outlook, Statistical Annex, Table J, and as detailed in Chapter 2 for Category 1 in Ireland.

22. Following the steep fall in unemployment rates in the second half of the 1990s, CE was scaled back from 40000 participants in 1998 to 20000 participants in 2003. At this level, spending on Direct job creation in Ireland remains relatively high (Table 1.2). The Back to Work Allowance (hiring subsidy) programme also experienced a sharp decline, with participant numbers falling from a peak of 35000 in 2000 to about 5000 in 2005, as numbers of long-term unemployed eligible for the programme fell and eligibility for it was, except for some relatively small groups, at the start of 2003 restricted to those unemployed for five years (restored to two years in 2006). Other changes have concerned programmes which have only a few thousand participants.

9. According to OECD statistics for labour market programme spending in the 1990s; under the revised classification used since 2002, the statistics no longer include spending on general apprenticeship programmes. 
23. Although there have been no major institutional changes to FÁS' job-broking and programme management responsibilities ${ }^{10}$ or to unemployment benefit administration, there have been procedural changes. A requirement for registration with FÁS was introduced in 1996 for young people aged 18 and 19 unemployed for more than six months. From September 1998, under the National Employment Action Plan (NEAP), people under 25 who reached six months duration on the Live Register were referred to FÁS. In March 2003, NEAP referrals were extended to people aged 25 to 54 (Indecon, 2005), and in 2006 and 2007 the referrals were extended to those unemployed for more than 3 months and to people aged 55 to 64 (see Chapter 3 for more detail on the NEAP). However, other core services still account for a greater proportion of FÁS Employment Services staff time.

24. Ireland does, however, also provide public funding for several smaller organisations providing advice and assistance in the areas of employment, labour market programmes and benefits. The Local Employment Service (LES) was created in 1995 in 12 Partnership areas (see above), later expanded to 25; at first it was independent of FÁS, although in 2000 its funding was transferred to FÁS which now manages it but only indirectly. Further employment services are provided through Congress Centres (managed by the ICTU) staffed by CE participants and, since 2000, by the DCGRA-funded Services for the Unemployed programme (mentioned above). In addition, local DSFA (Social Welfare) offices review caseloads for possible referral to suitable services, conduct eligibility and job-search review interviews with clients on unemployment payments, and have about 50 employment counselling staff, called Facilitators. Towards 2016 and other policy documents since 2006 indicate that DSFA is introducing an active case management approach for all its customers of working age.

25. Against this background, this study considers the effectiveness of the current employment service institutions and procedures for their traditional target groups, particularly the long-term unemployed, and the reforms needed to meet future challenges, including employment objectives for working-age people who are currently in receipt of inactive benefits.

10. Although within FÁS, responsibilty for the Community Employment scheme was transferred in 1997/8 from FÁS Employment Services division to the newly-formed Community Services division. 
DELSA/ELSA/WD/SEM(2009)01

\section{CHAPTER 2}

\section{INSTITUTIONAL ORGANISATION}

\subsection{Introduction}

26. This chapter discusses the institutional structure of the Irish PES and related institutions. It starts by outlining the roles of the main actors in labour market policy. It then presents the main characteristics of the employment service and discusses its office structure and internal organisation. The chapter concludes with some discussion of office resources from an international perspective, against the background of the challenge of "activating" the unemployed with the help of high-quality and well-resourced employment services.

\subsection{Actors in labour market policy}

27. It is useful to set the Irish employment service within the context of the complex variety of labour market actors. The main government departments with responsibility for labour market policy are (1) the Department of Enterprise, Trade and Employment (DETE) which, inter alia, supervises the Training and Employment Authority (FÁS, the Irish public employment service); and (2) the Department of Social and Family Affairs (DSFA), which manages the social security system, including pensions, family and unemployment benefits. Ireland belongs to the minority of OECD countries where the placement function of the employment service is separated from the benefit function. The Department of Education and Science which runs regional technical colleges and manages the Vocational Training Opportunities Scheme for long-term unemployed persons, and the Health Service Executive (an agency under the Department of Health and Children), which administers the Supplementary Welfare Allowance (a lastresort minimum income benefit) through its Community Welfare Officers, also play a role in labour market policy, broadly defined. ${ }^{11}$

28. Another actor of importance is Pobal, a non-profit company which manages the Local Development Social Inclusion Programme on behalf of the Department of Community, Rural and Gaeltach Affairs (see Box 2.1). It also runs the "social economy" programme (recently renamed the Community Services programme and currently employing nearly 2000 salaried workers in over 300 enterprises).

29. In its current composition, the DETE was set up in $1997 ;{ }^{12}$ it currently has slightly over one thousand staff (of whom, however, less than 100 are working on labour market policy issues). The list of objectives currently pursued by the Department in the area designated as "Quality Work and Learning" reveals a strong focus on skills development, with the first four of these objectives relating to adult

11. The HSE is the largest single employer in Ireland. Following the recommendations of a report by an Interdepartmental Review Group on the Core Functions of the Health Service (as well as several previous reports), the government plans to transfer the responsibility for SWA - including the some 700 community welfare officers (CWOs) who administer it, along with some other income support schemes - from the HSE to the DSFA (see also Chapter 4).

12. It was the Department of Labour from 1966 to 1993; the Department of Enterprise and Employment from 1993 to 1997, and DETE from 1997 onwards. 
learning and training issues, followed by support for the unemployed and the implementation of the European Employment Strategy (DETE, 2006). ${ }^{13}$

30. The Department contains seven divisions, among which those for $i$ ) Labour Force Development and ii) Employment Rights and Industrial Relations are of most relevance for this report. The former division is charged with ensuring the efficient operation of the labour market; preventing social exclusion; addressing the economy's skill needs; and administering the granting of work permits to immigrants. The Employment Rights division aims to enhance quality employment by enforcing employment rights and entitlements, including occupational safety and health standards, and promoting labour/management cooperation and effective dispute resolution.

31. Within the Labour Force Development division, the Labour Market Policy unit is responsible for designing active labour market measures aimed at re-integration into the workforce of the long-term unemployed and other marginalised groups, including the preventive measures under the National Employment Action Plan (NEAP) - the key mechanism for activating unemployed clients. Other main objectives are the integration of people with disabilities; and overseeing the financial allocations to FÁS and monitoring FÁS business plans and activities to ensure that these match Departmental strategic objectives. It is also charged with providing relevant statistical data as background for labour market policy initiatives. Another section, the ESF Policy and Operations unit, oversees all matters relating to the European Social Fund (ESF) in Ireland. It serves as secretariat to the Employment and Human Resources Development Operational Programme and contributes to the implementation of the EQUAL Community Initiative, which aims to address discrimination and inequality in the labour market. ${ }^{14}$

32. The DETE oversees and funds two bodies which decide on individual and collective labour disputes, the Labour Relations Commission (responsible for conciliation in collective industrial disputes) and the Labour Court and Employment Appeals Tribunal (which adjudicates in cases involving individual employment rights, such as employment protection, wage payment and anti-discrimination), as well as a number of other government and semi-state agencies, such as the Health and Safety Authority, the national Standards Authority, the Irish Productivity Centre and several Development Agencies [Forfás, Industrial Development Agency (IDA) Ireland, Enterprise Ireland, County and City Enterprise Boards, etc.], which promote job creation and training in connection with investment projects and enterprise development. But by far the largest of the DETE-supervised agencies is FÁS, which was established under the 1987 Labour Services Act and currently employs about 2300 staff. Of the 2007 DETE budget of EUR 1391 billion, close to half is channelled through FÁS (DETE, 2007a). ${ }^{15}$

33. DSFA administers the Irish social security system, including old-age pensions, illness and disability benefits, child benefits, one-parent family payment and supports for the unemployed, i.e. Jobseeker's Benefit and Jobseeker's Allowance. The Department employs over 4700 staff in total. The Social Welfare Services are the executive arm of the Department, which manages benefit claims and payments with the help of close to 2000 staff distributed over 58 Social Welfare Local Offices and

13. The first three goals listed are: i) Expand and develop lifelong learning opportunities; ii) Increase investment in in-company training, with a particular focus on the low-skilled; and iii) Enhance training and employment supports for people with disabilities.

14. The Department notes in its Statement of Strategy 2005-07 that it “... will develop ESF programmes for the 2007-13 period that address the training and employment support needs of the labour market". However, the role of the ESF in financing Irish ALMPs is currently much diminished compared with previous budget periods.

15. DETE was also a major player in the negotiation of Ireland's new partnership agreement Towards 2016 (valid for the period 2006-15, and succeeding the 2003-05 agreement Sustaining Progress), which outlines a number of key strategies to enhance national competitiveness and employability. 
68 branch offices, grouped in 10 regions. ${ }^{16}$ The Welfare Offices also provide services beyond benefit payment to encourage and support clients in taking up work, education or training. Staff called Facilitators have particular responsibility for assistance to the hard-to-place unemployed and lone parents through referral to appropriate employment and social services, as well as advising clients on their entitlements to Back to Work Allowance (paid to certain formerly long-term-unemployed clients when they enter education or employment) and PRSI Exemption (granted to employers who hire people from related target groups) (see Chapter 5).

34. DSFA has identified its most significant current challenges as follows: $i$ ) to develop policies that tackle the issues of poverty and social inclusion; and ii) to ensure that all those capable of engaging with the labour market receive the supports needed to secure that engagement (DSFA, 2005a). Indeed, DSFA is the main body responsible for implementing the National Anti-Poverty Strategy and the new ten-year National Action Plan for Social Inclusion (see Chapter 1 above).

35. Since 2007, both Departments produce an annual output statement listing qualitative and quantitative performance targets. For 2007, the DETE focuses on numerical targets relating to: i) upskilling; ii) processing of employment permits; iii) activation measures for "the marginalised"; and iv) increases in employment rates, particularly for women and older workers. DSFA, apart from listing the projected number of recipients of its benefit schemes, focuses on reducing processing times and verification of entitlement to benefits (DETE, 2007b; and DSFA, 2007b).

36. Ireland has become known internationally for having introduced a range of new governance processes, often characterised as partnerships, which operate both at national and local level (O'Callaghan, 2003). Most of the local partnership approaches were developed since the 1980s as a response to shortcomings in existing arrangements to tackle unemployment, poverty and other social issues. They have considerably widened the range of organisations involved in delivering employment services and in social and economic decision-making. The 12 pilot Area-Based Partnerships (ABPs), established in 1991 under the then national partnership agreement on Social and Economic Progress, have already been noted in Chapter 1. The ABPs were to operate in disadvantaged areas - both urban and rural - addressing economic disintegration and mass unemployment, as well as stimulating job creation. They are largely autonomous organisations, taking the form of limited companies with boards of directors drawn from a variety of actors - mainly government, social partner and community group representatives. During the 1990s their numbers increased, as did their funding under the EU Structural Funds. In the 2000 to 2006 period, Pobal was managing 71 different groups (OECD, 1996; Turok, 2001; OECD, 2006b; and www.pobal.ie/LDSIP/Pages/LDSIP.aspx). The ABPs have formed an association called PLANET (see Box 2.1).

37. As an additional step to decentralize labour market services, the Irish government set up Local Employment Services (LES) in the mid 1990s to provide more intensive guidance and placement services at local level to disadvantaged groups, in particular the long-term unemployed, and offer them better access to employment opportunities. ${ }^{17}$ Since a 1999 government decision to "mainstream" the service, they are identified as the second strand, along with FÁS Employment Services, of the Irish National Employment Service. There are now 25 LESs, all but one managed by the respective Partnership companies in the area (with the LES organised as a sub-committee under the Area or Community Partnership board). After having initially been financed directly by DETE, they are now funded by FÁS via (again with one exception) the Partnership companies, with which FÁS negotiates contracts for their management. Despite

16. The branch offices are relatively small and tend to be contracted out to private providers. Decisions on social welfare entitlements made by the local offices can be appealed at the independent Social Welfare Appeals Office (SWAO, 2007).

17. The LES office network was established based on proposals from the NESF and the 1994/95 Task Force on Long-term Unemployment. 
this, the organisational frameworks for the LES and FÁS Employment Services remain very much separate, but LES offices now use the FÁS computer system which makes information about clients mutually accessible.

\section{Box 2.1. The Local Development Social Inclusion Programme}

The Local Development Social Inclusion Programme (LDSIP) is a series of measures aimed at addressing the problems of social exclusion, poverty and unemployment through a partnership approach at local level. It forms part of the 2000-2006 National Development Plan (NDP).

It has been developed from the 12 Area-Based Partnerships established in 1991. The current framework of Partnerships includes 70 non-profit companies: 38 Area-Based Partnerships (in designated areas of disadvantage); 30 locally-based Community Partnerships (in smaller areas); and two so-called Employment Pacts (in Dublin and Westmeath). About a third (24) of the Partnerships also operate a Local Employment Service. The Partnership Boards usually comprise representatives of statutory bodies, the community and voluntary sector, public-elected representatives and the social partners (trade unions, the business sector and - in rural areas - farming organisations). A wide and well-functioning business network is considered a key element in the partnership strategy.

The Partnership companies initially operated in the most disadvantaged areas and communities of Ireland, but now have a nation-wide remit. They are charged specifically with i) developing and implementing social-inclusion-type programmes and projects; ii) facilitating policy co-ordination at local and regional level; and iii) leveraging additional funds from multiple sources. All partnerships have contracts with Pobal, which manages the overall programme on behalf of the Department of Community, Rural and Gaeltacht Affairs.

Actions under the LDSIP are organised around three types of measures: i) Services for the Unemployed (the largest of the programmes); ii) Community Development; and iii) Community-Based Youth Initiatives.

LDSIP targets a wide range of groups - examples include the unemployed, lone parents, disadvantaged women, travellers, low-income farm households and migrants. Under the Services for the Unemployed measure, the long-term unemployed (those unemployed for more than 12 months) make up the single largest group (about one-third). The type of support given to clients varies from providing employment guidance and training opportunities to advocacy with employers and linking clients to the LES. Between 2000 and the end of 2005, the caseload of adult individuals supported under the Services for the Unemployed measure totalled approximately 143000 (of whom 55\% were female). Over this period, $54 \%$ of the clients enrolled in education and training, $20 \%$ went into employment and $12 \%$ into self-employment. For 2006, Pobal reports that 31891 people (including 5701 individuals assisted by the LESN) were supported under the measure. Of those supported, $37 \%$ are reported as having participated in education and training programmes (of whom $63 \%$ female), $15 \%$ placed into employment and $6 \%$ having entered self-employment. The lower percentage in employment may only reflect the time when status is reported, i.e. the 2006 data refer to the proportion of a group of unemployed that has entered employment within six months or a year and the 2000-2005 data refer to the proportion that has entered employment over periods of up to several years.

In the past, the Partnership programmes were largely funded by EU Structural Funds. However, LDSIP is now primarily funded by the National Development Plan; for the period of 2000-2006 it was allocated about EUR 300m (approximately $0.5 \%$ of the total NDP budget). Expenditure on the Services for the Unemployed measure had the largest share (45\%), followed by $33 \%$ on Community Development and $22 \%$ on Community-Based Youth Initiatives.

In 2006, the impact of the Services for the Unemployed measure was assessed through independent research (Eustace and Clarke, 2006). A caseload sample of 861 clients from 16 partnerships showed "a significant turn-around in terms of employment and self-employment outcomes as a result of interventions", although the study did not have a control group of comparable people who did not benefit from measure.

In November 2005, in a speech launching Pobal, it was announced that "The LDSIPs will be extended to cover the whole state" and "there shall be in any one area, only one such area-based company [...to] deliver those programmes". In August 2007 Pobal announced that "A sum of up to EUR 100000 will be available for each county / area structure as a whole" for the extension of social inclusion coverage beyond existing areas. Overall funding trends are not clear insofar as the Pobal website as of December 2008 still stated that "It is funded by the National Development Plan 2000-2006". However, the number of adults supported by the Services for the Unemployed measure in 2007 (about 26 000, excluding those assisted through LES) was little changed from the 2006 level.

Sources: As cited and Pobal (2006b; 2007; and 2008); OECD (2006b); www.pobal.ie/LDSIP/Pages/LDSIP.aspx; www.pobail.ie/en/MinistersSpeeches/2005/November/htmltext,6628,en.html; and www.cpn.ie/network/Article94.html. 
38. The LES provides local community-based Contact Points which act as gateways for both long-term unemployed people and potential employers to the full range of available employment options. The Contact Point provides information on the range of training, education and employment options available. It also refers clients to local, national and voluntary services for training, education, job information, job clubs and other social services, and provides access to the Mediation Service, which provides intensive guidance and counselling as well as active placement and aftercare services. The LES seeks to engage specific groups disconnected from the labour market, such as lone parents, the disabled or early school-leavers, and also takes referrals of people likely to benefit from its services from the local FÁS employment office. These counselling, referral and placement operations are discussed further below (see Chapter 3).

39. The decentralised nature of employment services is also embodied by the many sponsoring organisations of the FÁS-financed Community Employment projects (CE). These sponsors are mainly from the community sector. One of the organisations operating across the country is the Congress Centres Network. There are currently 25 Congress Centres, under the direction of the ICTU and local trade union councils, staffed mainly by CE participants. These Centres provide welfare advocacy services, job-search support and Job Clubs as well as on-the-job training through participation in, and management of, local CE projects. ${ }^{18}$ Some of them also act as LES Contact Points.

40. The above list of labour market actors is by no means exhaustive. In the area of activation policy - in particular regarding hitherto "inactive" groups, such as lone parents and the disabled - a High-Level Activation Group has been set up, comprising representatives from several Government Departments/Agencies and the social partners. The Office for Social Inclusion aims to facilitate access to work for the disabled and other disadvantaged people of working age and is responsible for developing and co-ordinating the 2007-16 National Action Plan for Social Inclusion. There is also the National Disability Authority, which plays a role in reintegration of the disabled of working age.

41. In the area of public training programmes, quality assurance standards have become increasingly important in recent years, and the respective FÁS services must now meet the requirements of the Further Education and Training Council (FETAC), the Higher Education and Training Awards Council (HETAC) and of the National Qualifications Authority of Ireland (NQAI). There is also the levy-based National Training Fund, which finances as much as one-third of the FÁS budget. Finally, the Irish National Organisation of the Unemployed (INOU), which aims to defend the interests of unemployed people and benefit recipients, is a pressure group wielding sometimes considerable influence.

42. In sum, the following features characterize employment services in Ireland:

- A separation of the benefit administration function from the employment service function (except for a limited number of DSFA staff providing employment services);

- A range of actors providing employment services, with DETE and DSFA at ministry level, FÁS and Pobal as national executive bodies, and FÁS offices, LES offices (managed by Partnership companies under contract to FÁS), LDSIP services (managed by Pobal) and Congress Centres (managed by the ICTU, but also part of the FÁS Community Employment scheme) providing placement and counselling at local level; and

- An overriding focus on training and upskilling of the labour force, employed and unemployed alike.

18. Around 2000, there were 1000 staff members in Congress Centres, the majority of which were CE workers. This number has now gone down substantially, to below 500, in line with the major reductions in the number of participants in the CE programme. 


\subsection{Main characteristics of the Irish Public Employment Service}

43. As outlined above, there are two "strands" to the Irish employment service: the Training and Employment Authority FÁS (Foras Aiseanna Saothair) and the Local Employment Service (LES), with FÁS being the principal organisation founded in 1988, and the LES providing, since 1995, additional guidance and placement services to more disadvantaged groups at a local level. The two organisations form the National Employment Service (NES), although use of this term is not particularly widespread. The National Employment Service Advisory Committee is in place to coordinate both strands. The NES is mainly funded through the Exchequer, via the Department for Enterprise, Trade and Employment.

\section{FÁS legislative mandate}

44. The 1987 Labour Services Act charges FÁS with “... the provision of training and re-training for employment, the provision of work experience and the establishment of employment schemes and job placement services ... " (text from the Act's subtitle). While placement services are not mentioned as its primary task, the text nevertheless includes in the FÁS remit the need to match supply and demand on the labour market and provide information and guidance services in respect of choice of career and employment. It also entrusts FÁS with the role of a decentralised, local player that "facilitates and assists ... local community groups and co-operatives of workers or of members of local communities in the provision of employment". To carry out these tasks, FÁS "shall have all such powers as are necessary or expedient for the performance of its functions" (Section 4). Compared with most other OECD employment services, FÁS has an extraordinarily broad remit, in particular since it includes the organisation of training for employed and unemployed workers. One factor here is the size of the country: Ireland has the OECD's smallest labour force after Iceland and Luxembourg and small countries tend to attribute more functions to the PES so as to minimize the complexity of governance. But complexity can still arise even in small countries, as it has in Ireland due to the public funding of several other organisations to provide employment services.

\section{FÁS mission statement}

45. The organisation is now in its second formal Statement of Strategy which relates to the period 2006 to 2009. While mission statements were less formal previously, FÁS' principal objectives have not changed substantially since the mid-90s' OECD review which identified the upskilling of the labour force and the improvement of business competitiveness as its main goals (OECD, 1998b). The current strategy Statement, which is closely aligned to the policy goals of the DETE, aims to "promote a more competitive and inclusive knowledge-based economy, in collaboration with our stakeholders, by enhancing the skills and capabilities of individuals and enterprises" (FÁS, 2005). Consequently, the Statement lists as FÁS' main customer groups a) employers; b) employees requiring upskilling; c) jobseekers and unemployed persons; and $d$ ) apprentices.

46. With the highlighted management focus of the organisation on the professional and efficient delivery of training and job-creation programmes, job-matching and placement activities have traditionally not been in the forefront of mission statements, or even FÁS annual reports. This may, however, be changing, as witnessed by the listing of "Entry to the Labour Market" as the first among eight high-priority goals - a goal that includes a focus on professional guidance, the set-up of activation mechanisms for unemployed benefit recipients, and the use of FÁS' employment services branch as a "gateway" and referral point to other labour market services. 


\section{Board structure, social partnership and degree of autonomy}

47. FÁS operates under the direction of a Board made up by a Chairman appointed by the Minister for Enterprise, Trade and Employment and of 16 ordinary members representing ministries and various interest groups. There are four employer representatives on the Board, four trade union delegates, (usually) five representatives of Ministries (of which two from DETE), one representative of youth interests and two FÁS employees. The social partners can easily have a majority on the board, particularly if the chairman is appointed from their ranks, as is usually the case. ${ }^{19}$ Voting is by majority, with the Chairman having a casting vote in case of deadlock.

48. In addition to shaping policy on the FÁS Board, employers and trade unions are also represented on FÁS National Advisory Boards (previously Training Committees) which advise on training needs and course content in the various sectors, as well as in the 30 plus local FÁS Training Centres.

49. Despite the relatively low number of Ministry representatives on the FÁS Board (maximum 5 out of 16), and although there are no formal additional powers given to the ministry members on the Board, the Labour Services Act allows a significant degree of government (particularly DETE) authority over the organisation. DETE provides funding and issues policy guidelines on FÁS operational programmes. More generally, the government board members enjoy significant status as full-time civil servants with good knowledge of day-to-day operations.

50. The Minister may at any time remove the chairman or any of the ordinary members (and the Director-General, for that matter) from office. The law also contains quite drastic language as to the powers of direction incumbent on the Minister, who can require FÁS to provide, or refrain from providing, specific services and to incur expenditure of specified amounts. FÁS needs to furnish to DETE, and the Finance Ministry, a business plan for the forthcoming financial year, and once this plan has been approved by both Ministries, is not allowed to depart from the outline, carry on any activities not specified therein or incur any expenditure in excess of the specific estimates given in the report.

51. FÁS autonomy vis-à-vis DETE - as well as the role of the social partners in policy-setting - is thus curtailed by the letter of the law and involves mainly implementation and operational issues. Also, changes in legislation have, in the past, had much impact on FÁS' strategic objectives, on programme funding, and on its position as an actor in the field of employment services and labour market programmes. ${ }^{20}$ Similarly, since FÁS is not responsible for benefit administration, it needs to cooperate with DSFA in order to implement activation measures such as the NEAP (see Chapter 3).

52. As a rule, DETE's Labour Market Policy unit and FÁS discuss jointly any desired changes in employment and training programmes, to reflect the respective strategy statements, as well as the guidelines of the Department of Finance for the annual "budgetary estimates" exercise. At a later stage, the FÁS Board agrees on goals and targets at the programme level and here again consensus with the government board members is important. The targets are later monitored both by the FÁS board and by the Department. $^{21}$

19. For example, the current Chair for the period 2006-2010, Peter McLoone, is the President of the ICTU.

20. For example, the LES was established in 1994 outside the framework of FÁS, only to be (to some extent) reintegrated several years later; and Enterprise Ireland was established in 1998 to take over parts of FÁS' in-company training function.

21. Boyle, N. (2005) gives some examples of relative FÁS autonomy in labour market policy setting, showing for example how the FÁS Director can occasionally bypass the Board and work out policy on a one-to-one basis 


\subsection{FÁS and LES office structure and internal organisation}

53. Section 2.2 above has listed the range of actors involved in labour market policy and the delivery of employment services and programmes. Using the traditional definition of public employment services, the Irish PES is considered here as being composed primarily of FÁS Employment Services, the Local Employment Service, and the unemployment benefit administration function of DSFA. Some role is also played by the LDSIP Services for the Unemployed programme ${ }^{22}$ and by the Health and Safety Executive (HSE), insofar as entitlement to the Supplementary Welfare Allowance can be conditional on availability for work. However, it needs to be noted at the outset that over two-thirds of FÁS staff do not work in the employment services area:

- FÁS Training Services division organises apprenticeship training and a wide range of skills training courses through its network of 30 training centers and contracted training providers. Participants may be out of work for varying lengths of time, want to change jobs or have recently graduated. Courses are designed to address skills and labour shortages and to increase the prospects of trainees gaining or returning to employment. Some courses are adapted to people who have left school early and to those returning to the labour market after a long absence; and

- FÁS Services to Business division provides training to employers and to people in employment, aiming to increase the competitiveness of Irish companies. A major component is basic skills training for low-skilled employees. FÁS has considerably expanded - in fact quadrupled - its expenditure in this area since 2004 (FÁS, 2006; and 2007). It typically funds this type of training to the extent of 60 or $70 \%$ of the cost.

54. The above divisions employ about half of the organisation's staff, with financing mainly from the National Training Fund.

- The Community Services division manages a range of training services and employment programmes in co-operation with different community groups. This includes the large Community Employment programme, the network of Community Training Centres and various local training initiatives (see Chapter 5). This division also used to manage the (now transferred) Social Economy programme and continues to organise Job Clubs ${ }^{23}$ and job schemes for disabled clients. Most of its staff work from FÁS training centres rather than employment offices.

55. FÁS Employment Services division currently operates a network of 70-plus employment offices grouped in eight regions, as well as a number of part-time offices (clinics") established in remote areas and manned only for a few hours per week. As in other OECD countries, these offices deliver placement and guidance services and act as a gateway to training programmes and job-creation schemes. They offer modern self-service facilities to jobseekers, such as touch-screen kiosks to consult vacancies, self-help guidance facilities, access to internet and printers, and free use of telephone to contact employers.

56. The division also includes about 20 staff in the National Call Centre in Edenderry, which was established circa 2002. Clerical staff at the Centre deal with telephone vacancy notifications for the whole country, and also with validation of vacancies inserted online by registered employers. Counsellor-level

with the Minister (p. 41); how the Board may in fact reject Ministry proposals for policy change (p. 97); or how in the past EU funds went directly to FÁS, bypassing the Department of Finance and DETE (p. 47).

22. Although Congress Centres might also regarded as part of the PES, staff on the CE programme would conventionally be counted as programme participants rather than a contribution to the PES budget.

23. It is currently planned to transfer Job Clubs to the Employment Services division. 
staff deal primarily with calls for information and advice from jobseekers who are already registered with FÁS.

57. Local offices tend to be quite small and have few staff; for example, among the 7 local offices in Dublin North, not a single one has over 10 staff. The main hierarchical division is between Employment Service Officers (ESOs) and clerical staff. Each local office in Dublin North has between 2 and 6 ESOs (full-time equivalents). Multiple tasks and job rotation among ESOs are therefore commonplace, and there is usually no distinction between functional areas of service.

58. There is a major involvement by FÁS staff in external committees: an internal count found 1000 memberships of committees (some staff being on more than one committee). The main types of committee where FÁS was represented were Area and Community Partnership companies (including their subgroups) and county/city development boards. (Participation in "social economy" enterprises has decreased since this programme was shifted to Pobal). According to FÁS' Director O'Callaghan (2003), there is a net benefit to the organisation from such participation on local committees, even though the consultation processes involved can be very time-consuming.

\section{Performance targets and degree of regional autonomy}

59. Management by objectives and the use of performance targets have become widespread tools in public management generally, and OECD employment services in particular (Mosley et al., 2001). This often goes hand-in-hand with devolution of authority to lower levels. FÁS Annual Reports contain varying lists of indicators for measuring performance, although quantitative targets for future years are not published. In the 2005 Annual Report, these were, inter alia, the number of PES registrations; the number of vacancies notified; the proportion of the Live Register and of the long-term unemployed who started employment programmes; the share of female participants; and the proportion of participants that completed their programme. In addition, internal FÁS Business Planning documents specify a range of four priority goals, broken down further into 22 objectives and 100 or more detailed principles of action. Most of these are qualitative by nature; the few quantitative targets relate to the speed of vacancy follow-up; the desired rate of increase of the FÁS vacancies market share; the employer satisfaction rating; and the number of disabled people placed in employment.

60. The degree of independence of the PES agency from the Ministry was discussed above; on the other hand, how autonomous are FÁS regional offices from the agency's headquarters? Boyle, N. (2005) argues that, in the 1990s, regions could use their budgets more flexibly and make their own tradeoffs regarding cheap vs. expensive programming. By contrast, it seems that their autonomy was curtailed after internal FÁS reorganisation in the early 2000s. However, regions continue to be consulted when programmes are being designed at the national level.

61. Subsequently, regional offices are responsible for overseeing the delivery of training and employment supports to clients in their regions. They need to respect the national definition of eligibility and target groups and do not design labour market programmes on their own, but they determine how budgets are spent and how programmes are best delivered, within the national parameters, but having regard to local or regional circumstances. There is thus some scope for the regions to deliver programmes in an innovative manner; for example, if the demand for apprenticeship places is particularly high in a region, meeting that demand might be given priority over other programmes.

62. FÁS regional offices are also responsible for outsourcing/contracting delivery of a range of programmes, e.g. Job Clubs and Community Employment. Local offices themselves decide on the selection of job-club suppliers and negotiate annual targets for the Local Employment Services (LES) on 
the basis of their local expertise. On the other hand, except for the annual targets, the wording of the FÁS contracts with Partnerships for the management of the LES is nationally uniform.

\section{Liaison with the benefit administration}

63. Until 1971, unemployment benefits were administered by local offices of the Department of Labour, but since then unemployment benefits have been administered by the Department of Social and Family Affairs and its predecessor (the Department of Social Welfare, DSW, from 1947 to 1997). DSFA's Social Welfare Services are organised into 10 regions and deliver services through 58 local offices and 68 branch offices. There is thus no complete regional or local correspondence between employment service and social security offices (FÁS having 70-plus offices grouped into eight regions). It is nevertheless standard practice to locate new FÁS and DSFA premises in the same building, or at least close to each other.

64. Up to the early 1990s, there used to be limited co-operation between FÁS Employment Services and the benefit payment offices; for example, while benefit recipients had to sign on monthly in the benefit office, DSFA did not normally require benefit recipients to register with FÁS and did not rely on FÁS to verify job search and assess claimants' availability for work. However, since the 1990s DSW strengthened its employment support services, creating 30 posts of "Job Facilitator" (now called "Facilitator") by 1994 in connection with the introduction of the Back to Work Allowance (see Chapter 5; and Ronayne, 1996). Operational co-operation with FÁS began in 1996 when DSW required people aged 18 and 19 and unemployed for more than six months to register with FÁS. This approach was extended with the introduction of the National Employment Action Plan (NEAP): DSFA referred over-25s to FÁS after 12 months' unemployment from 1998 and subsequently this threshold was progressively advanced (currently after three months' unemployment).

65. Considering that the NEAP started in 1998, it might be considered surprising that not until 2004 did FÁS and DSFA sign a Memorandum of Understanding, envisaging the establishment of joint local and regional structures to assist in the effective management and co-ordination of the process. ${ }^{24}$ Terms of reference were agreed for regular regional/local meetings on the basis of the Memorandum, and meetings between FÁS counselors and DSFA benefit administrators and Facilitators now take place more or less regularly in all areas to discuss any problems with the NEAP referral process and individual - often notprogression-ready or perhaps non-co-operative - clients. ${ }^{25}$

\section{The LES and its relationship to FÁS}

66. As noted above, the LES provide locally responsive specialist service for the most disadvantaged and intensive mediation oriented towards employment and training outcomes. Although the decision to "mainstream" the LES and put it under the roof of FÁS (it was previously under direct authority of DETE) was taken in 1999, the 2003 Fitzpatrick Report still noted a low degree of service coordination between the two "strands" of the Employment Service and a low level of contact between their frontline staff. The report recommended the creation of a national organisational framework, with common entry points and a single employment service "brand". It remains true that FÁS offices do not track specific operational

\footnotetext{
24. There is also a high-level inter-departmental group overseeing the NEAP.

25. The Memorandum of Understanding was reviewed in 2006 and was scheduled for updating in 2008 in light of feedback received and the respective organisations' current Strategy Statements (DETE, 2007c).
} 
details in nearby LES offices. ${ }^{26}$ However, the Partnership Company in each area manages the LES under contract from FÁS, which specifies performance details. FÁS is also represented on the Partnership boards.

67. According to the "Guidelines for the Operation and Administration of Local Employment Services Networks" (previously the LES Operational Framework) negotiated between FÁS and the partnerships, its main target groups are the long-term unemployed and their dependent partners, FÁS referrals under the NEAP process and additional groups with a considerable distance from the labour market (FÁS, 2006b; Fitzpatrick Associates, 2003). ${ }^{27}$ Further detail on required activities and priority groups is given in the Funding Agreements negotiated between FÁS and the Partnerships. These agreements are identical except for the locally-negotiated quantitative targets. They contain a commitment from the LES to submit regular performance reports, use the FÁS caseload management system and provide rights of access to FÁS inspectors. ${ }^{28}$ They also specify that under no circumstances shall FÁS be deemed to be the employer of LES staff, although it provides the funding and its standard pay rates apply as well to LES staff, who also undergo the same type of training.

68. Corresponding to their outreach mandate, LES staff operate from a large number of small offices spread over the 25 LES areas, so that their number easily surpasses that of FÁS employment offices - for example, in the Dublin region there are 20 FÁS and 43 LES offices. Each LES outlet is manned by 1 to 3 staff, while the average area staff is 12 . One or more of the contact points in each area are designated as Local Employment Centres that provide more intensive services than those available elsewhere. Since the LES covers only a portion of the whole country, it can be assumed that in a number of areas as many LES as FÁS counsellors are actively working with the unemployed and other target groups.

69. While the LES have about $60 \%$ as many staff as FÁS Employment Services (see next section), expenditure levels are closer to 50\% (the LES in 2006 had a budget of EUR 17.7 million, FÁS employment services of EUR 33.9 milion). ${ }^{29}$

\section{LDSIP Services for the Unemployed}

70. In 2006, financing for LDSIP as a whole was EUR $47.4 \mathrm{~m}$ and at local group level $40-65 \%$ of this funding was allocated to Services for the Unemployed (Pobal, 2007, pp. 15-17). This suggests that public expenditure on LDSIP Services for the Unemployed totaled slightly more than spending on the LES (see also Section 2.6 below).

71. It is not clear to what extent Services for the Unemployed are integrated with the Local Employment Services, where these exist in the same Partnerships. Pobal (2007) states that Services for the Unemployed in 2006 supported 31891 people of whom 5701 were assisted by the LES "through an

26. Since the Fitzpatrick Report, some progress in achieving a closer working relationship between FÁS and the LES has nevertheless been achieved. Several national structures now work to co-ordinate the dual-stranded public employment services, among which) the National Employment Service Advisory Committee and the FÁS/LES/PLANET Committee.

27. Each regional funding agreement specifies these additional target groups and usually adds targets for client troughput per LES mediator and for client "progressions". If the specified targets are not achieved, the funding will be adjusted pro rata.

28. It is not entirely clear when the use, by LES, of FÁS Client Database and Management Information Systems started and whether events are recorded in a comparable way. DETE (2005c) reports annual registrations, employment progression and training/education progressions for LES back to 2002, but the number of LES progressions claimed in 2004 was well above the number of LES registrations.

29. FÁS central services such as IT must contribute to the operations of both areas, but perhaps more to the FÁS side (see also the section below). 
integrated series of interventions". Registration and progression data (entries to employment, self-employment and training) for Services to the Unemployed are entered into a central database located at Pobal (and formerly ADM, its predecessor) (DETE, 2005b; and Eustace and Clarke, 2006). This probably has different reporting standards from FÁS and DSFA databases (for example, FÁS staff can access the DSFA system to check the social welfare/Live Register status of clients, which does not seem to be the case for Partnership staff), with many cases of overlap (individuals recorded in both Pobal and FÁS information systems).

\subsection{Office networks and staff resources}

72. Table 2.1 give an impression of the current office networks, staff resources and workload of the Irish PES, allowing a comparison of PES resources over time between 1996 and 2006. In late 2007, all FÁS units combined, including training services and the management of employment schemes, employed over 2200 staff. However, consistent with previous OECD reviews in this area, the comparison of PES staff numbers should concentrate on employment services and not include the implementation of training and job-creation programmes (other than central administration). For over a decade, placement and counselling services in Ireland have been provided by the LES network as well as FÁS. Despite the complexity of the institutional arrangements, both strands are therefore included in the analysis of PES staff here. The table shows staff figures and workload ratios for FÁS alone, and for FÁS and LES staff combined, demonstrating that without the LES the country's PES infrastructure would be considerably understated. ${ }^{30}$

73. Considering FÁS and LES together, there were 1934 wage and salary earners in Ireland in 2006 per employment office staff member (including regional and head office management). Some other internationally comparative figures for the staff of the PES are available for the mid-1990s and for 1999. For Australia and countries of Northern and Western Europe, which are relevant points of comparison for a country which has a comprehensive benefit system, the ratio of dependent employment (i.e. wage and salary earners) to PES staff not including the benefit administration function averaged 700 to $800,{ }^{31}$ less half the level in Ireland. ${ }^{32}$

74. FÁS Employment Services (ES) staff currently number slightly over 500 in full-time equivalents, a $20 \%$ increase over 1996 . LES staff number 311 , a $60 \%$ increase over the same period. The large majority of FÁS-ES staff are employed in local offices and only $6 \%$ in headquarters. This is even more true for the LES which does not have a head office. Offices are relatively small in international comparison, with 6 to 7 staff on average in the case of FÁS, and even fewer in the LES network. The number of regional office

30. Facilitators in Social Welfare Offices could also be included in the definition of overall placement and related PES staff in Ireland. They and other staff (e.g. in Community Services and Central Services divisions) also contribute to OECD Category 1 (PES and administration) of the LMP expenditure database.

31. Averages for Belgium, Denmark, Finland, the Netherlands, Portugal, Sweden and the United Kingdom in the mid-1990s (OECD, 2001a, p. 54) and for Australia, Denmark, France, the Netherlands and Sweden in 1999 or 2000 (Lippoldt and Brodsky, 2004, Table 7.4) are both between 700 and 800 . For total staff in the PES including unemployment benefit administration (in data for a partly-different list of countries, since for example Germany can be included in this list) the average number of wage and salary earners per PES staff member was about 500 at both dates. Expenditure data suggest that in EU countries the resources of the PES increased on average after 2000 (Grubb and Puymoyen, 2008, Annex B).

32. Although the figures for other countries refer to the staff of PES bodies that do not have the benefit administration function, they do in some cases administer active labour market programmes. If the calculation for Ireland were reworked to include about 300 staff in FÁS Community Services division who administer Community Employment and local/community training initiatives, the calculated number of wage and salary earners per FÁS and LES staff member in 2006 would be about 1400 rather than 1934. 
staff working on employment services is also quite small - the number in the table is inflated by the about 20 staff working in the national call centre.

Table 2.1. Employment office networks and staff resources, 1996 versus 2006

\begin{tabular}{|c|c|c|c|c|}
\hline \multirow{2}{*}{ PES staff } & \multicolumn{2}{|c|}{1996} & \multicolumn{2}{|c|}{2006} \\
\hline & FÁS & FÁS + LES & FÁS & FÁS + LES \\
\hline Total, incl. training services & 2030 & & 2263 & \\
\hline Total, excl. training services & 430 & 620 & 511 & 822 \\
\hline \multicolumn{5}{|l|}{ Of which in: } \\
\hline Local offices & .. & & 439 & \\
\hline Regional (intermediate-level) offices & .. & & 42 & \\
\hline Head office & .. & & 30 & \\
\hline \multicolumn{5}{|l|}{ PES office network } \\
\hline Regional offices & 10 & & 8 & \\
\hline Local offices & 50 & & 70 & \\
\hline Average area of a local office $(\mathrm{km})$ & 1406 & & 1000 & \\
\hline Average population of a local office (thousands) & 72 & & 59 & \\
\hline Average workforce of a local office & $6-7$ & & $6-7$ & \\
\hline \multicolumn{5}{|l|}{ Stock per PES staff member } \\
\hline Population & 8367 & 5803 & 8043 & 5000 \\
\hline Labour force & 3475 & 2410 & 3933 & 2445 \\
\hline Wage and salary earners & 2405 & 1668 & 3112 & 1934 \\
\hline Registered unemployed & 649 & 450 & 307 & 191 \\
\hline Benefit recipients & 608 & 422 & & \\
\hline Notified vacancies & .. & .. & 60 & 37 \\
\hline \multicolumn{5}{|l|}{ Annual flows per PES staff member } \\
\hline New registration of unem ployed & .. & .. & 142 & 89 \\
\hline Vacancy inflow & 105 & 73 & 301 & 187 \\
\hline Placements $^{a}$ & 40 & 28 & 139 & 86 \\
\hline \multicolumn{5}{|l|}{ Memorandum items: } \\
\hline \multicolumn{5}{|l|}{ Annual average stocks (thousands) } \\
\hline Population & \multicolumn{2}{|c|}{3598} & \multicolumn{2}{|c|}{4110} \\
\hline Labour force & \multicolumn{2}{|c|}{1494} & \multicolumn{2}{|c|}{2010} \\
\hline Wage and salary earners & \multicolumn{2}{|c|}{1034} & \multicolumn{2}{|c|}{1590} \\
\hline Registered unemployed & \multicolumn{2}{|c|}{279} & \multicolumn{2}{|c|}{157} \\
\hline Benefit recipients & \multicolumn{2}{|c|}{262} & \multicolumn{2}{|c|}{126} \\
\hline Notified vacancies & \multicolumn{2}{|c|}{.. } & \multicolumn{2}{|c|}{31} \\
\hline \multicolumn{5}{|l|}{ Annual flows (thousands) } \\
\hline New registration of unem ployed & \multicolumn{2}{|c|}{.. } & & 73 \\
\hline New benefit recipients & & 32 & & \\
\hline Vacancy inflow & & 5 & & 54 \\
\hline Placements $^{a}$ & & 17 & & 71 \\
\hline
\end{tabular}

Data not available.

a) Vacancies filled by FÁS referrals.

Source: OECD (1998b) for 1996; information supplied by FÁS for 2006; and OECD Labour Force Statistics database.

75. At FÁS, 54\% of ES-staff (about 275 persons) are ESOs involved in placement and counselling; $7 \%$ are management grades and the rest are clerical staff. At the LES, the 160 Mediators (in full-time equivalents) also represent over half of total staff. These high ratios of professional counselors and placement officers to total staff reflect organisations that do not suffer from high bureaucratic overheads. 
76. The stock and flow figures per staff member in the table show that despite the growth in staff numbers, the labour force and dependent employment grew even faster since 1996. However, the number of registered unemployed (Live Register) to be serviced by one staff member declined significantly up to 2007 , to a ratio of 1 to below 200. The rising vacancy inflow to FÁS in this decade's more buoyant labour market has also meant more vacancies and more successful placements (187 and 100, respectively, in 2006) handled per staff member.

77. Clients on the Live Register are not necessarily the most suitable measure of PES staff/client ratios, since some of them never set foot in an employment office. A different type of measure is the number of NEAP clients per FÁS-ESO, or the number of active clients on the officer's caseload at any given time. Considering that in recent years there have been between 38000 and 52000 NEAP referrals (of whom a third tends not to show up for the requested interview), an average ESO may be in contact with 100 NEAP clients in a given year. The average stock figure of 30 active NEAP clients on caseload per employment officer communicated to the OECD review team during one office visit, also seems relatively low; however, NEAP interviews and follow-up are only one element of staff activity and since FÁS also services other client groups - walk-in clients, labour market returners, job changers, persons recently made redundant - the actual workload is much higher.

78. Information is available for the breakdown of staff by age and gender and by contract status. First, all FÁS-ES staff are public servants, while approximately $5 \%$ are seconded civil servants. The overwhelming majority (79\%) of staff is female; however, half of the female staff work in clerical positions ( $14 \%$ of men), and only $3 \%$ in managerial posts ( $20 \%$ of men). About half of FÁS-ES staff are over the age of 45 .

79. As in other countries where unemployment benefit is handled by a Ministry dealing with Social Security more generally, it is difficult to separate out the number of staff working on unemployment benefits. DSFA local and branch offices perform a variety of functions: a comprehensive information service including directed referral to other agencies; the processing of retirement, sickness, disability and family benefits: and the allocation of the Personal Public Services Number, the unique social services identifier. A large part of the activity, however, focuses on administering the range of unemployment schemes, including the implementation of the NEAP. It can be estimated that at least half of the local Social Welfare office staff works in this area, which would correspond to about 1000 staff.

80. In addition, half of the Department's Labour Inspectorate works on unemployment schemes administration and control, which would correspond to about 200 staff. Finally, the Department's Employment Support Service with its Facilitators and corresponding support staff counts about 60 staff. In total, this would give 1260 staff working on the benefit function, including control and "activation", i.e. about 50\% more than the staff working at FÁS and LES on placement, counselling and referral to active programmes. By contrast, most OECD countries have more staff working in placement and counselling units than on the benefit function, often with a relationship of close to 2 to $1 .^{33}$

\subsection{Expenditure on the Public employment service and administration function}

81. To compare the level of expenditure on placement and related services or the PES (including benefit administration) in Ireland with that in other countries, total spending in Category 1 of the Eurostat/OECD LMP database needs to be estimated according to the OECD definition. ${ }^{34}$ The

33. The exception is Belgium, where the benefit agency (ONEM) also has more staff than the three regional placement agencies combined.

34. In the OECD definition, Category 1 includes the cost of placement and related services including placement-focused programmes (e.g. job-search training and job clubs); the overhead administration costs 
responsibilities of national institutions vary widely, in some cases including functions such as implementing labour market programmes (e.g. vocational training, in Ireland) that belong in another category of the LMP database, and implementing programmes that are outside the scope of the LMP database. ${ }^{35}$ Detailed analysis may be needed to generate approximately accurate estimates. Table 2.2 shows results from such an analysis for Ireland. In order to maximize the time-series continuity of OECD data, the estimates are made for years back to 1998 .

82. FÁS accounts identify six areas of direct staff costs: Training Services; Community Services; Services to Business; Employment Services; Regional Support; and Central Support. However, Regional Support and Central Support themselves are overheads that support the delivery of outputs in the first four areas. ${ }^{36}$ Based on the distribution of staff costs across the first four services, about $1 / 3$ of FÁS costs in 1998 , rising slightly to about $40 \%$ in 2006 , support employment services and the administration of labour market programmes other than training. Table 2.2 includes this share of FÁS non-programme costs (including travel, pension costs, establishment, i.e. buildings and maintenance, IT costs, etc.) as expenditure within the scope of Category 1.

83. There is a statistical break in the data for FÁS staff costs in 2004 when the accounts began to include full estimates of staff pension liabilities; by 2006, these were about a quarter of direct staff costs. Only a limited proportion of the pension costs now reported appear to have been included in accounts prior to 2004 .

84. In 2000, the line Total FÁS staff costs and overheads, which is based on figures in FÁS accounts, increased by nearly $50 \%$. This reflects the integration of staff of the former National Rehabilitation Board (NRB). Table 2.2 includes the NRB counselling/guidance function in the line IE-22 Counselling/guidance even before 2000, so that the shift of these staff between institutions does not result in a statistical break in the Category 1 total lines.

of other active programmes (although the attributable management and implementation costs of measures in Categories 2 to 7 are allocated to the relevant measure); and the administration costs of passive benefits that are within the scope of the LMP database (unemployment benefits, any other benefits conditional on availability for work, and early retirement for labour market reasons, but not "inactive" benefits). See the note on scope and comparability at www.oecd.org/els/employment/data.

35. The Eurostat definition of Category 1 includes the total budget of PES institutions, with PES institutions identified as the bodies delivering placement-type services. This may or may not include expenditure on non-PES functions such as labour inspection, the administration of benefits that are inside or outside the scope of the LMP database, and the costs of labour market programmes that are inside or outside the scope of the LMP database.

36. The FÁS Employment Service budget excluding regional and central support would not be comparable with the total budget of an institution that delivers placement and related services in another country, nor would it represent the full cost of the services finally delivered. 
Table 2.2. Estimation of Category 1 Public employment services and administration in OECD data for public expenditure on labour market programmes, 1998-2006

Million euros

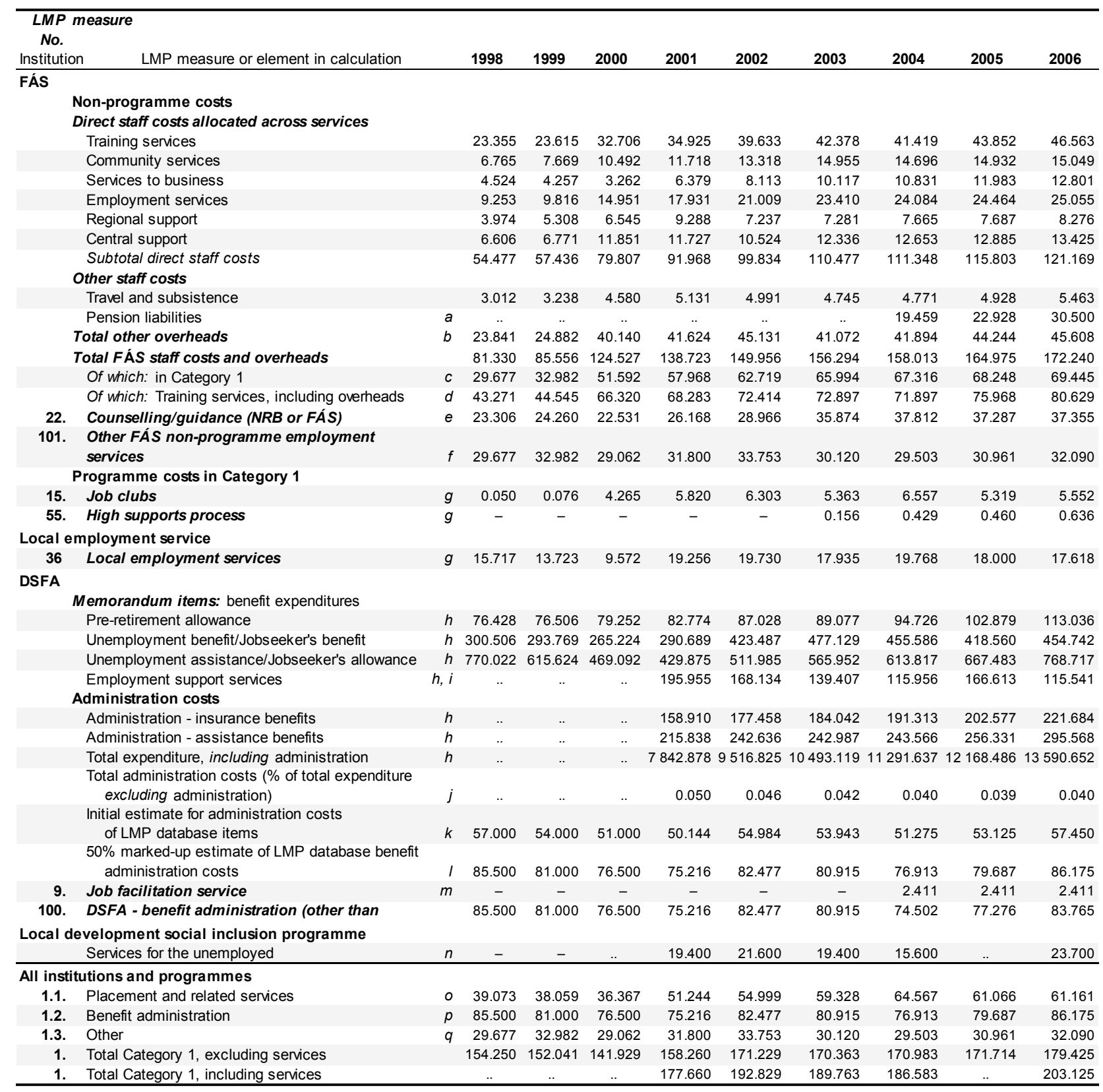

.. Data not available.

- Nil or less than half of the last digit used.

a) Pension liabilities were not separately listed and were not fully included in FÁS accounts prior to the adoption of FRS 17 accounting standards.

b) Other overheads include: Depreciation; Establishment Costs; Maintenance and Development of Training; Communications and Information Technology; Insurances; Staff Training and Development; and Other.

c) FÁS total Staff costs and overheads, multiplied by the share of Community Services and Employment Services within the first four staff cost lines.

d) This is a memorandum item used elsewhere (to estimate the cost of training programmes); calculated similarly to the previous line.

e) The figures shown for counselling/guidance in 1998 and 1999 represent expenditure by National Rehabilitation Board, not included in FÁS accounts. The NRB was abolished with transfer of its staff to FÁS in 2000. 
f) FÁS non-programme employment services and programme administration costs, other than IE-22 counselling/guidance: starting 2000 , this is calculated by subtracting counselling/guidance from the total for non-programme employment services and programme administration costs (see previous note).

g) Item treated as programme expenditure in FÁS accounts. Expenditure data are taken from Eurostat LMP data when available, otherwise from FÁS accounts.

h) Data from 2001 onwards as reported in DSFA Annual Reports 2001 to 2006. Figures for 2006 were preliminary. Benefit expenditure data for 1998 to 2000 are as reported in Eurostat LMP database.

i) Employment Support Services administer the Back to Work, Back to Work Enterprise and Back to Work Education Allowances.

j) Calculated from the three lines above, which appear to include the administration costs of Employment Support Services.

k) Expenditure on the benefit items separately listed, multiplied by the global ratio of administration costs to non-administration costs from the previous line. Values for 1998 to 2000 are "guesstimates" taking into account that DSW benefit administration costs in 1996 were reported to OECD as IEP 44.6 million (EUR 57 million) and the higher volume of unemployment benefit claims in the 1990s.

I) Initial estimate marked up by $50 \%$ to account for the relatively higher administration costs of unemployment payments as compared to other major benefits: see text.

$m$ ) Data reported in the Eurostat LMP database: the values reported appear to be approximate (the Job facilitation service has operated since 1993) but the calculation in the following line ensures that this does not affect Category 1 total expenditure.

n) Estimates including administrative costs for 2001 to 2004 as reported in DETE (2005b); estimate for 2006 represents $50 \%$ of total LDSIP budget for that year (see main text).

o) Measures 22, 15, 55 and 36: these do not include Community Services staff costs and overheads.

p) Measure 100: includes administration costs of DSFA labour market programmes (Back to Work/Back to Education schemes).

q) Measure 101: this probably includes some spending on placement services, but mainly represents Community Services (i.e. the administration of Community Employment and other local schemes).

Source: FÁS Annual Reports 1998 to 2006, Notes to the Financial Statements (www.fas.ie/en/About+Us/Publications+and+Resources/Annual+Reports.htm); Eurostat LMP database; Grubb and Puymoyen (2008); DSFA Annual Reports 2001 to 2007; DETE (2005); and Pobal (2007).

85. Three items which FÁS accounts list as programme costs rather than staff costs are also counted as part of Category 1 expenditure, i.e. Job Clubs, the High Supports Process and Local Employment Services. Total Category 1 spending, excluding benefit administration, is thus estimated at EUR 93.25 million in 2006. About $2 / 3$ of this is allocated to Subcategory 1.1 Placement and related services.

86. Category 1 also includes the administration costs of benefits within the scope of the LMP database (i.e. benefits conditional on availability for work, and early retirement benefits for labour market reasons). For years up to 2006, DSFA has only reported administration costs for two broad categories insurance benefits and assistance benefits - without any more detailed breakdown. Table 2.2 makes an initial estimate by applying the administration cost ratio for all benefits to expenditure on the benefits within the scope of the LMP database. The true administration cost ratio for unemployment payments will be much higher than for old-age pensions ${ }^{37}$ and probably also higher than for several other large benefits which involve no (or infrequent) retesting of eligibility such as Child Benefit, Invalidity Pension and Disablement Allowance. But it might be lower than for other benefits where the administration has to handle frequent changes in individual circumstances: the Supplementary Welfare Allowance, another fairly large benefit, had an administration cost ratio of $7.5 \%$ in 2005 (DSFA, 2006b, Table 3.1).

87. Given these considerations, Table 2.2 applies a $50 \%$ mark-up so that the administration cost ratio finally applied to unemployment and related payments in 2006 is $6 \%$. Total DSFA administration costs, within the scope of the LMP database, are thus estimated at EUR 86 million in 2006. This is nominally allocated to Subcategory 1.2 Benefit administration, although in fact part (probably about

37. According to estimates for 2007 (reported in DSFA, 2008), the administration cost ratio in terms of directly-allocated staff was $1.5 \%$ for the area "retired and older people" and 3.3\% for the area "working age". These figures do not include DSFA expenditure on "operational capabilities": if this expenditure is allocated proportionally, the full administration cost ratio for the area "working age" can be estimated as $5.0 \%$. 
EUR 10 million) ${ }^{38}$ of this total represents the administration of Employment Support Services, i.e. the Back to Work and Back to Education schemes, which are treated as labour market programmes (Categories 2, 4 and 7) in the Eurostat/OECD LMP database (see Table 5.1).

88. The estimates on the basis of Table 2.2 seem fairly consistent with related information supplied to OECD by national authorities. ${ }^{39}$ The final lines in the table sum the spending in different "measures" in the table (the non-measure lines are only intermediate steps in the calculation). Total spending on Category 1 PES and administration in Ireland in 2006 was EUR 179.4 million, about 15\% lower than previously estimated, and about $0.10 \%$ of GDP rather than $0.12 \%$ (the figure previously published by OECD for 2006). Previous estimates overstated the amount of FÁS expenditure that falls within Category 1. The current estimates assume that a share of regional and central support staff, pension liabilities and overheads - such as the building and maintenance costs - should also be counted as costs of training services.

89. Including estimates of total spending on LDSIP Services for the Unemployed, the total would be pushed back up to $0.11 \%$ or $0.12 \%$ of GDP; however, spending estimates for this programme are incomplete and some of its services may not merit inclusion. ${ }^{40}$ At the same time, it should be noted that expenditure as a percentage of Gross National Income (GNI) would be about 0.02 percentage points higher than it is as a percentage of GDP.

\subsection{Summary of main points}

- Ireland belongs to the minority of OECD countries where the placement function of the employment service is separated from the benefit function.

- FÁS, the major strand of the Irish public employment service, was established under the 1987 Labour Services Act and currently employs about 2300 staff. It has a broad remit, including placement and guidance services but also the organisation and implementation of training for employed and unemployed workers. The law allows FÁS only limited autonomy vis-à-vis DETE, involving mainly implementation and operational issues.

- $\quad$ FÁS Employment Services division operates a network of 70-plus relatively small employment offices, which deliver placement and guidance services and act as a gateway to training programmes and job-creation schemes. The eight FÁS regional offices are responsible for FÁS training centres and contracting for a range of programmes, e.g. purchased training, Job Clubs and Community Employment. They determine how budgets are spent and how programmes are best delivered.

38. Apart from the advice and support services delivered by Facilitators, other sections of DSFA are involved in administering the schemes comprising ESS, including Social Welfare Local Offices, the Pensions Service Office (Sligo) and the Social Welfare Service Office (Longford) (WRC, 2006b).

39. In 2006, the annual budget was EUR 33.9 million for FÁS Employment Services: this is less than is reported to Eurostat for the "counselling/guidance" function alone (and not including the LES), so it probably does not include all overheads. OECD was advised that the 2006 annual budget for DSFA Regional Functions (including salaries, travel, energy and accommodation) was EUR 93.9 million. These offices work mainly on unemployment schemes but some of their work - for example the work of Social Welfare Inspectors - relates to a wider range of programmes. Against this background, the estimate of EUR 86.2 million for DSFA benefit administration (including Facilitation service) in Table 2.2 seems reasonable.

40. For example, if Services to the Unemployed make cash grants to individuals to support their entry to training or self-employment, that should be counted as programme expenditure. 
- The Local Employment Service, set up in the mid-1990s, is a second strand of Ireland's National Employment Service; it provides more intensive guidance and placement services at local level to disadvantaged groups. Corresponding to their outreach mandate, LES staff operate from a large number of small offices spread over 25 areas; the number of LES offices surpasses that of FAS employment offices, although they have fewer staff per office. In most of its areas of operation, the LES is managed by the local or area Partnership Company under contract from FAS, which specifies quantitive performance targets for the LES via Funding Agreements.

- Another actor of importance is Pobal, a non-profit company which manages the Local Development Social Inclusion Programme - a series of measures aimed at addressing the problems of social exclusion, poverty and unemployment. This programme is carried out by 71 Partnership Companies operating throughout Ireland.

- FÁS Employment Services staff currently number slightly over 500 in full-time equivalents, a $20 \%$ increase over 1996. LES staff number 311, a 60\% increase over the same period. When using dependent employment (wage and salary earners) as an indicator of the potential client workload, however, staff/client ratios have not improved, since dependent employment has grown faster than this staff total. By this measure, the Irish PES is still under-resourced when compared to other countries of Northern and Western Europe. The number of registered unemployed (Live Register) to be serviced by one staff member declined significantly over the decade while the increased vacancy inflow to FÁS in the more buoyant labour market of recent years increased the number of vacancies and placements per staff member. In terms of overall staffing resources, Ireland is also an outlier in international comparison in the sense that more staff are working on the unemployment benefit function than on the placement function.

- A review of data for expenditure on Category 1 PES and administration of the OECD LMP expenditure database has concluded that expenditure in 2006 was $0.10 \%$ of GDP, of which slightly more than half is for DSFA benefit administration. If LDSIP Services for the Unemployed is included the total is $0.12 \%$ of GDP and $0.14 \%$ of Gross National Income, which arguably is a more appropriate denominator for Ireland. The last of these figures is below the average for other OECD countries of Northern and Western Europe, but above the estimate for Norway, Switzerland and a number of OECD countries in other regions. 


\section{CHAPTER 3}

\section{EMPLOYMENT AND PLACEMENT SERVICES}

\subsection{Introduction}

90. This chapter first describes some operational features of employment and placement services and current procedures for jobseeker and vacancy registration. It then outlines the methods used for vacancy advertising and display and discusses patterns of client activation, job-search assistance, career guidance and employer outreach. This is followed by an analysis of employment services by the LES Network and of referral processes under the National Employment Action Plan (NEAP). The last section of the chapter outlines some quantitative trends in jobseekers, vacancies and placements and analyses measures of PES market share.

\subsection{The National Employment Service}

91. The term "National Employment Service" refers to FÁS Employment Services together with the Local Employment Service (LES). ${ }^{41}$

\section{Overview of FAS Employment Service operations}

92. The primary responsibility for job matching and placement in Ireland lies with FÁS Employment Services (FÁS-ES). As in other OECD countries, employment offices deliver placement and guidance services to registered unemployed and other walk-in clients and act as a gateway to training and job-creation programmes (although guidance as regards employment subsidies is mainly provided by DSFA). To jobseekers, they offer the now internationally-standard self-service facilities, such as touchscreen kiosks to consult vacancies, self-help guidance facilities, promotional literature, access to internet and printers, and free use of telephone to contact employers. To employers wishing to advertise vacancies they provide a free recruitment service, and assist them with access to jobseeker CVs. FÁS offices also provide information on job opportunities in other EU member states under the EURES programme and assist employers in obtaining staff from abroad.

93. In contrast to the 1990s, employment services have, in recent years, been operating in a labour market characterized by close-to-full employment (with a labour force survey unemployment rate of between 4 and 5\%). Also in 2000 a number of staff of the National Rehabilitation Board were, with its abolition, transferred to FÁS and disabled clients were mainstreamed into FÁS' guidance/counselling function. There have been some attempts at engaging more systematically with other client groups on inactive benefits. Thus FÁS-ES have increasingly responded to the needs of those who are most distant from the labour market and who present special difficulties of reintegration.

41. DETE (2000) already stated that "The National Employment Service will incorporate the specialist Local Employment Service for long-term unemployed", and as from 2001 the LES was listed in Financial Statements of FÁS Annual Reports. The term has been more widely used specifically to include the Local Employment Service since about 2005, following recommendations for closer integration. 
94. Local offices employ Employment Service Officers (ESOs) and Clerical Officers (COs), with ESOs accounting normally for just over half of total office staff. The clerical staff provide welcome services, input jobseeker data and handle the electronic transfer of funds for employment programmes. FÁS estimates the ESO pattern of time-use as: ${ }^{42}$

- $30 \%$ on interviews with/support for clients caseloaded under the NEAP;

- $25 \%$ on interviews with/support for non-NEAP clients (lay-offs, job changers, unemployed persons registering with FÁS early on, etc.);

- $15 \%$ on vacancy matching and employer contact;

- $10 \%$ on disability support; and

- $20 \%$ on course recruitment, EURES, various working groups, meetings with other organisations, etc.

95. Apart from matching vacancies with available jobseekers and providing an infrastructure for independent job-search, among the more fundamental aims of FÁS-ES are to mobilize labour supply and stem the flow into long-term unemployment. They do so by focusing most of their activity on specific target groups, in particular:

- Clients referred under the NEAP;

- Early school leavers;

- Employees threatened by redundancy;

- Disabled jobseekers;

- Clients coming out of FÁS training and employment programmes; and

- $\quad$ The long-term unemployed (a responsibility shared with the LES).

\section{Jobseeker and vacancy registration}

96. In Ireland, registration for placement is not a precondition for benefit (see Section 3.3). When unemployed persons apply for benefit at a Social Welfare office, they are not immediately advised to register with FÁS, although many claimants voluntarily present at FÁS Employment Offices for assistance. This is done for operational reasons, since many claimants sign off within a month and the employment service is inclined to save scarce resources that might otherwise be spent unnecessarily. DSFA then advise all claimants, after one month "signing-on", to register with FÁS. The downside of this is that a full registration interview with the placement service only occurs relatively late in the unemployment spell and FÁS is not engaged in screening of availability as a precondition for benefit entitlement or of job-search evidence as a precondition for continuing payment.

97. A number of unemployed jobseekers decide to register early both with DSFA for benefit, and with FÁS for placement assistance. These clients, as well as those referred to FÁS after a month or more, receive an intensive registration and guidance interview in a FÁS local office. ${ }^{43}$ This registration interview includes a vocational assessment, based on information gathered on the individual's aptitudes, interests and

42. Reply by FÁS in response to a question asked by the review team, December 2007.

43. However, in 2006 a sizeable group (18\%) reported that they did not receive a registration interview (FÁS, 2007d). 
professional attainments. Key personal details, such as work history, type of employment sought, interest in a FÁS employment or training programme, are then keyed into the electronic system. The interview also serves to identify whether jobseekers are directed to self-service facilities or whether they require additional supports (as in the case of disabled clients, early school leavers, or women returning to the labour force). In the latter case, ESOs will usually decide to "caseload" the client for more intensive follow-up. Caseloaded clients - under the NEAP or otherwise - usually receive priority in terms of referral to intensive support programmes.

98. The 2006 FÁS Customer Satisfaction Survey (FÁS, 2007e) throws some light on the type of clients registering with FÁS and the reasons for registering. 62\% of clients in 2006 were unemployed when registering, while $22 \%$ were employed and $9 \%$ were classified as being on "home duties". About $60 \%$ sought employment or wanted to apply for a specific job, while a large minority - over one-third - said they registered to apply for a specific training course.

99. Vacancies are inserted online by registered employers on a FÁS vacancy site or are collected via telephone by the National Contact Centre (NCC) in Edenderry, whose staff also validates the vacancies that are submitted online. Employers specify the number of candidates sought and the method of vacancy display. They are informed that the duration of vacancy display will be four weeks, but are given the choice to request eight weeks (the standard up to 2007). Standard information requirements include job title, location, type of business, hours, salary and special skill requirements. The contact centre assigns an identification number and occupation code and sends out the FÁS contract, detailing how long the vacancy will be displayed, the employer's responsibility to inform FÁS about a vacancy filled, etc. The doubling of vacancies received since 2000 is considered to be due, in large part, to the introduction of the call-centre which represents a dedicated resource for contact with employers.

100. Corresponding to an international trend, practically all vacancies notified to FÁS are openly advertised both on the website and on daily-updated notice boards, and are available for PES clients who wish to self-refer. ${ }^{44}$ There is thus little practice of ESOs keeping vacancies in a closed file for pre-selection of jobseekers to be referred (employers ask for pre-selection interviews only occasionally). FÁS is little involved in public sector vacancies, most of which are filled by the Civil Service Commission.

\section{Client activation and employer outreach}

101. Prior to the client follow-up procedures progressively developed since 1996 (see the discussion of the NEAP further below), there was little systematic approach to interacting with the unemployed in Ireland. OECD (1998b, p. 205) concluded that there was no "well established system of intensified interviews or referral to additional job search help for the long-term unemployed". There has been much progress since then: the ESO time-use study cited above suggests that slightly over half the interview/support contact now occurs within the NEAP framework.

102. In 2006, according to survey results, six to nine months after registration the average number of contacts per client was 2.4 (all client categories combined), with the average figure reflecting widely varying contact density: one-quarter of clients had, respectively, no contact at all or four or more contacts during that period. NEAP clients reported 3.5 post-registration contacts on average. These contacts could conceivably consist mainly of clients contacting FÁS; however, about half of the clients surveyed stated that they had been contacted by FÁS - a figure that went up to over two-thirds for clients involved in the NEAP who generally have the highest contact density. ESOs contact clients for various reasons - from providing access to training to proposing participation in a CE project - but above all to notify vacancies,

44. This is in contrast to the situation in the mid-90s, when most vacancies at FÁS were on semi-open display (OECD, 1998b). 
either by letter, telephone, email, text alert service, or during personal interviews; in 2006, a bit over one-third of registered clients said they received such notifications (FÁS, 2007e).

103. Administrative records show that ESOs make direct referrals of unemployed clients to employers who also receive self-referrals for the same vacancies. For example in 2006, 163000 direct referrals were made to the 154000 notified vacancies. As about 72000 jobseekers registered with the service in 2006, this means that every newly registered jobseeker was on average referred to just over two vacancies. This is not a very high number, given the advantages of direct referral, such as bringing jobseekers who use inefficient search strategies into contact with vacancies that might otherwise be ignored. ${ }^{45}$ Of course, these benefits need to be weighed against the costs for staff time involved in active matching.

104. The general approach seems to be, however, to give priority to the self-service facilities. The office in Tallaght, for example, pointed out to the OECD review team that active matching is only done when the self-service system encounters difficulty. The 2007 NCC Employer Customer Survey (FÁS, $2007 \mathrm{~b}$ ) reported that in the first half of 2007 almost two-thirds of companies received over ten applications per vacancy, which seems to show both the wide availability and intensive use of FÁS' vacancy information, while active referrals are only a relatively small part of the overall picture.

105. Even among those who self-refer, a majority tend to have received some assistance from FÁS in applying for jobs. Over half report that they received help with interview tips, setting up their CV, drafting job applications and career guidance. Clients may receive such assistance in personal sessions with counsellors or through referral to a Job Club or Pathways Guidance programme which provides support in a group context. Job Clubs are aimed primarily at helping clients who are "job-ready", developing skills which they can use to find a job. Any client who is ready to work and is between 16 and 64 years of age can join a Job Club - in recent years almost one out of ten newly registered unemployed joins a Club (for example, 7600 persons in 2005; see Eurostat, 2007). Training topics include information on the world of work, CV preparation, career planning, job targeting and job-search techniques, application skills, assertiveness, interview techniques, and mock interviews. Job Club training duration is usually three to five weeks, but can go up to three months.

106. While placing clients into jobs is arguably the principal task of an employment service, FÁS does not usually publish administrative statistics on "placements". This is mainly because feedback on referral outcomes is inadequate. ${ }^{46}$ Employers are normally asked to inform the office that a vacancy has been filled and whether it has been filled with a person referred from the employment service, but such feedback on referral outcomes is notoriously difficult to obtain from Irish employers - a feature already noted in OECD (1998b), but also observed in other countries' employment services. Information from jobseekers about the (negative) outcome of referrals is normally obtained at the next regular interview (if positive, the jobseeker deregisters at DSFA). The share of employers stating that they had been contacted by FÁS subsequent to a

45. OECD (2007a) estimated that the frequency of direct referrals was zero in one OECD country, one to three per year (per person in the average stock of registered unemployed) in nine countries (Ireland being one of them) and four to nine per year in six countries (e.g. six in the United Kingdom). The estimate for Ireland can be considered fairly low, given Ireland's flexible labour market.

46. ESOs can see from computer records that a referred client is off DSFA benefits, but in order to enter this into the IT system as a placement they need to obtain confirmation of the person's status from the jobseeker and/or the likely employer (e.g. by telephone). This is time-consuming and often not practically possible and is considered by some ESOs not a particularly good use of their time, so the placements entered into the IT system represent only a fraction of those actually achieved according to survey information. FÁS (2006a) states that "During the year, the service placed 15560 jobseekers in training, 17336 in employment and 24966 on employment programmes", but this information is not regularly published. 
vacancy notification ranged from 19 to $26 \%$ in recent years. While there was a number of "don't know" responses, the fact that one-half of companies say that they have not been contacted, and that this share has not declined over the years, indicates that much remains to be done in relation to FÁS' employer contacts, as well as to the upkeep of its vacancy and jobseeker register (FÁS, 2007d).

107. The OECD's 1998 review had noted that FÁS did little active job acquisition with employers (p. 103). Already at that time, policy papers had stressed the importance of improving the provision of services to employers; there was also some discussion as to shifting resources towards employer outreach. However, a decade later, despite the launching of a FÁS "Employer Strategy" and corresponding training of ESOs (see FÁS, 2006a), the need for more resources in this area is still being felt; local office staff pointed out to the OECD review team that there was a need for more specialist staff to actively look for vacancies through calls and visits to enterprises. Lack of resources notwithstanding, some local offices have entered into contracts with some large companies aiming to receive preference in vacancy receipt and candidate referral. FÁS also developed an "employer pack", consisting of comprehensive information on services available to them, and suggesting the use of the agency as an intermediary in recruitment. However, a 2006 survey among employers asking about their use of FÁS services showed that there is still a strong need to raise employer awareness of the availability of these services.

\section{Career guidance}

108. The 1987 Labour Services Act gives FÁS a formal responsibility for developing career information and guidance, supplementing the vocational guidance provided through the education system. To this end, it has developed the Career Directions database as its principal product. The database allows clients to view about 1000 careers on-line, together with detailed information such as skill requirements; pay and opportunities; entry routes; and adult learning opportunities. The Career Directions Matching programme can identify suitable careers based on client interests and qualifications. ${ }^{47}$

109. FÁS staff are encouraged to enroll in university courses in adult guidance and counselling. Normally, career guidance staff are present within FÁS training centres.

\section{Collective dismissals}

110. Another area of FÁS intervention is collective dismissals, where the agency benefits from the legal requirement to companies to notify DETE ahead of redundancies to step in with placement efforts, career guidance and referral to training courses.

\section{Employment services by the LES network}

111. As noted above, the second strand of the National Employment Service, the LES, currently employs 311 staff, a $60 \%$ increase over the past decade. LES staff is charged with providing locally responsive specialist services for the most disadvantaged and intensive guidance to prepare for employment and training outcomes. The central element of the service is the intensive "mediation" process. There are clerical employees for administration and "first contact"; coordination/management staff, mediators, career counsellors and employer liaison officers. Almost three out of five staff (about 180) are in the latter three categories, which are often all referred to as "Mediators".

47. To use the matching programme, clients are asked to log on as a user and answer a series of questions before suggested careers are shown. 


\section{LES Funding Agreements}

112. All LES funding agreements (negotiated between FÁS and the Partnerships) set annual targets for clients to be registered. In 2007, for example, the 25 LES were committed to register 17800 clients nation-wide, of which $32 \%$ were to be long-term unemployed; $22.5 \%$ NEAP-referrals; $12.5 \%$ lone parents; and about $8 \%$, respectively, early school leavers and ethnic minorities/refugees. Other categories specified in the funding agreements are the disabled; dependent spouses and woman "returners"; ex-prisoners; and travellers. The detailed shares of these target groups may vary by area and annual contract, depending on which groups are considered to present the most problems; for example, in the 2007 Funding Agreement with the Tallaght LES, NEAP referrals constituted the largest category, followed by the long-term unemployed and early school leavers. End-of-year returns from Local Employment Centres usually show that a majority of clients registered were placed into jobs, employment schemes or education and training programmes. There is also a target for client throughput per LES Mediator and one for client "progressions", broken down by job placements, participation in an employment scheme, and enrolment in training or education. If the specified targets are not achieved, the funding to the Partnership will be adjusted pro rata.

113. According to the annual funding agreement, the Partnership Company agrees to provide a local employment service ("LESN"), which shall " ... provide career guidance and information, mediation, referral to appropriate training/education courses and other services for the unemployed and those most distant from the labour market, with a view to placing them into employment. In this regard the Partnership Company agrees to targets for the relevant activities and outcomes which have been locally negotiated and agreed".

114. The agreement further notes that:

- The agreement is only for a year and does not represent a commitment to subsequent work;

- The partnership company needs to ensure that the LES is co-ordinated and managed to a level and quality of service satisfactory to FÁS;

- The company will provide regular reports to FÁS on the performance of the LES;

- Complete records of all interactions with clients will be maintained, using the Caseload Management System provided by FÁS; and

- Rights of access and inspection will be given to FÁS, to the Auditor-General and to the European Commission relating to all matters relevant to verifying LES compliance.

115. The locally negotiated targets then follow in Schedule A to the Agreement. This schedule details the services to be provided - see the example of the Northside Partnership LES (Box 3.1) - and sets out the exact number of new clients to be registered, by client category. It usually points out that each LES Mediator will have a throughput of between 120 and 150 target group clients per year, lists a required average placement/progression rate of $50 \%$ and provides for a reduction of the funding level in case the targets are not achieved. It ends with a listing of outcomes, with a detailed number attributed to each outcome category. ${ }^{48}$ A particular LES may itself set more ambitious targets than agreed in the contract. Schedule B then sets out the agreed staffing levels required to carry out the activities under Schedule A and the corresponding funding to be provided by FÁS.

48. Normally, there are seven such outcome categories: full-time employment; part-time employment; self-employment; referral to a FÁS employment programme; referral to FÁS training; other education or training; and referral to other supports/agencies. 


\section{Box 3.1. Services to be provided by Northside Partnership LES}

Labour Market Information: Provision of information and advice on a range of areas that relate to the client labour market situation such as welfare-to-work issues; education, employment and training opportunities, including referral of the client to related services. This includes outreach work.

Mediation \& Guidance: Registration and orientation; provision of intensive personalised guidance leading to development of a career path plan; career counselling; referral to other LES and $3^{\text {rd }}$ party agencies as required; assistance with securing active labour market programmes and employment; post-placement supports.

Group Guidance: Provision of tailored options to meet the needs of a specific client group.

Client Employer Liaison: Contact with employers, identification of jobs suited to clients; advocating on behalf of clients; information and referral to job vacancies.

Post-Employment Programme Assistance: Provision of full range of LES supports to persons experiencing difficulty in accessing employment from labour market programmes.

Post-Training Programme Assistance: Provision of full range of LES supports to persons experiencing difficulty in accessing employment from employment-related training.

Source: Schedule A to Local Employment Service Funding Agreement, FÁS and Northside Partnership, Ltd.

116. A considerable number of clients contact an LES office directly. Where these self-presenting clients fit into one of the target groups, the LES deals with them directly. Otherwise the client is referred to another provider, more appropriate for the particular case (mainly FÁS). There is also much outreach activity to attract clients that are neither referred nor walk in on their own initiative, such as advertising through promotional posters; door-to-door calling in local housing estates; and information stands at local Social Welfare offices and shopping centres.

117. The client throughput per year and mediator can actually be much higher than set out in the Funding Agreement and can go up to 250, but the active caseload - people whom the mediator is actively working with on a week-to-week basis, is probably closer to 30. Importantly, and different from the usual service offer by FÁS, Mediators also carry clients on their caseload that have already been placed into a job, for the purposes of aftercare.

\section{LES staff categories}

118. The Guidelines for the Operation and Administration of Local Employment Services (previously LES Operational Framework) define the roles of the principal LES staffing categories: the Co-ordinator; the clerical and "first-contact" personnel; the Mediator; and the Employer Liaison Officer.

119. The Guidelines define Mediation as "a way of working with a job-seeking client to address that client's occupational needs. It is generally a one-to-one, confidential process of exploring options and planning a career path for the client". While Mediators may refer clients to training and other types of counselling, their ultimate aim is to empower the client to gain employment. To this end, they are supposed to organise activities in conjunction with the Partnership and also keep contact to the local Council, for example to identify employment opportunities in local construction and development work. Contacts with the client are usually much more intensive than at FÁS, including during the NEAP intervention phase (see further below): at the Northside LES in Coolock, for example, a mediator will usually see a client on a one-to-one basis about seven times during the period on the LES caseload. 
120. The Employer Liaison Officer's role includes liaising with employers to identify employment opportunities for LES clients, and match jobseekers with vacancies. Where a vacancy cannot be filled from the Mediator's caseload, the officer communicates details of the vacancy to the local FÁS office. The Employer Liaison Officer maintains and operates the local employer database and also provides after-placement mediation support to both employers and clients placed in jobs.

121. Careful management of the mediator's caseload is needed to ensure that all clients receive adequate services and are actively supported as they progress towards employment. A formal process is in place for managing each mediator's caseload, supported by a joint FÁS-LES computerised system that enables counsellors of both agencies to schedule and record interventions with their clients, chart their progress towards employment, and share information as necessary.

122. Every mediator has at his disposal some funds to respond flexibly to client needs (the Mediator Fund). This fund can be used, for example, for exam fees, course materials, travel to interviews or clothing. The amount provided in 2007 per mediator was about EUR 2 700; the maximum amount that could be spent per jobseeker was set at EUR 1270.

\section{Statistics on progression}

123. At the $10^{\text {th }}$ anniversary of the LES network in 2006, statistics were generated to show the total number of clients who received LES assistance, as well as their progressions. Within that decade, there had been over 222000 clients, of whom over 60000 were placed in employment (full- or part-time) and 75000 were referred to education and training. Mediators had organised almost 1 million guidance sessions. The most recent progression data available to the OECD relate to 2006, when 6031 LES clients were placed in employment (full-, part-time or self-employment) and 9182 clients were placed on an employment or training programme (information provided by the LES).

124. Progression statistics from the various LESs are somewhat more detailed, since they usually distinguish between placements into jobs; referrals to employment schemes; and referrals to education or training. In 2006, in the Northside Partnership LES, for example, only $43 \%$ of the "general" client caseload was listed as having progressed to any of the three main outcomes, and even less (37\%) of the NEAP caseload. Consequently, there was a high carry-over rate of clients, and in particular NEAP referral cases, from one year to the next. This can be explained by progression rates slowing down as more clients with complex issues are being referred. The Northside Partnership reports increasing difficulties in dealing with NEAP clients: they are taking longer at orientation stage, taking two or three sessions to build even a basic trust level; and they show increasingly chaotic behaviour, i.e. not turning up or turning up late for appointments, and not keeping to agreed action plans (Northside Partnership, 2007a, and 2007b).

125. Of those LES clients that achieved outcomes at Northside during the years 2000 to $2006,31 \%$ of all clients that were "progressed" were placed into jobs, 33\% into an employment scheme; and 36\% into education and training. Of NEAP clients, by contrast, almost half of those that achieved an outcome were placed into employment, a notable achievement when compared with the progression data of NEAP clients presented in Section 3.4 below (considering that the LESN deals with the more hard-to-place clients). ${ }^{49}$

\section{LDSIP Services for the Unemployed}

126. LDSIP Services for the Unemployed are integrated with the Local Employment Services, where these exist in the same Partnerships. As noted in Box 2.1, according to Pobal (2007) Services for the

49. FÁS and LES data on progression to employment are difficult to evaluate since they do not provide any information on job stability and quality). 
Unemployed in 2006 supported over 30000 people, of whom just under one-fifth were assisted by the LES through an integrated series of interventions. The long-term unemployed make up the single largest target group (about one-third) of clients. Registration and progression data (entries to employment, selfemployment and training) for Services to the Unemployed are entered into a central database located at Pobal. This appears to be again separate from FÁS and DSFA databases.

127. Between 2000 and the end of $2005,20 \%$ of the adults supported by this measure went into employment and $12 \%$ into self-employment (see the participation and outcome statistic cited in Box 2.1 in Chapter 2). However, such figures give no particular evidence its impact: plausibly $20 \%$ of those who registered over the years 2000 to 2005 would have been in employment by the end of 2005 without this assistance. ${ }^{50}$ And although "achieved certification" was a key outcome against targets for the 2000-2006 programme, other programmes such as the Vocational Training Opportunities Scheme (VTOS) and Back to Education Allowance (BTEA) probably account for a large proportion of the public expenditure input in such cases (DETE, 2005b; Eustace and Clarke, 2006; Pobal, 2006b, and 2007).

128. The support given includes providing guidance about employment and training opportunities, advocacy with employers, linking clients to the LES, and assistance to individuals starting up an enterprise. Cash payments, e.g. grant assistance to individuals starting up a small business, appear to be made: but it is not clear whether this was a significant use of Services for the Unemployed funds (payments might be made from a separate Partnership budget that supports business start-ups, for example). Based on the evidence available, it seems that the funding of Partnerships to provide Services for the Unemployed has provided mainly information and advice about other services and - although this is not entirely clear small grants to help unemployed people enter other self-employment or training programmes where larger amounts of support are provided. It seems questionable whether these are really cost-effective uses of public funds: much information and advice is already available from several other local office networks (DSFA offices, FÁS offices, VTOS centres and some others) and in recent years the internet. ${ }^{51}$ If there is significant spending on grants to help unemployed people enter other programmes, little centralised (or even decentralised) information on the amounts paid is available.

\subsection{DSFA's role in employment and placement services}

\section{Benefit application and regular signing on}

129. After application for benefit, DSFA deciding officers will only award payment of JB or JA in cases where they are satisfied that the client is available for and capable of work. Spotchecks on initial claims tend to lead to a certain number of rejections. Benefit claims must be maintained by signing monthly at the local Social Welfare (DSFA) office except for those who live more than six miles from such an office who may return a claim form by post (www.welfare.ie/EN/OperationalGuidelines/Pages/ ja_jobseekall.aspx).

50. Eustace and Clarke (2006) report findings from a "tracking sample" of 84 clients, where $43 \%$ were employed or self-employed (and 35\% unemployed) in June/July 2005 and $67 \%$ were employed or selfemloyed (and 8\% unemployed) in January/February 2006. Aggregate data appear to show much less rapid rates of progress.

51. Even before LDSIP Services for the Unemployed were introduced, the Office of the Comptroller-General (1998) remarked that "The current proliferation of sources of information and advice should be reviewed with a view to rationalising the responsibilities of the various organisations involved". Ten years on, it seems that little has been done to implement this sensible recommendation. 


\section{Availability reviews}

130. Monthly signing-on at local Social Welfare offices does not involve job-search monitoring. Job search is verified in availability reviews (interviews) that take place, currently, after 7 months and again at 12 months, prior to possible transfer to JA (given that Jobseeker's Benefit is exhausted at 15 months). Another one occurs at 15 months to determine whether clients are suitable for inclusion in the High Support Process. The first availability review was previously conducted after three months, and was put back to seven months when DSFA began to make NEAP referrals at the three-month point (see below). It is not clear how systematic availability reviews are, i.e. what proportion of long-term claimants have had the required two (or three) interviews near these points.

\section{DSFA employment counselling and referral services}

131. As noted in Chapter 2, DSFA has a significant role in the provision of employment services, in particular by means of its jobs facilitation programme established in 1993. Facilitators run the Back to Work Allowance scheme (under which participants who start a job retain a percentage of their social welfare payment for a specific time period), and coordinate with FÁS in finding special solutions for hard-to-place clients, for example as part of the High Support Process. They are also supposed to liaise with the area-based partnerships to identify employment opportunities and propose any other initiatives or measures which would encourage the unemployed to move towards employment.

132. There is a network of (in 2005) 46 Facilitators supported by 10 regional coordinators who operate in over 30 locations around the country (Eurostat, 2007). ${ }^{52}$ This number may have increased since: the "Towards 2016" agreement anticipated increasing it to 70 in the medium term. A higher number would make it possible to have one Facilitator present in every local welfare office. However, the number seems still too low for DSFA to respond efficiently to the range of issues faced by the more difficult clients on the Live Register.

\section{DSFA profiling, activation and active case management}

133. As documented further in Chapter 4, DSFA Local Area Control Teams in principle profile the jobseeker client caseload, ${ }^{53}$ and at local level target particular groups for a "customer activation" procedure. A full activation procedure including the establishment of individual action plans does not appear to be commonly implemented, but there are procedures which involve interviewing client target groups with referral to further services, often a FÁS counsellor or the DSFA Facilitator.

134. In line with some other recent policy documents, "Towards 2016" envisages the introduction of "an active case management service for social welfare customers of working age", which will "... place activation on a level with service delivery and control as a central part of the core business of the Department ...". This mandate would, for example, imply the set-up of customer-profiling at the first point of engagement with DSFA, and the intensive follow-up of not-progression-ready clients or of cases referred back to the Department after an unsuccessful NEAP outcome; as a result, it would seem to require much larger resources than currently spent.

52. But as mentioned in Section 2.5 above, the DSFA Employment Support Service counting also the corresponding support staff who work with Facilitators has about 60 staff.

53. Profiling until now has been done as time permits and on a qualitative or judgmental basis: O'Neill (2007) describes a recent experiment with model-based profiling. 


\subsection{The National Employment Action Plan}

\section{Policy reform}

135. In October 1996, DSFA introduced a requirement for young people aged 18 and 19 unemployed for more than six months to register with FÁS. From 1998, under the Irish National Employment Action plan (NEAP), FÁS engaged unemployed young people and adults in a programme of intensive follow-up. The programme commenced with the referral by DSFA to FÁS of persons under 25 years of age who had reached six months on the Live Register. Persons aged over 25 were referred after 12 months unemployment up to July 2000, when the threshold was reduced to 9 months ${ }^{54}$ With successive versions of the NEAP, the process has been extended to other groups of unemployed. From March 2003, the "Preventive Strategy" 55 was extended as all people aged 25-54 were included as they crossed the six-month threshold. In July 2006, the Strategy was extended to persons aged 55 to 64, and from October 2006, the referral threshold for all age groups was reduced from six months on the Live Register to three months (DETE, 2007c). Currently, all unemployed persons (JB and JA recipients) between the ages of 16 and 64 , who remain unemployed three months after "signing on", are supposed to be referred to FÁS for interview and intensive engagement.

136. Under the NEAP, FÁS employment officers provide guidance to those referred in relation to appropriate return-to-work strategies or participation in education or training courses, including the possible referral to the Local Employment Service for more intensive counselling and placement efforts. The programme envisages, inter alia, the set-up and monitoring of individual action plans which outline the measures to be followed by the client during his/her time on caseload. It probably mobilises more resources overall than the other DSFA activation measures. ${ }^{56}$

\section{The NEAP referral process}

137. When jobseekers approach 10 weeks on JB, the Social Welfare Services computer system automatically selects them for inclusion under the NEAP. The jobseeker is then allocated an interview slot (usually 40 minutes) in a FÁS Employment Office ${ }^{57}$. FÁS ESOs caseload the referred clients and set up an Action Plan and interview schedule. The action plan, which may take two interviews to establish, is usually implemented within 6 weeks of initial contact with FÁS. ESOs are asked to structure the guidance interview so as to match the individual jobseeker's needs and circumstances. The NEAP is split into several stages (initial contact; set-up of action plan; review/evaluation of action plan) and, depending on jobseeker needs, the amount of time spent in the various stages may vary. On average the ESO may see a

54. The NEAP was adopted by the Irish Government in response to the European Employment Strategy (also known as the Luxembourg process), which called for each EU member state to draw up a National Action Plan (NAP) outlining its actions to implement the guidelines.

55. The European Commission from about 1999 defined the preventive strategy in terms of targeting unemployed young people before 6 months and adults before 12 months, and Ireland soon became one of the main users of this term.

56. The 274 FÁS ESOs spend about 30\% of their time on implementation of the NEAP, i.e. it engages about 80 FÁS staff in full-time equivalents as well as a number of DSFA staff.

57. DSFA sends out a standard letter to the jobseeker, indicating the date of the interview, the reason for referral (job-search assistance) and the consequences of failing to attend the interview. The initial interview is scheduled not earlier than the third week after identification. The jobseeker details and interview arrangements are entered by DSFA onto the electronic NEAP system. The information is then passed on to the relevant FÁS ESO. 
client two to three times during caseload, although the frequency of contact may be higher depending on the individual circumstances of the client. ${ }^{58}$

138. According to the action plan agreed with the particular client, the employment officer may pursue various courses of action: for example, clients may be referred to a group-based "Pathways Programme", a job club, a training course or to a CE scheme. The focus can also be on direct referrals to job vacancies or on placements via a job subsidy scheme; on the other hand, clients may also be given more time for their own job search. Action plans can also be reviewed and changed if they have not produced the desired results. Some job-search monitoring - although much less formalised than in the UK, for example - may be part of subsequent interviews.

139. The NEAP interviews appear to be almost the only compulsory (or quasi-compulsory) placementfocused interviews most Irish jobseekers would experience. FÁS IT systems recorded about 70000 interviews with NEAP-caseload clients in $2007 .{ }^{59}$ Whether this figure is compared to the stock of over 150000 persons on the Live Register, to the annual inflow of 70000 to 80000 FÁS registrants, or to the more than 50000 first referrals of persons from DSFA to FÁS under the NEAP procedure in 2007, the average frequency of compulsory interviews that effectively take place is low. Within FÁS Employment Services, the 274 ESOs, spending $30 \%$ of their time on NEAP processes, represent a total time input of about 150000 hours annually, which is about 5 hours per NEAP client who attended an initial interview (see Tables 3.1 and 3.3 below) or about 2 hours per interview when taking second and subsequent interviews into account. This time input covers a range of NEAP-related tasks outside the interviews themselves (e.g. other types of contact with caseloaded jobseekers, follow-up of no-shows, IT entries, and contacts with DSFA and service providers concerning individual cases). FÁS considered, before the downturn, that resources to handle the flow of referrals, with a benchmark figure of 30 active NEAP clients per ESO, were adequate. Experience from other countries suggests that a refocusing of existing resources, allowing a marked increase in the frequency of (compulsory) face-to-face contacts with the unemployed, would be possible. ${ }^{60}$ At the same time, the intensification of activation measures beyond a certain point plausibly would require an increase in the total resources of the PES on the side of placement and related activities.

58. Some offices may provide more intensive follow-up. The Tallaght FÁS office noted that caseloaded clients (under NEAP or otherwise) are offered a maximum of five or six 40-minute interviews during their time on caseload.

59. The estimate of about 70000 includes intake interviews for NEAP caseloading. FÁS advised OECD that there were about 37000 interviews with NEAP caseload clients in 2007 but it seems likely that this total did not include the 32000 intake interviews reported in Tables 3.1 and 3.3 here).

60. In the United Kingdom in 2007-8, JobCentre Plus Personal Adviser staff (about 10000 full-time equivalents) conducted 10.3 million Work-Focused Interviews (www.publications.parliament.uk/pa/ cm200708/cmselect/cmpubacc/532/532.pdf), i.e about 1000 interviews per full-time equivalent adviser per year. The number of NEAP interviews per FÁS ESO in 2007 was much lower in gross terms, but becomes similar if the fact that only $30 \%$ of ESO time is spent on the NEAP process is factored in and no comparable adjustment is made to the calculation for the United Kingdom (in practice, although Personal Advisers are more specialised in the Work-Focused Interview function they do have some other duties). Each country has other types of compulsory interview: JobCentre Plus also conducts short fortnightly jobsearch review interviews, while DSFA conducts review interviews at the $7^{\text {th }}$ month of unemployment, the $12^{\text {th }}$ or $15^{\text {th }}$ month, and subsequently (for about 1 million JSA recipients, and for about 150000 people on the Live Register respectively, before recent increases). OECD (2005) examines evidence about the impact of job-search monitoring and other activation measures on outcomes: among more recent studies, McVicar (2008) provides evidence from Northern Ireland. 


\section{Information sharing between DSFA and FÁS}

140. The role of IT has been central to the implementation of the NEAP referral process, since it facilitates the tracking by both organisations of the status of NEAP clients and the activities that have taken place (Indecon, 2005b). As mentioned above, at 10 weeks of a claim, the computer system automatically generates a list of benefit recipients for referral to FÁS. ${ }^{61}$

141. Results of FÁS-client interaction are communicated to DSFA electronically via codes. A range of codes - such as job-placed, did-not-attend, or not-progression-ready - are used to describe the status of each particular client. ${ }^{62}$ This updating of information continues until NEAP activity has ceased. Certain codes entered by FÁS would require the local Social Welfare Officers to take action. However, one criticism raised with the OECD review team by officials, particularly in Social Welfare Offices, is the lack of specific information available from the codes to ensure consistent action between FÁS and DSFA. ${ }^{63}$ For certain client situations, DSFA would not have the detail behind the codes that is available on the FÁS IT system, and this seems to imply a risk of misunderstanding about client status. Currently, DSFA is in process of developing a code better suited to alert welfare officers to make contact with the FÁS ESO for further information on the case. ${ }^{64}$ Another IT-related issue regards the timing of referral. The timing of referral at ten weeks is based on accumulated time in unemployment (i.e. the sum of previous unemployment spells), which implies that clients with multiple unemployment spells may have been unemployed only for a few weeks and still be selected for referral.

142. Substantial efforts are needed to improve the exchange of data, not least since the current system does not facilitate addressing those unemployed who fail to engage in the NEAP process. For example, while inadequate availability can be reason for a sanction, due to the technical difficulties noted above, DSFA may not have sufficient information to justify applying a sanction. Both partners are aware of the need for improvement, and a joint data exchange group is currently reviewing the existing management information systems.

\section{Support for special client groups}

143. One of the key outcomes of NEAP has been the emergence of so-called "not progression ready" clients. Clients in this category face significant barriers such as health, literacy or drug-related problems that prevent them from moving into employment or participating in training, and therefore require different types of specialist interventions. Earlier studies estimated that this group amounted to about $10 \%$ of total NEAP referrals (O'Connell, 2002). However, more recent figures show that the proportion of this group is closer to 5\% of all referrals: for example, in 2004 there were about 2500 not-progression-ready clients among 52000 referrals (Indecon, 2005b). Clients profiled by DSFA in that category in some cases are not referred to FÁS at all, while in other cases they are referred to FÁS but then handed over to the LES.

61. The NEAP system excludes certain categories of workers such as casual and seasonal workers and those signing on to the Live Register for credits without any payment. A person with at least one contribution paid in either of the last two tax years, and available for work, can get "credits" under Jobseeker's Allowance even if the social welfare payment is zero owing to means-testing (e.g. a married women may be disqualified from JA by the husband's earnings).

62. Indecon $(2005 b$, p. 10f.) shows a detailed list and description of these codes.

63. The lack of information on specific codes and their potentially different interpretations is also highlighted in Indecon (2005b).

64. In addition, social welfare officers can ask for more details of a case through local meetings between FÁS and DSFA staff. These meetings tend to be held each quarter and discuss the type of problems faced by individual clients and the appropriate support strategy for them. 
144. The development of a High Support Process (HSP) in 2003 was a step towards intensive case management of this group. Under the HSP, a multi-agency approach was adopted where joint information sessions involving staff from DSFA, FÁS and the HSE are held to encourage these clients to engage in intensive follow-up. To this end, employment officers can avail of the Technical Employment Services Grant (TESG) which can be used to purchase short-term training or provide other employment-related assistance such as interview travel costs, and purchase of tools and/or clothing. ${ }^{65}$ The main client groups eligible for this support include long-term participants on the Job Initiative Scheme and those defined as "not progression ready" under the preventive strategy. ${ }^{66}$ The maximum amount of the grant now stands at EUR 2500 per person, an increase from EUR 2200 in previous years.

145. In 2005, approximately 1400 clients were interviewed under the HSP, half of whom received financial support (EUR 700 on average) provided through the HSP budget (FÁS, 2006a). However, no further breakdowns of this group are available.

\section{NEAP evaluation studies}

146. The Irish NEAP, which has considerably strengthened PES interventions in the unemployment spell, has now been operating for ten years. Over this period, evaluation studies have largely indicated that it has been an effective policy tool.

147. O'Connell (2002) concluded that "...the decline in long-term unemployment since 1995 has been due both to a reduction in the inflow to long-term unemployment and an increase in the exit rate. ... the [NEAP] process of referral, interview, guidance and counselling appears to have been successful in achieving a substantial movement off the Live Register". This conclusion was only tentative since the proportion of exits from the register that would have been achieved in the absence of the NEAP intervention (for example, due to the dramatic improvement in labour market conditions) could not be identified. ${ }^{67}$

148. Corcoran (2002) gives some indication of the impact of the NEAP, based on experience with pilot initiatives. A particularly relevant "experimental" group consisted of pilot projects in two localities (Kilkenny and Ballyfermot) where in 1999 and 2000 all unemployed of over six-month duration were referred under the NEAP, in contrast to the national procedure where over-25s were only referred if they crossed the nine-month threshold and the existing stock of long-term unemployed was not covered. The joint evaluation of both pilots concluded that NEAP-type intervention can have a positive and durable impact on the level of unemployment.

65. The TESG results from the integration between the Customised Training Fund (CTF) and funding under the HSP. The CTF was established in 1999 to give employment officers greater flexibility in responding to the needs of specific caseload clients. Based on recommendations contained in external evaluations of the CTF and HSP, the FÁS Executive Board, in January 2007, gave approval for the integration of the CTF and the HSP grant, renamed the Technical Employment Support Grant (DETE, 2007c).

66. In addition, any jobseekers who are considered to be distant from the labour market (ex-prisoners, members of the Traveller Community) and who need such flexible supports, can avail themselves of TESG (DETE, 2007c).

67. However, OECD (2003a, Box 4.8) remarks, in relation to Corcoran (2002), that overall, $64 \%$ of those referred to NEAP left the register within three months and $93 \%$ left within 12 months, which are much higher proportions than the usual exit rate from unemployment of about $30 \%$ per quarter (which can be estimated from Live Register statistics). Such evidence suggests, even in the absence of an econometric analysis, that a large proportion of the exits did represent the impact of NEAP. 
149. In 2005, a review of the NEAP was commissioned by DETE from Indecon Economic Consultants. Indecon (2005b) estimated the impact of the NEAP on participants' rate of "signing off" the register, on the numbers on the Live Register over the period 1998-2003 as well as the net savings in social welfare payments. An econometric model was also used to estimate the net impact of NEAP programme participation on employment and exit probabilities against a control group. ${ }^{68}$ Both the econometric and non-econometric analyses showed that NEAP participation impacted "positively and significantly" on labour market outcomes. The NEAP process was considered to have encouraged early exit from the Live Register and to have reduced the likelihood of long-term unemployment. The econometric analysis suggested an improvement in exit probabilities of between $10 \%$ and $20 \%{ }^{69}$ According to Indecon, the NEAP was also proven cost-effective, with likely savings on unemployment benefit payments of up to $5 \%$ of total expenditure.

\section{Client outcomes}

150. This section examines some overall trends in referrals and progressions of NEAP clients between 2003 and 2007. The data used are based on the monthly departmental progress reports and show the situation of all those referred under the NEAP during the period January to end December for each of the corresponding years ${ }^{70}$. Table 3.1 shows the initial outcomes for referrals of clients from DSFA to FÁS for an interview. The number of DSFA referrals reflects, in part, the NEAP roll-out, but also trends in the Live Register. In particular, the number of referrals has increased from 2006 to 2007, in line with a rise in unemployment and with the advance of the NEAP referral date from six to three months ${ }^{71}$. In contrast, the number of intake interviews that took place has actually fallen since 2004. This can be largely attributed to the proportion of those who did not attend the interview, which increased from $22 \%$ in 2005 to $35 \%$ in 2007.

68. The European Community Household Panel (ECHP) for Ireland provides detailed data on unemployed people which were used for the control group. The dataset allowed to track individuals over time so that it was possible to compare NEAP outcomes with those of similar unemployed persons who did not benefit from the NEAP process. The control group included individuals that were unemployed in 1998 and $1999-$ a time period where most unemployed would not have reached the relevant NEAP thresholds, although the NEAP was officially introduced in September 1998.

69. According to one econometric model the probability of escape from unemployment after two years for a baseline case was $42 \%$, which increased to $64 \%$ for NEAP participants. Using a "refined" control group and a broader definition of unemployment (including people who entered inactivity rather than employment), the probability for the baseline case was 30\% which increased to $42 \%$ for NEAP participants.

70. The annual data are available in the January reports of each following year.

71. The number of jobseekers on the Live Register dropped significantly from 172000 in 2003 to 157000 in 2005. However since then, it rose again continuously to reach 162000 in 2007, and was approaching 300000 in late 2008. 
DELSA/ELSA/WD/SEM(2009)01

Table 3.1. Outcomes of NEAP referrals 2003-2007

Numbers and percentages ${ }^{a, b}$

\begin{tabular}{lrrrrrrrrrr}
\hline & \multicolumn{2}{c}{$\mathbf{2 0 0 3}$} & \multicolumn{2}{c}{$\mathbf{2 0 0 4}$} & \multicolumn{2}{c}{$\mathbf{2 0 0 5}$} & \multicolumn{2}{c}{$\mathbf{2 0 0 6}$} \\
\cline { 2 - 8 } Total DSFA referrals & $\mathbf{4 3 5 9 5}$ & $\mathbf{1 0 0 . 0}$ & $\mathbf{5 2} \mathbf{3 2 8}$ & $\mathbf{1 0 0 . 0}$ & $\mathbf{4 0 7 1 8}$ & $\mathbf{1 0 0 . 0}$ & $\mathbf{3 7} \mathbf{9 5 8}$ & $\mathbf{1 0 0 . 0}$ & $\mathbf{5 1 4 5 2}$ & $\mathbf{1 0 0 . 0}$ \\
Interviewed by FÁS & 28646 & 65.7 & 35136 & 67.1 & $\mathbf{2 8} 714$ & 70.5 & 25186 & 66.4 & 32124 & 62.4 \\
Did not attend & 12051 & 27.6 & 13045 & 24.9 & 9139 & 22.4 & 10053 & 26.5 & 18190 & 35.4 \\
Pending interview & 2898 & 6.6 & 4147 & 7.9 & 2865 & 7.0 & 2719 & 7.2 & 1138 & 2.2 \\
Left live register & 25184 & 57.8 & 30133 & 57.6 & 24282 & 59.6 & 22280 & 58.7 & 32359 & 62.9 \\
\hline
\end{tabular}

a) Percentages in italics.

b) Data include all referrals made during the calendar year. Subsequent status is reported at end January of the following calendar year, i.e. 1 to 13 months after the referral.

Source: DETE (2004-2008), Employment Action Plan, Monthly Progress Reports.

151. The proportion of clients who do not attend the FÁS interview after being referred from DSFA mainly reflects the normal pattern of flows through registered unemployment. Table 3.2 shows that a significant proportion of those who did not attend their interview had "signed off" the Live Register, either leaving for inactivity or entering employment or education. This percentage varied between $74 \%$ and $78 \%$ between 2003 and 2007. Only about a quarter of the non-attendees were people who stayed on the Live Register and thus a priori should have attended.

Table 3.2. Outcomes for those who did not attend the NEAP interview, 2003-2007

Numbers and percentages ${ }^{a, b}$

\begin{tabular}{|c|c|c|c|c|c|c|c|c|c|c|}
\hline \multirow[b]{2}{*}{ Did not attend } & \multicolumn{2}{|c|}{2003} & \multicolumn{2}{|c|}{2004} & \multicolumn{2}{|c|}{2005} & \multicolumn{2}{|c|}{2006} & \multicolumn{2}{|c|}{2007} \\
\hline & 12051 & 100.0 & 13045 & 100.0 & 9139 & 100.0 & 10053 & 100.0 & 18190 & 100.0 \\
\hline Left live register & 8966 & 74.4 & 9934 & 76.2 & 7091 & 77.6 & 7578 & 75.4 & 14135 & 77.7 \\
\hline Of above entering employment/education & 3298 & 36.8 & 3639 & 36.6 & 2700 & 38.1 & 2715 & 35.8 & 6639 & 47.0 \\
\hline
\end{tabular}

a) Percentages in italics.

b) Data include all referrals made during the calendar year. Subsequent status is reported at end January of the following calendar year, i.e. 1 to 13 months after the referral.

Source: DETE (2004-2008), Employment Action Plan, Monthly Progress Reports.

152. Table 3.3 shows the situation of the clients who were indeed interviewed by a FÁS employment officer. The proportion of interviewees who progressed to jobs fell from $17.5 \%$ in 2003 to $12.8 \%$ in 2007 in terms of outcomes recorded by FÁS but the total number who progressed to jobs as recorded also by DSFA was little changed. The increase in total numbers interviewed and the decline in the positive outcome rate in 2004 reflect the roll-out of the NEAP process to the stock of existing long-term unemployed: there were 16000 referrals in this category in 2004, compared with about 4000 in 2003 . The inclusion of 55-64 year olds may have reduced this progression rate in 2006, while the advancement of the threshold from six months to three months would have increased it in 2007, given that the shorter-term unemployed generally have higher job-entry rates.

153. The exit pattern from unemployment differed between those who did and those who did not attend the first interview. Those who did not attend more often left the Live Register and entered employment or education. This is to be expected, since entry to employment or education usually involves leaving the Live Register and often makes the NEAP interview unnecessary.

154. Interviewees who did not leave the Live Register are of particular concern. The proportion of those receiving ongoing support from their FÁS officer (e.g. guidance and job-search assistance) has declined and the proportion of those for whom no current action is being taken has increased over the same 
period from around 20 to $25 \%$. It is not clear whether this reflects a caseload that is harder to help, an evolution of ESO behaviour, or perhaps more rapid recoding to the "no present action" status without change in the actual level of support provided. However, assuming that perhaps half of those "receiving on-going support" are eventually allocated to the "Did not leave Live Register - no present action" status, between 25 and $30 \%$ of those initially referred to NEAP will have this as the final outcome. By now probably most people who are long-term unemployed on the Live Register have been through the NEAP process, with such an outcome. This group is to a large extent 'parked', since DSFA does not generally refer people to NEAP a second time and alternative DSFA caseloading procedures are quite limited in coverage. Many of them are probably considered "not progression ready", with only a minority receiving intensive follow-up.

Table 3.3. Progressions of FÁS interviewees under the NEAP process, 2003-2007

Numbers and percentages ${ }^{a, b}$

\begin{tabular}{|c|c|c|c|c|c|c|c|c|c|c|}
\hline \multirow[b]{2}{*}{ Number of those interviewed } & \multicolumn{2}{|c|}{2003} & \multicolumn{2}{|c|}{2004} & \multicolumn{2}{|c|}{2005} & \multicolumn{2}{|c|}{2006} & \multicolumn{2}{|c|}{2007} \\
\hline & 28646 & 100.0 & 35136 & 100.0 & 28714 & 100.0 & 25186 & 100.0 & 32124 & 100.0 \\
\hline Of these placed in jobs/ programmes & 8450 & 29.5 & 9718 & 27.7 & 6804 & 23.7 & 6429 & 25.5 & 7621 & 23.7 \\
\hline Placed in jobs & 5011 & 17.5 & 4932 & 14.0 & 3383 & 11.8 & 3223 & 12.8 & 4110 & 12.8 \\
\hline Placed in FÁS programmes & 2245 & 7.8 & 3393 & 9.7 & 2382 & 8.3 & 2077 & 8.2 & 2665 & 8.3 \\
\hline Other training/education & 1194 & 4.2 & 1393 & 4.0 & 1039 & 3.6 & 1129 & 4.5 & 846 & 2.6 \\
\hline Did not leave live register & 12429 & 43.4 & 14937 & 42.5 & 11523 & 40.1 & 10365 & 41.2 & 13900 & 43.3 \\
\hline Referred to a programme place ${ }^{c}$ & 1522 & 5.3 & 1929 & 5.5 & 1280 & 4.5 & 1534 & 6.1 & 2216 & 6.9 \\
\hline Receiving on-going support & 4927 & 17.2 & 4300 & 12.2 & 4404 & 15.3 & 3055 & 12.1 & 3608 & 11.2 \\
\hline No present action ${ }^{d}$ & 5979 & 20.9 & 8708 & 24.8 & 5839 & 20.3 & 5776 & 22.9 & 8076 & 25.1 \\
\hline Unrecorded movement off live register ${ }^{e}$ & 7768 & 27.1 & 10481 & 29.8 & 10387 & 36.2 & 8273 & 32.8 & 10603 & 33.0 \\
\hline Other interviewed who progressed to jobs ${ }^{f}$ & 1968 & 6.9 & 2717 & 7.7 & 3279 & 11.4 & 2222 & 8.8 & 3349 & 10.4 \\
\hline Total progressed to job & 6979 & 24.4 & 7649 & 21.8 & 6662 & 23.2 & 5445 & 21.6 & 7459 & 23.2 \\
\hline
\end{tabular}

a) Percentages in italics.

b) This category includes clients referred to FÁS employment or training programmes who have an offer to commence the programme within four weeks.

c) This includes clients referred to training or educational programmes and FÁS programmes and have an offer to commence the programme within four weeks.

d) This category refers to clients who are on hold (i.e. who are currently unable to participate in FÁS services due to acceptable personal circumstances), those who have "dropped out", those categorised as "not progression ready" and "other inactive" clients.

e) This refers to clients without a recorded FÁS placement.

f) Outcomes recorded only by DSFA (additional to the previous lines which include only outcomes recorded by FÁS).

Source: DETE (2004-2008), Employment Action Plan, Monthly Progress Reports.

155. Related to this, many clients who cross the 10 -week threshold are not referred to NEAP. As noted above, in 2007 over 51000 persons were referred to FÁS under the process. However, data on the survival rate of spells on the Live Register, supplied by DSFA, indicate that approximately 160000 clients crossed the 10-week threshold in 2007. Of these, only 77000 - i.e. less than half - were identified for referral. One reason for this is that clients who have already been through the NEAP process are not identified for referral again (although the facility to re-refer "repeat" claims for the NEAP selection is being developed). Moreover, the total number actually referred (51 000) was even lower. Local Social Welfare offices examine the group of those identified for referral and may not actually refer all of them due to several factors:

- Some people automatically selected at 10 weeks have left the Live Register before the DSFA referral to FÁS, which occurs in principle at 13 weeks;

- For some clients, referral is not considered realistic given the individual's circumstances; and 
- Local Social Welfare offices have agreements with local FÁS offices concerning the flow of referrals, and must limit referrals to match FÁS capacity.

156. Among those referred in 2007, by end January 200819000 were still on the Live Register, and of these over 4000 are likely to have been given a "no-show" (did not attend) status in the database returned by FÁS to DSFA. DSFA attempts to contact this group, which may result in re-referral under the NEAP process, the identification of specific barriers with referral to other services, or a benefit sanction decision. Based on Table 3.2, the numbers concerned have increased from about 3000 in 2003 to 4000 in 2007. Thus, the NEAP continues to be a resource-intensive process for DSFA as well as FÁS.

\section{Extension of activation to other client groups}

157. The parties negotiating the Towards 2016 agreement agreed to consider the extension of the NEAP referral process to other groups such as lone parents and people with disabilities as a policy priority. Several recent FÁS/DSFA joint pilots have attempted to engage both target groups on a voluntary basis. Despite enormous efforts to bring in the client groups, results have been disappointing to date.

158. In 2006/07, in several cities and counties FÁS invited individuals on the FÁS register, in receipt of One Parent Family Payment and not currently on any FÁS training or employment programme, to information events designed to encourage them to participate in employment and up-skilling. EAPN (2007) describes "Choices Days" in Cork and Dublin. Attendance rates were about 10\%, and considering the staff resources that FÁS devoted to the programme, it was decided not to replicate the approach. An evaluation concluded that, while women non-attendees were generally motivated to be active in the labour force, non-attendance was mainly due to the difficulties women face in accessing jobs and training due to lack of childcare facilities, and to work schedules not conducive to parental childcare. Added to this is the fear of losing benefits (Fine-Davis et al., 2007).

159. DSFA (2007) announced increased engagement with people on disabilities to maximise their labour market opportunities. Several pilots in the Midlands region have tried to facilitate participation in employment and training supports. The 2005 Disability Allowance Project ("Midlands Pilot") was a multiagency (FÁS, DSFA, and HSE) initiative to test the capacity of an integrated approach to delivering such supports to young recipients between the ages of 16 and 25 . This initiative failed to the extent that only about $29 \%$ of the people invited to participate attended for interview (WRC, 2006a).

160. Both types of initiatives, for lone parents and disabled, in the absence of any obligation to participate appear to be cost-inefficient because a large effort has to be expended to bring in a relatively small number of participants. A possible approach, which has been used in Australia and the United Kingdom, is to make participation in "work-focused interviews" compulsory for specific groups. Following other countries' examples, a 2006 Government Green Paper suggested revisions of the lone-parent benefits system implying an obligation to participate in interviews, followed by a move to JA after age 7 of the child (see Chapter 4).

\subsection{Quantitative indicators of job-broking activities and labour market penetration}

161. Given the goal of helping jobseekers to obtain jobs and employers to fill their vacancies, some obvious performance indicators for employment services are the number of registered jobseekers, including their share among all jobseekers, PES-registered job vacancies relative to all job openings, the number and share of openings filled with PES referrals and the share of total new hires in the economy mediated by the PES. Registered jobseekers and notified vacancies can be shown either as stocks or flows, while PES placements or vacancies filled with PES referrals are measured as flow data. However, such measures of market share suffer from many data deficiencies. In particular, appropriate measures of total 
hires in the economy tend to be difficult to obtain, and PES placements are increasingly difficult to record in an age of "self-service" computerised vacancy information.

162. The FÁS administrative data base contains monthly inflows of jobseeker registrations and vacancy notifications, as well as the end-of-year stock of "active" vacancies - i.e. those that have neither been filled nor withdrawn. In addition, FÁS-led survey data are available since 2003 for the number and share of vacancies filled (and those that remained open) two months after notification, as well as the number and share of those filled by FÁS referrals. These include self-referrals. The statistical concept of PES vacancies filled by PES-registered unemployed can be estimated, although this differs from a more traditional notion of "PES placements" resulting from direct referrals (FÁS, 2007a; and 2007b). By contrast, no relevant average annual stocks of FÁS-registered unemployed are available from FÁS records, since FÁS has in the past not consistently cleaned up its register. However, DSFA in recent years has been able to provide data for the stock of people on the Live Register who are also registered with FÁS.

163. Figure 3.1, Panel A shows the evolution of the Live Register since 1996, of the stock of persons on the Live Register who are also registered with FÁS, and of the end-of-year stock of open vacancies at FÁS (for the latter two measures, data are only available since 2002). First, the Live Register fell by $2006 / 07$ to below $8 \%$ of the labour force (below $10 \%$ of dependent employment), corresponding to about 150000 persons, while it was close to $20 \%$ in the mid-1990s. By contrast, the number of Live Registrants also registered with FÁS has increased from 77000 in 2002 to over 100000 in 2006. As a result, the proportion of Live Registrants registered with FÁS among the total Live Register has increased from less than half in 2002 to around two-thirds in 2006. This seems to be due, above all, to the referral processes under the NEAP and is in sharp contrast with the situation in the 1990s, when there was no compulsory registration of benefit recipients with the employment service.

164. The end-of-year stock of "active" vacancies fluctuated between 6000 and 12000 during this period and remained at below $1 \%$ of the labour force. Using this measure, throughout this period, the number of Live Registrants looking for jobs with FÁS has been far greater than the number of available vacancies (a common ratio has been less than 10 vacancies for 100 jobseekers from the Live Register). Using the alternative survey-based figure of vacancies still open two months after notification to the employment office - the figure was 31000 in 2006 - the ratio would be more favourable, at about 25 to 30 per 100 registered jobseekers. It should be noted, however, that these figures do not account for the fact that not all jobseekers with FÁS come from the Live Register.

165. Available flow data are likely to present a more realistic measure of employment service performance and workload in Ireland. Figure 3.1, Panel B shows data on FÁS registrations and vacancies in the form of annual flows. In line with improving labour market conditions, annual jobseeker registrations as a share of the labour force more than halved since 1997, to a bit over $3 \%$ in 2007, while their absolute number declined by over one-third (to around 70000 in 2007). By contrast, the annual inflow of vacancies grew from $3.5 \%$ to almost $8 \%$ of the labour force (to $10 \%$ of dependent employment), corresponding to over 169000 in 2007 (a bit over 150000 without employment schemes and work-permit applications). ${ }^{72}$ In the chart the respective curves intersect in 2003 , after which the number of inflowing vacancies has been consistently and increasingly higher than the number of new jobseeker registrations. The annual flow data thus give a more positive picture than the average stock data as to the availability of vacancies for FÁS-registered unemployed.

72. In 2004 to 2006 , vacancy notifications to FÁS were between two and three and a half times more numerous than vacancy ads in the leading newspaper, the Irish Times (FÁS, 2007b). 
Figure 3.1. Employment services performance indicators, 1997-2006

A. Stocks, percentage of the total labour force ${ }^{a}$

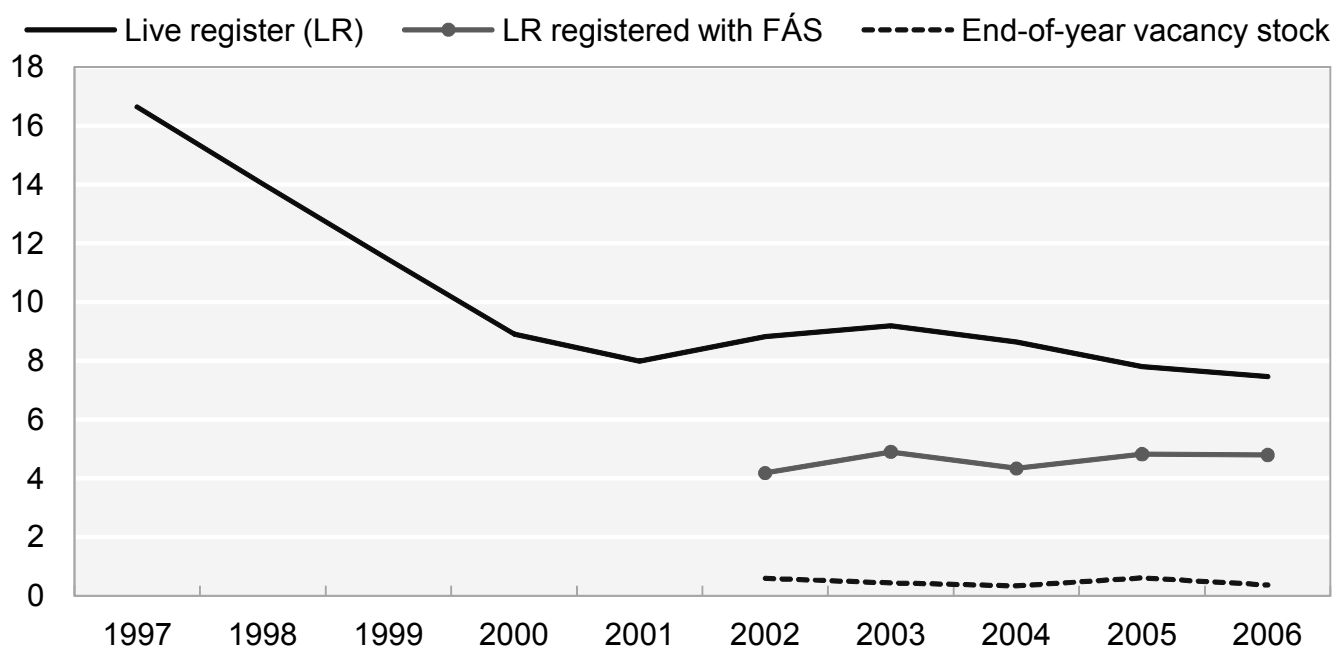

B. Flows, percentage of the total labour force ${ }^{a}$

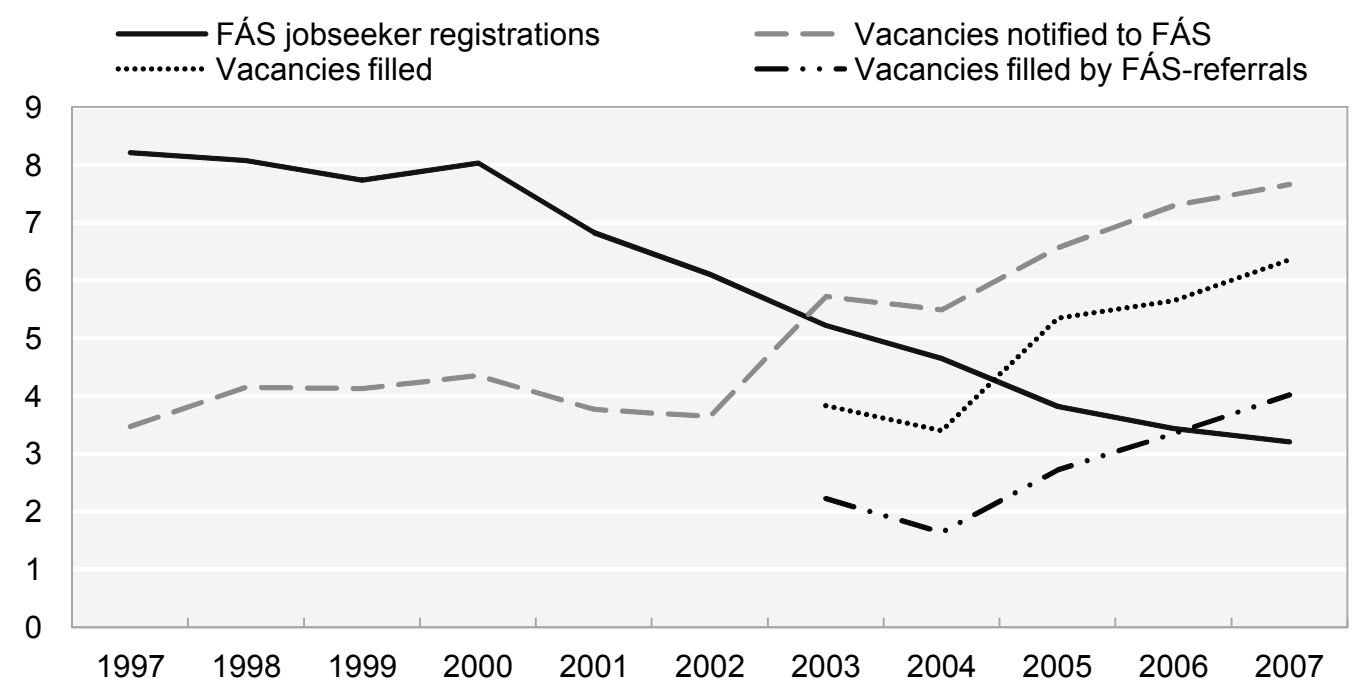

a) OECD estimates for 2006 and 2007

Source: FÁS, and OECD Labour Force Statistics database.

166. The share of filled vacancies in total vacancies received by the employment service, as assessed by on-going employer surveys, has increased from two-thirds in 2003 to $83 \%$ in $2007 .^{73}$ The share of vacancies filled by clients referred from FÁS - or at least registered with FÁS - has increased to over 50\%

73. This is an ongoing FÁS telephone survey with a sample of employers two months after they had notified a vacancy. Employers answer whether they have filled "at least one of their vacancies ... within eight weeks of notification". The actual filling rate may therefore be lower since a small minority of vacancy notifications concern multiple vacancies. However, the filling rate could also be somewhat higher, since some vacancies may still be filled more than two months after notification. 
in 2007, again a significant increase over 2003/04. ${ }^{74}$ The Figure shows the relation of the two "vacancies filled" measures to vacancy inflows and its changes (i.e. a clear trend increase) between 2003 and 2007. ${ }^{75}$

167. Available survey data allow calculation of FÁS' market share indicators. An employment service's market share can be considered from the perspective of: $i$ ) the share of vacancies in the economy handled by the service; ii) the share of unemployed jobseekers registered with the service; and iii) the share of total hires in the economy mediated by it.

168. Full data on market shares by the above definitions are available for 2006 (see FÁS, 2007c). First, the share of Irish companies that notified FÁS of vacancies was $21 \%$ in 2006, and the share of companies that had a vacancy filled through FÁS - or by persons registered with FÁS - can be estimated at $11 \%$. Next, using available data on labour turnover and job growth in 2006 , it can be assumed that private-sector companies generated 332000 vacancies in 2006, of which they filled about $257000 .{ }^{76} \mathrm{FÁS}$ market share in total vacancies, measured as the percentage of total vacancies reported to the employment service, can therefore be estimated at 43\% (144000), while the share of registered vacancies in total hirings is estimated at $56 \%$.

169. Over half of those vacancies reported by employers as having been filled two months after they had notified them to the employment service were filled by jobseekers referred by - or registered with - FÁS, so the employment service market share in total vacancies filled can be estimated at $23 \% .{ }^{77}$

170. Two measures may be particularly relevant for estimating the share of unemployed jobseekers registered with the service. First, between 2002 and 2006, 54 to 58\% of unemployed according to the quarterly labour force survey said that they had contacted FÁS. Second, as already noted above, $65 \%$ of persons on the Live Register were also registered with FÁS in 2006, a much higher share than in 2002, when it was only $46 \%$. The share of NEAP referrals that actually report to FÁS for an interview is also around two-thirds.

171. Table 3.4 compares market share indicators between 2006 and 1996. The increase in FÁS' involvement in vacancy handling and hirings is immediately evident. On top of the improvements in market shares, there has also been an increase in the share of vacancies received that were filled with FÁSreferred or FÁS-registered candidates ("placements" in the table).

74. The concept of vacancies filled by "FÁS-referred" clients is based on employer responses to the survey, and reflects what job-applicants tell the employer. It therefore includes self-referrals of FÁS-registered clients who had seen the particular vacancy in an employment office or on the FÁS website. The shares were calculated for use in Chart 3.1, Panel B, by distributing employers' "don't know" answers equally between "FÁS-referred" and "non-FÁS-referred" clients.

75. A much lower number than the over 70000 vacancies filled by "FÁS-referred" clients is obtained when calculating placements of FÁS clients, actually recorded as such by ESOs. This number was 17000 in 2005 (FÁS, 2006a).

76. This calculation assumes a private-sector labour turnover of $17 \%$ and private-sector net job growth in 2006 of 42000 posts (FÁS, 2007b).

77. This is, again, when distributing employers" "don't know" answers equally between "FÁS-referred" and "non-FÁS-referred" jobseekers. Without this redistribution, the market share would be $20 \%$. 
DELSA/ELSA/WD/SEM(2009)01

Table 3.4. Indicators of FÁS market share, 1996 and 2006

Percentages

\begin{tabular}{lcc}
\hline & $\mathbf{1 9 9 6}$ & $\mathbf{2 0 0 6}$ \\
\cline { 2 - 3 } Monthly hiring rate (approximately) & 1.6 & 1.5 \\
FÁS-registered vacancies/all vacancies &.. & 43 \\
Registered vacancies/hirings & 22 & 56 \\
Registered vacancies/dependent employment & 4 & 9 \\
Placements/hirings & 8 & 23 \\
Placements/dependent employment & 2 & 4 \\
Placements/registered vacancies & 38 & 41 \\
\hline
\end{tabular}

Source: FÁS (2007a; 2007b).

172. Overall, the use of FÁS services remains limited, with less than four out of ten companies reporting that they have ever used FÁS. However, this share rises to half among companies with 10 or more employees, and to two-thirds in companies with over 100 employees. In the periodic surveys of private sector employers carried out on behalf of FÁS, many companies seem little aware of FÁS services and only recall specific services when prompted. For example, only a minority of companies are aware of the National Contact Centre. Thus, there still seems a strong need for awareness-raising among employers, especially small firms, and the provision of more and better information about the variety of services provided (FÁS, 2007c).

173. In the 2006 survey, FÁS recruitment services were mentioned spontaneously by $24 \%$ of employers - a figure which however increased to $67 \%$ when prompted. Employers continue to prefer other channels for their recruitment: the public employment service only comes in fourth, after newspapers, word of mouth and private placement services. Likewise, it comes in third in labour force surveys, after the study of advertisements and word of mouth. Although FÁS is rated highly compared with other recruitment methods on suitability of candidates, speed of response and "value for money", certain negative images, such as inefficiency, traditionality and slowness to change, remain in force. On the other hand, among those employers that had used FÁS for recruitment, the level of satisfaction is high: in one survey of 2007, the rating was over four among a range of five possible levels (FÁS, 2007b).

\subsection{Summary of main points}

- The primary responsibility for job matching and placement in Ireland lies with FÁS Employment Services (FÁS-ES). Employment offices deliver placement and guidance services to registered unemployed and other walk-in clients and act as a gateway to training and job-creation programmes. About 30\% of ESO time is devoted to clients caseloaded under the NEAP process, and $40 \%$ to support for walk-in clients, contacts with employers and vacancy matching.

- The LES - the "second strand" of the National Employment Service - provides locally responsive specialist services for the most disadvantaged to prepare for employment and training outcomes. The central element of the service is the intensive "mediation" process. This ranges from giving intensive counselling sessions to liaising with local employers to identify vacancies for LES clients. In the 10-year existence of the LES, of about 220000 clients serviced, about one-quarter was placed into full-time or part-time employment. To improve employment outcomes, the LES may benefit from following more systematic procedures and requiring some groups to participate in its services.

- FÁS' handling of vacancies appears to be efficient thanks to the processing of notifications via the National Contact Centre and the priority given to self-service procedures. However, 


\section{DELSA/ELSA/WD/SEM(2009)01}

employment offices should not lose sight of the advantages of direct referral, which is used only to a minor degree. The significant increase in FÁS market share - in terms of vacancies received and vacancies filled with FÁS-registered candidates - suggests that the centralisation and automation of the placement function, as well as the increase in the number of staff involved in vacancy-handling, has increased the quality of service for users.

- In 2006, under the National Employment Action Plan, the threshold for referring the unemployed on the Live Register to FÁS for interview with a view to job placement or training changed from after six to after three months of unemployment. Subsequently, the number of referrals to FÁS has been growing reflecting both the changes in referral period and the recent increases in unemployment. However, FAS lacks additional resources to handle the increased client inflows. The procedure of automatically referring clients to the NEAP after three months, starting an action plan procedure which often includes referral to a labour market programme, is likely to be difficult to implement effectively.

- Furthermore, concerns remain over the increasing proportion of NEAP clients for whom FÁS takes no action (clients with 'no present action' status) once they begin the NEAP process. This may reflect a caseload that is difficult to place into either a job or a labour market measure. The proportion of these clients is likely to increase in the downturn, which will requiring greater attention to monitoring and follow-up to ensure further progression of such groups. 


\section{CHAPTER 4}

\section{UNEMPLOYMENT AND RELATED BENEFITS}

\subsection{Introduction}

174. This chapter analyses Ireland's unemployment and related benefits. Section 4.2 presents some international comparisons of recipiency rates for several benefits focusing on comparisons with Australia, New Zealand and the United Kingdom whose benefits systems, reflecting common historical roots, share key features with Ireland's. Section 4.3 examines entitlement conditions for the main benefits and secondary benefits, and trends in benefit replacement rates. Section 4.4 examines unemployment benefit eligibility criteria, and DSFA requirements for regular reporting, DSFA control activity, activation measures and administration. Section 4.5 discusses some actual and potential reforms to inactive benefits to extend availability-for-work and related conditions to other target groups and improve incentives.

\subsection{Benefit recipiency rates}

\section{International and historical comparisons}

175. Carcillo and Grubb (2006, Figure 3) present long time-series data for recipiency rates of unemployment, disability and lone-parent and/or non-categorised social assistance in 16 countries. Key features in the data for Ireland are:

- The number of lone-parent recipients grew dramatically from $0.6 \%$ of the population of working age in 1980 to $3.5 \%$ in 2001 .

- Unemployment benefit recipiency at its peak in 1993 reached $12.2 \%$ of the population of working age, a level that at least in the past 50 years has probably only been exceeded by one OECD country (14.4\% in Finland in 1994).

- The unemployment benefit recipiency rate fell sharply to reach $5.0 \%$ of the population of working age by 2001 , but then stayed in the range of 5.0 to $5.9 \%$, which was above the 16-country average of about $4.1 \%{ }^{78}$

- The incapacity (sickness and disability) benefit recipiency rate in Ireland in the 1980s and 1990s fluctuated in the range of $5 \%$ to $6 \%$ and in years around 2000 was close to the international average. However, it has increased recently and now at $7 \%$ seems relatively high, especially given that Ireland has a relatively young population.

176. Some more detailed international comparisons are made with Australia, New Zealand and the United Kingdom where the benefit systems, share with Ireland key features that are absent from the systems in most other OECD countries:

78. The data collection runs to 2004 for most countries (2002, 2003 or 2005 in a few), but the available data suggest the 16-country average will not have changed much from 2002 to 2007. 
- Unemployment insurance benefits do not exist in Australia and New Zealand, ${ }^{79}$ and are paid at a fixed rate ${ }^{80}$ corresponding to the maximum rate of unemployment assistance benefit in Ireland and the United Kingdom. Related to this, the unemployment insurance replacement rate is low for people on average earnings or above, and the majority of the compensated unemployed are on an assistance benefit. ${ }^{81}$

- Assistance benefits are nationally-financed and nationally-managed. This contrasts with the situation in Canada, the United States and most continental European countries.

- Assistance benefits are differentiated by type of social risk (i.e. unemployment, lone-parent, sickness, disability and a few more minor categories, for people of working age). Most other countries - particularly where regional or local governments are responsible for financing assistance benefits - have general social assistance benefits that are not differentiated by type of risk, i.e. which combine the roles of unemployment, lone-parent and often incapacity assistance benefits. $^{82}$

- Assistance benefit replacement rates (benefit levels relative to earnings) are intermediate, in comparison with other OECD member countries (see below).

177. Nevertheless as compared with the systems in Australia, New Zealand and the United Kingdom, Ireland's system has some distinguishing features:

- In the 2000s, about $40 \%$ of unemployed recipients received Unemployment Benefit (the unemployment insurance benefit) rather than Unemployment Assistance, more than in the United Kingdom (about 20\%). ${ }^{83}$

- The coverage of Ireland's One-Parent Family Payment (OFP) is (as noted in Chapter 1) broader than that of any other OECD country, making payments to the lone parent until the youngest child is aged 18 , or 22 if in full-time education. ${ }^{84}$

79. However, unemployment assistance in Australia and New Zealand can be paid to people with substantial assets. In Australia, Newstart benefit at the full rate is payable (possibly after a waiting period) to a single person non-homeowner with assets below AUD 296 250; in Ireland the Jobseeker's Allowance rate is reduced when assets exceed 20000 EUR (www.centrelink.gov.au/Internet/Internet.Nsf/payments/ newstart_iat.htm; www.welfare.ie/EN/OperationalGuidelines/Pages/meansassess.aspx). Thus experienced workers with some assets, who could qualify only for the insurance benefit in Ireland, would often qualify for the assistance benefit in Australia.

80. The benefit rate is unrelated to salary for full-time workers, but Ireland has a part-time rate for workers with whose earnings in work were below a low threshold (which is lower than a full-time minimum wage).

81. In most continental European OECD countries, although there are some exceptions, only a minority of the compensated unemployed are on an unemployment assistance and/or social assistance benefit. Contribution conditions for insurance benefit may be stricter than in Ireland or the United Kingdom, but often insurance benefit levels are higher (so there is a stronger incentive to qualify for, and to remain on, insurance benefit), insurance durations are longer or (especially in Southern Europe) assistance benefits are limited.

82. The United States, unusually, has a specific lone-parent benefit (AFDC/TANF) alongside very limited general social assistance (General Assistance in some states, and federal Food Stamps).

83. Jobseeker's Benefit in Ireland is paid for up to 15 months, whereas Jobseeker's Allowance (contributionbased) in the United Kingdom is paid for up to 6 months. 
- Ireland has a last-resort social assistance benefit called Supplementary Welfare Allowance (SWA) which through most of the 2000s has had 25000 or more recipients of basic weekly payments. This safety-net benefit plays a greater role than its counterparts in Australia, New Zealand or the United Kingdom.

- In Ireland, many claimants have to apply for three different means-tested benefits from separate administrations (for a main income-replacement benefit, a rent-related benefit, and a medical card). The HSE (formerly Health Boards) administered one of the major benefits (Disability Allowance) until 1996, and still administers the SWA and rent supplements for people in private rented housing, while each Local Authority independently administers a system of means-tested differential rents for people living in council housing. By contrast, in Australia, New Zealand and the United Kingdom, the main income-replacement benefits are near-completely centralised, and rent assistance also seems somewhat more centralized (e.g. the central authority pays Rent Assistance in Australia and housing benefit in New Zealand).

178. As shown in Table $4.1{ }^{85}$ in the area of incapacity (sickness and disability) benefits, Ireland has three relatively large income-replacement payments: the contribution-based Illness Benefit and (for those permanently incapable of work) Invalidity Pension, and the means-tested Disability Allowance. Together, these had over 200000 recipients by end $2006 .{ }^{86}$ Until 2003, the incapacity recipiency rate (as a percentage of the population of working age, 15-64) was lower than in the United Kingdom; but after 2003 the rate began to decline in the United Kingdom and by 2006 Ireland's rate was nearly one point above the United Kingdom rate, two points above Australia's and three points above New Zealand's.

179. Ireland also - because caseloads in the other three countries declined rapidly after the year 2000 has from 2002 had the highest rate of unemployment benefit recipiency of the four countries. Compared with the average for the other three countries, the rate was 37\% higher on average from 2000 to 2006, and $71 \%$ higher in 2006 (see below for a discussion of the contrast between these rates and unemployment rates reported in the labour force survey). ${ }^{87}$

180. Despite its very rapid growth from 1980 to 2000, the recipiency rate for lone-parent benefit in Ireland remained lower than in Australia or New Zealand. The rate in Ireland has declined slightly since 2003, but this was also the case in New Zealand and the United Kingdom. Major reforms in Australia (starting 2006) and in the United Kingdom (starting 2008) may further reduce their rates in the fairly near future. In continental Europe, the numbers of lone parents in receipt of benefits are probably lower.

84. Ireland also has separate benefits payable to separated spouses without children, the Deserted Wife's Benefit and Allowance, which have no parallel in most other countries. Although these were discontinued for new claimants after 1996, they still had over 10000 recipients in 2006 (DSFA, 2007c, Table C7).

85. Data in Table 4.1 differ slightly from those presented in Carcillo and Grubb (2006). In Ireland this reflects the use of December figures rather than (estimated) annual averages, the inclusion of Blind Person's Allowance in the total for disability and non-inclusion of Deserted Wife's Benefit in the total for lone parents.

86. Ireland also has three more minor incapacity benefits with altogether about 5000 recipients, i.e. Blind Pension, Injury Benefit, and "Sick no benefit" cases of payment of Supplementary Welfare Allowance (see DSFA, 2006b; and 2007c), as well as Disablement Pension which is a compensatory payment not an income-replacement benefit.

87. As already noted in Chapter 1, Ireland recipient numbers would be somewhat lower if reported on a full-time equivalent basis. In recent years, unemployment expenditure levels have been about $4 \%$ lower than would be expected be if all reported recipients were paid at the full weekly rate. 
Table 4.1. Recipiency rates for incapacity, unemployment, lone-parent and safety net benefits, Ireland, Australia, New Zealand and United Kingdom, 2000-2007

Levels and percentage of working-age population (15-64)

\begin{tabular}{|c|c|c|c|c|c|c|c|c|c|}
\hline Benefit type & Benefit & 2000 & 2001 & 2002 & 2003 & 2004 & 2005 & 2006 & 2007 \\
\hline \multicolumn{10}{|c|}{ Australia (June) } \\
\hline \multirow[t]{2}{*}{ Incapacity } & Sickness Allowance & 10773 & 10942 & 9522 & 8755 & 8478 & 8367 & 7510 & 7624 \\
\hline & Disability Support Pension & 602280 & 623926 & 658915 & 673334 & 696742 & 706782 & 712163 & 714156 \\
\hline \multirow[t]{2}{*}{ Unemployment } & Newstart Allowance & 589911 & 580703 & 582945 & 512332 & 483093 & 453614 & 438560 & 417793 \\
\hline & Youth Allowance (other than students) & 82408 & 85053 & 90339 & 87486 & 84665 & 79573 & 75186 & 68698 \\
\hline Lone parents & Parenting Payment (Single) & 391393 & 416661 & 427846 & 436958 & 449312 & 449000 & 433370 & 395495 \\
\hline Safety-net & Special Benefit & 10971 & 12712 & 13315 & 12228 & 11216 & 9408 & .. & 6244 \\
\hline \multicolumn{2}{|c|}{ Working-age population (15-64) } & 12766857 & 12947951 & 13127204 & 13317148 & 13513382 & 13668031 & 13822671 & 14037203 \\
\hline \multicolumn{10}{|c|}{ Ireland (December) } \\
\hline \multirow[t]{4}{*}{ Incapacity } & Invalidity Pension & 48663 & 50615 & 52147 & 53414 & 55864 & 58352 & 51954 & \\
\hline & Illness Benefit & 46940 & 50715 & 54590 & 57464 & 58726 & 61845 & 65774 & \\
\hline & Disability Allowance & 54303 & 57655 & 62783 & 67720 & 72976 & 79253 & 83697 & 2004 \\
\hline & Blind Pension & 2229 & 2125 & 2095 & 2061 & 2027 & 1985 & 1476 & 189593 \\
\hline \multirow[t]{2}{*}{ Unemployment } & Jobseekers' Benefit & 46565 & 59884 & 66416 & 70090 & 57699 & 52754 & 50542 & \\
\hline & Jobseekers' Allowance & 69504 & 66563 & 71566 & 75249 & 73840 & 75357 & 75801 & \\
\hline Lone parents & One-Parent Family Payment (OFP) & 74119 & 77142 & 79195 & 79296 & 80103 & 80366 & 83081 & \\
\hline Safety-net & $\begin{array}{l}\text { Supplementary Welfare Allowance - } \\
\text { basic payments }\end{array}$ & 25094 & 29167 & 32073 & 31217 & 29748 & 28066 & 25330 & \\
\hline \multicolumn{2}{|c|}{ Working-age population (15-64) } & 2538590 & 2588340 & 2653900 & 2703400 & 2751800 & 2821700 & 2905500 & 2984700 \\
\hline \multicolumn{10}{|c|}{ New Zealand (June) } \\
\hline \multirow[t]{2}{*}{ Incapacity } & Sickness & 32294 & 33620 & 36380 & 39902 & 44128 & 45646 & 47559 & \\
\hline & Invalid's & 55392 & 59812 & 64529 & 68507 & 72342 & 74796 & 77046 & \\
\hline Unemployment & $\begin{array}{l}\text { Unemployment Benefits paid } \\
\text { to unemployed people }\end{array}$ & 139042 & 124561 & 111312 & 96692 & 67016 & 49589 & 38990 & \\
\hline \multirow[t]{2}{*}{ Lone parents } & Domestic Purposes Benefit - Sole & & & & & & & & \\
\hline & Parents or $\mathrm{EMA}^{a}$ & 103003 & 101587 & 101644 & 102516 & 102324 & 98829 & 94613 & \\
\hline \multirow[t]{2}{*}{ Safety-net } & Emergency benefit (under age 65) & 6335 & 6004 & 3977 & 4376 & 4129 & 3478 & 3738 & \\
\hline & Unemployment benefits - hardship & 2995 & 3032 & 2882 & 2635 & 1739 & 1125 & 762 & \\
\hline \multicolumn{2}{|c|}{ Working-age population (15-64) } & 2511800 & 2531200 & 2577100 & 2632200 & 2674600 & 2706100 & 2737000 & 2765400 \\
\hline \multicolumn{10}{|c|}{ United Kingdom ${ }^{b}$ (average) } \\
\hline Incapacity & Incapacity benefits $^{c}$ & 2700028 & 2753438 & 2764308 & 2776925 & 2774373 & 2733810 & 2687363 & \\
\hline Unemployment & Jobseeker's Allowance (claimant count) ${ }^{d}$ & 1088225 & 971325 & 945275 & 934000 & 853550 & 861225 & 943700 & \\
\hline Lone parents & Lone Parents on Income Support (IS) & 917190 & 896863 & 869833 & 847035 & 817038 & 787590 & 777688 & \\
\hline Safety-net & Other Income Support (working age) ${ }^{e}$ & 205603 & 179363 & 167693 & 155438 & 156690 & 153618 & 154995 & \\
\hline \multicolumn{2}{|c|}{ Working-age population (15-64) } & 37014000 & 37241000 & 37441000 & 37615000 & 37801000 & 38008000 & 38222000 & 38465000 \\
\hline \multicolumn{10}{|c|}{ Percentages $^{f}$} \\
\hline \multirow[t]{4}{*}{ Incapacity } & Australia & 4.80 & 4.90 & 5.09 & 5.12 & 5.22 & 5.23 & 5.21 & 5.14 \\
\hline & Ireland & 5.99 & 6.22 & 6.47 & 6.68 & 6.89 & 7.14 & 6.98 & \\
\hline & New Zealand & 3.49 & 3.69 & 3.92 & 4.12 & 4.35 & 4.45 & 4.55 & \\
\hline & United Kingdom & 7.29 & 7.39 & 7.38 & 7.38 & 7.34 & 7.19 & 7.03 & \\
\hline \multirow[t]{4}{*}{ Unemployment } & Australia & 5.27 & 5.14 & 5.13 & 4.50 & 4.20 & 3.90 & 3.72 & 3.47 \\
\hline & Ireland & 4.57 & 4.89 & 5.20 & 5.38 & 4.78 & 4.54 & 4.35 & \\
\hline & New Zealand & 5.54 & 4.92 & 4.32 & 3.67 & 2.51 & 1.83 & 1.42 & \\
\hline & United Kingdom & 2.94 & 2.61 & 2.52 & 2.48 & 2.26 & 2.27 & 2.47 & \\
\hline Lone parents & Australia & 3.07 & 3.22 & 3.26 & 3.28 & 3.32 & 3.29 & 3.14 & 2.82 \\
\hline & Ireland & 2.92 & 2.98 & 2.98 & 2.93 & 2.91 & 2.85 & 2.86 & \\
\hline & New Zealand & 4.10 & 4.01 & 3.94 & 3.89 & 3.83 & 3.65 & 3.46 & \\
\hline & United Kingdom & 2.48 & 2.41 & 2.32 & 2.25 & 2.16 & 2.07 & 2.03 & \\
\hline Safety net & Australia & 0.09 & 0.10 & 0.10 & 0.09 & 0.08 & 0.07 &.. & 0.04 \\
\hline & Ireland & 0.99 & 1.13 & 1.21 & 1.15 & 1.08 & 0.99 & 0.87 & \\
\hline & New Zealand & 0.37 & 0.36 & 0.27 & 0.27 & 0.22 & 0.17 & 0.16 & \\
\hline & United Kingdom & 0.56 & 0.48 & 0.45 & 0.41 & 0.41 & 0.40 & 0.41 & \\
\hline
\end{tabular}

a) EMA in New Zealand refers to Emergency Maintenance Allowance, which is a lone-parent benefit for teenage single people.

b) Data refer to the average of February, May, August and November. Except for the unemployment claimant count, data do not include Northern Ireland.

c) Data include Incapacity Benefit "credits-only" cases, the majority of which are in receipt of Income Support.

d) Claimant count data may slightly exceed the number of actual recipients of Jobseekers' Allowance (contribution-based plus income-based).

e) Refers to working-age claimants who are on income-related benefits but not also receiving Jobseeker, Incapacity, Lone Parent or Carer benefits.

f) The benefits shown are not necessarily payable to all people in the 15-64 age group, e.g. UK working-age benefits are not usually paid to women aged 60-64. Recipiency rates calculated using a narrower definition of the population potentially covered by the benefit would be higher.

Source: Ireland: DSFA (2007c); Australia: DFCSIA (2006) and Departmental Annual Reports (DEWR, 2007; FACSIA, 2007; and earlier reports in the same series); New Zealand: MSD (2007) and earlier reports in the same series. United Kingdom: DWP (2008); and OECD Labour Force Statistics database (www.oecd.org/els/) for the working-age population. 
181. Table 4.1 also shows the recipiency rate for safety-net assistance benefits. In Ireland, SWA basic payments were made to about $1 \%$ of the working-age population, several times the incidence of approximately comparable benefits in Australia and New Zealand, and over twice the level in the United Kingdom. ${ }^{88}$ However, the other countries have to some extent developed separate categorised benefits for situations that are covered only by SWA in Ireland. ${ }^{89}$

\section{Unemployment benefit recipients and labour force survey unemployment}

182. Ireland has at most times over the last two decades had the highest ratio of unemployment benefit recipients to labour force survey unemployment of any OECD country (Table 4.2). In the early 2000s, as labour force survey unemployment fell, the ratio of the Live Register (which includes some active JB and JA claims without a payment in the reference period, as well people claiming insurance credits), rose well above 2, although it declined more recently. The figures for Ireland in Tables 4.1 and 4.2 include only the recipients of a positive weekly payment, without other beneficiaries (qualified adults and children) or credits-only cases: there is no obvious reason to believe that, due to conceptual and reporting issues for the included benefits, the benefit recipiency rates shown for Ireland are exaggerated as compared with those shown for other countries. ${ }^{90}$

183. A large difference between the Live Register (which also includes about 10000 people whose only benefit is credited contributions, not counted in Table 4.2) and labour force survey unemployment has long been noted. Walsh (2003) commented:

"... the published Live Register series now contains a disclaimer to the effect that the Live Register is not designed to measure unemployment.' The reasons given are that, in addition to the three categories listed above [Systematic short-time workers; Smallholders entitled to Unemployment Assistance; Persons aged under 65 on pre-retirement schemes] that are excluded from the headline LR figure, it includes part-time workers working up to three days a week, seasonal, and casual workers, who are entitled to benefit or assistance. However, the numbers in these categories do not appear large enough to account for much of the discrepancy."

88. An Appendix in DSFA (2004) compared SWA with social assistance schemes in the Netherlands, Portugal and Sweden, but in these countries there is no separate assistance benefit for unemployed people with insufficient contributions, i.e. the scheme fulfils the role of Unemployment Assistance as well as the role of SWA.

89. Basic assistance for asylum seekers in the United Kingdom is not provided by Income Support: it is governed by Part 6 of the Immigration and Asylum Act 1999 (Joint Committee on Human Rights, 2007).

90. However the coverage of benefits is arguably incomplete for some other countries shown in Table 4.2. France's minimum income benefit (RMI) has about 1 million recipients and although entitlement to it is not conditional on unemployment, about half of its recipients are unemployed: if they are included in the unemployment benefit recipient total, on an estimated basis, the average ratio shown for France would be nearly 1 rather than 0.8 . The ratios shown for Germany, the Netherlands, Norway, Portugal, Spain and Sweden may be to some extent understated for a similar reason. In Canada and Denmark, the figures include unemployed social assistance recipients, and no such issue arises for Australia, Finland, Ireland, New Zealand or the United Kingdom (the safety-net assistance benefits listed in Table 4.1 have relatively few recipients, only a limited proportion of them being unemployed). 
DELSA/ELSA/WD/SEM(2009)01

Table 4.2. Ratio of the number of unemployment benefit recipients to the number of labour force survey unemployed, 2000-2006

\begin{tabular}{lcccccccc}
\hline & $\mathbf{2 0 0 0}$ & $\mathbf{2 0 0 1}$ & $\mathbf{2 0 0 2}$ & $\mathbf{2 0 0 3}$ & $\mathbf{2 0 0 4}$ & $\mathbf{2 0 0 5}$ & $\mathbf{2 0 0 6}$ & $\begin{array}{c}\text { Average } \\
\text { of years shown }\end{array}$ \\
\cline { 2 - 6 } Australia & 1.12 & 1.01 & 1.06 & 0.98 & 1.00 & 1.00 & 1.01 & 1.03 \\
Canada & 1.03 & 0.99 & 0.89 &.. &.. &.. &.. & 0.97 \\
Denmark & 0.97 & 1.00 & 0.97 & 0.91 &.. &.. &.. & 0.96 \\
Finland & 1.31 & 1.32 & 1.31 & 1.32 & 1.33 &.. &.. & 1.32 \\
France & 0.71 & 0.81 & 0.86 & 0.82 & 0.81 &.. &.. & 0.80 \\
Germany & 1.03 & 1.04 & 1.06 & 1.11 & 0.98 &.. &.. & 1.04 \\
Ireland & $\mathbf{1 . 5 5}$ & $\mathbf{1 . 9 4}$ & $\mathbf{1 . 7 9}$ & $\mathbf{1 . 7 6}$ & $\mathbf{1 . 5 6}$ & $\mathbf{1 . 4 8}$ & $\mathbf{1 . 3 6}$ & $\mathbf{1 . 6 4}$ \\
Japan & 0.29 & 0.29 & 0.26 & 0.21 & 0.19 &.. &.. & 0.25 \\
Netherlands & 0.79 & 0.79 & 0.72 & 0.66 & 0.67 &.. &.. & 0.73 \\
New Zealand & 1.22 & 1.21 & 1.08 & 1.02 & 0.82 & 0.63 & 0.48 & 0.92 \\
Norway & 0.59 & 0.59 & 0.60 & 0.67 & 0.69 &.. &.. & 0.63 \\
Portugal & 0.94 & 0.91 & 0.81 & 0.83 & 0.86 & 0.78 &.. & 0.85 \\
Spain & 0.42 & 0.59 & 0.57 & 0.57 & 0.57 &.. &.. & 0.54 \\
Sweden & 0.83 & 0.74 & 0.68 & 0.73 & 0.73 &.. &.. & 0.74 \\
United Kingdom & 0.70 & 0.72 & 0.65 & 0.67 & 0.63 & 0.64 & 0.59 & 0.66 \\
United States & 0.40 & 0.47 & 0.45 & 0.42 & 0.38 &.. &.. & 0.43 \\
\hline
\end{tabular}

Source: Unemployment benefit recipient data: Table 4.1 for the countries shown; Carcillo and Grubb (2006), Annex 1, for the other countries (with data revisions for Portugal and the United States); Labour force survey unemployed: OECD Labour Force Statistics database (www. oecd.org/els/).

184. The monthly CSO release cites the estimated number of casual and part-time workers on the Live Register which, through the early 2000s, was typically about 19000 (8 000 males and 11000 females), around one eighth of the total. Problems such as claims from false addresses, working while signing and long periods without verification of active job search remain significant, even though intensified control activity probably contributed to the significant reduction in the ratio of recipients to LFS unemployment after the early 2000s (see the discussion of DSFA control strategy below).

185. Activation measures may be expected to reduce the ratio of benefit payments to LFS unemployment, because they cause some benefit claimants who are not actively searching to drop their claim and/or cause some to start active search (and thus, become ILO unemployed). An opposite effect could arise in some circumstances, e.g. Ireland's NEAP activation strategy at first bypassed a large number of older long-term benefit claimants who may be less often actively seeking work (i.e. be less likely to be ILO unemployed). However, the experience of other countries suggests that activation does reduce this ratio. ${ }^{91}$ Arguably, one outcome from an effective activation strategy should be to keep the ratio of benefits in payment to ILO unemployment below, or at least not above, one. A significant proportion of ILO unemployed (in particular, unemployed spouses of employed people in couples) are not expected to qualify for assistance benefit. There are also cases of people who qualify for assistance benefit but are not expected to be counted as ILO unemployed due to low but positive working hours, but this situation is usually not so common.

91. Manning (2005, Figure 4) charts the UK claimant count and ILO unemployment; a decline in the ratio of the first to the second appears to be linked to introduction in 1996 of the Jobseeker's Allowance with stricter eligibility conditions and implementation procedures, although the limitation of the duration of insurance benefit (now called JSA - contribution based) to six months must be another factor. The 2004 decline in the ratio in New Zealand matches the timing of several new activation programmes (see OECD, 2005, Chapter 4). 


\subsection{Entitlement conditions for the main benefits}

\section{Contribution requirements and means tests}

186. The contribution-based unemployment insurance benefit in Ireland is called Jobseeker's Benefit (JB) and the unemployment assistance benefit is called Jobseeker's Allowance. ${ }^{92}$ In Ireland, as in the United Kingdom, initial entitlement to the contribution-based benefit is based on the contribution record of a previous tax year or two previous tax years. This appears to be a relatively archaic arrangement: unemployment insurance in the United States refers to the contribution record over quarterly accounting periods, and most other European countries take monthly earnings and contributions over the year (or another period) preceding the date of separation from work into account. Ireland might consider whether information technology now allows more up-to-date information to be used. ${ }^{93,}{ }^{94}$ Where weekly earnings were particularly low (less than EUR 150 per week, for claims starting in 2005: even at the 2005 minimum wage of EUR 7.65 per hour, this would arise only when working less than 20 hours), Jobseekers' Benefit is paid a lower rate.

187. Jobseekers' Allowance (JA), by contrast, is an entitlement subject to the availability-for-work conditions and a means test. ${ }^{95}$ The standard rates of payment are the same for JB and JA: in 2007, EUR 185.80 per week, plus EUR 123.30 for an adult dependent with no independent income, and child supplements.

\section{Replacement rates in international comparison and through time}

188. Owing to the fixed-rate nature of JB, the replacement rate (ratio of benefit payment out of work to earnings in work) that it provides will be relatively low for people on average or above-average earnings as compared with the replacement rate for unemployment insurance benefits in most other countries, which are related to former earnings (usually up to a ceiling that is sometimes below and sometimes well above the level of average earnings).

189. The level of benefit on unemployment assistance can be assessed considering Table 3.2. Net replacement rates for six family types: long-term unemployment, 2005 of OECD (2007d). The net replacement rate averaged across four single-earner family types (single person and one-earner couple, with no children and with two children), comparing net income on benefit with net income when in work at $100 \%$ of the average wage (AW) level, in 2005, was $45 \%$ in New Zealand and Australia, $54 \%$ in the

92. Until October 2006, these benefits were called Unemployment Benefit and Unemployment Assistance. Information about entitlement conditions for these benefits is available from OECD's Benefits and Wages publications and country background notes (www.oecd.org/els/social/workincentives).

93. The use of a tax-year reference period with a long delay may help prevent fraudulent claims: by the time a claim is made, the authorities have had time to check whether the company that paid the contributions made a tax declaration and declared (taxable) sales approximately covering the declared salaries. With a short lag between contributions and benefit entitlement, some frauds (benefit claims based on contributions paid on fictive, or partly fictive, salaries) will be easier. However, such problems appear to be manageable in other countries.

94. Initial entitlement to Jobseekers' Benefit (JB) arises when at least 39 paid contributions have been made in the second-last calendar year (i.e. calendar year 2006, for new claims to JB in 2008) or 26 paid contributions in both the current and the previous year. Requalification is possible when 13 weeks of contributions have been paid 156 days (26 weeks) after the expiration of a preceding JB claim (www.inou.ie/welfarerights/unemployment_payments.html).

95. For example, above a certain disregard level each EUR 1000 of capital assets is counted as equivalent to an income of EUR 4 per week: see DSFA (2006b, Table 7.1). 
United Kingdom and $64.5 \%$ for Ireland. However, the Irish figure is calculated using data for earnings that exclude higher-paid salaried workers. ${ }^{96}$ Using a more comprehensive measure, net incomes in work would be $25 \%$ or $29 \%$ higher and the net replacement rate using an average wage concept would be around 50-52\%, slightly higher than in Australia or New Zealand but lower than in the United Kingdom, ${ }^{97}$ just above a median level in international terms (Figure 4.1).

Figure 4.1. Net replacement rates in long-term unemployment, 2005

\begin{abstract}
Unweighted average of net replacement rates at $100 \%$ of the average wage, for the cases of a single person and a couple, with no children and with two children
\end{abstract}

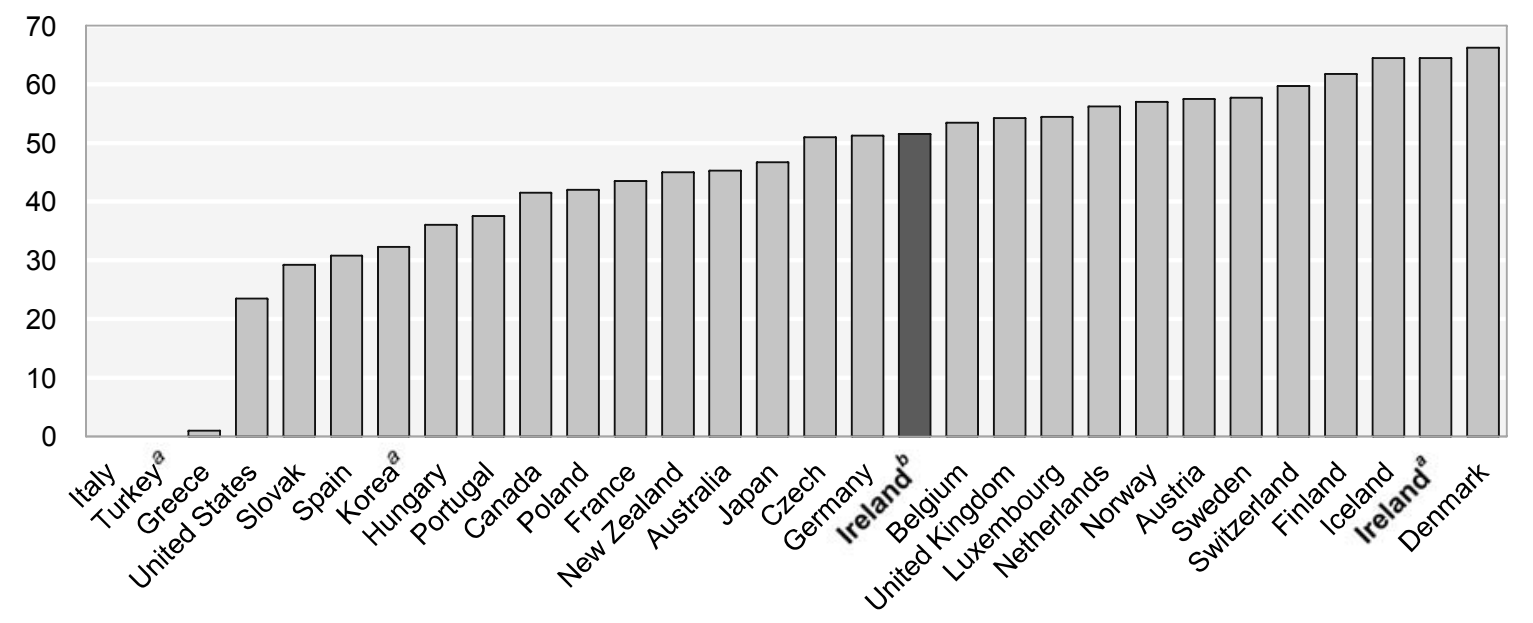

a) Calculation based on Average Production Worker wage (for Ireland, EUR 28894 in 2005).

b) Calculation based on average gross annual earnings in industry and services of full-time employees in enterprises with 10 or more employees (for Ireland, EUR 40462 in 2005).

Source: OECD (2007, Table 3.2) and the tax-benefit calculator at www.oecd.org/els/social/workincentives; and Eurostat (http://epp.eurostat.ec.europa.eu).

190. From an historical perspective, the net replacement rate has undergone swings in the past, with an illustrative replacement rate for a married couple with two children and one earner, relative to the disposable income from an average industrial wage, rising from about 50\% in 1980 to $63 \%$ in 1984 and then declining slowly to about $52 \%$ in $1999-2002$, rising again to about $58 \%$ in 2005 (FÁs, 2006b, Figure 3.1). ${ }^{98}$

191. Policy attention in Ireland has focused on the lowest adult social welfare rate. This fell slightly relative to earnings from 1994 to $2000,{ }^{99}$ but from 2000 to 2007 it increased by about $32 \%$ more than

96. In 2005, APW earnings were EUR 28 994, but the average wage in industry and services of full-time employees in enterprises with 10 or more employees was EUR 40462 (http:/lepp.eurostat.ec.europa.eu Population and social conditions - Labour market - Earnings) and the average wage per full-time equivalent employee was EUR 42517 (OECD, 2007a, Table I). The resulting difference in net earnings can be estimated using the tax calculator at www.oecd.org/els/social/workincentives.

97. The calculation of the 2005 rates includes significant levels of housing benefit in both Ireland and the United Kingdom.

98. The OECD Summary Measure of Benefit Entitlements from 1961 onwards (which takes into account the duration of insurance benefits and long-term benefit rates, but is on a pre-tax basis) also shows a sharp rise up to 1983, somewhat lower levels from 1995 to 2001, and a slight rise to 2005 (OECD, 2007d, Figure 3.4).

99. A higher long-term rate (applying after 15 months of unemployment) was paid for many years, but it was scaled down in the 1990s. By 1997 it was only 3.2\% higher than the short-term rate and in 2001 the long-term rate at IEP 85.5 per week was 1.8\% higher than the short-term rate of IEP 84 per week. In 2002 the higher rate was abolished. 
earnings (from $15.8 \%{ }^{100}$ of earnings in 2000 to $21.0 \%$ in 2007 : Figure 4.2 ). This was due mainly to a commitment in the national anti-poverty strategy (DSCFA, 2002) to raise the lowest adult rate to EUR 150 per week "in 2002 terms" by 2007, which will be maintained subsequently. ${ }^{101}$

192. These increases from 2005 to 2007 will probably have increased the replacement rate on the conceptual basis of Figure 4.1 to about 57\%, above the level in Australia, New Zealand and the United Kingdom, and close to the level reported for Norway and Sweden in 2005. International experience suggests that, although benefits at this level can be compatible with keeping unemployment at low levels, this often involves strict activation requirements and high levels of spending on active labour market programmes (ALMPs). The high spending is illustrated by the fact that the six OECD countries with the highest net replacement rates spend on average over $1 \%$ of GDP on ALMPs, whereas countries with slightly lower replacement rates such as Australia, Canada, Ireland and the United Kingdom spend on average less than 0.5\% (Grubb, 2007a). ${ }^{102}$ Benefit dependency rates in Ireland are increasing rapidly during the current recession, and there is a risk that higher rates, once established, will persist unless activation policies become more effective.

Figure 4.2. Lowest adult social welfare rate, 1994 to 2007

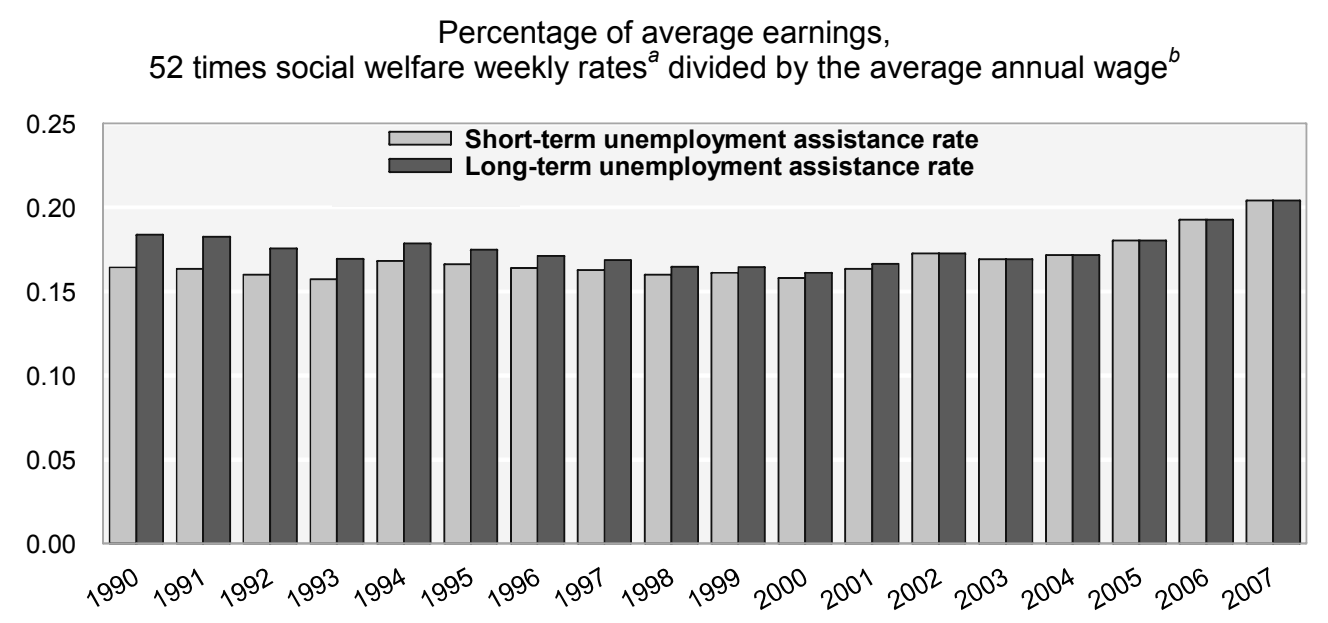

a) Data refer to rates that were introduced during the calendar year in question; 1990 to 1993 estimated using published indices for short-term and long-term rates based on $1990=100$

b) Average wage per full-time equivalent employee, i.e. total annual wages and salaries from the National Accounts divided by the total number of employees (with part-time workers converted to full-time equivalent basis) from the Labour Force Survey.

Source: For social welfare rates; Eardley et al. (1996), DSFA (2007c), and several earlier issues; www.oneparent.ie/pdfs/1_End_Child_Poverty30Jan07.pdf. For average wage per full-time equivalent employee: see OECD (2008), Table I (estimated for 2007).

100. Typical net replacement rates are of course much higher because unemployed people will typically re-enter work at below $100 \%$ of the average wage, the wage in work is subject to tax and social insurance contributions, whereas when out of work income supplements (e.g. for a dependent adult and for rent) are often paid.

101. Since the actual rate in 2002 was EUR 118.80 per week, the commitment was to increase the lowest adult rate by $26 \%$ from 2002 to 2007. Department of the Taoiseach (2006) envisages maintaining the increased rate through to 2015 , subject to available resources.

102. The immediate monetary incentive to work declines rapidly at high replacement rates, e.g. if the net replacement rate is increased from $70 \%$ to $80 \%$ of in-work earnings, net income out of work rises by one-seventh but the return to entering work falls by one-third (from $30 \%$ to $20 \%$ of in-work earnings). Thus at the higher rates the large-scale implementation of active programmes, making it relatively difficult for people to receive benefits on a passive basis, often becomes a financially-optimal strategy for government. 


\section{Benefit tapers and disregards}

193. The basic personal rate is the same for most working-age benefits, except for Deserted Wife's Benefit, Carer's Benefit/Allowance and Invalidity and Disablement Pensions which are paid at slightly higher basic rates (DSFA, 2007c, Table A18). However, the treatment of part-time earnings varies considerably by type of benefit. In 2008 the rules were as follows (www.welfare.ie/EN/OperationalGuidelines/Pages/meansassess.aspx):

- $\quad$ For Jobseekers' Allowance: (from September 2007) earnings are calculated net of PRSI (social security contributions) and pension contributions, but not net of income tax. Then EUR 20 per day for a maximum three days per week, i.e. EUR 60 per week, are disregarded together with $40 \%$ of earnings above this (i.e. $60 \%$ of earnings above this are deducted from benefit);

- For Disability Allowance (from June 2006): the first EUR 120 of net weekly earnings (calculated as above) from employment of a rehabilitative nature are disregarded, together with half of any additional earnings up to EUR 350 per week;

- For One-Parent Family Payment (OFP): (from May 2007): the first EUR 146.50 per week of gross earnings is disregarded and half of the remainder of the gross earnings up to EUR $400 ;{ }^{103}$ and

- For Supplementary Welfare Allowance (SWA): all net earnings of the household are deducted from the benefit amount (DSFA, 2006b).

194. At the gross minimum wage for an experienced adult worker (EUR 8.65 per hour since July 2007), people on the latter two payments can work about 17 hours per week with no effect on their benefit. Under this type of arrangement (with a more generous treatment of part-time earnings for lone-parent and disability benefits as compared with unemployment benefit) the incentive to move into part-time work is stronger for the non-employment benefit recipients, whereas the incentive to move from part-time work into full-time work is stronger for the unemployment benefit. Australia similarly provides more generous disregards for "pensions" (including Parenting Payment - Single and Disability Support Pension) than for the unemployment benefit (Newstart). ${ }^{104}$ A policy of generous disregards for part-time work improves incentives when it is applied to a target group that is not at all capable of working full-time. However, it should be kept in mind that full-time work often remains the norm for broadly-defined target groups including those which face employability barriers: in the United Kingdom nearly $70 \%$ of lone parents in employment in 2005-06 were working 30 or more hours per week (Bell et al., 2007). For the large number of people who are working full-time, or would otherwise be working full-time, generous benefit disregards or tapers represent a potential incentive to reduce working hours and not to increase them.

\section{Secondary benefits}

195. In Ireland, as in Australia, the loss of a medical card is often cited as a disincentive for unemployed people to take up work. In New Zealand and the United Kingdom, this appears not to be the case because most of the health-services offer to the unemployed (the National Health Service) is

103. For lone parents, income as a Home Help is not assessed: this was also the case for SWA but DSFA (2006b, p. 160) "could see no valid reasons for a continuation of the disregard" in this case.

104. By contrast, in some other countries unemployment benefit programmes are more likely to include earnings disregards whereas social assistance (often paid to lone parents) is likely to be withdrawn on a “dollar-for-dollar" or "euro-for-euro" basis (OECD, 2007c, p. 101). 
universal, i.e. not withdrawn when income exceeds a certain level. ${ }^{105}$ In Ireland, the authorities have attempted to address this issue by allowing long-term unemployed people to retain the medical card for up to three years after entry to work (www.inou.ie/welfarerights/secondarybenefi/medicalcard.html).

196. SWA rent supplement (see below) is also cited as a secondary benefit creating a disincentive to taking up work. Although there were 60000 recipients of SWA rent supplement at the end of 2005, only 15000 of them were receiving it as a supplement to an unemployment payment (DSFA, 2006b, Table 8.6). This represents only $10 \%$ of unemployment benefit recipients. Rental benefits that take the form of meanstested reductions in rents for public sector housing (see DSFA, 2006b, Appendix 10) are more common, so that rental benefits overall are quite often part of the benefit package. When SWA rent supplement is paid, it is a significant disincentive to taking up work: it covers up to $100 \%$ of rent costs and was, until 2006, withdrawn at a 100\% rate above a EUR 60 per week disregard level for earnings. The United Kingdom has recently reformed its Housing Benefit to reduce work disincentives, and Ireland should probably consider something similar. ${ }^{106}$

\subsection{Unemployment benefit eligibility criteria and their administration}

\section{Eligibility criteria according to legislation and guidelines}

197. Many of entitlement and eligibility conditions apply to both Jobseekers' Benefit (JB) and Jobseekers' Allowance (JA). ${ }^{107}$ Some noticeable points are:

- Benefit payments before entitlement is determined. When a person applies for JB but a decision has not been taken, they can apply for SWA if their means are insufficient (Part 2.k). When a person's application for Illness Benefit is disallowed because she/he has been found "capable of work" by the Medical Assessor, and she/he has appealed against this decision, JB is payable but "it would be unreasonable to expect her/him to produce evidence to the effect that she/he is actively seeking full-time work" (Part 3.a - Capable of Work). These arrangements (as well as "interim" payments of SWA, see below) appear to make benefits payable before final entitlement has been determined, with a risk that they are not recovered if the original application or appeal fails. It would seem better to allow people (in cases of doubt about their entitlement) to apply for two or more benefits and have a system of crisis loans granted only if, according to the evidence presented at that point, the application for regular benefit is likely to succeed and the person concerned has no history of default on this type of loan.

- Occupational mobility. A person who has recently become unemployed would be regarded as available where she/he is seeking to become re-employed in his/her usual employment, provided

105. Although in the United Kingdom some significant health costs (prescription charges, dental treatment and glasses or contact lenses) are reimbursed on a means-tested basis (see NHS leaflet HC11, www.ppa.org.uk/pdfs/ppc/hc11.htm).

106. In the United Kingdom, Housing Benefit was throughout the 2000s paid to over 3 million people on assistance benefits (Income Support, including lone-parent and incapacity payment and income-based JSA) (www.dwp.gov.uk/asd/hbctb.asp). In 2008 it was replaced by the Local Housing Allowance, where the maximum amount payable to tenants is determined by the size, composition and location of the household, unrelated (with some exceptions) to the actual rent level. The new Allowance is still withdrawn when income rises (at a 65\% rate, not 100\%: e.g. see www.cpag.org.uk/cro/wrb/wrb202/housing.htm), but it limits benefit disincentives that can arise from collusion between landlords and their tenants, or from the high replacement rates that arise when rents are high.

107. Entitlement and eligibility criteria for Jobseeker's Benefit (JB) are set out in considerable detail at www.welfare.ie/EN/OperationalGuidelines/Pages/jb_jobseekben.aspx. 
there is a reasonable prospect of this: but after three months the range of employment sought must be broadened (unless the person can actively demonstrate reasonable prospects in the usual field of employment). (Part 3.a - Available for full-time work).

- Job-search requirements. Guidelines allow a variety of actions including reading the Situations Vacant column in the newspaper to count as job search. Guidelines suggest that multiple "steps to prove genuinely seeking employment" may be required. They envisage verification of job-search efforts by retrospective interviews repeated periodically (at least once every three months under the Customer Activation approach, see below). It is not expected that a counsellor will have given the jobseeker a certain number of steps to be undertaken by a given date. Failure to prove "Genuinely seeking work" status leads to failure to qualify for benefit and not a fixed-duration (up to nine-week) sanction (see below) ${ }^{108}$ (Part 3.a-Genuinely Seeking Work).

- Disqualification from benefit for up to nine weeks. These benefit sanctions apply e.g. in cases of refusal of employment and voluntary job quit, with no basis for a stricter sanction in cases of repeated refusal: Hasselpflug (2005) scores these as relatively mild arrangements in international comparison (2 and 1 respectively on a scale of 5).

- Voluntarily leaving employment. "Good cause" for leaving is not defined ("it is for the Deciding Officer to apply a common sense meaning"). (Part 4.b - Disqualifications for up to nine weeks). Other countries have fairly complex guidelines in this area: good cause may be limited to lay-off by the employer (production-related reasons), or it may include personal reasons for leaving a job (e.g. spouse moved job to another area; left work to care for a sick relative for five weeks).

- Obligation to participate in labour market programmes. The nine-week disqualification may be applied for refusal or neglect to avail of training provided by or approved by FÁS. However, Community Employment schemes are not considered to be FAS training opportunities. This is a weak eligibility requirement since in most other OECD countries participation in official employment (job-creation) programmes can be made obligatory, as well as participation in training. ${ }^{109}$ The guidelines do not mention failure to attend or to co-operate with FÁS (or any other) employment services, so such events can only indirectly give rise to a sanction (e.g. if they constitute evidence of "failure to avail of the opportunity of suitable employment").

- Availability requirements during programme participation. A person is deemed to be available for work while participating in a course of education, training or development approved by the Minister (Part 3.c - Available for full-time work). This means that the person is not obliged to

108. Note that the consequences of failure to qualify for benefit may not be particularly severe, since the applicant may re-apply soon afterwards presenting additional evidence that they are "genuinely seeking work".

109. Legislation in France appears to require participation in training but not employment programmes. In Canada, the Unemployment Insurance Act 1970-71-72, c. 8, s. 1, explicitly specified disqualification for failure to attend "a course of instruction or training" when referred, whereas "no claimant is disentitled or disqualified from receiving benefit under this Part by reason only of his voluntarily leaving or refusing to accept employment on a job creation project." (www.hrsdc.gc.ca/en/ei/legislation/ei_act_entry_page.shtml). This was replaced in 1996 by the Employment Insurance Act which makes no distinction between training and employment activities, although these are not obligatory until the claimant agrees to them. Most countries' legislation either specifies a general obligation to participate in ALMPs, or states that created jobs are assimilated to regular jobs. Legislation in Denmark makes participation in training obligatory but, by longstanding practice, employment programmes are called "job training". 
apply for or take up an opportunity for regular employment for the duration of the course, which again appears to be a relatively weak requirement. ${ }^{10}$

\section{Implementation}

\section{Regular reporting to DSFA}

198. People on the Live Register must sign on in person generally once a month at their local Social Welfare Office to ensure continuity of payment (only once every 12 weeks for those living over 10 miles away). ${ }^{111}$ Many claimants collect benefits weekly from their local post offices, but others were paid directly into their bank account until recently (see references to EFT below).

199. Despite the monthly signing requirement, there have been many reports that people are able to claim while habitually residing (and sometimes working) far away from their Social Welfare Office. The special Live Register sample of the labour force survey in 1996, which obtained LFS responses from the addresses of 2175 people on the Live Register (LR), found that in 679 cases the person on the LR was not reported as a usual resident (OECD , 1998b, Box 4.1). Benefit administration in 1996 seems to have been generally weak, ${ }^{112}$ and was subsequently tightened. However, a 2003 report on DSFA control activity (see below) found similar evidence. At the time of this review, blog entries recounted cases of people collecting Irish welfare payments while living and working in the United States, regularly living in Germany, Poland, and Portugal, and "travelling". ${ }^{113}$ Although this is "anecdotal" evidence, in July 2008, after some months of sharp increases in the LR, DSFA issued a press release:

110. The exemption from the requirement to take up an opportunity for regular employment applies to education and training programmes but not necessarily employment programmes. According to Hasselpflug (2005), the majority of countries require participants in ALMPs to be available to start a regular job. While this is true in some countries, information is not always clear: Hasselpflug attributes a score of 5 (maximum strictness) to Ireland on this point, which is the opposite of the interpretation made here. OECD (2007a, Table 5.5) reports that the majority of countries, including Ireland, do not require continuing job search.

111. The frequency of signing-on is not regulated and in 2003, although signing was monthly "in a number of areas", the most usual arrangement was "for people to sign on once a week" (Comhairle, 2003). Until 2004. about 40000 people receiving unemployment payments (those living more than six miles from their local Social Welfare Office) were allowed to sign on instead at their local Garda (police) station (www.welfare.ie/press/pr04/pr261004.html).

112. DSFA (1996) describes a social security system where the registration of births, marriages and deaths was not computerised; different organisations were using different customer identifiers; changes in an individual's income identified by one agency were not notified to "all other agencies where the customer has a claim", and one agency would conduct an investigation without knowing that another agency was already investigating the same issue.

113. Located on www.angelfire.com, http://thumped.com, www.boards.ie, and www.irishhealth.com. Other remarks here include "Irish guys used to travel over to London to do same in the eighties", "There are people labouring on building sites or working in warehouses all over the country claiming disability!!" and "In relatively small communities, it seems that the world and his father knows who is getting away with scamming the system, but nothing is ever done about them." In the United Kingdom, probably related to the stricter regime of contacts with the employment service, there do not seem to be similar reports in relation to JSA (unemployment benefit), although newspapers have reported cases of incapacity benefit (which is paid with far fewer ongoing requirements) being paid to people working somewhere elsewhere in the United Kingdom (www.people.co.uk/news, article by Boulton and Dorman, 3 June 2007) and they have highlighted transfers of UK benefit entitlements to Poland, which are allowed under EU rules (e.g. www.express.co.uk/posts/view/69513/Dole-for-1m-migrants-after-they-go-home). 
Since September of last year officials in the Department have been monitoring new people signing on the Live Register and their residency status. Since then some 2048 cases of people on the Live Register who were being paid through their bank accounts were investigated to see if they were still resident or were getting the benefit they were entitled to. Of these 182, almost $10 \%$, were found not to be resident at the time they were claiming benefits or were claiming a level of benefits which they were not entitled to. Stopping these claims alone resulted in savings of over EUR 1.5 million in that period. Minister Hanafin said "every person who is entitled to their benefit - either jobseekers benefit or jobseekers allowance - will get their payment every week at their local post office." ... Officials in the Department ... will be intensifying their control activities over the coming months in order to ensure that only those who have an entitlement are paid the appropriate amount. They will monitor residency for both non-Irish nationals and Irish people who are signing on through regular home visits by Inspectors. (www.welfare.ie/EN/Press/PressReleases/2008/Pages/pr210708.aspx).

200. Thus there is a history of such evidence being reported and steps to tackle the problem being announced but not, in retrospect, proving fully effective. Despite the NEAP process, attendance at FÁS employment offices is cited by claimants as a constraint much less than attendance at local Social Welfare offices. In most of the other 14 OECD countries that require frequent in-person attendance, this is at an employment service office. ${ }^{114}$

\section{$D S F A$ requirements for registration with $F A ́ S$}

201. DSFA currently advises new claimants that if they have not already registered with FÁS, they should not do so for at least a month (OECD, 2007a). Benefit entitlement does not depend directly on registration status, and claimants appear to report being summoned to FÁS only at the time of entry to the NEAP, so this requirement is not rigid. Comhairle (2003) suggested that registration with FÁS could help people show that they are genuinely seeking work when making a new claim. There is some evidence that registration with FÁS is required in some areas but not others ( $w w w$.boards.ie/vbulletin/showthread.php? $p=56524276$ ). Registration with FÁS is likely to be taken into account in the DSFA eligibility review conducted after seven months (see below).

202. In 2002 there were about 110000 new registrations with FÁS (DETE, 2004b). Live Register statistics show 306611 new claims and suggest (based on the duration structure of the Live Register) that about 110000 claims passed the four-month threshold. This suggests that registration with FÁS on average took place well after one month, or perhaps that registration with FÁS at the time of an earlier benefit claim meets the requirement for second and subsequent benefit claims.

\section{DSFA Activation Programmes}

Customer Activation

203. In 2000, DSFA issued guidelines for a Customer Activation implemented by Local Area Control Teams. ${ }^{115}$ It is not clear to what extent they are currently implemented. Under this programme clients are interviewed to check the extent to which they satisfy the availability and genuinely seeking work conditions:

114. See OECD (2007a, Table 5.1). In-person reporting every two weeks is to the benefit administration in Australia and in some cases in Portugal, but in other cases to the employment service (which is often also the benefit administration).

115. See www.welfare.ie/EN/OperationalGuidelines/Pages/custact.aspx. 
the customer is expected to provide sufficient and convincing evidence (both documentary and non-documentary) of satisfying this condition...Ideally, such evidence (either written or oral) should span the period between the 'profiling' interview and the substantive interview and be from a range of employers.

The interviewer should remind the client of the service offer available and:

a plan of action must be agreed with and co-signed by the customer... employment/educational/training/rehabilitative supports will more than likely be identified as part of the action plan or "contract" agreed with the customer... If at all possible, an appointment should be made with the Job Facilitator, FÁS Placement Officer or other service provider (as appropriate)... Local Offices should be innovative and proactive in this regard and a range of service referrals (as appropriate to the customer) should result i.e. literacy programmes, resource centre, LES, VTOS, employers etc. Any subsequent call for referral interview with the customer should include an indication that there will be an employment or educational opportunity offered... No customer should be without face-to-face contact for a period exceeding three months.

204. There is no recent evidence that DSFA clients have the "plan of action" that was described in 2000. Procedures for profiling jobseekers at local level and interviewing selected target groups, with a view to referring them to further services, are in place but the frequency of this intervention probably remains fairly low. Most DSFA referrals to FÁS are made under the NEAP (see Chapter 3), and internal referrals to Facilitators would be limited by the small number of staff in this grade. In the 2003 revision of strategy, control strategy was given a more traditional focus on minimising fraud, abuse and error and recovering debts, etc. (www.welfare.ie/EN/OperationalGuidelines/Pages/control_structure.aspx).

Activation programme

205. Recent policy documents refer to plans for DSFA activation (or a "more active approach") for all social welfare clients of working age:

Introducing an active case management service for social welfare customers of working age, including collaboration to ensure that customers, agencies and service providers in this area engage actively with each other. This will place activation on a level with service delivery and control as a central part of the core business of the Department of Social and Family Affairs. (Department of the Taoiseach, 2006, referring to plans for a three-year period).

Activation in a social welfare context ... involves engaging with all people of working age in a similar way, whether they are unemployed, lone parents, people with a disability or in some other category (DSFA, 2008b).

206. In 2006 the Disability Sectoral Plan described an Activation Programme for people of working age where "the expected outcomes will not lie exclusively in labour market activity". O'Donnell (2008) states that EUR 5 million was spent on the Activation and Family Support Programme (AFSP) in 2007 and makes a separate reference to the Activation Sub-Programme of the National Development Plan 2007-2013 which will involve an investment of EUR 50 million in an Activation sub-programme over the lifetime of the plan. To support this process 30 Facilitators are being recruited in addition to the current 40 (Minister for Social and Family Affairs, http://debates.oireachtas.ie/Xml/30/DAL20080513A.pdf, 13 May 2008) the strategy provides EUR 6 million to provide high quality information for families and enhanced support for training/development needs and EUR 3 million for a Technical Assistance and Training (TAT) Allowance in 2008 (Faughnan, 2008). 


\section{Determinants of effectiveness}

207. In international terms, where benefits are administered separately from employment services the unemployment benefit administration often does not have a substantive counselling, advisory and referral function. Two countries where it does are Denmark, where the union insurance funds have such a role (this is however the OECD's most expensive unemployment benefit administration in percent of GDP: see Table J of the OECD, 2007a), and Belgium where, since 2004, the benefit administration ONEM implements a programme called "activation of job-search behaviour" (ONEM, 2008). ${ }^{116}$ Benefit administrations in Canada and some states of the United States (and a separate state department in France) invite selected claimants to an interview to check their job-search record, but with limited counselling and referral content. Such activity helps to keep the benefit administration in touch with labour market issues and objectives, and couuld be productive in terms of referrals to other benefits (since some claimants may be invited to make a disability claim). Nevertheless, effective enforcement of job-search and availability-for-work conditions for benefit requires input from employment services, with in particular a capacity to refer clients to specific job vacancies and to labour market programmes, since self-reported evidence of job-search and occasional client interviews do not by themselves allow reliable detection of non-availability.

208. The effectiveness of intensive efforts to engage with people on inactive benefits without conditionality is likely to be limited by the difficulty and high cost of getting clients to participate, as evidenced by the FÁS pilots for lone parents and the disabled (see Chapter 3). In order to make participation obligatory, specific subgroups of social welfare clients, to which the obligations will apply, need to be defined. Most countries take people on unemployment benefits as the main target group for obligatory measures, and define the de facto coverage of this group by restricting access to other benefits. A variant approach used in some countries is to define specific target groups and at the same time compulsory intervention regimes for them: examples of such target groups are the unemployed with severe barriers (referred to the Personal Support Program in Australia), people on rehabilitation benefits (who, except in-between measures, should participate continuously in an ALMP in Norway), the disabled who have remaining work capacity (referred to Flex-jobs in Denmark), or lone parents according to specific rules and most disabled (referred to Work-Focused Interviews in the United Kingdom).

209. Since the DSFA "activation" programmes involve no participation requirement they may be better described as an enhanced service offer. Other DSFA proposals do include participation requirements for lone parents (see below) but not partners of the unemployed (except perhaps as part of OFP reform, discussed below) or disability benefit recipients. ${ }^{117}$

\section{DSFA control activity}

210. Office of the Comptroller and Auditor General (2003) describes departmental control activity to detect and deter fraud and error in payments. Unemployment payments accounted for $73 \%$ of the detected overpayments across all schemes, but only $41 \%$ of the total value of overpayments (lone-parent schemes accounted for another $9 \%$ and assistance-type old-age pensions where assets were not correctly declared for 24\%). An investigation in 2002 of a random sample of 442 cases on Unemployment Assistance recommended that in $16 \%$ of cases the rate of payment should be changed, mainly because means (which could be capital assets, unearned income or earned income) had been understated. A review by the Special

116. ONEM's programme is modelled on Ireland's in at least one respect: a new post of "Facilitateur" has been created to implement it.

117. Watts (2008) states that considerable time and effort are expended ensuring that people fit into the right category (i.e. Lone Parent, Disability, Unemployment, etc.) but he only highlights a negative consequence of this gatekeeping function (i.e. that people are "treated according to the rules governing the category which they are placed in"), and specifies that for people with disabilities there will be no conditionality. 
Investigation Unit in Wexford of all claimants in receipt of Unemployment Benefit or Unemployment Assistance who were being paid by EFT (electronic fund transfer) was ongoing but had already resulted in $23 \%$ of those investigated signing off. ${ }^{118}$ The policy thrust set out in Office of the Comptroller and Auditor General (2003) is continuing: DSFA (2007a) mentions a continuing emphasis on combating claims involving identity fraud.

\section{Statistics for benefit sanctions and refusals}

211. Data for benefit sanctions and stops in Ireland are weak because the most stops are reported broken down only by two legal grounds ("not available" or "not genuinely seeking work") and by duration (closures or suspensions). Table 4.3 nevertheless attempts to allocate the available statistics to categories that have been used previously for international comparisons.

212. In 2006, for Jobseekers' Benefit and Jobseekers' Allowance together there were 1057 suspensions and 6177 closures on the grounds "not available". It seems possible that the suspensions tend to have the character of a sanction related to labour market behaviour (e.g. if an interview reveals that the client has previously undeclared domestic commitments) and that the closures more often do not (e.g. if the client declares an event such start in education or leaving the country): but in the absence of further information, Table 5.4 only interprets as sanctions (i.e. it only includes) the suspensions (disqualifications, for up to nine weeks) on grounds of "not genuinely seeking work".

213. The legal heading "not genuinely seeking work" in Ireland includes sanctions for several reasons other than insufficient evidence of job search. Separate figures are available for the subcategories "refused work" ( 2 in 2006) and "refused a (training) course" (8 in 2006), but there is no further breakdown by reason of the other cases (1 692 in 2006). Apart from refusal of work/training, the main grounds are:

- As listed at www.welfare.ie/EN/OperationalGuidelines/Pages/jb_jobseekben.aspx: (a) Loss of employment through misconduct; (b) Voluntarily left employment; (e) Failure to avail of opportunity of suitable employment; and $(f)$ Receipt of redundancy lump sum; and

- As listed at www.welfare.ie/EN/OperationalGuidelines/Pages/decreasons.aspx, a variety of other reasons, including: did not act on advice given by an officer of the Minister concerning the availability of employment; voluntarily moved from a location with higher job prospects; left employment; and failed to produce sufficient evidence of realistic, consistent or genuine job search.

214. Based on these two sources, some examples of appeal cases (e.g. see www.welfare.ie/EN/OperationalGuidelines/Pages/appealsubs.aspx and publications of the Social Welfare Appeals office), and international experience (where often a large proportion of benefit sanctions relate to voluntary job leaving), we might guess that about half the not-genuinely-seeking-work sanction cases (not including refusal of work/training) relate to inadequate evidence of job search and the other half to voluntary job leaving. Applying this assumption in Table 4.3, the rate of sanction for voluntary job-leaving as a percentage of all new benefit claims is estimated at $0.5 \%$ from 2004 to 2006 , and the annual rate of sanction for insufficient job search (but in fact including some other reasons) as a percentage of the average stock of benefit claims is estimated at $0.8 \%$ in 2004 , falling to $0.6 \%$ in 2006 .

118. DWP in the United Kingdom phased out older methods in favour of Direct Payment (i.e. payment by bank transfer) in 2004, arguing that this method is popular and safe (http://news.bbc.co.uk/go/pr/fr//2/hi/business/3686356.stm; www.dwp.gov.uk/directpayment/), whereas in Ireland a July 2008 press release (cited above) DSFA announced that electronic payments will be scrapped. 
Table 4.3. Unemployment benefit refusals and sanctions, Ireland, 2004-06

Persons and percentages

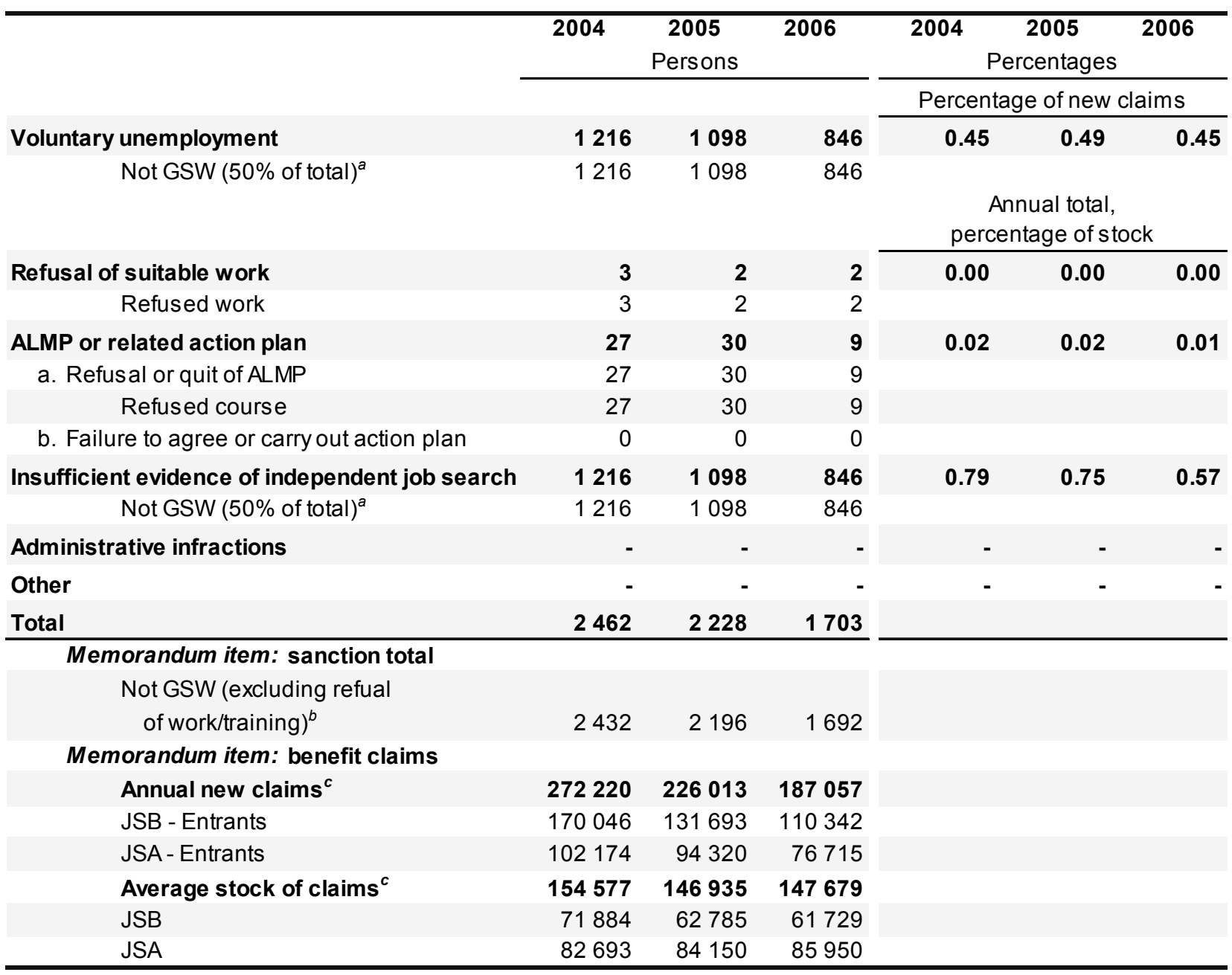

GSW: Genuinely Seeking Work; JSA: Job Seeker Allowance; JSB: Job Seeker Benefit.

a) Illustrative calculation assuming that half the benefit suspensions are for voluntary leaving, half for failure to provide adequate evidence of job search: see text.

b) Refers to suspensions (also called disqualifications or disallowances) for not genuinely seeking work. Does not include data for refusal of work/refusal of a course, which are listed separately.

c) Jobseekers' Benefit/Jobseekers' Allowance data for annual new claims and the annual average stock of claims are as reported in Eurostat LMP data publications. In the case of average stock data, these match national sources for persons on the Live Register with a JSB/JSA claim (excluding credits cases), which are about $15 \%$ higher than than national data for JSB/JSA recipients that are reported in Table 4.1.

Source: Data for claims suspended because not Genuinely Seeking Work (code PSP07), refused work (code BSP04) and refused course (code BSP05) supplied by national authorities. Data for annual new claims and average stock of claims as reported in Eurostat (2008), Labour Market Policies 2006 and earlier publications in the series.

215. An international benchmark table for these rates is given in Gray (2003), Table 1. In a sample of 13 countries in the latter $1990 \mathrm{~s}:{ }^{119}$

119. Gray (2003), Table 1 is taken from an OECD source but with the data for Canada corrected. Current OECD work on activation policies should generate some more updated figures in the future. 
- The rate of sanction for voluntary job-leaving in the late 1990 s was lowest in New Zealand at $0.5 \%,{ }^{120}$ and the international median level was $3.5 \%$;

- The rate of sanctions per beneficiary-year for refusal of work was $0.00 \%$ (when rounded to the nearest $0.01 \%$ ) in one country (Japan), with a median value of $0.60 \%$; and

- The rate of sanctions per beneficiary-year for refusal of an ALMP place or a related action plan was $0.02 \%$ in Japan but much higher elsewhere, with a median of $1.5 \%$.

216. Thus, the sanction rates in Ireland shown in Table 4.3 are either the lowest or close to the lowest in international comparative terms in three areas: sanctions for voluntary job leaving, refusal of work and refusal of an ALMP place. This conclusion would not be greatly changed under variant interpretations of the available statistics, e.g. if suspensions for reason "not available" (1 057 in 2006) were all interpreted as sanctions for voluntary job-leaving, the total would still be close to the lowest.

217. In the fourth area, insufficient job search, it can only be said that Ireland's sanctions rates are below typical levels (in the latter 1990s) in the countries that require frequent reporting (e.g. via a Job-search Diary or "active signing": Australia, Switzerland, United Kingdom, United States), but well above those in Canada, another country that checks via occasional retrospective interviews. A higher rate in Ireland as compared to Canada seems plausible since checks, although not frequent, follow a systematic schedule: DSFA guidelines call for checks at 7 months of unemployment, 12 or 15 months depending on benefit type, and annually thereafter. Several other countries have zero rates and/or missing data as regards sanctions for insufficient job search. ${ }^{121}$

218. Total sanctions, as shown in Table 4.3, declined substantially from 2004 and 2006. Written answers to parliamentary questions (Dáil Eireann, 2004b) cite the number of clients disallowed as not genuinely seeking work as 5320 in 2001, 3567 in 2002 and 4024 in 2003. Thus the total number of unemployment benefit disallowances on these grounds in 2006 (1 703) was less than a third of its level in 2001, although the total stock of people on unemployment benefits was unchanged (see Table 4.1). The majority of these benefit sanctions were perhaps generated by the Customer Activation strategy implemented by DSFA Local Area Control Teams, which as discussed was prioritised in 2000 but then partly faded away.

219. At the same time, the extremely low rate of sanction for refusal of work/refusal of a course shown in Table 4.3 suggests that FÁS counsellors rarely make direct (unilateral and compulsory) referrals to job vacancies or training courses. ${ }^{122}$ This is consistent with FÁS policy which is to develop an agreed Action Plan, and avoid coercing clients into participation on programmes that they do not believe are useful, which would often be unproductive since an unwilling trainee is unlikely to gain much from participation. The low sanction rate may be related also to the close links with programme implementation within FÁS. In most countries, one way an ESO can deal with an uncooperative client is to make a compulsory referral to an ALMP: since ALMP providers are under contract to the employment services they cannot easily refuse such difficult clients. Within FÁS, ESOs could be reluctant to impose difficult

120. Sanction rates in New Zealand probably increased when activation strategies, which resulted in the sharp fall in benefit recipient numbers shown in Table 4.1, were applied in the early $2000 \mathrm{~s}$.

121. In some countries, insufficient job search leads to benefit stops on availability grounds rather than a fixed-term sanction, and the absence of statistics may reflect this.

122. Probably the majority of referrals by FÁS to DSFA for a possible benefit sanction result from "DNA" (did not attend) codings under the NEAP process (see Chapter 3). In such cases, DSFA invites the client to an interview before taking a sanction decision. 
clients on their colleagues working in Training Services (or in Community Services, but in this case the legal basis for making participation compulsory is absent). It can also be argued that Irish social norms make FÁS (and other) employment services reluctant to impose sanctions, although would be true also for many countries, particularly at local level.

220. To implement more effective activation strategies, Ireland probably needs to improve management information on benefit sanctions, analyse the issues discussed here, and redesign employment services so that jobseekers on benefit are more often referred to a job vacancy or an ALMP with a risk of sanction in cases of refusal. If the sanction risk for clients who comply with the NEAP procedures in other respects but take up none of the concrete opportunities offered is indeed near zero, this will have progressively become known, so that the NEAP process tends to lose the "threat" effect (a high rate of signing-off upon first referral or early in the process) that it had in early years.

\section{Administration and staff management issues}

221. As documented further below, administrative reforms including the "localisation" of OFP payments and the transfer of SWA administration to DSFA have proceeded slowly due to staff opposition. But this also affects specific administrative procedures, e.g.:

- In a case where a Social Welfare payment was suspended because the person failed to turn up for an interview, but claimed he had not received notification of it, a second letter of notification had not been sent as required by regulations: the Citizen's Information Centre was told "that there was a union objection to this and that it was not being implemented"; ${ }^{123}$ and

- Recently as regards the initiative "Local Office staff to use the ERIN system to record local office activities including reviews and savings, appeals, customer interviews, Personal Public Service (PPS) Number application checks, NEAP fallout, commencement of employment data matching and special projects as well as the outputs from the activities", the union representing lower-level clerical and administrative staff issued an instruction to its members to withdraw co-operation. ${ }^{124}$

222. The government needs to gain more effective control of its administration to allow more better implementation of benefit eligibility criteria and delivery of other individualised or targeted assistance and generally efficient management. Other countries (including Australia, New Zealand or the United Kingdom) seem to experience less delay in implementing particular procedures or institutional reforms.

\subsection{Reforms of lone-parent and disability payments and the Supplementary Welfare Allowance}

\section{Lone-parent and partner payments}

\section{Lone-parent payments}

223. As noted above, Ireland experienced rapid growth in the lone-parent beneficiary numbers between 1980 and 2000, although the exact structure of the benefits involved has changed (earlier assistance benefits for lone parents were replaced by a Lone Parents' Allowance in 1990, which in turn was replaced by One-Parent Family Payment, OFP, in 1997).

123. See http://comhairle.ie/publications/social/social_update_2002part1.html.

124. See the DSFA $4^{\text {th }}$ Phase Progress Report and Letter at www.cspvg.gov.ie/verification-docs/phase-4-1 and for a description of relevant unions www.eurofound.europa.eu/eiro/studies/tn0712017s/ie0712019q.htm. 
224. DSFA (2006a), Table 5.1 lists lone-parent participation in a range of other passive and active measures (at end 2004 or 2005). OFP recipients made up:

- $61 \%$ (9000) of the total of 14700 recipients of Family Income Supplement, a payment to low-income families with children working a minimum of 19 hours per week;

- $22 \%$ (13 000) of the total of 60000 recipients of Rent Supplement and 27\% of those in receipt for over 18 months (these long-term cases are targeted for transfer to local authority housing when appropriate: see below); ${ }^{125}$

- $26 \%$ of the total of 22000 participants in the Community Employment programme (see Chapter 5 for further description of the active programmes);

- $23 \%$ of the participants in Jobs Initiative and $22 \%$ of the participants in the Social Economy Programme;

- About 25\% (1 254) of the circa 5000 participants in Back to Work Allowance, ${ }^{126}$ and

- About 25\% (1 309) of the circa 5200 participants in Back to Education Allowance.

225. Taking into account also Child Benefit and the cost of specific tax credits for lone parents, total expenditure on lone parents in 2005 was estimated at about EUR 1.35 billion, with the OFP payment accounting for only $57 \%$ of this total. This is a large amount in the Irish context, e.g. 2005 spending on Unemployment Benefit and Unemployment Assistance totalled less than EUR 1.1 billion (see Table 5.1 of Chapter 5). And although this estimate includes the cost of specific tax credits for lone parents, it does not include the general loss of tax revenue that arises from the low employment rate of lone parents: full-time employment rates around 20 percentage points higher are common in other countries.

226. By 2000, a perception that benefit dependency was a poor outcome for lone parents and their children, as well as its costs, were major concerns. The first policy response was to increase benefit disregards and other financial incentives for lone parents to take up part-time work (see above and OECD, $2003 b){ }^{127}$ Lone parents also have easier access to labour market measures and/or more favourable conditions during participation in measures than the unemployed (e.g. JA recipients qualify for BTWA after two years whereas OFP recipients - as well as Disability Allowance and Invalidity Pension recipients - qualify after 15 months: and the increase in net income from participation on employment schemes is much greater for lone parents, as discussed in Chapter 5).

227. Three other countries that have a specific lone-parent benefit - the United States, Australia and the United Kingdom - have not been satisfied with outcomes and eventually adopted an approach which makes income support for lone parents (with children above a certain age) conditional on availability for

125. DSCFA (2000) stated that only $27 \%$ of OFP recipients live alone ( $66 \%$ live with their parents), so the 13000 with a rent supplement may represent more than half of the OFP recipients who live alone.

126. Statistics cited for the Back to Work Allowance by Irish authorities sometimes include cases of Back to Work Enterprise Allowance; it is assumed here that the 1254 figure does not include the latter payment. See Table 5.1 in Chapter 5 for the overall participant numbers.

127. Arguably no country (although Ireland has the one-parent family tax credit) provides major financial advantages to lone parents in full-time work on average earnings because this would create a visible "marriage penalty" for other working mothers. Given this constraint, disregard policies can only sharply increase financial incentives for entry to part-time work or jobs with relatively low earnings. 
work. ${ }^{128}$ New Zealand by contrast introduced a work test for its Domestic Purposes Benefit in 1999, but rescinded it four years later (see OECD, 2007c for further discussion).

\section{Policy reviews and prospects for policy change}

228. In 2000 the Review of the One-Parent Family Payment (DSCFA, 2000) reported that:

developments in relation to compulsory work tests and/or time limits on claiming may be neither practical nor acceptable at this point in time, the former because of the lack of an affordable childcare infrastructure required to support such a development and the latter because of the ambiguous societal attitudes referred to above. Following much debate by the Group, it was agreed that the question of a work test and/or a time limit should be reviewed when the childcare structure is more developed.

but went on to say:

The ever increasing cost of the scheme, changing attitudes towards parents working outside the home and the fact that a scheme of this nature is, increasingly, out of step with other EU/international social welfare systems makes it almost inevitable that a more fundamental change to the arrangements, which may introduce some conditionality on claiming, will take place at some stage.

229. A key recommendation (announced as a decision already taken in principle) in 2000 was that the administration of the OFP should be devolved to the Department's network of local offices around the country. Implementation of this change has been slow: in 2006 the Minister was still referring to preparations for it (Dail Eireann, 2006). By 2008 almost all local offices were handling new OFP claims although completion of the localisation was still an objective (Faughnan, 2008; and DSFA, 2008b).

230. Childcare provision in Ireland is weak, with some subsidised provision available (e.g. through CE and other job-creation schemes, see Chapter 5) but the remaining provision being thin and too expensive for low earners. ${ }^{129}$ In December 2005, the government announced a five-year childcare strategy involving capital investment, training of childcare personnel and grants towards the staffing costs of community sector childcare providers in disadvantaged areas; this was expected to create up to 50000 childcare places, in addition to 40000 created under an earlier (2000-06) strategy. An Early Childcare Supplement

128. The United States reduced the effective tax rate on earnings for Aid to Families with Dependent Children (AFDC) from 100\% to 67\% between 1967 and 1981, when it was put back to $100 \%$. At the same time the "waiver" provision, allowing states to experiment (at variance with the general federal legislation, e.g. in terms of participation requirements) with "community work programs, work supplementation programs, heightened job search, and other programs to strengthen the emphasis on work" was introduced leading eventually to the major welfare reform of 1996 (Moffitt, 2002). Australia introduced conditionality for lone parents with youngest child aged 6 or over from July 2006 (at the same time putting lone parents onto benefit entitlements similar to those for the unemployed). In the United Kingdom, from November 2008 lone parents not in work with youngest child aged 12 and over will have to claim Jobseeker's Allowance, and this will apply to lone parents with youngest child 10 or over from October 2009 and aged 7 or over from October 2010 (www.dwp.gov.uk/welfarereform/parents.asp).

129. OECD $(2003 \mathrm{~b})$ gives a detailed description of childcare arrangements. Based on calculations of net income out of work and in work taking childcare cost into account, OECD (2007b) concludes that "In Ireland and the United Kingdom, the costs of childcare can be so high, that in the short-term work does not pay for many second earners in couple families and this applies to sole-parent families in the Canadian province of Ontario, Ireland, France, and the city of Zürich in Switzerland." 
of EUR 1000 per year paid to parents for each child aged under 6 was introduced, although entitlement to this is not linked to actual spending on child care.

231. The recent Green Paper Proposals for Supporting Lone Parents (DSFA, 2006a) documented the high cost of lone-parent provision (as cited above), again pointing to poor outcomes:

...unacceptable numbers of children remain in poverty. Aspects of the present approaches combine to effectively lock lone parents into a system which pays them a "social exclusionary" wage, in which there are a number of poverty traps and which is patently anti-family [and] increasingly out of step with tried and tested policies implemented abroad... While earnings disregards have facilitated the take up of employment, they also can trap lone parents in part-time and low paid employment.

232. This text recognises that increases in the generosity of benefit tapers or labour market programme conditions can attract some additional participants into low-paid work or programmes, but beyond a certain point conditions for participants become too attractive relative to full-time unsubsidised work.

233. The Green Paper proposed the creation of a new Parental Allowance (PA) payable, subject to income thresholds, to both one and two-parent families ${ }^{130}$ and time-limited in respect of the age of the youngest child (taken as age 7 for illustrative purposes): "When the child reaches the end of their $7^{\text {th }}$ year, payment of PA will cease. If the parent is not in employment, education or training, they would then apply for Unemployment Assistance". Although this proposal did not meet with outright opposition, ${ }^{131}$ there is no particular lobby for this tougher approach - and although some later official references to it have been clear, many others have not. Department of the Taoiseach (2006) envisaged extending the National Employment Action Plan referral process over 2005-2016 to groups such as lone parents "in a supportive and positive manner working in an inclusive way with the customer". DSFA (2008b) anticipates that through to 2010 "a specific policy focus will be on progressing the Government Discussion Paper" where "proposals include ... the introduction of a new social assistance payment for low-income families with young children".

234. Ireland and New Zealand will soon be the only OECD countries that pay a lone-parent benefit without availability requirements when the youngest child is aged more than seven. Ireland has the lowest lone-parent employment rate in the OECD and New Zealand has the highest rate of lone-parent benefit recipiency (OECD, 2007c, Table 4.1, Table 4.6, and Figure 3.7). A causal link seems highly plausible, and there is little evidence that easier access to benefits leads to better outcomes in terms of children's poverty, welfare and later life prospects. ${ }^{132}$ Therefore the strategy of transferring lone parents from OFP to

130. Parental Allowance will end the cohabitation rule which applies to OFP; but it will not change the financial incentive for a lone parent to conceal cohabitation with a partner who has significant income, which will still extinguish entitlement to the Parental Allowance.

131. NWCI (2006) and OPEN (2006) did not oppose the general principle of applying the genuinely seeking work condition to lone parents with older children, which appears to contrast with the reaction of lone-parent support groups described in DSCFA (2000). They called for OFP-like earnings disregards to be extended beyond child age seven, more extensive childcare provision and childcare subsidies, and other improvements. EAPN (2007) states that the proposals "recognise that this policy can't succeed unless all necessary supports are in place, but it isn't clear how, or whether, this will be achieved".

132. Pronzato and Mogstad (2008) evaluate a "workfare" reform of the Norwegian system for lone mothers which increased the maximum benefit amount but also imposed activity requirements and limited time on welfare: "The results were striking: the workfare reform has not only led to increased earnings and educational attainment - in the process lowering welfare caseloads and therefore easing the government's financial burden - but also reduced poverty." 
Jobseekers' Assistance set out in the 2006 Green Paper, with appropriate accompanying measures, should be implemented. This should be not be conditional not on a consensus that the availability of childcare (or other supports) is adequate nationwide, but on the availability of adequate childcare in the individual case. ${ }^{133}$ At the same time, labour market polices need to establish a situation where the openly-unemployed are placed in jobs rapidly before adding new hard-to-place groups to the employment service caseload: short-term prospects for this deteriorated as the economy entered recession in 2008.

\section{Availability conditions for spouses}

235. In Ireland, a couple can claim income support including a Qualified (i.e. dependent) Adult supplement when one of the partners is unemployed or disabled, even if the other partner could work but does not do so (e.g. due to loss of secondary benefits, they may consider it not worthwhile: see the October-December 2003 Social Policy Quarterly Report at www.citizensinformationboard.ie). About 50000 Qualified Adult supplements for working-age benefits were in payment in December 2006. Although not subject to any availability requirements, Qualified Adults are in many cases eligible to participate in active labour market programmes (e.g. Community Employment).

236. Australia, New Zealand and the United Kingdom introduced work requirements for spouses without children some time before they reformed lone-parent payments. Australia individualised benefit entitlements, thus requiring both partners to seek and be available for full-time work, in 1995 (OECD, $2001 \mathrm{~b}$ ); New Zealand introduced work-testing of spouses progressively (for spouses of sickness and disability recipients, in 1998 and 1999) and retained it when work-testing of lone parents was later rescinded; and the United Kingdom since 2001 requires couples with no children to make "Joint Claims", such that both partners have to fulfil the obligations of Jobseekers' Allowance (JSA) claimants (www.psi.org.uk/research/project.asp? project $i d=86$ ). Current proposals suggest that Ireland will reform availability requirements for lone parents before reforming those for partners. ${ }^{134}$ Few social assistance systems in other OECD countries would recognise an adult dependent/carer status for spouses.

\section{Disability payments}

237. Disability benefits and employment policies will not be described in detail since they are covered in OECD (2008b). However, there are important links between disability benefits and activation policies. Gate-keeping for disability benefits - complicated by the fact that these include three distinct long-term payments with different eligibility criteria plus a sub-category of SWA clients - is poor. The distinction between unemployment and disability status is not very clearly implemented and many people are probably on the "wrong" payments. ${ }^{135}$ One consequence is that many people with work capacity are on payments without activation. Another consequence is that people with work capacity limitations are on a

133. This is the situation in Germany for lone parents with children aged over 3 years (as described at www.york.ac.uk/inst/spru/research/childben22/questionnaires/Germany.doc).

134. DSFA (2006a) discussed this issue noting that Qualified Adults "would continue to exist within the social insurance system. This inconsistency is recognised by the Group. It is accepted however that change tends to be incremental in nature and that this could be examined as a next stage of reform."

135. There is no automatic referral of sickness claims at specified dates, and because of capacity constraints many claims are not examined directly by DSFA's medical assessors (OECD, 2008b). One conclusion from the evaluation of the Midlands pilot (WRC, 2006a) was that "the quantity and quality of the information on DA [Disability Allowance] recipients held by the DSFA was inadequate to support a 100\% accurate identification of persons 'capable of progression' and for whom the pilot meeting could have provided an opportunity to assist such progression." Long-term "Sick no benefit" claims for Supplementary Welfare Allowance are accepted without a second opinion because "There is no provision in legislation to allow this second medical opinion to be sought." (DSFA, 2006b). 
long-term unemployment payment, which in turn may be one of the reasons that activation requirements are not stringently implemented for the long-term unemployed. More intensive contact and activation at all points in the unemployment spell would promote identification of both work capacity limitations and remaining work capacity by both clients and the employment service, allowing more effective delivery of appropriate support.

238. Overall, Ireland's benefit system is fairly similar to a non-categorised minimum income scheme, i.e. benefit is conditional on means but is not strongly conditional on availability for work or evidence of incapacity for work. Levels of spending on benefit administration may to some extent be too low to allow a better result, especially given the duplication of functions in some parts of the social services system. High benefit dependency rates then tend to result unless benefits are kept relatively low, which was the case around 2000 but not so much now (see Subsection 4.3 above). It probably would always have been better to spend more on implementing the eligibility criteria for benefits, and not only the means tests.

\section{Supplementary Welfare Allowance}

\section{General}

239. Ireland's Supplementary Welfare Allowance (SWA) has, particularly in the 2000s, had an unusually large number of recipients given that it is supplementary to a system of assistance benefits that already covers the main social risks (Jobseekers' Allowance, Disability Allowance, One-Parent Family Payment).

240. Following the introduction of SWA in 1977, its caseload increased rapidly. SWA expenditure increased steadily from $1.09 \%$ of total DSFA expenditure in 1983 to $6.00 \%$ in 2003 (DSFA, 2004). This is a relative growth rate of nearly $9 \%$ per year on average for 20 years. Such rapid growth is in line with other countries' experiences following the introduction of a new assistance benefit. ${ }^{136}$ In general, when the time elapsed since the creation of a new benefit - rather than its legislated entitlement conditions or the state of the labour market - plays a key role in determining its caseload, this suggests that a learning process has operated e.g. applicants learn from each other of the benefit's existence and how to qualify for and apply for it, while on the administrative side interpretations vary but decisions to grant benefit tend to be taken as precedents, ${ }^{137}$ although the latter process comes to an end as the need for restrictive measures is recognised.

241. Particular factors driving the growth of SWA in Ireland recently seem to be:

- The large number of asylum seekers in the early 2000 s;

- High housing costs: through their effect on rent levels, strong demand conditions in the early 2000s may have increased the demand for rent supplements; and

136. Reviewing the history of a number of lone-parent and social assistance programmes after their introduction, OECD (2003a) described caseload dynamics as follows: “... the period of growth in beneficiary numbers has usually been 15 years or longer... Growth rates of beneficiary numbers averaged close to $10 \%$ per year or more, over a decade or more... Commonly, the numbers have stopped rising at a time when entitlements were restricted or activation measures were introduced."

137. DSW (1996) remarked "There is a very high level of discretion in the administration of the SWA schemes with individual CWOs required to make decisions, very often at short notice, in relation to a customer's entitlement." 
- The introduction in 1998 and later intensification of the NEAP process, which drove some people off unemployment payments. ${ }^{138}$

242. DSFA (2004) provides detailed information on the 2003 SWA caseload of about 31000. One-third consisted of non-nationals, the majority of whom were probably Asylum Seekers (unable to claim Unemployment Allowance because they did not have a work permit). Approximately 3500 more were homeless and "Sick No Benefit" cases. ${ }^{139}$ Approximately half, 15 000, were on an "interim" SWA payment awaiting a DSFA payment. Of these, 600 were appealing a negative decision on an unemployment payment (DSFA, 2004, Appendix 6 and Table 5). In the case of a benefit sanction e.g. for refusal of work, SWA is paid until the appeal case is heard, but if the decision on appeal is negative SWA is refused. When entitlement under another benefit scheme is granted (retrospectively) for a period when SWA has been paid, the other benefit scheme refunds the SWA scheme; in 2003, gross expenditure for SWA basic payments was EUR 215.2 million, of which EUR 54.6 million was refunded.

243. The EUR 215.2 million expenditure on basic payments in 2003 was only just over a third of total SWA expenditure. The largest expenditure item was rent supplement, in payment to nearly 60000 recipients at end 2003. The cost of Exceptional Needs Payments (4 700 per week in 2003) was also significant.

244. SWA is administered by 700 Community Welfare Officers (CWOs), 53 superintendant CWOs and 196 clerical support staff who provide the service from 1050 locations (DSFA, 2004), which is many more than the circa 130 locations of DSFA local offices and branch offices (see Chapter 2). Outside the larger urban areas, the only regular service at these locations may be a half-hour clinic once a week: an analysis for three counties with 141 locations delivering SWA found that the total opening time available to the public for the SWA scheme ${ }^{140}$ averaged less than an hour per week per location (DSFA, 2006b). The administration costs of SWA in 2003 were estimated at EUR 45 million, about 7\% of gross SWA expenditure and $8 \%$ of net SWA expenditure.

245. The Working Group on the SWA scheme (DSFA, 2006b) considered that the scheme had gone beyond the "safety net" role that was originally intended for it, and identified extensive duplication of administrative functions (such as assessment of claimants' needs) between HSE and DSFA. It recommended that income support and maintenance schemes including SWA basic allowances and short-term rent supplements should be transferred from HSE to DSFA: in particular, basic SWA payments should be delivered at DSFA local offices. ${ }^{141}$ This was also in line with the recommendations of the Core Functions of the Health Service Report (DoHC, 2006). Since SWA applies a different means test from

138. At the end of 2001, a basic SWA payment was being made to 975 people pending a decision on appeal against a negative Unemployment Benefit or Unemployment Assistance decision (DSFA, 2006b, Table 4).

139. The categorised assistance benefits in Ireland do not cover short-term illness: Illness Benefit is conditional on an insurance contribution record, while Disability Allowance is not conditional on a contribution record but covers only injury, disease or disability that has continued or is expected to continue for at least one year. Categorised assistance benefit systems in other countries probably also do not cover short-term illness. Incapacity Benefit in the United Kingdom requires a contribution record, although some exceptions are made for people who became unfit for work before the age of 20 or 25 and there is a special provision for young people who have recently returned from living abroad (JobCentre Plus, 2008).

140. CWOs also provide some health-related services.

141. "The Working Group concluded that in the case of interim basic supplementary welfare allowance payments it was inefficient to provide an income support service that required two separate applications, at two different locations, by two different service providers in order to address the one income support need.... The Group was satisfied that this was poor customer service and represented poor value for money." (DSFA, 2006b). 
DSFA schemes (e.g. different schedules for the income equivalent of capital), it recommended that the means assessment be standardised and different welfare schemes should ultimately adopt a shared means database. ${ }^{142}$

\section{SWA rent supplement}

246. SWA rent supplement payments are being reformed by a different route. Even before 2000, several reports had acknowledged that it was inappropriate to use the "safety net" structures of SWA to cover high rent or mortgage payments on a long-term basis. In 2004 the government introduced a Rental Accommodation Scheme under which those who have received SWA rent supplement for 18 months or more (more than half of the stock of recipients: DSFA, 2006b, Table 5.4) are referred to local authorities for a full housing needs assessment. This assessment is expected to determine in some cases that the rents paid are excessive and the claimant should accept local authority housing or private rented accommodation within the Rental Accommodation Scheme (under which local authorities supervise the private accommodation and the rent charged for it).

247. In 2004 a survey of rent supplement recipients carried out by the Dublin Inner City Partnership found that $60 \%$ of those surveyed had refused alternative accommodation for reasons such as that the customer "did not like it", or it was "not large enough", it was in an "undesirable neighbourhood", or it was "unsanitary". Tenant contributions (the difference between rent and SWA rent supplement) are quite small (EUR 13 per week or less in 52\% of cases: DSFA, 2006b, Table 5.14, which may be compared with an average rent supplement payment of about EUR 120 per week), so there is not often a direct incentive to move into cheaper housing. Some policy of linking tenant contributions to the rent level, or increasing the tenant contribution if cheaper accommodation has been refused, indeed seems to be necessary to limit the cost and work disincentives arising from rent supplements. Current advice to tenants under the Rental Accommodation Scheme appears to represent a tightening of conditions: "You are entitled to refuse up to three offers of accommodation within a set period. After the third offer, you will not be entitled to rental supplement for one year." (www.dublincity.ie/Housing/RAS/Pages/InformationforTenants.aspx).

\section{Other situations covered by SWA}

248. As discussed above, other situations of need covered by SWA include assistance for asylum seekers and for people unable to work due to short-term illness (who are not available for work and thus cannot claim an unemployment payment), and interim payments to people who are awaiting a DSFA decision or appealing against a benefit sanction. Arguably each of these functions of SWA should be subjected to a policy review, leading to the definition of entitlements which so far as possible meet the needs but also minimise administrative and benefit costs and enhance incentives. For example a system of crisis loans managed by DSFA could handle situations where people are awaiting a decision on their benefit application or appealing a sanction.

\section{Pre-retirement allowance}

249. The stock of recipients of Pre-Retirement Allowance (PRETA) was steady at about 11000 since 1999, so that this benefit has a relatively small caseload in the Irish context (until the current

142. Two unions representing the majority of CWOs ( 575 CWOs and 50 superintendent welfare officers) in mid-2006 expressed their strong opposition to the proposed transfer to DSFA: the proposal "could seriously undermine the quality and range of services that community welfare officers provide to some of the most vulnerable people in communities across Ireland". DoHC (2006) notes that previous reports going back to the 1986 Report of the Commission on Social Welfare have recommended that the administration of SWA be moved from the Health Boards (now HSE) to DSFA: so the implementation of reforms believed at management level to be necessary remains very slow, if not impossible. 
recession six other working-age income-replacement benefits each had caseloads in the range 50000 to 85000 ). Its cost as a percentage of GDP is about half the average for the LMP database Category 9 Early retirement (for labour market reasons) (OECD, 2008a, Table J). It was payable to people who have been on JB or JA for 15 months or more under the same conditions as JA, except that recipients do not have to sign on. This is similar to the principle of "exemption from job-search requirements" which applied above a certain age (57.5 years) to unemployment insurance benefits in France or the Netherlands. In line with policy trends in other countries, PRETA was closed to new applications in July 2007. Most of its caseload will therefore progressively be transferred to JA, except insofar as the signing-on and other requirements associated with this JA status result in higher rates of return to work among the older-worker target group than occurred under the PRETA status. As mentioned in Chapter 3, the NEAP process was extended to over-55s in July 2006 - which should do something to increase the older worker employment rate, but also increases the NEAP caseload and the hard-to-place component within it.

\section{Strategic considerations for the extension of availability conditions}

250. The phasing-out of PRETA represents an extension of availability-for-work and genuinely-seeking-work conditions for benefit entitlement for older workers. Other extensions outlined here would apply conditionality to certain lone parents, adult dependents and people with partial work capacity. However in strategic terms, the first priority is to activate the unemployed more effectively, so as to establish a situation where most people on these payments enter work, or if necessary are placed in work or a programme, fairly rapidly and relatively few are allowed to become long-term unemployed. From such a starting-point, the transfer of groups that are currently on inactive benefits to an unemployment status or similar can generate sharp increases in their employment rates - rather than overwhelming employment service capacity to the point where the outcomes even for more-employable groups deteriorate. In 2008, the first priority is no doubt to tackle the cyclical rise in unemployment. However, some groups with no more employability barriers than the average unemployed person, such as dependent adults without children, might still be transferred any time that this is feasible. And for major reforms, delays in the process imply that action now is needed in order to achieve implementation some years ahead.

\subsection{Summary of main points}

- Ireland has a comprehensive system of categorised assistance benefits which are paid, with limited exceptions, at the same basic rate. But controls on an individual's eligibility for a particular benefit, such as the enforcement of availability requirements for unemployment and verification of sickness and disability status for disability payments, appear to be fairly weak.

- In the 2000-06 period, despite favourable economic conditions, recipiency rates for both unemployment payments and disability payments became considerably higher than in the three other OECD countries that have comparable systems, Australia, New Zealand and the United Kingdom, which had by then done more in terms of activation and benefit gatekeeping.

- Benefit replacement rates fell significantly between the mid-1980s and the early 2000s, which may have contributed to the fall in benefit dependency rates. However from 2002 to 2007, under the National Anti-Poverty Strategy, the lowest benefit rates increased by about 25\% more than earnings. Replacement rates are now closer to those of Nordic and some other European countries, which are only able to contain benefit dependency through strict and/or expensive activation measures.

- There is longstanding evidence that a significant proportion of recipients on unemployment payments are not effectively available for or searching for work. DSFA staff actively enforce these conditions, but this not as effective as frequent contact with employment counsellors who 
can refer clients to specific job vacancies and labour market programmes. Benefit sanction rates for placement-related reasons (sanctions for refusal of work or a training programme place) are very low in international comparative terms, probably because even in the context of the NEAP process FAS rarely makes compulsory referrals. The recently-introduced DSFA "activation programme" does not define any target group that will face additional participation requirements, and thus represents mainly an increase in the availability of DSFA counselling services.

- The implementation by DSW/DSFA of significant reforms that were announced some years earlier has been slow; to allow more effective policy-making in this area the government needs to gain better control of its own administration.

- For lone parents, Ireland has adopted a policy of generous benefit disregards for part-time work and conditions for access to labour market programmes but this approach has probably reached its limits, given the need to leave some incentive to move on to full-time work. Ireland and New Zealand will soon be the only OECD countries that pay a lone-parent benefit without availability requirements when the youngest child is aged more than seven.

- Reviews of the rent assistance function of the Supplementary Welfare Allowance have led to the introduction of more targeted provisions which are more incentive-compatible. However, discretionary decisions have defined the de facto entitlements to SWA in several other situations, which should now be reviewed in a similar way.

- Major reforms to inactive benefits need to be strategically planned and sequenced in conjunction with activation of unemployment benefits. A first priority is to reduce the high numbers on long-term unemployment payments. When unemployment is for most people only a temporary situation, the transfer of some groups currently on inactive benefits to an unemployment or similar status is more likely to succeed in terms of rapidly increasing their employment rates. 


\section{CHAPTER 5}

\section{ACTIVE LABOUR MARKET PROGRAMMES}

\subsection{Introduction}

251. This chapter is organised as follows: Section 5.2 gives an overview of active labour market programmes (ALMPs) in terms of expenditure and participant levels; Sections 5.3, 5.4 and 5.5 describe the content of the programmes under the headings of direct job creation, employment incentive and start-up incentive schemes, and labour market training; Sections 5.6 and 5.7 discuss programmes for youth and the disabled, with a brief overview of these groups' participation in the mainstream programmes and a more detailed description of some specialised programmes. Section 5.8 considers programme outcomes and impact evaluations and Section 5.9 provides a summary of main points.

\subsection{Overview of active labour market programmes}

\section{Expenditure and participant numbers}

252. In 2006, public expenditure on active labour market programmes (ALMPs) in Ireland not including Category 1 PES and administration was $0.49 \%$ of GDP, slightly above the OECD overall average of $0.43 \%$ but below the average for OECD-EU countries. Expenditure as a percentage of GDP was however only half its level ten years earlier ${ }^{143}$ because ALMP participant numbers were reduced in line with the large decline in unemployment since the mid-1990s.

253. Table 5.1 shows expenditure and participant numbers for different active labour market programmes. ${ }^{144}$ Eurostat Qualitative Reports provide short descriptions of all these programmes, and many of them are discussed further below. ${ }^{145}$ In line with the defined scope of the Eurostat/OECD database, Table 5.1 does not include FÁS' provision of Phase 2 of apprenticeships - which accounts for a large share of the cost of FÁS training centres and FÁS staff costs in employing training instructors.

143. Figures quoted are for spending on Eurostat/OECD database Categories 2 to 7 only (not including Category 1, PES and Administration). Expenditure in 1996 according to the current classification and scope of the database is estimated at $1.00 \%$ of GDP.

144. Annex 5.A and Table 5.A.1 present data on the average annual cost of programmes per participant-year derived from Panels A and B of Table 5.1, along with some technical interpretation.

145. DETE (2005b) covers most of the same programmes as Table 5.1. It discusses a programme called Revenue Job Assist which was not reported to Eurostat, and does not cover the PRSI Exemption Scheme which appears to be more significant in expenditure terms. It includes some background information for the part-time job incentive (measure IE-7 in Table 5.1): it recommended the abolition of this and Revenue Job Assist programme, both of which had few participants in 2004. It provides some net programme cost information (i.e. the cost of participation as compared to the alternative of staying on passive benefits) and comparisons of net incomes for participants with net incomes on passive benefits for various client groups. 
254. Against the background of a limited increase in total ALMP spending, trends since 1998 include: ${ }^{146}$

- Spending in Category 2 Training has increased sharply in euro terms. Among the FÁS-managed programmes, spending on Specific Skills Training declined towards the end of the period, but spending in the area of Community Training/Community Training Centres/Local Training Initiatives increased considerably. Spending on two schemes which provide income support while allowing the unemployed to participate in a variety of non-FÁS training - the Back to Education Allowance and Vocational Training Opportunities Scheme (VTOS) - approximately doubled from 1998 to 2006.

- Spending in Category 4 Employment incentives has fallen due to measures, described below, which restricted access to the Back to Work Allowance (BTWA) and Back to Work Enterprise Allowance (BWEA) particularly after 2002; spending on these two programmes together peaked in 2000 at over EUR 160 million, but by 2005 was below EUR 60 million.

- Spending in Category 5 Supported work and rehabilitation increased sharply. This is due partly to gaps in the earlier data since the Supported Employment Scheme is first reported in 2003 but it existed before then. However, the Wage Subsidy Scheme had by 2006 several times the expenditure level that the Employment Support Scheme, its predecessor, had in 1998. It should be noted that the large Specialist Training Providers programme, also targeted on the disabled, is reported in Category 2.

- Spending in Category 6 Direct job creation has, since 2003, remained below its 1998 level in nominal terms.

- Spending in Category 7 Start-up incentives is no longer separately reported, but the number of participants on the Back to Work Enterprise Allowance recently has been similar to the levels of the late 1990s. ${ }^{147}$

146. The general trends in ALMP spending since 1998 also remain the same in real terms.

147. Based on information underlying Table 5.1, not directly visible in the table. 
Table 5.1. Public expenditure, participant stocks and expenditure per participant in labour market programmes, 1998-2006

\section{A. Expenditure}

Million euros

\begin{tabular}{|c|c|c|c|c|c|c|c|c|c|c|}
\hline \multicolumn{2}{|c|}{ Measure Programme name } & \multirow{2}{*}{$\begin{array}{r}1998 \\
0.1\end{array}$} & \multirow{2}{*}{$\begin{array}{r}1999 \\
0.1\end{array}$} & \multirow{2}{*}{$\begin{array}{r}2000 \\
4.3\end{array}$} & \multirow{2}{*}{$\begin{array}{r}2001 \\
5.8\end{array}$} & \multirow{2}{*}{$\begin{array}{r}2002 \\
6.3\end{array}$} & \multirow{2}{*}{$\begin{array}{r}2003 \\
5.4\end{array}$} & \multirow{2}{*}{$\begin{array}{r}2004 \\
6.6\end{array}$} & \multirow{2}{*}{$\begin{array}{r}2005 \\
5.3\end{array}$} & \multirow{2}{*}{$\begin{array}{r}2006 \\
5.6\end{array}$} \\
\hline 1.1 & 15 Job clubs & & & & & & & & & \\
\hline 1.1 & 22 Counselling/guidance ${ }^{a}$ & 23.3 & 24.3 & 22.5 & 26.2 & 29.0 & 35.9 & 37.8 & 37.3 & 37.4 \\
\hline 1.1 & 36 Local employment services & 15.7 & 13.7 & 9.6 & 19.3 & 19.7 & 17.9 & 19.8 & 18.0 & 17.6 \\
\hline 1.1 & 55 High Supports Process & 0.0 & 0.0 & 0.0 & 0.0 & 0.0 & 0.2 & 0.4 & 0.5 & 0.6 \\
\hline 1.1 & 9 Job facilitation service & 0.0 & 0.0 & 0.0 & 0.0 & 0.0 & 0.0 & 2.4 & 2.4 & 2.4 \\
\hline \multicolumn{2}{|l|}{1.1 Subtotal } & 39.1 & 38.1 & 36.4 & 51.2 & 55.0 & 59.3 & 67.0 & 63.5 & 63.6 \\
\hline & FÁS - administration of LMP measures & & & & & & & & & \\
\hline 1.2 & 101 and staff pay (excl. training) $)^{b, c}$ & 53.5 & 57.7 & 66.0 & 71.3 & 73.2 & 67.9 & 78.3 & 83.7 & 91.1 \\
\hline 1.2 & 59 Basic Education Workplace Scheme & 0.0 & 0.0 & 0.0 & 0.0 & 0.0 & 0.0 & 0.0 & 1.1 & 2.1 \\
\hline 1.2 & 100 DFSA - Benefit administration ${ }^{d}$ & 57.6 & 49.5 & 40.8 & 40.3 & 47.2 & 48.0 & 47.0 & 46.6 & 52.9 \\
\hline 1.2 Subtotal & & 111.0 & 107.2 & 106.9 & 111.5 & 120.5 & 116.0 & 125.3 & 131.4 & $\overline{146.1}$ \\
\hline 1 Total PES anc & ministration $^{c}$ & 150.1 & 145.2 & 143.2 & 162.8 & 175.5 & 175.3 & 192.3 & 194.8 & 209.7 \\
\hline 2 Mixed & 51 Specialist Training Providers & 25.7 & 26.8 & 30.5 & 28.9 & 39.2 & 39.8 & 42.4 & 44.9 & 49.4 \\
\hline 2Mixed Subtotal & & 25.7 & 26.8 & 30.5 & 28.9 & 39.2 & 39.8 & 42.4 & 44.9 & 49.4 \\
\hline 2.1 & 102 FÁS - training staff costs - Cat $2-1^{e}$ & 0.0 & 0.0 & 0.0 & 0.0 & 0.0 & 0.0 & 34.0 & 35.4 & 35.0 \\
\hline 2.1 & $\begin{array}{l}10 \text { Back to education allowance (BTEA) } \\
\text { VTOS (Vocational training opportunities }\end{array}$ & 20.7 & 25.3 & 29.1 & 30.6 & 35.4 & 38.3 & 44.2 & 46.7 & 52.1 \\
\hline 2.1 & 35 scheme) & 34.5 & 34.5 & 39.6 & 44.1 & 48.5 & 51.3 & 60.3 & 57.0 & 61.9 \\
\hline 2.1 & 16 ESF training & 23.2 & 23.2 & 0.0 & 0.0 & 0.0 & 0.0 & 0.0 & 0.0 & 0.0 \\
\hline 2.1 & 20 Industry training & 56.1 & 66.2 & 75.8 & 79.1 & 0.0 & 0.0 & 0.0 & 0.0 & 0.0 \\
\hline 2.1 & 21 Local enterprise & 6.4 & 6.1 & 0.8 & 2.4 & 0.0 & 0.0 & 0.0 & 0.0 & 0.0 \\
\hline 2.1 & 38 Bridging Foundation & 0.0 & 0.0 & 10.0 & 13.6 & 16.6 & 21.1 & 15.1 & 21.9 & 20.6 \\
\hline 2.1 & 39 Specific Skills Training & 0.0 & 0.0 & 0.0 & 0.0 & 65.0 & 59.8 & 35.8 & 38.0 & 37.6 \\
\hline 2.1 & 43 Return to Work & 0.0 & 0.0 & 0.0 & 0.0 & 6.7 & 6.2 & 2.9 & 2.7 & 2.8 \\
\hline 2.1 Subtotal & & 140.9 & 155.2 & 155.4 & 169.7 & 172.2 & 176.7 & 192.3 & 201.6 & 209.9 \\
\hline 2.2 & 42 Linked Work Experience & 0.0 & 0.0 & 0.0 & 0.0 & 1.7 & 1.2 & 1.1 & 0.0 & 0.0 \\
\hline 2.2 & 44 Job Training Scheme & 0.0 & 0.0 & 0.0 & 0.0 & 0.9 & 1.0 & 0.0 & 0.0 & 0.0 \\
\hline 2.2 Subtotal & & 0.0 & 0.0 & 0.0 & 0.0 & 2.6 & 2.2 & 1.1 & 0.0 & $\overline{0.0}$ \\
\hline 2.3 & 103 FÁS - training staff costs - Cat $2.3^{f}$ & 0.0 & 0.0 & 0.0 & 0.0 & 0.0 & 0.0 & 8.3 & 10.3 & $\overline{11.5}$ \\
\hline 2.3 & 24 Re-integration training & 13.3 & 15.6 & 30.7 & 37.7 & 0.0 & 0.0 & 0.0 & 0.0 & 0.0 \\
\hline 2.3 & $\begin{array}{l}25 \text { Community training } \\
\text { (Foundation/Progression in) Community }\end{array}$ & 23.2 & 25.5 & 26.8 & 28.4 & 0.0 & 0.0 & 0.0 & 0.0 & 0.0 \\
\hline 2.3 & $\begin{array}{l}41 \text { Training Centres/Workshops } \\
\text { Community Youth Training Programme/ }\end{array}$ & 0.0 & 0.0 & 0.0 & 0.0 & 33.7 & 35.3 & 34.0 & 38.9 & 42.4 \\
\hline 2.3 & 46 Community Training Programme & 0.0 & 0.0 & 0.0 & 0.0 & 11.6 & 3.5 & 0.0 & 0.0 & 0.0 \\
\hline 2.3 & 45 Local Training Initiative & 0.0 & 0.0 & 0.0 & 0.0 & 16.8 & 20.4 & 18.2 & 26.1 & 26.3 \\
\hline 2.3 & 34 Youthreach $^{g}$ & 18.6 & 18.6 & 18.6 & 29.8 & 35.1 & 37.2 & 43.2 & 45.3 & 51.7 \\
\hline 2.3 & 40 Traineeship & 0.0 & 0.0 & 0.0 & 0.0 & 16.7 & 23.5 & 14.3 & 20.6 & 22.7 \\
\hline 2.3 Subotal & & 55.0 & 59.7 & 76.1 & 95.8 & 113.8 & 119.9 & 118.0 & 141.3 & 154.7 \\
\hline 2 Total Training & & 221.7 & 241.7 & 262.0 & 294.5 & 327.9 & 338.6 & 353.7 & 387.8 & 414.0 \\
\hline 4.1 & 31 Jobstart & 5.6 & 3.0 & 3.5 & 2.2 & 0.0 & 0.0 & 0.0 & 0.0 & 0.0 \\
\hline 4.1 & 32 Workplace & 1.8 & 0.3 & 0.2 & 0.2 & 0.0 & 0.0 & 0.0 & 0.0 & 0.0 \\
\hline 4.1 & 4 Back to work allowance ${ }^{h}$ & 86.0 & 113.5 & 132.5 & 102.7 & 129.1 & 97.4 & 65.7 & 53.6 & 56.5 \\
\hline 4.1 & 47 Social Economy Programme ${ }^{i}$ & 0.0 & 0.0 & 0.0 & 0.0 & 21.1 & 39.4 & 39.4 & 30.3 & 0.0 \\
\hline 4.1 & 5 PRSI Exemption scheme ${ }^{j}$ & 0.0 & 0.0 & 0.0 & 0.0 & 0.0 & 0.0 & 0.0 & 0.0 & 0.0 \\
\hline 4.1 & 7 Part-time job incentive scheme & 1.9 & 1.7 & 1.6 & 1.3 & 1.1 & 1.1 & 1.2 & 1.3 & 1.3 \\
\hline 4 Total Employm & incentives $^{k}$ & 95.3 & 118.5 & 137.8 & 106.4 & 151.3 & 137.8 & 106.4 & 85.2 & 57.8 \\
\hline 5.1 & 17 Workplace/equipment grants & 0.2 & 0.2 & 0.0 & 0.0 & 0.0 & 0.0 & 0.0 & 0.0 & 0.0 \\
\hline 5.1 & 18 Employment support scheme & 1.6 & 1.8 & 1.4 & 2.5 & 2.6 & 2.9 & 3.1 & 2.7 & 0.0 \\
\hline 5.1 & 52 Supported Employment Scheme/Programme & 0.0 & 0.0 & 0.0 & 0.0 & 0.0 & 6.1 & 6.5 & 6.6 & 7.7 \\
\hline 5.1 & 54 Pilot Employment Programme & 0.0 & 0.0 & 0.0 & 0.0 & 0.0 & 2.0 & 0.0 & 0.0 & 0.0 \\
\hline 5.1 & 60 Wage subsidy scheme & 0.0 & 0.0 & 0.0 & 0.0 & 0.0 & 0.0 & 0.0 & 4.9 & 7.2 \\
\hline 5 Total Supporte & mployment and rehabilititation & 1.8 & 2.1 & 1.4 & 2.5 & 2.6 & 11.0 & 9.6 & 14.2 & 14.9 \\
\hline 6 & 23 Community employment scheme & 392.5 & 407.8 & 380.0 & 368.7 & 337.3 & 287.1 & 263.9 & 295.8 & $\overline{325.4}$ \\
\hline 6 & 37 Job Initiative & 0.0 & 0.0 & 36.3 & 45.1 & 46.3 & 43.6 & 39.1 & 37.5 & 37.9 \\
\hline 6 Total Direct jok & eation & 392.5 & 407.8 & 416.3 & 413.8 & 383.6 & 330.7 & 303.0 & 333.4 & $\overline{363.4}$ \\
\hline 7 & 3 Back to work enterprise allowance (BWEA) ${ }^{\prime}$ & 44.5 & 41.9 & 35.4 & 54.9 & 0.0 & 0.0 & 0.0 & 0.0 & 0.0 \\
\hline 7 Total Start-up & ntives $^{m}$ & 44.5 & 41.9 & 35.4 & 54.9 & 0.0 & 0.0 & 0.0 & 0.0 & $\overline{0.0}$ \\
\hline 8.1 & 1 Unemployment benefit $^{n}$ & 300.5 & 293.8 & 265.2 & 290.3 & 423.5 & 477.1 & 465.5 & 418.1 & $\overline{455.1}$ \\
\hline 8.1 & 2 Unemployment assistance ${ }^{n}$ & 770.0 & 615.6 & 469.1 & 429.9 & 512.0 & 566.0 & 613.8 & 667.5 & 768.7 \\
\hline 8.4 & 49 Redundancy Payments & 17.7 & 23.5 & 21.7 & 28.1 & 54.3 & 89.5 & 152.2 & 149.5 & 166.5 \\
\hline 8.5 & 50 Insolvency Payments & 2.1 & 2.6 & 2.0 & 5.5 & 6.1 & 10.1 & 5.5 & 4.6 & 4.3 \\
\hline 8 Total Out-of- $\mathrm{n}$ & income support and maintenance & 1090.3 & 935.5 & 758.0 & 753.7 & 995.9 & 1142.6 & 1237.1 & 1239.6 & 1394.6 \\
\hline 9.2 & 12 Pre-retirement allowance & 76.4 & 76.5 & 79.3 & 82.8 & 87.0 & 89.1 & 94.7 & 102.9 & 113.0 \\
\hline 9 Total Pre-retir & ent benefits & 76.4 & 76.5 & 79.3 & 82.8 & 87.0 & 89.1 & 94.7 & 102.9 & $\overline{113.0}$ \\
\hline Total 1-7 Active & grammes total $^{\mathrm{C}}$ & 905.9 & 957.2 & 996.1 & 1034.8 & 1040.9 & 993.4 & 965.0 & 1015.4 & 1059.7 \\
\hline Total 2-7 Active & grammes except PES & 755.8 & 812.0 & 852.9 & 872.0 & 865.4 & 818.1 & 772.7 & 820.5 & 850.0 \\
\hline Total 8 and $9 \mathrm{~Pa}$ & e programmes ${ }^{c}$ & 1166.8 & 1012.0 & 837.2 & 836.5 & 1082.9 & 1231.6 & 1331.8 & 1342.5 & 1507.6 \\
\hline
\end{tabular}

.. Not available.

- Measure not started or ended (includes situations where the similar spending starts to be reported under a different programme name).

See notes at the end of the table. 
DELSA/ELSA/WD/SEM(2009)01

Table 5.1. Public expenditure, participant stocks and expenditure per participant in labour market programmes, 1998-2006 (cont.)

\section{B. Participant stocks}

Number of participants

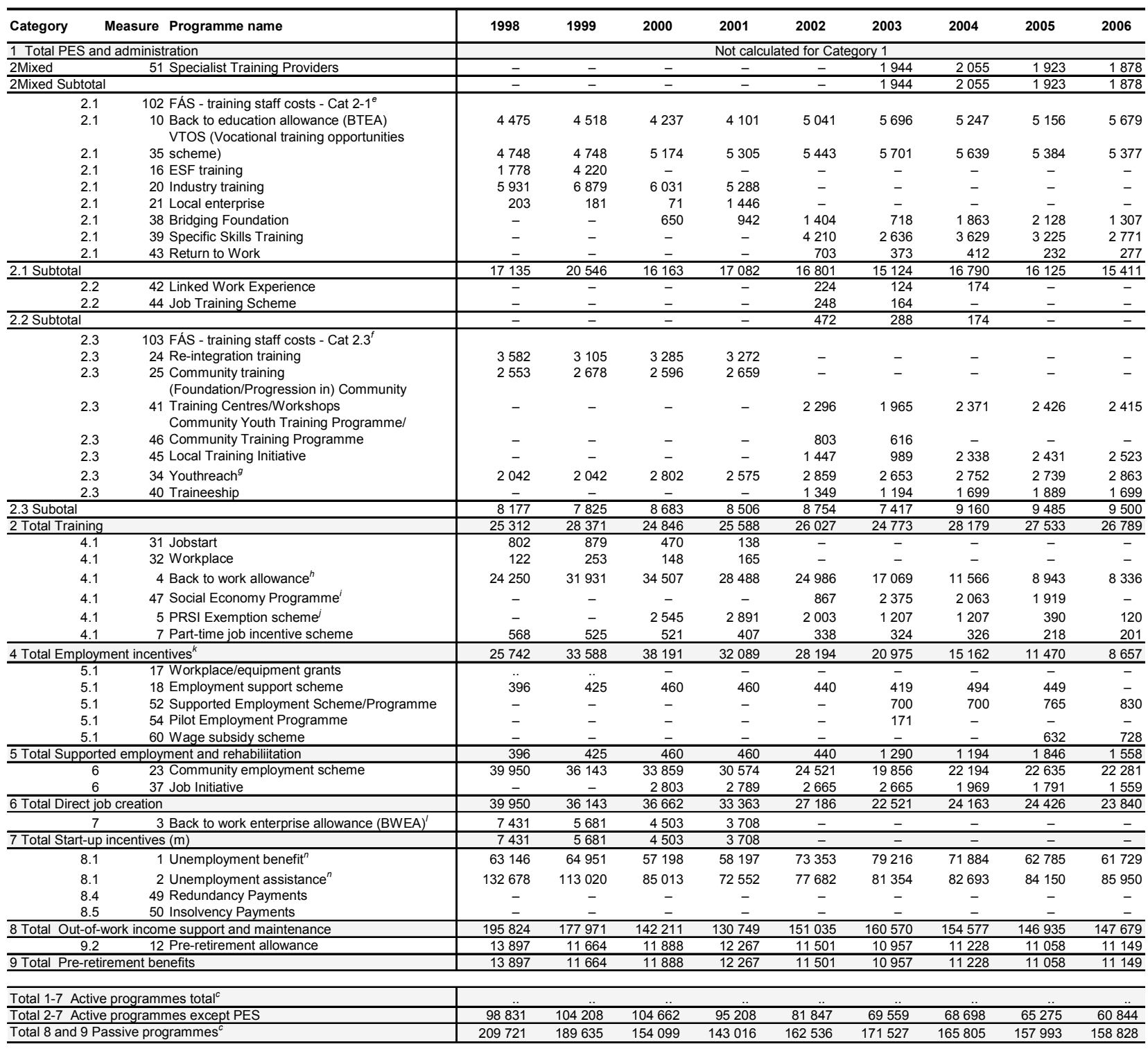

Not available.

- Measure not started or ended (includes situations where the similar spending starts to be reported under a different programme name).

a) IE-22 Counselling/guidance refers to a subset of the activities of FÁS Employment Services

b) IE-101 FÁS - administration of LMP measures and staff pay (excluding training) is calculated as total FÁS expenditure on administration, less spending on counselling/guideance (IE-22), Training staff and Services to Business staff costs. See Chapter 2 for details (including revised estimates).

c) This table includes the estimates for IE-100 DSFA - Benefit administration and IE-101 FÁS - administration of LMP measures and staff pay (excluding training) published in recent issues of the OECD Employment Outlook. Revised estimates for these variables as presented in Chapter 2 will be incorporated in future OECD publications.

d) IE-100 DFSA-Benefit administration is an estimate of DSFA expenditure on the administration of unemployment benefits (except for the cost of Facilitators, listed separately). See Chapter 2 for details (including revised estimates).

e) IE-102 FÁS -training staff costs - Cat 2.1 is an estimate of the Sub-category 2.1 share of total FÁS training staff costs. Prior to 2004 this expenditure was included directly in the spending reported for individual training measures. See also Table 2.3. 
f) IE-103 FÁS - training staff costs - Cat 2.3 is an estimate of the Sub-category 2.3 share of total FÁS training staff costs. Prior to 2004 this expenditure was included directly in the spending reported for individual training measures. See also Table 2.3 .

g) IE-34 Youthreach in these data appears to refer only to participants at VEC centres: with Youthreach participants at Community Training Centres being reported under the measure IE-41 (Foundation/Progression in) Community Training Centres/Workshops.

h) IE-4 Back to work allowance (BTWA): data include IE-3 Back to work enterprise allowance (BWEA) from 2002 onwards.

i) IE-47 Social Economy Programme: at the end of 2005 this programme was renamed the Community Service Programme and transferred to the Department of Community, Rural and Gaeltacht Affairs (DCRGA), and criteria for hiring were relaxed. The expenditure still exists in 2006 but is now interpreted as spending on Community Services rather than an active labour market programme

j) IE-5 PRSI Exemption scheme: although no recent estimates are available, expenditure on this programme in 1998 was estimated at EUR 18 million and spending probably continued at about a quarter of spending on measure 4 Back to Work Allowance. Participant data appear to include only non-BTWA cases, a small proportion of the total (see also the text).

k) 4 Total Employment Incentives: see previous note.

l) IE-3 Back to work enterprise allowance (BWEA): see note above on measures IE-4 Back to work allowance.

m) 7 Total Start-up incentives: see previous note.

n) IE-1 and IE-2 (Unemployment payments) participant data (in Tables $5.1 \mathrm{~B}$ and 5.A.1) are on a Live Register basis, i.e. including registered claimants whose actual payment in the reference period was zero (about $20 \%$ of the total for IE-1 and $10 \%$ for IE-2). For data that include only people receiving a non-zero payment amount see Table 4.1. in Chapter 4.

Source: Eurostat/OECD database on labour market programmes 1998-2006 (data as published in Eurostat, 2007 and other publications in this annual series, with some historical revisions), with some further additions and revisions as described in Grubb and Puymoyen (2008).

255. Panel B of Table 5.1 shows participant numbers for the programmes discussed above. Although expenditure on training doubled since 1998, this reflects cost increases. Participant numbers in the category Training as a whole only increased slightly from 1998 to 2006. Increases for the BTEA, FÁS Bridging/Foundation courses and Youthreach programmes - although only Bridging/Foundation grew much more rapidly than Ireland's labour force - were offset by declines in other areas. Participant stocks in BTWA/BWEA together fell by nearly three-quarters between 2000 and 2006. Participants stocks in Community Employment approximately halved, from 40000 in 1998 to 20000 in 2003, after which they recovered slightly.

256. The participant numbers illustrate that, despite the substantial reduction in unemployment and particularly long-term unemployment through to 2006, Ireland retained an extensive range of ALMPs for the unemployed. Table 5.2 compares the total stock of participants in ALMPs with numbers of ILO unemployed and numbers of claimants on the Live Register. From 2000 to 2002, the number of programme participants reached a level which was about $2 / 3$ of the number of people on the Live Register but about $4 / 3$ of the number of people ILO unemployed (the Live Register and ILO unemployment totals differ sharply, as discussed in Chapter 4). After 2002, the number of ILO unemployed increased significantly, while the decline in ALMP participant numbers continued. By 2006, ALMP participant numbers were down to about $40 \%$ of the number on the Live Register, and $75 \%$ of the number of ILO unemployed, but were still over twice the number of long-term unemployed on the ILO basis. 
DELSA/ELSA/WD/SEM(2009)01

Table 5.2. Participation in active programmes and in open unemployment compared, 1998-2005

Levels and percentages

\begin{tabular}{|c|c|c|c|c|c|c|c|c|c|}
\hline & 1998 & 1999 & 2000 & 2001 & 2002 & 2003 & 2004 & 2005 & 2006 \\
\hline \multicolumn{10}{|l|}{$\begin{array}{l}\text { Total participants in an active labour } \\
\text { market programmes (ALMPs) }\end{array}$} \\
\hline (Categories 2 to 7, stock) & 98831 & 104208 & 104662 & 95208 & 81847 & 69559 & 68698 & 65275 & 60844 \\
\hline ILO Long-term unemployed & 70900 & 53500 & 33100 & 21600 & 22600 & 29300 & 28900 & 29700 & 31800 \\
\hline ILO Total unemployed & 126300 & 96700 & 74800 & 65300 & 76900 & 82400 & 84300 & 86600 & 92600 \\
\hline Live Register (annual average) & 227096 & 193237 & 155398 & 142253 & 162465 & 172414 & 166013 & 157117 & 157397 \\
\hline $\begin{array}{l}\text { ALMP participants, } \\
\text { percentage of Long-term unemployed }\end{array}$ & 139.4 & 194.8 & 316.2 & 440.8 & 362.2 & 237.4 & 237.7 & 219.8 & 219.8 \\
\hline $\begin{array}{l}\text { ALMP participants, } \\
\text { percentage of Total unemployed }\end{array}$ & 78.3 & 107.8 & 139.9 & 145.8 & 106.4 & 84.4 & 81.5 & 75.4 & 75.4 \\
\hline $\begin{array}{l}\text { ALMP participants, } \\
\text { percentage of Live Register }\end{array}$ & 43.5 & 53.9 & 67.4 & 66.9 & 50.4 & 40.3 & 41.4 & 41.5 & 41.5 \\
\hline
\end{tabular}

Source: For total participants in an ALMP, see Table 5.1B. For ILO unemployed and ILO Long-term unemployed: OECD employment statistics database (www.oecd.org/els/employment/data). The number of long-term unemployed is estimated multiplying ILO Unemployed by the incidence of long-term unemployment (incidence in 1998 and 2000 estimated by interpolation between 1997, 1999 and 2001 data). For Live Register: CSO Database direct (www.cso.ie/px/pxeirestat/database/eirestat/eirestat.asp).

\subsection{Direct job creation schemes}

257. This section describes three programmes: Community Employment, Job Initiative and the Social Economy Programme. From 2006 the latter has been moved outside the scope of the Eurostat/OECD data (Table 5.1). Sheltered employment for the disabled (not included in Table 5.1) is described briefly in Section 5.6 rather than here.

\section{Community Employment}

258. Community Employment (CE) offers participants temporary employment doing useful work within their communities on projects sponsored by local organisations and funded by FÁS. Projects are typically in the areas of social services, healthcare, heritage, arts, culture, tourism, sport, environment and education. Many projects are now long-standing activities working from a fixed location. Most staff in 25 ICTU (Irish Congress of Trade Unions) Resource Centres for the Unemployed (also called Congress Centres) are CE workers. Some CE projects provide crèche facilities, which facilitate participation by lone parents, and employ CE workers as crèche minders. This is an example of how CE may lead to regular employment - since regular public and private funding for children in Ireland should be growing, in line with female participation rates and the current drive to activate lone parents - but might compete with private provision of the same services.

259. FÁS funds projects to employ "high calibre" supervisors. ${ }^{148}$ Participants work part-time, ${ }^{149}$ and receive a $\mathrm{CE}$ wage: for the unemployed, this replaces unemployment benefit/allowance, but lone-parent and disabled participants are able to retain a large proportion of their benefits together with the $\mathrm{CE}$ wage. Participation in CE is in principle for one year: in 1997, renewed participation was allowed after

148. According to Boyle, N. (2005), in 1994 "high calibre supervisors were regarded as key to the success of the programme and salary and conditions for supervisors were accordingly attractive: supervisors were not seen as a cheap way to deliver the scheme. However, supervisors were to be employees of sponsoring organisations, not FÁS employees."

149. CE schemes provide work for an average of 19.5 hours per week (or 39 hours per fortnight) (OECD, 1998b, p. 166; www.inou.ie/welfarerights/active_labour_market_programmes.html). 
six months although waivers were sometimes given allowing renewal without an intervening break (OECD, 1998b, p. 166); there are now different rules for different target groups (see below).

260. CE was introduced in 1994 in response to the high levels of unemployment in the early and mid-1990s and has had a high profile in Irish politics. It grew rapidly and employed approximately 40000 participants (equivalent to over $3 \%$ of the labour force), absorbing $45 \%$ of direct programme spending, in 1996 (OECD, 1998b, p. 165). Boyle, N. (2004) regards FÁS management of CE as a great success: "CE involved a particularly striking mobilization of the community sector as project sponsors. FÁS here played a proactive role in searching out, cultivating and training activists; often people who were very alienated from 'the system'... churches and unions were absent in the most dysfunctional urban communities; professionals such as doctors and teachers did not live locally".

261. As unemployment fell in the late 1990s and early 2000s, two independent reviews of the programme (Deloitte and Touche, 1998; and Indecon, 2005a, which was first published in 2002) queried the appropriateness of maintaining the then-current levels of participation. These and other commentators criticised CE for its limited impact on participants' employment prospects in terms of entry to regular employment, repeat participation, lack of targeting, ${ }^{150}$ and limited training content despite the inclusion in principle of a training component from the start (see also OECD, 1998b; and O'Connell, 2002). In response to these criticisms and despite opposition from some of those involved in the programme, the number of CE places was progressively reduced.

262. The downsizing of CE has not been uniform: some activities and clients groups have been eliminated or sharply reduced, while others have been maintained, or nearly so. The key policies in this respect have been:

- Health sector places, child care and Drugs Task Force clients have been "ring-fenced" (i.e. protected) from reductions in CE participant numbers after 2002. Approximately 6000 places ( $27 \%$ of current total) are in these three ring-fenced sectors; ${ }^{151}$

- In 2000, the eligibility criteria for entry to and continuation in CE were tightened. The minimum age for participation in $\mathrm{CE}$ was raised from 21 years to 25 years. ${ }^{152}$ An individual's total CE participation after April 2000 was capped at three years (Dáil Éireann, 2000): because participation prior to this date was not taken into account, the direct impact of this restriction on participant numbers would only start in 2003. This measure aimed to discourage repeat participation and encourage unemployed persons to take advantage of either training or education options. In 2001 the three-year cap was partially relaxed to allow a fourth year for particularly

150. Surveys at times reported that some, possibly a large minority, of participants were not long-term unemployed (OECD, 1998b, p. 167).

151. See Dáil Éireann (2006b). In February 2003 about 2000 CE workers were working as full-time personal assistants, bus drivers, and other positions in the health service sector (www.finegael.ie/news/index.cfm/type/details/nkey/22207). In November 2004, 1815 CE places for workers directly involved in the delivery of child care services were ring-fenced (not counting other CE workers providing services such as playgroup assistants, administrators, and general maintenance: Dáil Éireann, 2004a). Most of the current 14 local Drugs Task Forces were established in 1997 (www.kccp.net/spon.htm); the ring-fencing refers to the reservation of $1100 \mathrm{CE}$ places for drugs misusers referred by these Drugs Task Forces (although as of January 2004 the actual uptake was 812: http://eddra.emcdda.europa.eu/pls/eddra/showQuest?Prog_ID=5916).

152. Exceptions to the age requirement were allowed for travellers, ex-offenders, refugees, people with disabilities, people referred by a Drugs Task Force, offshore island inhabitants, and 18 to 24 year olds referred through NEAP and unemployed for 18 months or more (Dáil Éireann, 2000). 
disadvantaged persons, limited to $20 \%$ of cases. In 2004 , it was raised to six years for those aged over 55, in recognition that older workers are particularly disadvantaged and may find it more difficult to progress into other schemes (Dáil Éireann, 2007); and

- Participation for those under 35 is limited to the "Integration" option, where participation is for a year, after which entry to full-time employment or education/training is expected (www.inou.ie/welfarerights/active_labour_market_programmes.html). Although this basic rule existed already in the 1990s, the limitation to one year may be more rigorously enforced in recent years.

263. These changes, combined with falling numbers of long-term unemployed, led to a sharp reduction in numbers of young and unemployed participants. From 1998 to 2003, total participant numbers fell from 40000 to 20000 ; within the total, the proportion aged under 30 fell from $21 \%$ to $13 \%$ and (in December figures) the proportion unemployed fell from $62 \%$ to $44 \%$ ( $40 \%$ in 2007). The proportion of lone parents has hardly changed, rising from $25 \%$ to $26 \%$ in 2003 but falling back to $23 \%$ by $2007 .{ }^{153}$ But the proportion of people with disabilities rose from $7 \%$ to $17 \%$ (23\% in 2007) and the proportion on other benefits (Carer's Allowance, Deserted Wife's Benefit and spouse/dependant cases) rose from 0 to $4 \%$.

264. These trends imply that the actual number of disabled participants has increased since the late 1990s, while the number of lone-parent participants has declined. This contrast possibly reflects specific aspects of the eligibility criteria - lone-parents being often affected by the specific treatment of under-25/under-35s whereas participation limits are extended by a year for the disabled (Dáil Eireann, 2007) - and a greater ability of lone parents to find regular employment in the tight labour market of the 2000s.

265. The ring-fencing of CE places, combined with the shift towards older and disabled unemployed participants, has changed the scheme partly in the direction of financing necessary social services ${ }^{154}$ and partly in the direction of providing long-term subsidised employment for individuals with reduced work or earnings capacity. However, Community Employment was designed from the outset - in contrast to the earlier Social Employment Scheme, which did not include training provision - as a training and employment programme. ${ }^{155}$

266. A recent measure to reinforce the education/training content, for at least a good proportion of participants, has been the introduction of the Individual Learner Plan (ILP) which tracks and records an individual's progress throughout their time on CE. The ILP was initially piloted in early 2006 and had a national roll-out to 22000 learners in September 2006. Prior to this, even though individual needs were being identified and training interventions were provided, they tended to be on a group basis. The ILP process identifies specific training needs of the learner and provides access to training opportunities which allow participants to obtain nationally-recognised Awards (FETAC Level 3-6 or higher) (FÁS, 2008). FÁS has developed three FETAC Major Awards, two at level 3 and one at level 4, designed to meet the training

153. Based on end-year figures from DETE (2005b) and a tabulation of December 2007 data supplied by DETE. The proportion in another category, CE Supervisors, stayed close to $6 \%$ throughout.

154. DETE (2005b) remarks "The ring-fencing of places determined the location of schemes in relation to services as opposed to the level of unemployment or disadvantage in some cases". But it also argues more generally that "A lot of the services provided under CE are now considered essential within the community and would require funding in their own right in the absence of this programme."

155. "the February 1994 Programme for Competitiveness and Work ... made clear that the new scheme was to be primarily a labour market scheme and only secondarily a community development/social employment scheme". In practice there was a "wild west" phase during the rapid start-up of the programme included and "it wasn't until 1996 that FÁS began to rigorously enforce training goals" (Boyle, N., 2005). 
and progression needs of learners who lack basic educational qualifications, participating on Community Services programmes. ${ }^{156}$ Each award is made up of nine modules and while some of these modules are core, the majority are optional which participants can achieve at their own pace and accumulate over time. In addition, CE participation itself (the work experience) now counts as one module at level 3. The new awards also provide a stepping-stone to higher levels on the National Qualifications Framework. ${ }^{157}$

267. In addition to the above, the Return to Education initiative is also an integral part of CE delivery, meeting the training needs of CE participants with literacy weaknesses. The programme was initiated in 1998 by the National Adult Literacy Agency (NALA) and involves FÁS and Vocational Education Committees (VECs). ${ }^{158}$ It meets certain basic learning needs, such as, reading, writing and numeracy skills, so that participants can further enhance their opportunities in finding employment or move on to further education and training. Under this scheme, CE participants can be released for nine hours per week, usually for 30 weeks, to attend intensive literacy tuition while still in receipt of their CE entitlements. Certification is also available upon completion of the programme.

268. Data on outcomes for participants leaving programmes show that the proportion of participants obtaining employment on exiting CE is low (see Table 5.3 and Section 5.8 below). Only $30 \%$ of participants who left CE in 2005 were in ordinary employment 15 to 19 months later. Almost as many, $29 \%$, had returned to CE or another job scheme and only $6 \%$ were in any form of education or training, which is lower than the percentages for any of the FÁS training programmes. This suggests that CE still functions for many participants as an alternative to regular employment. Apart from the nature of CE projects as providers of services to the local community, factors that limit its outcome rate include:

- Only a minority of participants are on the part-time integration option which, in principle, is limited to a year and leads into education or training; ${ }^{159}$

- For lone parents, $\mathrm{CE}$ often provides part-time work directly in child-care projects in local areas, but few comparable private-sector job openings may be available;

- For lone parents and the disabled, income from CE participation is either mainly or completely additional to income from lone-parent or disability benefits and the resulting net income may leave little incentive to enter low-wage full-time work. ${ }^{160}$ This results in a relatively high level of

156. In order to access FETAC awards, all FÁS programmes including CE have met quality assurance procedures. FÁS Community Services division is implementing a major quality assurance training programme for sponsors and supervisors of all its programmes. This training will take place over a two-year period and will be subject to external evaluation and validation by FETAC.

157. See the section on labour market training for more information on the qualifications framework in Ireland.

158. VECs are statutory committees of county councils and other local authorities (33 in total). They operate in accordance with the provisions of the Vocational Education Act 1930 and Amendments, which give them authority to identify and provide a wide range of education, training and support services within local communities.

159. In 2004 about $60 \%$ of CE participants were aged 40 or more (DETE, 2005b).

160. Table 5.6 in DETE (2005b) provides illustrative calculations for 2005: for two illustrative cases on UA/UB, CE participation increased net income by only EUR 24.40 per week; for three illustrative cases on OPFP (lone-parent benefit), Disability Allowance and Disability Benefit, the increase ranged from EUR 120 per week to EUR 181.80 per week. For the lone parent with two children, net income on CE was EUR 369.20 per week, whereas the gross minimum wage for a 39-hour week in 2005 was EUR 273 (based on monthly minimum wage data and the documentation at http://epp.eurostat.ec.europa.eu - population and social conditions - labour market - earnings). 
net income for lone parents and the disabled; a transition to a regular full-time job would increase their net income further but not so much proportionally as for other groups. For the long-term unemployed, CE provides only a small increase in net income, although it does allow retention of the medical card which is lost three years after entry to regular employment; ${ }^{161}$

- CE participants are on average more disadvantaged than participants in most other programmes, with lower educational attainment and a higher proportion being long-term unemployed before the programme (see Table 5.3 below); and

- In general, since entry to CE participation is voluntary, it is not surprising that many participants want to continue.

269. Overall in the 1990s, CE was successful in terms of defusing social and political tensions related to high unemployment thus allowing other policies to focus on broader economic development and growth objectives. It provided an alternative to continuing passive unemployment in many localities with high unemployment and few job opportunities, mobilising activists, and providing local services that would otherwise be lacking. But this background may also create a lobby for continued funding of CE projects unrelated to their effectiveness as labour market programmes and local demand for CE services may not be enough to justify their cost, or CE may not be the most efficient way of satisfying it. However in the 2000s $\mathrm{CE}$ has developed multiple strands so that for some participants it is similar to regular public sector employment (ring-fenced jobs in the health sector), sheltered employment (given the growing share of disabled participants), or an active form of early retirement benefit (in the case of long-term participation by older workers), while for participants aged under 36 the "integration" function has been strengthened. It is difficult to tell, without further research, which of these strands are relatively less or more necessary and effective.

270. According to macroeconomic reasoning, it makes sense for direct job creation measures to be managed in a counter-cyclical way, taking up some of the labour slack that emerges during periods of rising unemployment but conversely returning workers to the regular labour market in order to give them relevant experience and satisfy labour demand in periods of upswing. Particularly in strong demand conditions, the duration of individual participation must be kept short to ensure that participants enter regular unsubsidised work as rapidly as possible. It is not clear that it was reasonable to still have $1 \%$ of the labour force on CE, which remains in general terms a job-creation programme, in the mid-2000s after a long period of low unemployment. If places on CE had been cut back, there would have been more scope to use $\mathrm{CE}$ as a tool in response to rising unemployment in the current economic downturn. Job-creation measures can absorb part of a short-term cyclical increases in unemployment, but this involves a longerterm risk that the subsidies prevent the reallocation of labour according to market forces. Attention should be paid to programme development and quality, with a focus for most participant groups on achieving a transition to unsubsidised work.

271. Although CE has a variety of functions, provision in Ireland still lacks some features found in job-creation programmes in other countries. CE participation is not compulsory. Australia's Work for the Dole involves contracting service providers to manage projects (although half the providers are in fact subsidiaries of non-profit organisations) to create six-month places to which compulsory referrals can be made. Such a programme, without being very large in terms of participant numbers, implements a broader Mutual Obligations strategy. ${ }^{162}$ The United Kingdom and most of the European countries where benefit

161. See http://hse.ie/eng/Find_a_Service/entitlements/Medical_Cards/Your_Guide_to_Medical_Cards.html.

162. Under the Mutual Obligations strategy, long-term unemployed people must achieve a minimum level of activity (in part-time paid work, voluntary work, Green Corps, part-time study, or another official programme): those who do not (a fairly small proportion) are referred to Work for the Dole. 
replacement rates are relatively high also make some compulsory referrals to job-creation programmes (e.g. the Environmental Task Force in the United Kingdom). In Ireland, such an arrangement might be appropriate for NEAP participants who take up no other option, perhaps in the case of adults only for people entering NEAP for the second time. To allow this, some additions to or reforms of current CE projects and their management arrangements would probably be needed.

272. CE places are mainly in the non-market sector. Denmark's Flex-Jobs and Finland's Social Enterprises are examples of schemes paying long-term subsidies to private employers. Finland's Social Enterprises operate on a commercial basis but the wages of employees from the target groups are subsidised (50\% up to a ceiling of EUR 1300 subsidy per month since 2006) for up to three years, sometimes six, for disabled people and up to two years for the long-term unemployed (www.ouka.fi/ouluseutu/yrityspalvelut/howtosetup/company_forms.htm). In return for meeting certain standards, the subsidies are somewhat more generous than for ordinary private-sector employers. As compared with $\mathrm{CE}$, the social enterprise model creates employment in all types of sector and occupation, suited to a wider range of client preferences and needs; operation in a competitive environment opens up the range of potential employers and ensures that partly-disabled employees are used where they are most productive. However, Ireland might find it difficult to operate this type of model successfully at the moment: weak gate-keeping arrangements for disability benefits might result in poor targeting of the subsidy, and in recent history Social Economy enterprises which did not become self-financing as intended were nevertheless kept going. In any case, Finland's experience is that the growth of a Social Enterprise sector subject to market discipline takes some time.

\section{The Job Initiative and Social Economy Programmes}

273. The Job Initiative (JI) programme, launched in $1996,{ }^{163}$ was designed to provide full-time work (39 hours per week) for three years for individuals aged over 35 who have not had a job in the last five years. It operates in designated areas where the Local Employment Service (LES) is well-established. Local Sponsoring Committees were set up to administer the scheme. According to O'Shaughnessy (2005), "Community and voluntary organisations, many of these involved in the management of these initiatives, have availed of this measure to staff their services", while Teague (2006) cites examples of the maintenance and repair of local infrastructure. Although participation was originally intended to be for three years, DETE (2005b) reports that by early $200542 \%$ of the participants had been on the progamme for more than three years, some of them for more than eight years.

274. Although CE and JI are broadly similar, payment on JI is not determined by Social Welfare status and the participant does not receive any allowance for dependants, but may qualify for the Family Income Supplement (a measure available to persons in regular employment). Progression rates to regular employment were high as compared with most other programmes (66\% in 2000 , falling to $49 \%$ in 2003 ) including CE. At first sight this is a good result, since the educational level of participants is lower than for any other labour market intervention (DETE, 2005b). Unfortunately, the reported progression rate is the proportion of exits that enter regular employment. A more valid measure of the effectiveness of a programme is the hazard rate (the monthly or annual transition rate) to regular employment, which is the proportion of exits that enter regular employment multiplied by the rate of exit. A programme with a low outflow rate can well have a high "progression rate" even when its impact is negative, i.e. the hazard rate

163. JI started in 1996 as a pilot programme and was extended to all 38 partnership areas in 1998 (Dail Eireann, 1999): some other sources cite 1998 or 2000 as the starting date. 
to regular employment for its participants is lower than that of comparable non-participants who do not participate in any programme. ${ }^{164}$

275. The Social Economy (SE) programme, launched in 2001, was similarly targeted on individuals aged over 35 on unemployment or lone-parent benefits for over three years. By May 2003, 335 enterprises funded by the social economy programme, most of them less than 18 months old, were employing 2257 people (Teague, 2007). Programme sponsors were social economy enterprises including a) Community Businesses, which would be expected to become self-financing in the medium term b) "Demand-deficient" enterprises where "the demand for particular goods and services within a community is not matched by the community's ability to pay due to disadvantage or low density of population" and c) enterprises in disadvantaged communities supported by public sector contracts. Teague (2007) lists 13 funded initiatives, which are quite varied although in Dundalk three of the six were child-care businesses (crèches). Although grant support to the enterprises was for up to three years, no specific cap was placed on the duration of individual participation (Eurostat Qualitative Report 2005).

276. Following a review of FÁS employment schemes in 2004, important changes to both programmes were announced. ${ }^{165}$ First, with effect from November 2004 JI no longer recruits new participants. Second, the Social Economy Programme was transferred from FÁS to the Department of Community, Rural and Gaeltacht Affairs. One of the main reasons for this transfer was that despite making a positive contribution to the regeneration of local communities and providing employment opportunities for disadvantaged groups in the labour market, the scheme failed to help the established enterprises to become self-sustained. In addition, the majority of the employees in enterprises funded by the SE programme had previously participated in either CE or JI, reflecting the fact that time spent on CE or JI was taken into account in determining eligibility for SE. This heightened concerns about the likelihood of participants progressing to unsupported employment (Ronayne and Burrows, 2003).

277. The 2004 policy announcement included a commitment that there would be no compulsory layoffs from JI (DETE, 2005b). ${ }^{166}$ The age profile of JI showed a decline in the share of participants aged less than 40 from $23 \%$ in 1998 to $13 \%$ in 2004; this skewing of the age profile is likely to have continued following the decision in 2004 not to replace JI participants who leave (except, in some cases, with CE participants).

278. In the case of SE, the government announced as early as 2003 that no further money would be available for new initiatives but that financial commitments to existing projects would be met (Teague, 2006). From December 2005, the programme was renamed the Community Service Programme and transferred to the Department of Community, Rural and Gaeltacht Affairs (DCRGA), with Pobal responsible for management. The extension to the end of the year of contracts ending during 2006 was

164. Australia in the 1990 s calculated the "net impact" of programmes by comparing the employment rate across all individuals who had left the programme three months previously with the employment rate for a comparable sample of people who were in open unemployment three months previously: OECD (2001b, p. 220) gave a similar argument about the misleading nature of that measure.

165. "Originally, the national development plan, which was the designated budgetary source, had earmarked EUR 270.5 million for the programme, which it envisaged running for the period 2000-06... Yet by 2003, after being in operation for just two years and having spent EUR 55 million, the government announced that beyond meeting the financial commitments already made to projects no further money would be available to fund new initiatives." (Teague, 2007).

166. In line with the absence of a limit on duration, only $7 \%$ of JI leavers in 2005 were unemployed 15 to 19 months later. In contrast, $20 \%$ of CE leavers had become unemployed. Half of all JI leavers entered CE (Table 5.3). This may often concern older workers going part-time, with little loss of job security given that they can participate in CE for up to six years. 
"prioritised", and the requirement that participants be aged over 35 and 3 years unemployed was dropped, although new guidelines seek recruitment of at least $70 \%$ of participants from the Live Register or from CE/JI (www.pobail.ie/en/CommunityLocalDevelopmentProgrammes/CommunityServicesProgramme).

279. Ireland's experience with JI and SE parallels that of several other countries where the authorities at one point in history created a labour market programme paying a full-time wage on a non-commercial basis but soon afterwards - due to the programme's cost and low rates of transition to unsubsidised employment - closed it to new entrants, while at the same time it was felt politically or morally necessary to give existing participants a guarantee or near-guarantee of lifetime employment. In later years, the programme in question is expensive in terms of spending per participant-year (since it pays a full-time wage, sometimes with seniority increments), yet no longer contributes to handling the ongoing inflow of workers needing assistance. Such a legacy tends to dissuade the authorities from creating a similar programme for as much as several decades afterwards, so that measures of this kind remain relatively exceptional, and only help a fraction of potential participants. ${ }^{167}$

\subsection{Employment and Start-up Incentive Schemes}

280. The PSRI Exemption scheme introduced in 1992 exempts employers from payment of social insurance contributions. The Back to Work Allowance (BTWA) and Back to Work Enterprise Allowance (BWEA) schemes, introduced in 1993 and 1992 respectively, are payments to formerly-unemployed people who have entered work. These schemes are implemented by DSFA, and advocacy and advice about them was an important role for about 50 DSFA Facilitators prior to sharp cut-backs in BTWA in the early 2000s. The Wage Subsidy Scheme (which replaced the former Employment Support Scheme in 2005) is a disability employment measure, described in Section 5.6 below rather than here.

\section{PRSI exemption scheme}

281. Under this scheme, employers are exempted from making employer pay-related social insurance (PRSI) contributions during the first two years of employment. The work must be for at least 20 hours per week. As it operated from 1992 to 2003, PRSI exemption could be granted for hirings of lone parents, disabled, youths under the age of 23 taking up employment for the first time, people on the Live Register for at least 13 continuous weeks prior to hiring and people in receipt of the Back to Work Allowance. The new employee had to represent "a net increase in the workforce and the net increase must be retained throughout the two years of the exemption period." A similar condition applies to BTWA and it was stated that "Employers recruiting persons entitled to support from the BTWAS may also avail of the Employers' PRSI Exemption Scheme.” (Ronayne, 1996).

282. In 1998, PRSI exemption was granted for a stock of nearly 20000 employees at an estimated annual cost of EUR 18m (DoF, 1998). ${ }^{168}$ Since 2003, the exemption is granted to the employer only for the

167. In Luxembourg expenditure on the measure LU-2 Extraordinary works of general interest has been about EUR 3 million per year since 1998 (about 10\% of total ALMP expenditure in 1998, but only a few percent in recent years): this is Luxembourg's most expensive programme in terms of expenditure per participantyear (Eurostat/OECD database on labour market programmes; Grubb, 2007b, Tableau A3.2). In Japan "attempts in earlier decades to provide temporary employment for workers made redundant through the closure of military bases and the coal mines... have turned out to be very difficult to terminate and there is no desire to have further experiences of this sort" (OECD, 1993): Japan's spending on direct job creation programmes, which was 6\% of total ALMP expenditure in 1987/8, ceased some time in the 1990s.

168. The stock of 2545 participants reported in 2000 (Table 5.1) relates only to non-BTWA cases. Evidence for this statement is that (a) Eurostat Qualitative Reports do not mention BTWA as a case qualifying for PRSI exemption, and (b) Eurostat participant data sum PRSI exemption participants with BTWA participants, with no correction for double-counting. The cost of PRSI exemption is completely omitted from Eurostat 
first time that an employee claims BTWA. $^{169}$ The official description (www.welfare.ie/EN/OperationalGuidelines/Pages/prsi empprsiexemp.aspx) suggests that now only BTWA participants qualify for PRSI exemption, although Table 5.1 suggests that there are a limited number of non-BTWA cases.

\section{Back to Work Allowance and Back to Work Enterprise Allowance}

283. The BTWA provides an in-work benefit to support the recruitment of long-term unemployed workers in the private sector. The scheme operates by allowing individuals to retain secondary benefits together with a proportion of their social welfare payments for three years after take-up of a regular job. The allowance is paid on a declining scale: $75 \%$ of the full social welfare rate in year one, $50 \%$ in year two and $25 \%$ in year three. The work offered must be for a minimum of 20 hours per week. From its creation in 1993 through to 2000, BTWA was an entitlement for the long-term unemployed (on UB/UA for 12 months or more) and some other groups. Participant numbers (stocks, including BWEA) grew to about 13000 in 1996, 24000 in 1998 and 34500 in 2001 (DSW, 1999; and Table 5.1).

284. In 2001, the duration requirement in unemployed cases was raised from 12 months to 15 months. ${ }^{170}$ From $1^{\text {st }}$ January $2003,{ }^{171}$ the programme was reformed more drastically by increasing the duration requirement for unemployed cases to 5 years. The changes affected only those in receipt of unemployment payments, and not lone parents (who could still qualify after 15 months) and those in receipt of disability payments. Subsequently, the numbers benefiting from this allowance declined drastically. The number in receipt of unemployment payments declined by $35 \%$ from 2002 to 2003 while the numbers in other client groups broadly remained stable over the same period. Against this background, in 2006 entitlements for those in receipt of unemployment benefits were expanded again by reducing the qualifying criterion from 5 years to 2 years unemployment (www.welfare.ie/EN/OperationalGuidelines/Pages/btw_eall.aspx).

285. Early evaluation of the scheme suggested that it was successful in terms of enabling the long-term unemployed to access either employment or self-employment. For instance, at the end of 1995, about 12000 people had entered the BTWA and just over 10000 were continuing participants (DSCFA, 1999 , p. 13). However, it was less successful in promoting sustained employment due to high drop-out rate (O'Connell, 2002). More recent evidence shows a higher rate of completions. In a sample survey of 1370 participants who exited the scheme in $2004,58 \%$ had exited due to completion of the three-year subsidy period (DETE, 2005b, Table 6.8). The scheme has also been less successful in attracting female participants although their share has increased over time (from 15\% in 1990 to $30 \%$ in 2004).

286. A variant of the scheme, the Back to Work Enterprise Allowance, is similar providing continuation of welfare payments upon entry to self-employment, at a rate of $100 \%$ of the full social

data rather than being included in the BTWA expenditure data (evidence for this is that the expenditure reported consists of "transfers to individuals", with no "transfers to employers").

169. Perhaps without this restriction the employers of people on a lone-parent payment (who qualify for BTWA with no restriction on the duration of their benefit claim) could make frequent repeat claims, which would also allow the participant to restart BTWA at the highest rate, i.e. $75 \%$.

170. The 15-month requirement was reported in OECD's Ireland 2001 country chapter for Benefits and Wages (www.oecd.org/els/social/workincentives); a 12-month requirement still applied around 2000 (www.cesifogroup.de - DICE - labour market - employment conditional benefits).

171. This date is given in DETE (2004a): the sharp fall in BTWA participant numbers in 2002 shown in Table 5.1 is probably due to a statistical break which resulted in many participants being reported in the BWEA line instead (see also footnotes above, as regards the expenditure data). 
welfare rate in year one, $75 \%$ in year two, $50 \%$ in year three and $25 \%$ in year four. Entry is conditional on receipt of a welfare payment for a certain time (currently unemployment for 24 months or lone parent or disability benefit for 12 months) and upon approval of the business project by a local Partnership Company or the DSFA Facilitator in non-Partnership areas. Approval normally involves an interview with the applicant to assess the viability of the proposed project and to provide advice on funding or on "Start Your Own Business" courses.

287. The sharp restrictions on these schemes for unemployed cases in 2003 were probably motivated by their growing participant numbers and cost in the late 1990s and early 2000s (when the economy was booming and long-term unemployment had greatly declined); doubts about their impact (i.e. a suspicion that many beneficiaries would have found work without the subsidy) and the emergence of cycling behaviour (for the worker, loss of employment followed by a new claim for passive benefits and re-entry to BTWA; for the employer, repeat use of BTWA). Access to BTWA for the long-term unemployed was partly eased after 2003, but it remains considerably more restricted than previously. Any further easing should be cautious, due to the risk of cycling behaviour and also keeping in mind that BTWA payments are now larger, in line with the general increase of social welfare rates after 2002.

\subsection{Labour market training}

288. Although international evaluation evidence about the effectiveness of training programmes for the unemployed is mixed, the strategic case for a training focus in ALMP provision remains reasonably convincing. Ireland has achieved this thanks partly to ESF funding in the 1990s, but also to its replacement after 2000 by the National Training Fund. The outcome is that labour market programme provision for disadvantaged age groups, except the oldest, focus on the aim of "progression" into further training; and if they meet basic requirements, all unemployed people can quite easily access training up to Specific Skills Training (SST) level, and the longer-term unemployed are supported to participate even in third-level education (similar to the situation in Nordic countries, but not quite so costly).

\section{Institutional arrangements and funding}

289. Government policy in relation to vocational training is primarily the responsibility of DETE and is developed in collaboration with the Department for Education and Science (DES). The main providers of vocational education and training are FÁS and the DES which provides courses through the VECs. In addition, the National Training and Development Institute provides training for people with disabilities.

290. Training for young persons before entering employment and for the unemployed is funded mainly through DETE and DES. In 2004, DETE invested a total of EUR 834.3 million in training and employment programmes (DETE, 2005a). Under the Employment and Human Resources Development Operational Programme (EHRDOP), a part of the NDP 2000-06, Ireland continued to receive funding from the ESF but this was much less than in the 1990s.

291. The National Training Fund (NTF) was established under the National Training Fund Act (2000) to finance training for two groups - those in employment and those seeking employment. The Irish training levy $(0.7 \%$ of the wage bill) goes to the NTF, of which $95 \%$ is forwarded to FÁS. In 2005 , total NTF expenditure amounted to EUR 312 million. The NTF contributed about EUR 100 million to the training of apprentices, another EUR 23 million to training of those in employment (including FÁS courses and sectoral training grants by the development agencies) and almost EUR 180 million to training of the unemployed (Forfás, 2007, p. 59).

292. FÁS in Ireland combines the national employment service role with broad responsibilities for labour market programmes, managing Community Training Centres (CTCs) and Local Training Initiatives 
(LTIs), Community Employment and the disability employment measures (Specialist Training Providers, Supported Employment and Wage Subsidy Schemes). FÁS directly owns training centres and employs the training instructors who work in them. In most large OECD countries, labour market training is either managed by a separate national agency and/or separated local structures (e.g. the former MSC in the United Kingdom, the WIA in the United States, the AFPA in France) or is purchased by PES regional offices; and the PES does not implement apprenticeship training. ${ }^{172}$

293. Although it is internationally somewhat unusual, the integration of the placement and training functions in FÁS has some advantages:

- Arguably a small country in terms of population needs few institutions each with a relatively broad remit, and cannot support multiple training providers across the full range of occupations and training locations.

- FÁS' training function keeps management and staff in contact with the concerns of employers. FÁS' competence in policy implementation (emphasised by Boyle, N., 2005) may owe much to the fact that its key professionals work closely with employers and local communities, and not only with the unemployed and external labour market programme providers.

\section{The National Framework of Qualifications}

294. One of the major changes in the provision of vocational education and training in Ireland has been the development of a unified comprehensive framework for validation and certification of qualifications in Ireland. The Qualifications (Education and Training) Act (1999) established the National Qualifications Authority of Ireland (NQAI) in 2001. As a part of this Act, two Awards Councils were also established; the Higher Education and Training Awards Council (HETAC) and the Further Education and Training Awards Council (FETAC). The Framework was introduced because in the past there was a wide range of certification systems (including certification by FÁS) leading to confusion among employers. The NQAI has developed a 10-level outline Framework of Qualifications comprising awards from Foundation (Level 1) to Doctoral Level (Level 10). One aspiration for this national framework is that, because it puts vocational qualifications on the same scale as academic qualifications, vocational training certification to a sufficient level will be able to act as an entry route to positions where employers have traditionally recognised only standard academic qualifications. For FÁS, this has required the modification of every programme to allow it to provide qualifications within the framework established by FETAC, which makes awards for all learning in further education and training programmes at Levels 1-6.

\section{FÁS training for apprentices and employed adults}

295. In terms of annual flows, there are many more employed than unemployed participants in FÁS training programmes. However, most courses for the employed persons are very short - the single largest training programme, in terms of the number of participants, was the Safe Pass Programme, a one-day safety-awareness training programme for construction site personnel which was delivered to 125000 individuals. In 2003, in total there were 260000 participants in State-funded training for those in employment (Forfás, 2005, pp. 12-17; and Forfás, 2007, p. 57). Approximately EUR 173 million of public funds were spent on training of the employed, of which $60 \%$ was financed by the NTF. By contrast,

172. In the 1980s, the PES in Finland and Sweden managed a national network of training centres, but in the 1990s these were converted into separate organisations from which the PES purchases training. Greece, Portugal and Hungary are other OECD countries in which the PES directly manages a number of regional training centres. 
EUR 270 million was spent on training programmes for the unemployed which had about 33000 participants, mostly in FÁS programmes.

296. The delivery of Phase 2 of apprenticeships is the largest single activity of FÁS' network of 20 training centres, ${ }^{173}$ and apprenticeships are the largest programme of training for the employed in expenditure terms accounting for EUR 124 million of the total training budget in 2003. The number of participants on Apprenticeships has increased 59\% between 1998 and 2006. The Irish model of apprenticeship is quite heavily subsidised by public funds, as a FÁS training allowance is paid in lieu of wages during the training phases. The standards-based apprenticeship has seven phases: Phases 1, 3, 5 and 7 take place with the employer, Phase 2 in a FÁS training centre and Phases 4 and 6 in an Institute of Technology. At the end of 2005, there were a total of 28600 registered apprentices.

297. FÁS also provides training for employed through its Services for Business division. One of the major forms of support, in operation until 2002, was the Training Support Scheme (TSS). This Scheme provided financial grants to Small to Medium Enterprises (SMEs) (up to 150 employees) seeking to improve the skills of all levels of employees within a company. In 2003, TSS was replaced by the Competency Development Programme. Under this programme, subsidies are paid to reduce the cost of training courses. The rate of subsidy varies depending upon the region of the country (i.e. South and East Region or Border, Midlands and Western Region). In exceptional cases, in respect of unskilled employees, the subsidy can reach $100 \%$ of training course costs. Funding for the Competency Development Programme increased from EUR 8.5 million in 2004 to over EUR 35 million per annum in 2005 and 2006 (Forfás, 2007, p. 57). This reflects the greater emphasis placed by the Government on upskilling the existing work force, particularly low-skilled workers.

\section{FÁS training for the non-employed}

298. FÁS also runs programmes for non-employed groups, in particular the unemployed and the disabled. On FÁS-funded programmes for the unemployed and disabled all training costs, including training allowances, are paid by FÁS. Several of the training programmes for the unemployed shown in Table 5.1 are delivered partly in FÁS Training Centres:

- Bridging/Foundation courses are geared towards people who are not job-ready and need motivation, confidence-building and basic skills support prior to entering one of the mainstream skills training programmes. It includes some work experience. The "bridging" objective is to encourage participants to identify an intended field of work so that they can enter specific skills training (see below). Return to Work is a foundation course adapted for the needs of women returners to the labour market;

- Specific Skills Training (SST) provides, as its name indicates, vocational training in specific occupational areas. These include engineering, information technology, office and administration, sales, marketing, management, construction, electronics and clothing. Courses range from 12 to 52 weeks in duration and usually finish with a short work-experience module; and

- Traineeships also provide training in specific occupational areas but on an alternate basis i.e. alternative periods in full-time training with periods at a workplace under normal operational conditions. The employers partner with FÁS to address skill shortages and plan for future skills needs. Traineeships vary in duration from 6 to 24 months. Participant numbers on Traineeships

173. Twenty centres as cited by a Valerie Cowman of FÁS (www.bio-link.org/CBC2007/IrelandCowan.ppt). Employment service information has a large impact on whether FÁS runs a training course - which in turn influences the contracts of external providers. 
increased from 2002 to 2006, in contrast to declining numbers on SST. This may reflect employers' increased willingness to provide structured training during a long period of labour market tightness.

\section{Box 5.1. Community Training Programmes}

In the past, FÁS ran two training programmes involving training on community sponsored projects; the Community Youth Training Programmes and the Local training Initiative. These have now been merged under the heading Local Training Initiative. As such, although LTI are aimed at the unemployed in general, the term may be used to include Community Youth Training (aimed at unqualified unemployed young persons less than 25 years of age) and "Community Response" programmes aimed at unemployed with a leaving certificate. FÁS also runs a separate programme, Community Training Centres (formerly known as Community Training Workshops) which comprises formal, off-the-job, learning in small training centres for early school leavers. There is currently a relatively fixed set of Community Training Centres (43 are listed at: www.fas.ie/en/Communities/Community+Training+Centres/Centre+Locations/default.htm) whereas Local Training Initiatives can be specific projects that are temporary in nature and involve only a few people.

\section{Local Training Initiative}

LTI is a flexible Community Services programme designed to respond to specific local needs. It targets people primarily aged between 16 and 25 years who are unable to access other FÁS interventions for social, personal or geographical reasons. In 2003, more than $60 \%$ of the participants on LTI were under 25 years of age. This is in line with the defined target group for this group. Moreover, the programme is largely dominated by female participants. In 2006, there were 2523 participants in training on LTls and 2652 completed training during this period.

There is a variety of LTI schemes, with elements of both formal training (e.g. when participants are trained in the use of computer packages) and community service work experience (e.g. when participants enter genealogical records to build a database). An example of the LTI initiative is the restoration of a dilapidated house in the local community council housing based in Cox's Demesne, Dundalk. Project participants are young long-term unemployed or with a history of anti-social behaviour. The work here consists of painting, plastering, brick-layering and decorating. Training is delivered both in the house and also in a local Resource Centre - a community run facility. The training that takes place in the Centre includes Personal and Social Skills, Safepass, First Aid, Health and Safety and IT skills. Participants receive a full training allowance and on completion receive an award equivalent to FETAC Level 3 . In the previous year (2006), approximately 14 participants were involved in a similar project. This was widely recognised in the local community which has encouraged further co-operation from the local council housing authorities.

\section{Community Training Centres}

CTCs are community-based organisations funded by FÁS to respond to the training needs of early school leavers. Part of the training provided is linked to the Youthreach programme - a joint initiative between the DES and DETE. $100 \%$ of Youthreach participants but only $40 \%$ of participants in Foundation/Progression in Community Training Centres in 2005 were aged less than 25 (Eurostat, 2007).

The training on offer varies from centre to centre, often depending on the facilities available. However, basic subjects, such as English, Maths and, in many cases, computers, are generally covered by all trainees. Opportunities to improve literacy and numeracy are available in all centres. These courses are full-time and last for one year. Similar to other FÁS programmes, successful participant are awarded with a qualification such as a FETAC award which gives opportunities to move into more advanced training. Some trainees also choose to sit for Junior or Leaving Certificate qualifications. There were 2415 early school leavers in training in CTCs at the end of the year, and 1849 completed training during 2006.

299. Community Training and Local Training Initiatives are training/work projects carried out by local communities with financial support from FÁS. Box 5.1 provides more details and examples of these programmes, which are delivered through Community Training Centres or smaller structures. 
300. In the case of unemployed participants, none of these training programmes is strictly restricted to the long-term unemployed. There are important elements of targeting in that Bridging/Foundation courses are targeted on disadvantaged groups. Traineeships are often appropriate for early school leavers, and a training bonus of EUR 31.80 per week (2005 rate) is paid to long-term unemployed participants in SST and Traineeships. Nevertheless Ireland appears to be among the countries where a motivated short-term unemployed person can relatively easily enter long-term vocational training while receiving public income support.

301. FÁS acquired responsibility for the management of Specialist Training Providers (STPs) upon the disbanding of the former National Rehabilitation Board (NRB) (see Box 5.2 below). FÁS contracts with 20 STPs which deliver specialist training from 57 centres. FÁS pays the trainer a standard rate (EUR 13300 per trainee per year in 2006) (www.fas.ie/en/Equality/Disability/ Specialist+Training+Providers; Eurostat Qualitative Report 2006). The high total cost per participant of this programme, as shown in Annex Table 5.A.1, includes the cost of allowances paid to trainees, which are linked to the rates of disability allowances/benefits otherwise payable.

\section{Characteristics of participants in FÁS training programmes}

302. O'Connell and McGinnity (1997) identified education qualifications, duration of prior unemployment and economic status prior to participation as important participant characteristics. Table 5.3 (see further below, where post-programme outcomes are also discussed) shows that among the training programmes, participants in Return to Work and CTCs have the lowest educational attainment. SST has a low proportion of participants with primary level education (9\%) and a relatively high proportion with third-level education (23\%). The high incidence of third-level education among participants on LTI (23\%) is somewhat surprising since the programme is aimed at disadvantaged groups. A relatively large number of CTC and LTI participants were in education before entry to the programme. According to Eurostat participant data, CTC has a relatively young participant age profile but this is not so much the case for LTI.

303. The educational attainment profile of participants is higher for all the training programmes than it is for the CE programme. The proportion of participants who were previously long-term unemployed is relatively high (similar to the proportion for CE) for Bridging and Return to Work programmes, intermediate for Community Training Centres and Local Training Initiatives and low for skills training programmes (SST/Traineeships). ${ }^{174}$ This is broadly consistent with participants' educational background.

\section{Other labour market training measures}

304. The Back to Education Allowance (BTEA) is administered by the Department of Social and Family Affairs (DSFA). It is an entitlement for individuals on who have been on unemployment benefits, One-Parent Family Payment (OFP) or one of several disability benefits for six months, and who are participating in a second or third-level course. Courses must be publicly-funded, full-time, and lead to a recognised qualification. For third-level courses, the qualifying period was raised to 15 months in 2004 and brought back to 12 months, or 9 months in the case of NEAP referrals, in 2005. For post-graduate courses, a lower age limit of 24 applies (see www.welfare.ie/EN/OperationalGuidelines/Pages/bte_all.aspx and Eurostat Qualitative Reports). DSFA provides income support in the form of continued payment of benefits during education, which may be for up to several years. In unemployed cases, BTEA is not paid during the summer period, but participants who are unable to find employment may claim an unemployment payment.

174. Overall, the proportion of long-term unemployed on training programmes has declined. In 2006 , only $38 \%$ of participants on training programmes were unemployed for more than 12 months compared with $46 \%$ in the 2001 Follow-up Survey. 
305. The Vocational Training Opportunities Scheme (VTOS) is the largest single training programme in Table 5.1 in terms of expenditure, although in 2006 BTEA had become slightly larger in terms of participant numbers, and the FÁS training schemes together also have more participants. In contrast to FÁS training programmes, but in line with BTEA, the number of participants on VTOS over the past eight years has remained broadly stable. VTOS is designed to provide "second-chance" education for adults aged over 21 , with an emphasis on raising both the general education levels and specific vocational skills of participants. It is funded by the Department of Education and Science under the National Development Plan 2000-2006. It is delivered by the thirty-three VECs (Vocational Education Committees) from 107 VTOS Centres (listed at: www.vtos.ie/main/map.htm). The main condition for participation is to be in receipt of an unemployment payment or another welfare payment for at least six months. Training takes place in two modes: as a "core" student attending training delivered at a VTOS Centre or Adult Education Centre, or as a "dispersed" student usually attending a Post-Leaving Certificate College or a Further Education College.

306. VTOS was introduced in 1989 and is targeted at those in receipt of UA or UB, with a $10 \%$ cap on participation by people in receipt of OFP and disability allowance. In 1998, this $10 \%$ cap was lifted and the latter categories were allowed apply for a place on the programme on an equal footing. In 2005, there were approximately 5500 participants of whom $70 \%$ were female. A large proportion of the female participants are in receipt of OFP. One reason for this could be that funds are provided by DES to VECs for childcare support to encourage parents to take part. ${ }^{175}$

\subsection{Measures for youth}

307. Apart from regular education, the labour market programmes most strongly targeted on youth in terms of their participant profile are FÁS Apprenticehips and Youthreach. There is no explicit age targeting of apprenticeships, but low apprenticeship rates of pay ${ }^{176}$ appear to depress take-up by adults.

308. There are large differences in the age profile of participants between other programmes already described above. About half the participants in Traineeships and a third of the participants in Specific Skills Training in 2005 were aged less than 25 so that on a broad definition, Traineeships can be considered mainly a youth programme and SST a mixed youth/adult programme. By contrast, BTEA and VTOS are mainly adult programmes with less than a fifth of their participants aged under 25 . Youth shares in subsidised employment and direct job creation measures are much lower - the proportion aged less than 25 is about $5 \%$ in BTWA, lower still for Community Employment and the Social Economy Programme and zero for Job Initiative (Eurostat, 2007).

309. According to Eurostat data, Youthreach is the only labour market programme where all participants are aged under 25. It is targeted on unemployed young early school leavers aged 15 to 20 . Nationally, one child in ten leaves school with no qualifications and one in five leaves without completing the Leaving Certificate. Unemployment rates for those who enter the labour market with no qualifications are several times higher than for others. In addition to having left school early, many Youthreach participants have other difficulties. Family dysfunctions are reported in over $50 \%$ of cases and substance abuse in $25 \%$. There are high levels of literacy problems (35\%), poor physical and/or mental health (20\%)

175. As of April 2008, childcare/crèche costs can be paid up a maximum of EUR 63.50 per week (www.education.ie - students and trainees - FAQ).

176. In a small sample of trades, 2007/8 pre-tax rates of pay in Phase 2 of apprenticeships ranged from EUR 143.68 per week to EUR 242.58 per week ( $w w w$.fas.ie/en/Allowances+and+Grants/Apprentice+Wages.htm). This is about a quarter of the average wage and salary per full-time equivalent employee (EUR 42517 per year in 2005 on the basis of OECD, 2007a, Table I). 
and offending behaviour (20\%), and $30 \%$ of female participants are lone parents (www.ndp.ie/viewdoc.asp?fn=/documents/featured-projects/Youthreach.htm).

310. The Youthreach programme is generally full-time and lasts from 1 to 2 years. ${ }^{177}$ Participants receive an allowance of EUR 80.60 per week for 15 and 16 years olds, rising to EUR 197.80 per week for ages 18 and over. The programme content is described mainly as training: "You can concentrate on a core training area of your choice but basic subjects, such as English, Maths and Lifeskills, are generally covered by all trainees". If successfully completed it leads to a FETAC award, and participants can continue other skills training such as apprenticeships. (www.citizensinformation.ie - Education and Training $>$ Vocational education and training $>$ Training and apprenticeship programmes). Literature usually describes work experience as a component but this may be optional (www.youthreach.ie/rush/index.html) or available through follow-up programmes (www.wd-vec.ie/youthreach.htm). ${ }^{178}$

311. The programme is delivered (or was, slightly earlier in the $2000 \mathrm{~s}$ ) ${ }^{179}$ from over 120 centres throughout Ireland (open from 9:00 to 16:30, Monday to Friday), with 90 centres managed by the VECs, 45 Community Training Centres managed by local community-based management boards and ten "Justice Workshops" funded by FÁS and the Department of Justice Equality and Law Reform. In the VEC centres, $78 \%$ of students are aged under 19 whereas in the CTCs the percentage is approximately $51 \%$ (www.youthreach.ie/aatopmenu/AboutYR/about.html). ${ }^{180}$ In 2005 only 896 participants at CTCs were aged under 25: 63\% were aged 25 or more (Eurostat, 2007).

312. The objective in providing a large number of Youthreach centres throughout Ireland is to ensure that a local centre is easily accessible for the vast majority of potential clients in disadvantaged areas. This maximises the programme's effectiveness as an outreach and safety-net programme for youths neither in education or employment.

313. After the start-up phase of Youthreach in 1989-1992, Youthreach centres in 1993-1997 reported waiting lists. Subsequently early school-leaving increased, but this was due to young people taking jobs earlier with lower levels of qualifications, and Youthreach waiting lists fell (Youthreach national coordinators, 2000). Plausibly this remained the situation throughout the continuously tight labour markets of the 2000 s to date.

314. The relatively high cost of Youthreach and Community Training Centres per active participant (Table 5.1), despite the fact that allowances paid are probably relatively low, may be due to the outreach character of the programme, since staff devote time to bringing participants in and may find it difficult to keep facilities used continuously at full capacity; it also reflects a personalised and flexible approach with relatively small class sizes (www.youthreach.ie/aatopmenu/AboutYR/about.html mentions a tutor-learner ratio of 10.5:1, probably referring to the VEC centres).

177. Some local centres offer one-year only courses (www.wd-vec.ie/youthreach.htm) and others two-year only courses (www.cavanvec.ie/html/youthreach.asp).

178. The Linked Work Experience programme provides structured on-the-job training for Youthreach participants (Buck and McGinn, 2005).

179. The information cited appears to relate to about 2003; the number of Youthreach centres active in 2008 is slightly below 110 (www.youthreach.ie/yrbynetwork.htm).

180. And "A parallel programme in a culturally appropriate setting is delivered in the 33 Senior Traveller Training Centres (www.sttc.ie)". 


\subsection{Measures for the disabled}

315. The range of disability employment measures includes the following:

- More generous disregards for earnings: (as mentioned in Chapter 4) for Disability Allowance, earnings up to EUR 120 per week are disregarded for Disability Allowance and a 50\% withdrawal rate then applies up to EUR 350/week ( $c f$. for Jobseeker's Allowance, EUR 60 per week are disregarded and a $60 \%$ withdrawal rate applies thereafter);

- Specialist Training Providers, as discussed briefly in Section 5.5 above;

- There has been a drive to "mainstream" employment service provision, including the transfer of counselling responsibilities of the former NRB to FÁS (discussed in Box 5.2);

- All the major employment programmes such as Community Employment, BTWA, BWEA, VTOS, etc. are open to people on disability benefit on similar terms to unemployed people, and in several cases with less restrictive conditions in terms of claim duration. It is estimated that about $80 \%$ of the training for the disabled is delivered by Specialist Training Providers and the remaining $20 \%$ by mainstream providers;

- FÁS makes several types of one-off grant to help disabled employees apply for jobs and make the workplace more accessible or easier to use; and

- Three per cent of public service jobs are reserved for people with a disability (CIB, 2008).

316. To complete the picture, this section discusses the FÁS Supported Employment and Wage Subsidy Schemes and sheltered employment and/or work.

\section{Box 5.2. Mainstreaming of disability services and the transfer of the National Rehabilitation Board}

The National Rehabilitation Board (NRB) was a state-sponsored body which provided services to people with disabilities, worked to create an awareness of disability issues and advised the Government, public authorities and other organizations providing services to people with disabilities. Its main services were the Occupational Guidance Service, which helped people with disabilities to identify and reach employment goals and the Training and Employment Advice Service, which referred people with disabilities to training or work. It was dissolved in 2000, with the transfer of staff involved in occupational guidance and referral to FÁS Employment Services and the transfer to FÁS of responsibility for the administration and monitoring of vocational training for the disabled through outside providers (NDA, 2004).

Eurostat/OECD data from 1998 onwards include a line IE-22 Counselling/guidance (in Category 1 PES and administration) as from 2000 and a line IE-51 Specialist Training Providers (in Category 2 Training) also from 2000 (data for 2000 to 2002 are OECD estimates).

These changes reflect a push towards mainstreaming of disability employment services. FÁS local employment offices immediately caseload persons with disability who register with employment offices but no distinction is made between rehabilitation specialists and other ESOs.

Around 2000 there were "increasing efforts to include disabled individuals in mainstream provision" of rehabilitation (initial training and return to work) (TMA, 2001). By 2006 a limited proportion (20\%) of people with disabilities in training were attending courses outside the framework of Specialist Training Providers (Eurostat Qualitative Report 2006). Similarly, the introduction of the Supported Employment Scheme in 2000 and the replacement of the former Employment Support Scheme by the Wage Subsidy Scheme in 2005 reflect a continuing drive to increase the participation of people with disabilities in regular employment. 


\section{The Supported Employment Programme and Wage Subsidy Scheme}

317. These programmes, implemented by FÁS, focus on entry to regular employment. In the Supported Employment Programme, a Job Coach typically helps clients to identify the most suitable type of employment, finds appropriate work and matches the client to it, and provides the employee with necessary support and coaching in the workplace. The level of support should decrease over time as the employee learns the skills required and adapts to the workplace (Eurostat Qualitative Report 2006). Although this programme can provide lump-sum payments to individuals or to employers, the amounts involved are insignificant relative to the cost of the service provision (Eurostat, 2007).

318. The Wage Subsidy Scheme (WSS) in 2005 replaced the earlier Employment Support Scheme, which in principle was a payment to the employer to directly compensate for an employee's loss of work capacity, and would decline as work capacity improved. The wage subsidy is paid for work of 20 hours or more per week at two rates. The lower rate of EUR 7650 per year (2006) is payable for a productivity level of $80 \%-51 \%$ of normal performance. For person working 20 hours per week, a $20 \%$ loss of productivity is equivalent to an annual loss of only about 200 hours of working time, so the scheme appears to provide the employer with a strong incentive to hire, or keep in employment, people with low rates of capacity loss. Two other strands of the measure ${ }^{181}$ make payments to cover the additional supervisory, management, and other work-based costs for employers who hire two or more disabled workers. The employees must have the same terms and conditions as other workers. FÁS devoted considerable efforts to promoting the scheme in 2006 and 2007.

\section{Sheltered employment and/or work}

319. OECD and Eurostat data for Ireland do not include sheltered employment/work. According to TMA (2001), "Sheltered employment is mainly provided by voluntary organisations and funded by the Health Boards. Training is usually provided in sheltered employment, but it is not always clear whether this is designed to lead to open employment. In 1995, around 5,000 individuals were in sheltered work and long-term training and sheltered work." In 1997 there were 7900 people in 215 sheltered workshops (O'Hara and O'Shaughnessy, 2004) and ProjectAtlas (2004 - estimated date) states that there are "7 600 people with disabilities in 215 sheltered workshops in Ireland". In 2007 "More than 4000 people with intellectual disabilities are working in sheltered workshops doing such work as shrink-wrapping two-forone offers for supermarkets, putting inserts into mail shots or making cardboard boxes." (www.ireland.com/newspaper/frontpage/2007/0827/1187332635291.html). In such cases the direct pay rates can be far below the minimum wage, but they are paid as additions to disability benefits. ${ }^{182}$

320. Following controversy about such arrangements, ${ }^{183}$ in 2008 a code of practice for sheltered work was drafted and the Department of Health and Children was reviewing the funding of sheltered work (CIB, 2008). Probably only a limited proportion of this target group might be able to work in regular employment. However, the institutional/funding arrangements do not seem to reward providers for achieving transitions to regular employment, either in the case of voluntary organisations funded by Health

181. These other strands replace the Pilot Employment Programme which operated in 2003.

182. Even though sheltered work in this sense is productive, it may fall outside the scope of Eurostat/OECD data on labour market programmes under the guidelines that "Sheltered work provisions included here should have the aim of preparing people for integration into the regular labour market."; also participants whose hours do not correspond to at least "significant part-time" are not counted (Eurostat, 2006, § 7, and $\S 87)$.

183. Even at low rates of pay, sheltered work may offer more net additional income than regular work offers to people on unemployment payments. In 2005 the net additional payment from participation in CE for a single unemployed person was EUR 1.25 per hour (DETE, 2005b, Table 5.6). 
Boards or in the case of commercial operations employing people with disabilities exempted from minimum wage legislation.

\subsection{Programme performance, evaluation and research}

\section{Post-programme employment outcomes for FÁS programmes}

321. The FÁS Follow-up Survey records a range of information about a sample of participants who have left a FÁS programme. The information includes personal characteristics and status (e.g. unemployed, receiving particular benefits, educational attainment) before participation, reasons for non-completion of the programme, views on the usefulness of the programme, certificates obtained, whether they had looked for work after the programme and labour market status at the time of the survey interviews, which took place some time after the participant's exit from the programme. Table 5.3 presents a selection of the findings.

Table 5.3. Participant characteristics and post-programme outcomes for FÁS programmes

Participants who left FÁS programmes in the period June to September 2005

\begin{tabular}{|c|c|c|c|c|c|c|c|c|c|c|c|c|c|c|}
\hline & \multicolumn{2}{|c|}{$\begin{array}{c}\text { Highest qualification } \\
\text { achieved by } \\
\text { programme type }\end{array}$} & \multicolumn{7}{|c|}{ Labour market status before FÁS programme } & \multicolumn{5}{|c|}{$\begin{array}{c}\text { Labour market status circa } 15 \text { to } 19 \text { months after } \\
\text { leaving the programme } e^{c}\end{array}$} \\
\hline & Primary & Third level & Working & $\begin{array}{l}\text { Unemp- } \\
\text { loyed }\end{array}$ & $\begin{array}{l}\text { Of which, } \\
\text { long-term }\end{array}$ & $\begin{array}{l}\text { CE/Job } \\
\text { Scheme }\end{array}$ & $\begin{array}{l}\text { Other } \\
\text { FÁS } \\
\text { Course }\end{array}$ & $\begin{array}{l}\text { Educ- } \\
\text { ation }\end{array}$ & $\begin{array}{l}\text { Home } \\
\text { duties }\end{array}$ & $\begin{array}{l}\text { Employee } \\
\text { or self- } \\
\text { employed }\end{array}$ & $\begin{array}{l}\text { CE/Job } \\
\text { scheme }\end{array}$ & $\begin{array}{l}\text { Training } \\
\text { (FÁS or } \\
\text { other) }\end{array}$ & $\begin{array}{l}\text { Unemp- } \\
\text { loyed }\end{array}$ & Other \\
\hline & \multicolumn{2}{|c|}{$\%$ of participants } & \multicolumn{2}{|c|}{$\%$ of participants } & \% of $U P^{b}$ & \multicolumn{4}{|c|}{$\%$ of participants } & \multicolumn{5}{|c|}{$\%$ of participants } \\
\hline Bridging & 14 & 14 & 18 & 54 & 40 & 1 & 2 & 2 & 16 & 38 & 3 & 13 & 28 & 18 \\
\hline Community Training & & & & & & & & & & & & & & \\
\hline Centres (CTCs) & 29 & 0 & 14 & 34 & 42 & 5 & 5 & 35 & 5 & 41 & 5 & 13 & 31 & 11 \\
\hline Linked Work Experience & 0 & 0 & 29 & 29 & 0 & 0 & 0 & 29 & 14 & 39 & 7 & 18 & 14 & 17 \\
\hline Local training Initiative & 17 & 23 & 25 & 28 & 60 & 0 & 1 & 29 & 15 & 62 & 11 & 18 & 10 & 4 \\
\hline Return to Work & 26 & 13 & 5 & 40 & 75 & 5 & 0 & 5 & 40 & 34 & 9 & 13 & 21 & 23 \\
\hline Specific Skills Training (SST) & 9 & 24 & 27 & 45 & 30 & 2 & 4 & 7 & 9 & 58 & 2 & 8 & 23 & 9 \\
\hline Traineeship & 5 & 20 & 28 & 36 & 30 & 0 & 2 & 13 & 20 & 72 & 1 & 9 & 10 & 8 \\
\hline Total training ${ }^{a}$ & 14 & 17 & 22 & 43 & 38 & 2 & 3 & 12 & 14 & 48 & 4 & 12 & 22 & 13 \\
\hline Community Employment & 37 & 11 & 16 & 47 & 69 & 5 & 1 & 4 & 20 & 30 & 29 & 6 & 20 & 15 \\
\hline Job Initiative Scheme & 43 & 8 & 10 & 31 & 57 & 48 & 0 & 2 & 10 & 36 & 50 & 0 & 7 & 6 \\
\hline Total employment & 37 & 10 & 15 & 46 & 68 & 8 & 1 & 4 & 19 & 31 & 30 & 6 & 19 & 15 \\
\hline Total & 26 & 13 & 19 & 45 & 54 & 5 & 2 & 8 & 16 & 39 & 17 & 9 & 21 & 14 \\
\hline
\end{tabular}

a) Total training is average of the individual training programmes.

b) Percentage of unemployment participants.

c) Labour market status at the time of the survey, November 2006 to April 2007.

Source: FÁS, Follow up Survey of FÁS participants, 2006/07, Tables 6, 8, 10 and 18.

322. Overall, $64 \%$ of the participants on training schemes had a positive outcome when taking into account both those in employment (48\%) and those in education (16\%). Of those who were employed, the vast majority had found their first job within 3 months of leaving the programme. In terms of programme types, participants on the Traineeship (72\%) and LTI programmes (62\%) had the best employment performance followed by SST (58\%). Participants on other training programmes (Bridging, Community Training Centres, Return to Work) had lower employment rates and participants on Community Employment had lower rates again. The FÁS programmes with lower employment performance are also relatively large: in 2006 throughput (the number of persons who finished their programmes) was 8253 for Specific Skills Training and Traineeships, 13117 for the various types of Foundation skills training and 32126 for Employment programmes (FÁS, 2007a).

323. Traineeships and SST had the lowest proportion of participants going on to further education or training, reflecting the fact participants in these relatively advanced programmes are expected to enter employment whereas the bridging/founding type programmes are often an entry into Traineeships and SST. Given that both programmes aim to move people directly into the labour market, it is important that 
they reflect the skills demands of the economy and the local labour market. Traineeships involve long-term work experience with an employer, and the positive impact of this suggested by the outcomes in Table 5.3 would be in line with the experience of other countries. In the case of SST, although the proportion employed 15 to 19 months later was relatively high, the proportion of those who remained unemployed was more than double the proportion for Traineeships, and in 2006/07 it was higher than in any earlier survey. This possibly reflects the fact that participants have become more disadvantaged as long-term unemployment fell and participation in bridging/foundation courses increased. Another possibility is that people who do not really want a job have increasingly felt obliged to participate in something due to the NEAP process and chose training. Also, by 2006/07 social welfare rates had become considerably higher, relative to earnings.

324. The mix of FÁS training also suggests that the client group has become more disadvantaged. In $1998,49 \%$ of the "throughput" (completions) from total FÁS training (including apprenticeships) was in Skills Training (SST and Traineeships) and $28 \%$ in Foundation Training (Bridging/Foundation, Local Training Initiatives, Community Training Centres, Specialist Training Providers and Return to Work training). By 2006, Skills Training accounted for $20 \%$ and Foundation Training for $32 \%$ (FÁS, 2007a, Appendix 1.b).

325. The evidence of a positive impact of Traineeship and SST on unemployment has to be seen against the background of their relatively favourable participant profile, with relatively few long-term unemployed and low-educated participants. As seen above, there is a high proportion of long-term unemployed on Bridging and particularly on Return to Work. Plausibly the more-disadvantaged groups are more difficult and more costly to activate as well as having lower rate of successful outcomes. The LTI programme has a more favourable participant profile - a relatively low proportion having been unemployed before programme entry and a relatively high proportion having third-level education (see Table 5.3) - and it stands out as having achieved the highest positive outcomes.

326. VTOS has not been subject to major evaluation but monitoring data suggests that the programme has placed a substantial number of participants in employment, further education and training. In 2004, around three-quarters of participants who completed a one- or two-year course progressed onto employment, further education and training (DFSA, 2005b, Appendix E). However, this percentage was lower than in previous years, which could be explained by the increase in the number of lone parents who may not have the incentive to move into the labour market, given other factors that that discourage recipients of OFP from taking up employment.

\section{Issues for impact evaluation}

327. Although participants on the higher-level skills programmes and those closest to the labour market such as SST and particularly Traineeships were most likely to find a job after the programme, it should not necessarily be concluded that other programmes are less effective. From the perspective of formal programme evaluation techniques, the following factors need to be taken into account:

- What matters are not gross outcomes but estimated impacts i.e. outcomes to relative would have happened without participation in the programme. The less-disadvantaged participant groups would have had better outcomes even without the programme.

- Programme cost and duration should be taken into account. As noted above in the case of Job Initiative, the fact that the employment rate among people who have left a programme - the statistic shown in Table 5.3 - is high does not by itself mean that the programme is effective. If spells on the programme are long, rates of entry to unsubsidised work among participants may be 
actually lower than for comparable individuals who did not enter any programme. Formal evaluations would normally focus on these rates of transition to unsubsidised employment.

328. At the same time, several other factors which influence programme effectiveness are quite difficult to take into account with the data and econometric techniques currently available:

- Programme evaluation techniques typically focus on outcomes for their direct participants, but programmes may have external effects, e.g. a FÁS programme creating employment in a local crèche may prevent other operators from setting up a crèche on a commercial basis, to a certain extent creating the unemployment problem that it is designed to solve;

- Simple evaluation techniques only control for measured participant characteristics, such as level of educational attainment. Unmeasured characteristics are also important and they plausibly lead more motivated, work-oriented participants into the programmes that are closer to the labour market. If these characteristics were better controlled for (e.g. with more detailed data, complex econometric techniques or random assignment evaluations), the estimated impact of the programmes closest to the labour market might be less favourable;

- Even if a programme such as SST is more favourable in terms of estimated impact than Foundation-type training, the result relates to the programme's current participant profile. If, hypothetically, disadvantaged workers were assigned directly to SST the programme's impact would probably fall because the programme content is not appropriate for participants who lack appropriate motivation or basic skills; and

- As indicated by programme names (e.g. Bridging/Foundation), the objective of lower-level FÁS programmes is "progression". In contrast to SST and Traineeships, a relatively high proportion of Foundation participants enter further education/training. For the disadvantaged client group, progression first to higher-level training in specific vocational skills and then into a skilled job may be a better outcome than immediate entry to employment. Longer-term data where job stability and earnings in work are observed would be needed to capture the benefits that arise when the "progression" approach is successful, in terms of disadvantaged clients eventually making a transition into relatively skilled jobs. ${ }^{184}$

\section{Recent evaluations and policy reviews}

329. A culture of evaluation was relatively well developed in the 1990s when the share of EU Structural Funds devoted to the Irish labour market was high. In a general survey of evaluation practice Boyle, R. (2005) concludes:

- Since 1989, evaluation of the EU Structural Funds has been a formal requirement of those member states receiving this financial assistance, and has led to significant developments in evaluation practice in Ireland... This external push to promote evaluation has been a key determinant in systematizing the approach to evaluation compared to what had been a very

184. O'Connell (2002) summarises evaluation findings saying "skills training and employment subsidies - both of which are characterised by strong linkages to the labour market - have strong positive effects on subsequent employment outcomes". But he then adds "one of the policy implications stressed in these studies is not that less effective programmes should be discontinued... those suffering particularly severe labour market disadvantages... who might need to enter a reintegration process by participating in a programme with a weak link to the labour market, should be able to progress to more effective programmes with a strong link to the labour market." 
ad hoc approach previously. The independent evaluation units established during the 1989-1993 and 1994-1999 CSF periods were an important and innovative approach to building evaluation capacity where evaluation was not a significant function previously;

- In the case of the 2000-2006 CSF period, where Structural Funds were a much smaller part of the total National Development Plan, the decision was made to abolish the departmental-based independent evaluation units and develop the central evaluation unit. In the changeover period, the evaluation expertise built up in the departmental-based units was lost to the system, and developing and maintaining the staff complement of the enhanced central unit has proved problematic;

- As a small country of just over 4 million people, the number of potential suppliers of professional evaluation services in Ireland is limited. There is a strong reliance on a very small pool of researchers from which to draw evaluation expertise. The corollary of this point, however, is that a strong working relationship can be developed with professional experts who have developed a good working knowledge of the specific requirements of evaluation practice;

- It is possible to set over-ambitious goals and targets for evaluation practice. The ERI requirement [in the 1997 announcement of the Expenditure Review Initiative] that all expenditure programs be evaluated every three years was found to be unachievable. Attention needs to be paid to defining the reach and scope of evaluation practice; and

- Where programme personnel, with little if any previous evaluation expertise, are used to evaluate programmes, the quality of resulting reports can in some instances be problematic. Sufficient training and support for this work is needed. So too is the prioritisation of the evaluation work among the many other tasks such public servants are required to do. Without formal procedures and practices to integrate evaluation into decision-making, the impact of evaluation may be limited. This, in turn, may lead to decision-makers questioning the merits of putting effort into building evaluation capacity.

330. In the area of labour market programmes, most of the earlier formal statistical evaluation studies were conducted by the ESRI. However, the last such research appears to have been that discussed by O'Connell (2002) using 1994-1996 data. ${ }^{185}$ Other research includes studies by NESF and the INOU but these evaluations have been narrow in their scope.

331. Although there has been little or no formal econometric evaluation of programmes in the 2000s, government departments have continued to commission external reviews of key policy areas and instruments such as LES, BTWA, NEAP and CE, and have carried out policy reviews within government, including the relatively comprehensive Cross-Departmental Expenditure Review of Supports for the Long-term Unemployed (DETE, 2005). ${ }^{186}$ Such reviews examine the detailed characteristics of the

185. A preface states that O'Connell (2002) is part of a project funded "up to 70.76 per cent" by the European Commission.

186. Based on experience with the first two Cross-Departmental Expenditure Reviews (i.e. the review of public supports for the long-term unemployed published as DETE, 2005b, and a review of road safety), Boyle, R. (2006) identifies several issues for the success of these reviews. Prioritisation and resourcing issues included agreement between departments on terms of reference and resource commitments, including external consultants, other commitments of key personnel and the rotation of personnel during the evaluation process. Boyle also noted a need for specialist expertise that may not be available in line departments, to bring in elements of synthesis across diverse measures and programmes and allow a policy overview. 
programme(s) and therefore the recommendations can include retaining and strengthening some features (e.g. the training component of Community Employment) and dropping others. This is often more relevant from a policy point of view than an impact evaluation, which can only directly support a recommendation to abolish the less-successful programmes and expand the more-successful ones. ${ }^{187}$ They may also in some sense be more accurate than an econometric/statistical evaluation of impact would be, given that statistical evaluations often do not capture all relevant dimensions of outcomes and effectiveness.

332. In practice, the first difficulty in evaluating programmes is often a near-complete lack of comparable data, i.e. as mentioned in Section 5.2, key data for several programmes such as BWEA and PRSI exemption are unavailable and statistics for different training programmes (FÁS training centres, BTEA, VTOS) variously include or exclude the public cost of the training services delivered to their participants. In this non-uncommon situation, a review approach centred on basic data collection and qualitative information and judgments remains a key input to policy.

333. However, there are also risks in attempting to work without a statistical evaluation perspective. Policy reviews that are not rooted in an attempt at reasonably full modelling of programme impacts, costs and benefits may casually characterise programmes as successful or unsuccessful on the basis of easilyavailable information (such as the high "progression rates to regular employment" of the JI scheme) which is not technically valid. DETE and other departments should preferably conduct impact evaluations, using data from the 2000 s, which then are available as input to policy reviews.

\subsection{Summary of main points}

- $\quad$ The Community Employment programme still employed about 1\% of the labour force in 2006. Some of its specialised functions, such rehabilitation of substance abusers and a function similar to sheltered employment for the disabled, probably meet an ongoing need. But others should have been run down faster, with more emphasis on the placement of the target groups into regular employment, in the strong labour market conditions of the 2000s. None of the CE strands is comparable to Work for the Dole in Australia or compulsory job/training programmes in other countries, which play an important role in implementing mutual obligation principles, and thus in limiting the total cost of active and passive programmes.

- The Job Initiative and the Social Economy programmes, which provide full-time work paying an ordinary wage, suffered high cost per participant-year and low rates of exit to unsubsidised work, making them not viable as mainstream labour market programmes. In principle social enterprises, which employ people with reduced productivity in return for wage subsidies, should be encouraged to operate in competitive sectors of the economy and they can offer a wider range of work: but the requirement that they be partly self-financing would need to be enforced, and it would limit the number of places offered.

- $\quad$ The PRSI exemption scheme and BTWA are recruitment incentives paid to the employer and the worker respectively. Sharp restrictions on these schemes in 2003 were probably motivated by their growing cost in a context of falling levels of unemployment, doubts about their impact (i.e. a suspicion that many beneficiaries would have found work without the subsidy) and the emergence of cycling behaviour (loss of employment, followed by a new claim for passive benefits and re-entry to BTWA). Since 2003, access to BTWA has been partly eased, but a focus on the most disadvantaged should be maintained.

187. Arguably most statistical evaluations of ALMPs aim to define and measure impacts that are relevant for cost-benefit analysis, and potentially can support a recommendation to abolish the less-successful programmes. 


\section{DELSA/ELSA/WD/SEM(2009)01}

- FÁS' management of training centres, the status of its training instructors as FÁS employees, and the history of ESF funding and its replacement after 2000 by the National Training Fund, have given Ireland a strong training focus in its pattern of ALMP provision. Relatively short-term unemployed people can quite easily access skills training, and the longer-term unemployed are supported to participate even in third-level education. The strategic case for this training focus remains reasonably convincing, and the integration of placement and training functions in a single pubic institution has some advantages particularly for a smaller country where the private-sector offer of training may be relatively thin.

- Post-programme monitoring data demonstrate that some of Ireland's active labour market programmes have higher employment outcome rates than others, but participant profiles differ, and participation in some of the programmes is often followed by entry to other programmes, so the outcome data cannot easily support conclusions about the net impact of different programmes. The evaluation expertise developed in Ireland during the 1990s, related to an EU requirement for the evaluation of Structural Fund expenditure, was later dissipated and there has been little or no formal econometric evaluation of programmes in the 2000s. This is regrettable partly because modern statistical evaluations focus on hazard rates to ordinary employment, which are usually the most appropriate measure of programme outcomes. Government departments have continued to commission external reviews of key policy areas and instruments such as LES, BTWA, NEAP and CE, and to conduct occasional policy reviews within government. These probably give the best overall synthesis, but they remain resource-intensive. 
DELSA/ELSA/WD/SEM(2009)01

\begin{abstract}
ANNEX 5.A
The cost per participant-year of labour market programmes
\end{abstract}

334. Table 5.A.1 shows ratios of annual expenditure to participant stocks calculated from Panels A and B of Table 5.1. This Annex provides some technical remarks and analysis of the figures.

335. Readers should note that when total annual expenditure is divided by the average stock of participants, the result represents the average cost of the programme per participant-year, not cost per participant. For example a six-month training course with 100 places that are filled all year has total participant entrants and exits of 200 per year, but an annual average stock of 100 participants. If the programme costs EUR 500000 per year, its cost is EUR 5000 per participant-year. This is the type of figure shown in Table 5.A.1. The cost of the six-month course experienced by each individual participant, by contrast, is EUR 2500 .

336. In general, erratic year-to-year movements in Table 5.A.1 should be discounted since they may reflect the following factors:

- Annual expenditure data may relate to budgeted expenditure or to the time that payments were made to service providers: especially during the start-up or run-down phase of a programme, the year of actual service delivery can be different from the year under which expenditure is reported; and

- Although participant data would ideally report the annual average stock of programme participants, participants in some programmes are not registered on FÁS computer systems: participant information may be obtained through relatively ad hoc reporting and administrative surveys, and/or refer to a date that is not fully representative of the year as a whole.

337. If a programme appears to have high average cost in its start-up year (or when it is expanding rapidly) this might reflect the true situation (while buildings are being rented and equipped, and training manuals prepared, etc., costs per participant or participant-year will be high), but it might also reflect vagaries of timing of the expenditure data relative to the participant data (sources frequently do not specify the time frame for participant data). Thus, attention should be focused on cost per participant-year in years where spending and participant levels are fairly steady.

338. Reported expenditure levels are also influenced by the inclusion or exclusion of certain elements of expenditure. Over one third of expenditure on FÁS Specific Skills Training consists of "transfers to service providers", i.e. the cost of providing the training itself. ${ }^{188}$ By contrast, the reported expenditure on Back to Education Allowance includes only the costs of "transfers to individuals", not including the costs of administering the payments (administration costs for Back to Work and Back to Education allowances combined were probably about EUR 10 million in 2006: see the discussion of Table 2.3 above) nor the cost of providing second-level and third-level education, which are financed separately (not accounted for at all in Table 5.A.1).

188. The share was $36 \%$ in 2003, the last year in which the data for Specific Skills Training provided to Eurostat included the cost of FÁS training instructors (see the Eurostat publication for that expenditure year). 
Table 5.A.1. Expenditure per participant-year in labour market programmes, 1998-2006

Thousand euros per participant-year

\begin{tabular}{|c|c|c|c|c|c|c|c|c|c|}
\hline $\begin{array}{l}\text { Categor Measure Programme name } \\
y\end{array}$ & 1998 & 1999 & 2000 & 2001 & 2002 & 2003 & 2004 & 2005 & 2006 \\
\hline 1 Total PES and administration & & & & Not cal & ed for $\mathrm{C}$ & ry 1 & & & \\
\hline $\begin{array}{ll}\text { 2Mixed } & 51 \text { Specialist Training Providers } \\
\end{array}$ & .. & .. & .. & & 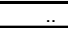 & 20.5 & 20.6 & 23.3 & 26.3 \\
\hline 2Mixed Subtotal & ... & ... &... & .. & ... & 20.5 & 20.6 & 23.3 & 26.3 \\
\hline $\begin{array}{ll}2.1 & 102 \mathrm{FA} S-\text { training staff costs }- \text { Cat } 2-1^{e}\end{array}$ & & & & & & & & & \\
\hline $\begin{array}{l}10 \text { Back to education allowance (BTEA) } \\
\text { VTOS (Vocational training opportunities }\end{array}$ & 4.6 & 5.6 & 6.9 & 7.5 & 7.0 & 6.7 & 8.4 & 9.1 & 9.2 \\
\hline 35 scheme) & 7.3 & 7.3 & 7.7 & 8.3 & 8.9 & 9.0 & 10.7 & 10.6 & 11.5 \\
\hline $16 \mathrm{ESF}$ training & 13.0 & 5.5 & - & - & - & - & - & - & - \\
\hline 20 Industry training & 9.5 & 9.6 & 12.6 & 15.0 & - & - & - & - & - \\
\hline 21 Local enterprise & 31.4 & 33.5 & 11.5 & 1.6 & - & - & - & - & - \\
\hline 38 Bridging Foundation & - & - & 15.5 & 14.5 & 11.8 & 29.4 & 8.1 & 10.3 & 15.7 \\
\hline 39 Specific Skills Training & - & - & - & - & 15.4 & 22.7 & 9.9 & 11.8 & 13.6 \\
\hline 43 Return to Work & - & - & - & - & 9.6 & 16.6 & 6.9 & 11.6 & 10.0 \\
\hline 2.1 Subtotal & 8.2 & 7.6 & 9.6 & 9.9 & 10.3 & 11.7 & 11.5 & 12.5 & 13.6 \\
\hline 42 Linked Work Experience & - & - & - & - & 7.7 & 9.6 & 6.0 & - & - \\
\hline 44 Job Training Scheme & _- & - & - & - & 3.7 & 6.0 & - & _- & _ \\
\hline 2.2 Subtotal & - & - & - & - & 5.6 & 7.5 & 6.0 & - & ב \\
\hline 103 FÁS - training staff costs - Cat $2.3^{f}$ & & & & & & & & & \\
\hline 24 Re-integration training & 3.7 & 5.0 & 9.3 & 11.5 & - & - & - & - & - \\
\hline $\begin{array}{l}25 \text { Community training } \\
\text { (Foundation/Progression in) Community }\end{array}$ & 9.1 & 9.5 & 10.3 & 10.7 & - & - & - & - & - \\
\hline $\begin{array}{l}41 \text { Training Centres/Workshops } \\
\text { Community Youth Training Programme/ }\end{array}$ & - & - & - & - & 14.7 & 18.0 & 14.3 & 16.0 & 17.6 \\
\hline 46 Community Training Programme & - & - & - & - & 14.5 & 5.6 & - & - & - \\
\hline 45 Local Training Initiative & - & - & - & - & 11.6 & 20.7 & 7.8 & 10.7 & 10.4 \\
\hline 34 Youthreach $^{g}$ & 9.1 & 9.1 & 6.6 & 11.6 & 12.3 & 14.0 & 15.7 & 16.6 & 18.1 \\
\hline 40 Traineeship & - & - & - & - & 12.3 & 19.7 & 8.4 & 10.9 & 13.4 \\
\hline 2.3 Subotal & 6.7 & 7.6 & 8.8 & 11.3 & 13.0 & 16.2 & 12.9 & 14.9 & 16.3 \\
\hline 2 Total Training & 8.8 & 8.5 & 10.5 & 11.5 & 12.6 & 13.7 & 12.6 & 14.1 & 15.5 \\
\hline $\begin{array}{ll}4.1 & 31 \text { Jobstart }\end{array}$ & 7.0 & 3.4 & 7.5 & 16.1 & - & - & - & - & - \\
\hline 32 Workplace & 15.0 & 1.1 & 1.5 & 1.0 & - & - & - & - & - \\
\hline 4 Back to work allowance ${ }^{h}$ & 3.5 & 3.6 & 3.8 & 3.6 & 5.2 & 5.7 & 5.7 & 6.0 & 6.8 \\
\hline 47 Social Economy Programme ${ }^{i}$ & - & - & - & - & 24.3 & 16.6 & 19.1 & 15.8 & - \\
\hline 5 PRSI Exemption scheme $e^{j}$ & - & - & - & - & - & - & - & - & - \\
\hline $\begin{array}{cc}4.1 & 7 \text { Part-time job incentive scheme } \\
\end{array}$ & 3.3 & 3.2 & 3.1 & 3.2 & 3.3 & 3.3 & 3.8 & 5.9 & 6.4 \\
\hline 4 Total Employment incentives ${ }^{k}$ & 3.7 & 3.5 & 3.6 & 3.3 & 5.4 & 6.6 & 7.0 & 7.4 & 6.7 \\
\hline $\begin{array}{cc}5.1 & 17 \text { Workplace/equipment grants }\end{array}$ & & & - & - & - & - & - & - & - \\
\hline 18 Employment support scheme & 4.0 & 4.3 & 3.1 & 5.4 & 6.0 & 6.9 & 6.4 & 6.0 & - \\
\hline 52 Supported Employment Scheme/Programme & - & - & - & - & - & 8.7 & 9.3 & 8.6 & 9.3 \\
\hline 54 Pilot Employment Programme & - & - & - & - & - & 11.4 & - & - & - \\
\hline $\begin{array}{cc}5.1 & 60 \text { Wage subsidy scheme } \\
\end{array}$ & - & - & - & - & - & - & - & 7.7 & 9.9 \\
\hline 5 Total Supported employment and rehabiliitation & 4.6 & 4.8 & 3.1 & 5.4 & 6.0 & 8.5 & 8.1 & 7.7 & 9.6 \\
\hline $\begin{array}{cc}6 & 23 \text { Community employment scheme }\end{array}$ & 9.8 & 11.3 & 11.2 & 12.1 & 13.8 & 14.5 & 11.9 & 13.1 & 14.6 \\
\hline $\begin{array}{cc}6 & 37 \text { Job Initiative } \\
\end{array}$ & - & - & 13.0 & 16.2 & 17.4 & 16.4 & 19.8 & 21.0 & 24.3 \\
\hline 6 Total Direct job creation & 9.8 & 11.3 & 11.4 & 12.4 & 14.1 & 14.7 & 12.5 & 13.6 & 15.2 \\
\hline $\begin{array}{cc}7 & 3 \text { Back to work enterprise allowance }(B W E A)^{\prime} \\
\end{array}$ & 6.0 & 7.4 & 7.9 & 14.8 & - & - & - & - & - \\
\hline 7 Total Start-up incentives ${ }^{m}$ & 6.0 & 7.4 & 7.9 & 14.8 & - & - & - & - & - \\
\hline $\begin{array}{ll}8.1 & 1 \text { Unemployment benefit }^{n}\end{array}$ & 4.8 & 4.5 & 4.6 & 5.0 & 5.8 & 6.0 & 6.5 & 6.7 & 7.4 \\
\hline 2 Unemployment assistance ${ }^{n}$ & 5.8 & 5.4 & 5.5 & 5.9 & 6.6 & 7.0 & 7.4 & 7.9 & 8.9 \\
\hline $\begin{array}{l}49 \text { Redundancy Payments } \\
50 \text { Insolvency Payments }\end{array}$ & .. & .. & .. & .. & .. & .. & .. & .. & .. \\
\hline 8 Total Out-of-work income support and maintenance & 5.6 & 5.3 & 5.3 & 5.8 & 6.6 & 7.1 & 8.0 & 8.4 & 9.4 \\
\hline $\begin{array}{cc}9.2 & 12 \text { Pre-retirement allowance } \\
\end{array}$ & 5.5 & 6.6 & 6.7 & 6.7 & 7.6 & 8.1 & 8.4 & 9.3 & 10.1 \\
\hline 9 Total Pre-retirement benefits & 5.5 & 6.6 & 6.7 & 6.7 & 7.6 & 8.1 & 8.4 & 9.3 & 10.1 \\
\hline Total 1-7 Active programmes total & & & & & & & & & \\
\hline Total 2-7 Active programmes except PES & 7.6 & 7.8 & 8.1 & 9.2 & 10.6 & 11.8 & 11.2 & 12.6 & 14.0 \\
\hline Total 8 and 9 Passive programmes & 5.6 & 5.3 & 5.4 & 5.8 & 6.7 & 7.2 & 8.0 & 8.5 & 9.5 \\
\hline
\end{tabular}

.. Not available.

- Measure ended or not started (expenditure and stocks are equal to 0 ).

See notes and source for Table 5.1 .

339. For another large measure, VTOS (Vocational training opportunities scheme), the reported expenditure does - according to the notes provided to Eurostat by national authorities - include some spending on "transfers to service providers" but the amount is not specified. There are 107 VTOS centres throughout Ireland which typically have several employees, but many of them are not working exclusively on the VTOS scheme. In this case, the amount of spending per participant-year shown in Table 5.A.1 is not very informative, since it might or might not include many millions of euros of expenditure on administering the payments to participants and implementing the training services delivered. 
340. Some features of the average costs in Table 5.A.1, and factors that might explain them, are:

- The average annual cost of unemployment compensation was EUR 7400 for Unemployment benefits and EUR 8900 for Unemployment assistance: Unemployment Assistance recipients more often receive supplements for adult and child dependents and probably less often have a reduced rate of payment due to earnings or assets (see also the table footnote about these participant data);

- The average annual cost of Back to Education Allowance (BTEA) was EUR 9200 which is somewhat higher than for either type of passive unemployment compensation. A likely factor is that BTEA is paid at a standard rate which is not means-tested (www.welfare.ie/publications/sw70.html): for people who were receiving a reduced rate of unemployment assistance, BTEA provides a higher income;

- Several programmes stand out as being relatively expensive: Specialist Training Providers for the disabled; the two job-creation programmes which offer full-time employment and pay a wage (Job Initiative and, until 2005, the Social Economy Programme); and the Youthreach and the Community Training Centres/Workshops programmes. Likely reasons for high average costs in these cases are discussed in the main text; and

- The average annual cost of FÁS' regular training programmes for the unemployed (Specific Skills Training, Bridging/Foundation and Traineeships), was intermediate (in the range of EUR 13000 to 16000 ) according to raw 2006 data. However, the inclusion of FÁS Training staff costs in the estimates could increase these figures by about $50 \%$. This would make FÁS Training on a full accounting basis considerably more expensive, per participant-year, than for example Community Employment. At the same time, the average duration of participation in programmes varies widely - four to six months for FÁS Training, about a year for CE and about three years for the Social Economy Programme according to 2005 Eurostat data: the large differences in programme duration are clearly the main influence on total cost per entrant or per programme completion.

Clearly the data should be interpreted with caution. There are some erratic year-to-year movements in reported spending per participant for reasons outlined above. But also the general level of expenditure per participant-year is influenced by the inclusion/non-inclusion of cost elements such as buildings, general administration staff costs (which in several cases relate to more than one programme), public service staff pension entitlements, participants' social insurance contributions (which may be counted as costs only when the programmes pay a wage), etc.

341. Some further information about programme costs is given in DETE (2005), which estimates the net cost of programmes as compared to the alternative of clients remaining on benefits. Again, due to the variety of schemes and institutions involved the cost data are not easily comparable across programmes. 


\section{CHAPTER 6}

\section{SUMMARY AND RECOMMENDATIONS}

\section{Overview}

342. The Irish labour market has been characterised by a dramatic turnaround in the 1990s. The economy doubled in size during that decade, and still achieved the fastest growth in the OECD area during the first half of the 2000s. As a result, GDP per capita has risen from well below the EU average to the third-highest in Europe (after Luxembourg and Norway). Some likely key contributing factors to this growth have been:

- A strategic approach to attracting and supporting foreign direct investment;

- Substantial funding from the European Community Structural Fund (CSF) in the 1990s, which supported investment in training and other labour market programmes as well as national infrastructure;

- A national commitment to raising education and training levels; and

- Efficient economic management in the context of national social partnerships agreements and a business-friendly regulatory environment.

343. Economic growth has been accompanied by a major improvement in labour market conditions since the mid-1990s. Together with Spain, Ireland's employment and labour force growth rates have been the highest in the OECD area; the employment rate is now above the OECD average, mainly due to more women entering the labour market. At the same time, survey unemployment declined from the very high levels of the 1980s (over 16\%) to a level of $4.5 \%$ of the labour force in 2007 , more than one percentage point below the OECD average. The share of long-term unemployment in total unemployment declined from two-thirds in 1990 to $30 \%$ in 2007, just above the OECD average.

344. However, vacancies and employment expectations in the construction sector fell sharply throughout 2007. In 2008 the economic slowdown spread through the economy and by November the Live Register, Ireland's administrative register of unemployment benefit and credit claimants, was 107000 $(66 \%)$ above levels a year earlier. A critical issue for Ireland's social and economic future is whether the labour market now enjoys a full cyclical recovery or returns to the persistently depressed conditions of the 1980s and 1990s. Recession overburdens all parts of the labour market policy administration, and negatively affects the programme outcomes, so it can be argued that this is not the right time to think of changing institutional arrangements or extend the target groups for activation measures. However, this report focuses mainly on structural and administrative factors which exert influence throughout the cycle. It contributes to policy debate, development and planning, which in any case sometimes take years before full roll-out in day-to-day operations, and are not less urgent now.

345. In the 1990s, a wide range of assistance was provided to the unemployed in terms of labour market programmes (e.g. in-work benefits, job-creation programmes, and training). However, it was generally possible to receive benefits without registration for placement or any other contact with 
employment services, or participation in active programmes. A requirement to register with FÁS, the Training and Employment Authority, was introduced for long-term unemployed youths in 1996. Activation principles were extended with the introduction of the National Employment Action Plan (NEAP) in 1998, which requires that after a certain number of months unemployed people must attend an interview to set up an individual action plan, which may include referral to a labour market programme. There is evidence that this shift towards activation, along with increased claim control activity by DSFA, substantially accelerated the fall in registered unemployment which previously had lagged behind economic expansion and the fall in survey-based unemployment. This was plausibly because - even though the activation requirements were less stringent than in many other countries - it was the first time that many of the unemployed had faced any such requirement.

346. Several institutions play an important role in implementing labour market policy in Ireland. The main government departments with responsibility for labour market policy are the Department of Enterprise, Trade and Employment (DETE) which supervises FÁS; and the Department of Social and Family Affairs (DSFA), which manages the social security system, including unemployment benefits. Ireland thus belongs to the minority of OECD countries where the placement function of the public employment service is separated from the benefit function. At the same time, several other publicly-financed institutions (detailed below) provide employment and related services such as information, counselling and emergency welfare assistance.

347. The number of staff in FÁS Employment Services (FÁS-ES) and the Local Employment Service, relative to the number of wage and salary earners in the economy, appears to be relatively low, about half the average level of staffing of institutions responsible for the placement function (without benefit administration) in Australia and Northern and Western Europe (other countries with a high rate of benefit coverage for unemployment). Funding for the PES as a whole (including benefit administration) as a percentage of GDP is also below the average for this group of countries, although it is comparable to the lower levels observed in countries such as Norway or Switzerland. Such statistics should be interpreted with care, because in Ireland some DSFA and LSDIP staff might be included in the count of placement and related staff, and public expenditure as a share of Gross National Income is higher than it is as a share of GDP.

348. Only a fairly limited proportion of FÁS-ES resources are devoted to the implementation of the NEAP, which continues to be the main form of quasi-compulsory face-to-face contact with an employment counsellor during a typical unemployment spell. In 2007, 70000 NEAP interviews (including second and later interviews with the same person) were conducted by FÁS Employment Service Officers (ESOs). But since the stock of recipients of unemployment payments was about 140000 , the average frequency of these interviews (which are quasi-compulsory in the sense that non-attendance leads to a "did not attend" notification to DSFA which will then re-examine benefit eligibility) averaged across all people on an unemployment payment was only about one every two years. People on unemployment payments must also sign on in person at their DSFA local office, usually once a month, and attend two eligibility review interviews by the $15^{\text {th }}$ month of unemployment, but these contacts have limited employment counselling content. In a number of other countries, the majority of unemployed people on benefit have a compulsory face-to-face contact with employment service staff once every two weeks (e.g. Portugal, Sweden and the United Kingdom) or once a month (e.g. France and Switzerland). A first general conclusion is that activation requirements for the unemployed should be greatly intensified. Experience from other countries suggests that a refocusing of existing resources could allow a marked increase in the frequency of face-to-face contacts with the unemployed. More complete implementation, which would also involve the development of some other types of intervention, would require an increase in PES resources on the placement and related side, particularly given the downturn. 
349. Probably related to the still-low intensity of availability and job-search requirements, unemployment benefit recipient numbers during the 2000s remained far higher than labour force survey unemployment. The difference between the two has fallen in recent years, probably reflecting the intensification of activation and benefit control activity. Nonetheless, it is still large and should be drastically reduced.

350. Given low levels of activation, one factor that limited benefit dependency levels in Ireland after the mid-1990s was a relatively low benefit replacement rate, with limited duration of the unemployment insurance benefit and means-testing of assistance benefits. But since most benefits are paid at the same basic rate, the authorities have not been under pressure to enforce strictly the eligibility conditions for individual benefits - such as the availability criteria for unemployment benefits and the medical criteria for incapacity benefits. Until the mid-1990s, unemployment payments had more recipients than lone-parent and incapacity benefits combined. However, from the early 1980s to 2000 recipiency rates for lone-parent benefits and a safety-net benefit (Supplementary Welfare Allowance) grew very rapidly. After 2000, these rates stabilized but recipiency rates for incapacity payments increased. By 2006, the number of people on these "inactive" benefits together was about $2 \frac{1}{2}$ times the number on unemployment payments. Means tests have been relaxed in recent years to facilitate part-time working while on benefit, but it seems unlikely that this affects the general picture (e.g. statistics relating to benefit-dependent individuals who report no work, if available, would show similar trends).

351. In 2002, the government pledged to raise the lowest adult social welfare rate, in 2002 terms, substantially by 2007 . The ratio of this lowest rate to average earnings may now be even $30 \%$ higher than it was in 2000. This could have significant implications for activation policies, because international comparisons suggest that countries where net benefit replacement rates are high (e.g. around $80 \%$, for people on slightly-below average earnings when in work, such as Denmark, Finland and the Netherlands) spend far more on both active and passive labour market programmes. The commitment to maintain social welfare rates at a higher level is another reason that Ireland now needs to develop stronger activation measures. This will require difficult adjustments: not only an increase in PES resources, but also a shift towards a more coercive approach, which currently has few active advocates within the social partnership process. This social partnership process has secured agreement for funding an "Activation Programme" implemented by DSFA, but in practice this involves no requirements to participate for any particular target group and only increases the supply of counselling services. In the history of other (mainly European) countries, intensive activation measures have often been adopted only after long years of high unemployment. Ireland needs to avoid this scenario, promoting greater public understanding of the underlying issues so that sufficient support and consensus around effective measures can arise without this. This will not be an easy task and will require a strong political commitment at the highest level.

\section{Institutions}

352. Public financing for employment services in Ireland is dispersed across a number of institutions. The main publicly-financed services are:

- FÁS-ES counselling/guidance services (about EUR 40 million per year in 2006; FÁS labour market programme management costs probably as much again);

- The Local Employment Service (LES; about EUR 20 million per year);

- $\quad$ The Services for the Unemployed programme (about EUR 20-25 million per year from 2000 to 2006) under the Local Development Social Inclusion Programme (LDSIP); and 
- DSFA employment services, which include not only the staff costs of Facilitators, but also other functions such as eligibility and job-search reviews with unemployed clients, the implementation of NEAP, and benefit sanctions and appeals related to availability/job search (these functions represent a significant proportion of total expenditure on unemployment benefit administration, which is estimated at about EUR 80 million in 2006).

353. These figures indicate that FÁS-ES receive less than half the total funding devoted to placement and employment counselling services in Ireland. Arguably most other OECD countries concentrate most of the resources available for these functions in one national employment service (or one employment service for each region, in federal countries), and none split the funding across different institutions to the extent that Ireland does. As a rule, providing basic job-matching services and high-quality assistance to voluntary and self-presenting callers should be the first call on employment service resources, and FÁS-ES offer automatic caseloading to disabled clients (see below). With these commitments and under the current structure of staffing and funding, FÁS-ES alone could not handle frequent visits by all registered unemployed, or greatly increase the volume of its intensive interviews and caseload work.

354. LES activities are focused on the long-term unemployed and other disadvantaged groups, but have hardly any activation content in terms of making benefit payments conditional on work-related activity. Given the relatively large size of the LES (with more than half the staff of FÁS-ES), and the requirements laid down in the Funding Agreements negotiated with FÁS, it puts significant resources also into outreach activities - attempting to persuade people to use its services on a voluntary basis, and thus potentially providing services also to people on inactive benefits or no benefit. An interesting comparison is with the role played by the Personal Support Program (PSP) in Australia. Unemployed people whose immediate employability is particularly limited are referred to this programme, rather than to a Job Network (subcontracted employment service) provider. However, in Australia PSP clients must attend regular meetings, and PSP service providers (selected by competitive tender) are expected to implement this requirement and are paid a fee for each employment outcome they achieve. In Ireland, FÁS refers to the LES some clients who are identified in the NEAP process as having relevant needs. But the LES needs to adopt NEAP-like procedures, i.e. require a defined group of the clients on benefits (identified from administrative registers, or referred by FÁS) to attend - with referral to DSFA for a possible sanction in cases of non-attendance, under current institutional arrangements - in order to increase its impact in terms of activation.

355. Another feature of PES structure in Ireland is that FÁS manages a range of activities, such as training of unemployed, apprentices and adult employed workers in its own training centres and by outside providers, as well as job-creation programmes and "local training initiatives" that provide local services. This range arguably gives FÁS as an organisation a particularly broad understanding of socio-economic issues, ranging from the skill needs of large and small businesses to the problems of drug rehabilitees, remote villages or inner-city housing estates. FÁS management of the training function seems sound: since FÁS also purchases training from outside providers, it is well placed to arbitrage between internal and external provision, although an external audit of this might be useful.

356. FÁS' involvement in running direct job creation schemes, such as Community Employment (CE) and some other initiatives, is perhaps more problematic. The status of FÁS ESOs as permanent civil servants helps them to represent national labour market policy interests. Nevertheless, in implementing job-creation programmes they work closely with local actors and voluntary organisations. More armslength contracting arrangements - again comparable to those for an Australian measure, "Work for the Dole", under which service providers are contracted to manage projects on a commercial basis - might be necessary if job-creation programmes are to be managed as activation measures, with compulsory referrals of clients to them being possible. 
357. Apart from the job counselling practiced at FÁS and LES, the benefit administration DSFA also has employment counsellors, called Facilitators: this is fairly unusual in international terms. Again there are some advantages with current arrangements, where a national benefit agency keeps the unemployment benefit administration to itself and even operates some employment services of its own, e.g. when DSFA works with disadvantaged customers, it can consider the possibility of transferring them to an incapacity payment, alongside possible employment service options. DSFA's job-search reviews, employment counselling and NEAP referral functions give it some employment service perspective, which arguably is not always the case for unemployment benefit administrations that have no employment service function. Overall, DSFA and FÁS have a degree of common understanding of client management issues including the need for activation of employable clients, but it needs to be further improved.

358. However, in general employment counsellors should be located in the placement service, so that direct referral to a job vacancy can always be the first option considered in a counselling relationship. OECD traditionally has recommended integration of the placement function with the unemployment benefit administration function. Such a first-best reform could involve DSFA devolving at least most of its client contact functions for the unemployed (taking claim details insofar as this requires face-to-face contact and monthly signing-on, as well job-search monitoring and employment counselling) to a network of much-expanded employment service offices. If Ireland does not opt for the integration of jobcounselling functions including those related to benefit eligibility in the placement service, one alternative could be for relevant DSFA staff - those involved in client profiling or job-search review interviews, as well as Facilitators - to use the same IT system as FÁS-ES for recording and recovering counselling information, although they might still have to refer clients to FÁS counsellors to make direct job referrals.

359. It is also true that if FÁS-ES, LES and LDSIP employment services were integrated into a single service focused on activation, with activities closely co-ordinated with those of DSFA, the frequency of compulsory placement-focused contacts with the registered unemployed could be significantly increased. Co-operation agreements between separate institutions might allow this in theory but seem unlikely to be fully effective in practice. However, activation measures are likely to be highly cost-effective through their impact on unemployment and related payments, and should be adopted one way or another.

360. Other institutions relevant for activation policies in Ireland include the Health and Safety Executive (HSE) in its role in issuing medical cards and managing Supplementary Welfare Allowance (SWA) basic payments and rent supplements. These can weaken the impact of benefit sanctions on DSFA beneficiaries (SWA can be paid pending the outcome of an appeal against a sanction) and can generate high replacement rates (covering high rent or mortgage commitments for people out of work). They also involve duplication of administrative functions, particularly means assessment. Successive audits have concluded that the administration of SWA should be transferred to DSFA and delivered from its local/branch offices, although SWA staff opposition has until now prevented this. It has also proven difficult to implement the decentralisation of lone-parent benefit administration within DSFA, a change decided in 2000, although the proportion of this client group being handled locally continues to progress. DSFA staff management issues seem to absorb some of the energy that should be going into substantive policy evaluation and reform agendas, such as the activation of lone-parent and disability payments. Government needs to manage its own institutions more effectively while, in a context of good human resource management practices, staff accept the government's right to manage, reforming institutions and procedures if necessary.

\section{The placement function}

361. Several publicly-funded services already mentioned, as well as Congress Centres (managed by the Irish Congress of Trade Unions, but staffed mainly by CE participants) and Ireland's 700 Community Welfare Officers (CWOs), can provide employment services, including advice on benefit entitlements 
(which FÁS-ES tends not to do). However, client information or direct referrals that actually lead Irish citizens into jobs or entry to labour-market programmes probably come primarily from FÁS-ES, and only secondarily from the LES and DSFA Facilitators (in the case of the BTWA/BTEA programmes). It is not clear that the "local" services, i.e. LDSIP and the LES, deliver such employment services in proportion to their relative funding level which is substantial. This might be related to their originally ad hoc organisation, (relative) lack of national supporting infrastructure, and limited geographical coverage as implied by their "local" nature, and not only client-group disadvantage. Individual LES services are fairly small units whose efficiency is likely to vary, but currently efficiency is not very directly promoted either by direct line-management arrangements (the LES are centrally funded at fifth hand, i.e. funds are transferred from the Ministry of Finance to DETE to FÁS to Area Partnership Companies and finally to the LES) or by performance management mechanisms (LES reporting of placement outcomes is not tightly supervised and there are no procedures to regularly replace the least efficient "providers"). One of these management mechanisms is arguably needed to focus services on an objective of achieving measurable outcomes for long-term benefit recipients, which is an important element in an activation strategy.

362. DSFA recommends that unemployed clients register with FÁS after a month, and takes this into account in its later assessments of the genuinely-seeking-work requirement. However, FÁS-ES does not then require any particular action before participation in the NEAP process. This occurred after six months of unemployment until October 2006, when the threshold was advanced to three months: but with limited resources and in 2008 increasing unemployment inflows, it is doubtful whether the more-advanced threshold can be effectively implemented. The individual plans established in the NEAP process often involve referral to a labour market programme, but few, if any, other countries have a systematic procedure for making referrals to a labour market programme so early in the unemployment spell. Since even an effective and motivated job-seeker may sometimes take several months to find the right job match, automatic referral to a labour market programme after three months would be premature. Against this background, it might be cheaper and no less effective to provide only a lighter counselling session reviewing job-search efforts to date, and presenting vacancies - at three months, and initiate a more complete action plan procedure only for those still unemployed after six months.

363. The number of people who participate in NEAP but exit the process with a 'no present action' status has been increasing since 2005. It is important to monitor the proportion of people placed in this category and develop a follow-up strategy. In principle, the more marginalized individuals may now be assisted through intensive case management within the "High Supports Process", but the size of this initiative only allows it to handle a small proportion of clients.

364. Under the regular NEAP procedure, the same person is not referred a second time however long he/she is unemployed. This implies that FÁS-ES almost never calls the very long-term unemployed or individuals in a second or subsequent spell of unemployment (after a spell where NEAP was implemented) to interview (DSFA and FÁS have engaged occasionally in a re-referral procedure for the long-term unemployed and envisaged its extension, but this seems to be rare). An activation strategy needs to include these client groups as well. This does not necessarily imply that repeat participation in the NEAP should be scheduled: some countries have tried to create additional and different activation measures, e.g. referral to a private service provider as an alternative to repeat participation in the UK "New Deal for Young People".

365. In 2007, about $30 \%$ of ESO time was devoted to NEAP processes, and about $40 \%$ to support for non-caseload (e.g. walk-in) clients and to employer contact and vacancy matching. FÁS handling of vacancies appears to be now highly efficient thanks to the processing of notifications via the National Contact Centre, while the significant increase in FÁS market share suggests that the centralisation and automation of this function has increased the quality of service for users. It can also be noted that since the abolition of the National Rehabilitation Board in 2000, FÁS automatically puts disabled callers on caseload, implying individual counselling and regular reviews of progress with key events entered into the 
IT system. About a quarter of FÁS "caseload" interviews in 2007 were with non-NEAP client groups, probably many of them disabled. In the case of FÁS-ES, the basic employment service functions cut significantly into the time available for activation measures such as NEAP, and this time may have been squeezed further during 2008 with the recent rise in unemployment.

\section{Unemployment and related benefits}

366. The OECD's Reassessed Jobs Strategy (OECD, 2006a; and 2006b) documented that, according to the majority of studies, benefit generosity has quite a strong impact on the level and persistence of unemployment. It emphasised the need for unemployment benefits to be set at moderate levels and, especially where they are relatively generous, be made conditional on work-availability criteria and "activation" measures. In the early 2000s, unemployment benefits in Ireland were in line with the Jobs Strategy recommendations. However (as already mentioned in the Overview above) there has been a sharp increase in benefit levels since then which raises the risk of persistent high unemployment unless administration becomes more effective.

367. Ireland probably has made quite significant progress in the area of benefit conditionality over the past decade in terms of controlling benefit fraud. But the obligations associated with an unemployment benefit claim remain relatively weak, and not only because of the limited coverage of the NEAP process. Two other factors are:

- Ireland still uses a monthly "signing-on" procedure: many other countries have abandoned this approach in favour of contacts that have placement content. Job-search monitoring takes place at most through occasional retrospective interviews. There is no measure in Ireland comparable to the Job Seeker Diary in Australia, or regular reporting of job search to the placement service in the United Kingdom.

- Although Ireland has high spending on job-creation programmes, benefit entitlements are not made conditional on participation in them. This possibility exists in other countries, such as within Australia's Mutual Obligation strategy, the UK New Deal strategy, and in various ways in many other European countries.

368. Ireland is in the small group of countries where the rates of sanction decision for refusal of work and for refusal of a place on an active labour market programme (ALMP) are well below 0.1\% per unemployed person per year. These sanction rates are many times below the median rates in the available international data. The rate of sanctions for availability and job-search-related reasons in Ireland is not adequately reported, but it does not appear to be particularly low: this type of sanction is probably generated by the DSFA client interviews scheduled after 7 months of unemployment and again at 12 or 15 months. This pattern is evidence that FÁS rarely makes compulsory referrals of clients to job vacancies or to labour market programmes, even within the NEAP framework. A relevant recommendation is that employment service procedures and referrals should play a much greater and more direct role in the assessment of clients' eligibility for unemployment benefits: the DSFA assessment of availability based on the client's general circumstances should, as unemployment continues, be backed up by more concrete checks on willingness to apply for and accept jobs that the employment service is able to propose.

369. Ireland now needs also to "activate" recipients of its "inactive" benefits. Around 2005, FÁS piloted voluntary initiatives to engage lone-parents and disabled people in employment services, but it had to devote a lot of resources to outreach measures - attempting to persuade the target group to attend information sessions - with only limited success. Probably most of these benefit recipients in Ireland are aware that employment services are available, and have chosen not to avail of them for various reasons. In the United Kingdom, contracted providers paid by results have had some success in terms of attracting lone 
parents and, to a more limited extent, disabled clients to use their services on a voluntary basis, and they could be invited to set up a few operations in Ireland. However, fully systematic engagement with those on inactive benefits involves making the benefits conditional on participation in employment services, which probably implies also making them conditional on availability for work for certain client groups currently receiving them.

- For lone parents, Ireland some years ago introduced generous benefit disregards (i.e. part-time working while on benefit was made financially attractive) and made it easier to enter attractive ALMPs. The strategy of making part-time work (or ALMP participation) more attractive relative to no-work situations has probably reached its limits, because it at the same time makes full-time work - in which people do not depend on benefits at all - less attractive relative to part-time work. The government, in a 2006 Green Paper, proposed transferring lone parents to Jobseekers' Allowance when their youngest child reached a certain age, e.g. seven years. DSFA is continuing work on identifying barriers to training and employment, but major reform depends on additional supports and services from other Departments and Agencies (such as FÁS-ES). While this situation continues, lone parents in Ireland escape work requirements until their youngest child is aged 18 or 22, making Ireland a sharp outlier in international comparisons. Once child-care and employment services are resourced and managed similarly to other countries, there will be no case for not activating lone parents.

- In the case of incapacity benefits, requirements (the person may be required to be available for part-time work, or for full-time work in a limited number of occupations or with a permanent wage subsidy or other assistance provided) can only be imposed on a subgroup of the caseload that has significant remaining work capacity. An investment in gatekeeping procedures, to provide reasonably uniform assessment of remaining work capacity, is probably necessary before this approach can be implemented systematically. Sickness, Disability and Work: Breaking the Barriers, Volume 3 (OECD, 2008) reviews these and a range of other issues for Ireland.

370. Ireland should proceed with reforms to the main inactive benefits along these lines, but as part of a coherent strategy. Priority should be given to intensifying activation measures for the unemployed, so that it becomes more difficult for relatively-employable people to stay long-term on unemployment benefit. Policy reforms that extend benefit conditionality to a large group on lone-parent or incapacity benefits can even be counterproductive if they transfer limited placement service resources away from more-employable people, and as a result even this group is less-effectively activated.

371. Ireland's safety-net benefit, the SWA, is exceptional (and possibly unique) internationally in terms of its delivery structure, offering the service from over 1000 locations, many of them manned for as little as half an hour or an hour per week. Although there are now plans for transferring its administration to DSFA, this transfer in itself may not reduce the benefit's recipiency rate, which at about $1 \%$ of the working-age population is exceptionally high for a "safety-net" assistance benefit. SWA covers a number of functional areas, apart from exceptional needs payments: last-resort support for asylum seekers; "sick no benefit" situations; interim payments while an initial benefit application is being processed; emergency payments (probably only in selected cases) to people on a benefit sanction; and subsidisation of the housing costs of people on minimum income assistance benefits. However, the de facto entitlements to benefit in such situations appear to reflect custom and precedents from discretionary decisions on individual claims (or in some cases, assessments by the administrative appeal body). The treatment of each situation should preferably be redefined after a policy review that considers incentives and related service provision, etc. In several situations, SWA coverage could be replaced by more specific arrangements: SWA housing supplement is currently being partially reformed alone these lines. Similar to accurate gatekeeping for incapacity benefits, tight administration of other benefits contributes to the effectiveness of activation policies. 


\section{Active labour market programmes}

372. Ireland's low resourcing of placement services is not matched by low levels of overall spending on other active labour market programmes (ALMPs). Ireland spent $0.49 \%$ of GDP on these other ALMPs in 2006, far higher than the average percentage for Australia, New Zealand and the United Kingdom $(0.15 \%$ of GDP) and close to the level for European countries with high benefit coverage mentioned above $(0.64 \%$ of GDP).

373. Active labour market programmes in Ireland have a strong focus on i) vocational training, and ii) direct job creation. There are several types of FÁS vocational training for the unemployed, as well as two measures (BTEA and VTOS) providing income support for unemployed people who enter other types of long-term education and training. Even programmes for disadvantaged groups are described as "foundation" or "bridging", i.e. preparation for subsequent entry to vocational training. Even if this training provision is not particularly successful as a strategy for keeping unemployment low, it is probably successful in terms of using unemployment spells productively, improving skill levels in the labour force and allowing the more motivated and resourceful unemployed to find better and more stable jobs than they might otherwise have done. Nordic countries and some Western European countries provide examples of activation strategies with a strong training component, fairly different from the strategies of Australia or the United Kingdom. The adoption of more intensive activation measures does not need to imply any reduction in the training function, unless that is dictated by budgetary considerations.

374. Ireland's Community Employment (CE) job-creation programme in the 1990s was successful in terms of providing an alternative to continuing passive unemployment benefits, while also offering local services that would otherwise be lacking. Arguably the broad outlines of the initial scaling-up of CE in 1994 and its incomplete scaling down in the early 2000s have been determined largely at political level, while policy experts in DETE and FÁS have striven to maximise its effectiveness as a labour market programme. CE now functions for some participants as low-paid public-sector employment (ring-fenced jobs in the health sector), sheltered employment (for the growing share of disabled participants), or a form of active early retirement (in the case of long-term participation by older workers). At the same time, participants aged under 35 are only allowed to enter the "integration" option, limited to one year, after which in principle if market work is not found they are expected to enter a formal training measure.

375. During the late 1990s, CE participant numbers of about 40000 , represented about $3 \%$ of total employment. In the 2000s they were reduced to about 20000 , which is still about $1 \%$ of employment, and costs more than the whole of LMP Category 1 (Public Employment Service and administration, including benefit administration). Even allowing for the diversity of CE, Ireland should have scaled it back further during the long period of low unemployment, when its participants could more easily find regular jobs. And individuals and local governments should, so far as possible, decide whether to purchase services such as crèches or maintenance of the local environment based on prices that reflect cost and not CE provision which, at local level, can only be very erratic.

376. Ireland's experience with two other programmes, Job Initiative and the Social Economy Programme, illustrates why labour market programmes that create full-time jobs paying an ordinary wage are usually not viable policy options. They are expensive in terms of cost per participant-year; owing to the full-time and ordinary-wage nature of the jobs, rates of voluntary exit to unsubsidised work are low, and politicians may cede to pressures to make the jobs permanent; programmes then have to be closed to new entrants and, although their budgetary costs continue, cease to function as instruments of labour market policy.

377. Ireland should consider two different models of job creation or subsidised employment. As an activation measure, Australia contracts with providers (often non-profit organisations) to run Work-for-the-Dole projects, which helps to implement a broader Mutual Obligations strategy because referrals 
can be compulsory. Also, the take-up of subsidies for employing very long-term unemployed and partlydisabled people should be increased. This approach offers different types of work as compared with CE and ensures that people with reduced work capacity are using it in the most productive way. It can support enterprises specialised in rehabilitation, along the lines of Social Enterprises in Finland. However, wage subsidisation has to remain partial, with the rest of the wage being covered by commercial operations, avoiding calls for the creation of completely subsidised permanent jobs, even for disadvantaged target groups.

\section{Box 6.1. Summary of main recommendations}

\section{Overview}

- Activation measures for the unemployed should be greatly intensified. Experience from other countries suggests that a refocusing of existing resources could allow a marked increase in the frequency of face-toface contacts with the unemployed. More complete implementation, which would also involve the development of some other types of intervention, would require an increase in total PES resources, particularly given the downturn.

- Efforts should be made to increase the recognition among participants in the social partnership process of the importance of activation measures as part of a comprehensive strategy to reduce unemployment and benefit dependency and increase employment.

\section{Institutions and administration}

- $\quad$ Placement and counselling institutions, currently split across three departments (DETE, DSFA and DCRGA) and four funding channels (FÁS Employment Services and LES are separated), need to be integrated to ensure that employment services, after integration, have enough resources to engage with unemployed clients systematically and not only with those who self-present.

- The placement and benefit administration functions should be integrated: DSFA could devolve its client contact functions to a much expanded network of employment service offices, responsible for taking claim details (insofar as this still needs in-person contact), monthly signing-on and most initial sanction decisions (or submissions to DSFA decision officers) related to labour market behaviour, as well job-search monitoring, employment counselling and job-broking. One less-optimal alternative could be for relevant DSFA staff - those involved in client profiling or job-search review interviews, as well as Facilitators - to use the same IT system as FÁS-ES for recording employment counselling information, though they might still have to refer clients to FÁS counsellors to make direct job referrals.

- In the field of benefit administration, the implementation of reforms already announced should be more rapid.

- $\quad$ LES management remains relatively decentralised and either direct line management or performance management principles should be strengthened. This would achieve further real integration of what is already described as the National Employment Service, encompassing FÁS-ES and the LES.

- More arms-length contracting arrangements might be necessary if job-creation programmes (currently micro-managed by FÁS staff) are to be managed as activation measures with compulsory referrals of clients to them being possible.

\section{NEAP process}

- The provision of high-quality assistance to voluntary and self-presenting callers should be the first call on employment service resources. But it should not be allowed to squeeze the time available for activation measures, such as NEAP.

- The NEAP intervention strategy could be revised so that clients participate initially in a lighter counselling session, with an individual action plan to be established at the six-month point.

Activation strategies should be developed for people who were left in the "no present action" category at the end of the NEAP process, and for those who have participated once (currently this group is not usually referred again, in cases of prolonged or repeat unemployment). 


\section{Local Employment Service processes}

- The Local Employment Service should also apply activation requirements to at least some client groups, implementing a NEAP-like process with referral to DSFA for a possible sanction in cases of non-attendance at scheduled interviews.

\section{Unemployment benefit administration}

- Ireland currently uses a monthly "signing-on" procedure for unemployment benefits, and the benefit agency reviews job-search activity through occasional retrospective interviews. Employment service procedures and referrals should play a greater role in the assessment of clients' eligibility for unemployment benefits.

- The possibility of making benefits conditional on participation in job-creation programmes should be introduced.

\section{Inactive benefits}

- Ireland needs also to introduce activation requirements for the recipients of its "inactive" benefits.

- $\quad$ Contracted providers paid by results have had some success in terms of attracting lone parents and, to a more limited extent, disabled clients to use their services on a voluntary basis in other countries. They could be invited to set up a few operations in Ireland.

- There should be an investment in disability gatekeeping procedures that provide a reasonably uniform assessment of clients' remaining work capacity, as well as investment in child-care facilities to prepare for transferring many lone parents to Jobseekers' Allowance.

- Attention should be paid to the sequencing of activation requirements for those on unemployment benefits and those on "inactive" benefits. If resources remain limited, as at present, it would be important to strengthen activation measures and actually reduce benefit dependency among the relatively more-employable people currently on unemployment benefits, before giving the employment service responsibility for activating "inactive" benefit recipients who are likely to be harder to place. Benefits that are currently inactive should then be made conditional on availability for work, for certain client groups.

- The current set of de facto entitlements to Supplementary Welfare Allowance, based on precedent and discretionary decisions in individual cases, should be redefined based on policy reviews that take incentive effects, related service provision, etc. adequately into account.

\section{Active labour market programmes}

- Ireland's levels of spending on vocational training measures for the unemployed should be maintained.

- The existing Community Employment (CE) programme should not be expanded greatly, even if unemployment increases as a result of the weaker economic conditions, partly because it was not downsized enough during the years of low unemployment.

Two different models could be considered for job-creation programmes, i.e. Australia's Work for the Dole, and an expansion of subsidised employment for highly disadvantaged groups but subject to a strict requirement that wage subsidisation remains partial, with the rest of wage costs being covered by commercial operations, along the lines of Finland's Social Enterprises. 


\section{BIBLIOGRAPHY}

Bell, K., M. Brewer and D. Phillips (2007), "Lone parents and 'mini-jobs"”, Joseph Rowntree Foundation (www.jrf.org.uk).

Boyle, N. (2004), “Consensus and Institutional Capacity in Irish Policymaking: the 'Irish Model' and active labor market policy 1987-2004", paper for 2nd Pan-European Conference on EU Politics, June 24-26 2004, Bologna, Italy.

Boyle, N. (2005), FÁS and Active Labour Market Policy, 1985-2004, Trinity College, Dublin, Studies in Public Policy No. 17 (www.policyinstitute.tcd.ie/publications.php).

Boyle, R. (2005), "Evaluation Capacity Development in the Republic of Ireland”, ECD Working Paper No. 14, World Bank Operations Evaluation Department (www.worldbank.org/oed/ecd).

Boyle, R. (2006), "Cross Departmental Expenditure Reviews: Lessons from the Pilot Exercises", Committee for Public Management Research (CPMR) Discussion Paper No. 34, Institute of Public Administration (www.ipa.ie).

Buck, S. and K. McGinn (2005), "Initial Vocational Education and Training in Ireland: Draft report prepared by FÁS on behalf of Cedefop in accordance with Cedefop guidelines" (www.fas.ie/en/pubdocs/InitialVocationalEducationTraining2005.pdf).

Carcillo, S. and D. Grubb (2006), "From Inactivity to Work: The Role of Active Labour Market Policies", Social, Employment and Migration Working Paper No. 36 (www.oecd.org/els/workingpapers).

Central Statistics Office, Database Direct, www.cso.ie/statistics/LabourForce.htm, Ireland.

CIB (Citizens' Information Board) (2008), "Entitlements for people with disabilities", Twelfth edition (www.citizensinformationboard.ie).

Comhairle (2003), "Becoming Unemployed", Relate, Vol. 30, No. 11, August (http://citizen.ie/publications/relate/august2003.pdf).

Corcoran, T. (2002), "Retrospective analysis of referral under the Employment Action Plan (EAP)", FÁS, February, mimeo.

Dáil Éireann (1999), Adjournment Debate. - Job Initiative, Vol. 510, 11 November (http://historicaldebates.oireachtas.ie/en.toc.dail.html).

Dáil Éireann (2000), Written Answers - Community Employment Schemes, Vol. 516, 23 March (http://historical-debates.oireachtas.ie/en.toc.dail.html).

Dáil Éireann (2004a), Written Answers - Community Employment, Vol. 591, 2 November.

Dáil Éireann (2004b), Written Answers - Social Welfare Benefits, Vol. 592, 9 November. 
Dáil Éireann (2006a), Priority Questions. - Social Welfare Benefits, Vol. 614, 9 February.

Dáil Éireann (2006b), Written Answers - Community Employment Schemes, Vol. 628, 5 December.

Dáil Éireann (2007), Written Answers - Community Employment Schemes, Vol. 632, 28 February.

Deloitte and Touche (1998), Final Report Review of Community Employment Programme, September (www.entemp.ie/publications/labour/1998/communityemployment/index.htm).

Department of the Taoiseach (2005), National Reform Programme: Ireland, Submission to the European Commission responding to the Integrated Guidelines for Growth and Jobs agreed by the European Council under the Lisbon Agenda (www.taoiseach.gov.ie - publications).

Department of the Taoiseach (2006), Towards 2016: Ten-Year Framework Social Partnership Agreement 2006-2015, Dublin, The Stationery Office.

Department of the Taoiseach (2007), An Agreed Programme for Government: June 2007.

DETE (Department of Enterprise, Trade and Employment) (2000), "Ireland: Employment and Human Resources Development Operational Programme 2000-2006", September.

DETE (2001), Annual Report 2000, Dublin: The Stationery Office (www.entemp.ie - publications).

DETE (2004a), National Employment Action Plan 2004: Ireland (www.entemp.ie/publications/labour/2004/employmentactionplan.pdf).

DETE (2004b), "First Report on the Implementation of the Revised European Social Charter of the Council of Europe" (www.entemp.ielemployment/ilo_councilofeurope).

DETE (2004-2008) "Tackling youth unemployment and preventing long-term unemployment", Employment Action Plan, Monthly Progress Report”, No. 112, January 2008; No. 100, January 2007; No. 88, January 2006; No. 76, January 2005; No. 64, January 2004.

DETE (2005a), Annual Report 2004, Dublin: The Stationery Office.

DETE (2005b), Cross Departmental Expenditure Review of Supports for the Long-term unemployed 1998-2003", mimeo.

DETE (2007a), Annual Report 2006, Dublin: The Stationery Office.

DETE (2007b), Annual Output Statement 2007, Dublin: The Stationery Office.

DETE (2007c), Agreed Programme for Government Progress Report April 2007, Dublin.

DEWR (Department of Employment and Workplace Relations) (2007), Annual Report 2006-7 (www.dewr.gov.au/dewr/Publications/AnnualReports/).

DFCSIA (Department of Families, Community Services and Indigenous Affairs) (2006), "Statistical Paper No. 3: Income Support Customers: a Statistical Overview 2004"

(www.facsia.gov.au/internet/facsinternet.nsf/research/stps-nav.htm). 
DoF (1998), “Tax Strategy Group TSG 98/21: Employment Schemes” (www.finance.gov.ie - Policy Areas \& Publications - Tax Strategy Group).

DoHC (Department of Health and Children) (2006), Core Functions of the Health Service Report (www.dohc.ie/publications/core functions.html).

DSCFA (Department of Social, Community and Family Affairs) (1999), Review of Expenditure Programmes: Back to Work Allowance Scheme (www.welfare.ie/EN/Publications/exp_rev/Pages/index.aspx).

DSCFA (2000), Review of the One-Parent Family Payment Scheme (www.welfare.ie/EN/Publications/exp_rev/Pages/index.aspx).

DSCFA (2002), Building an Inclusive Society: Review of the National Anti-Poverty Strategy (www.welfare.ie/EN/Publications/naps/Pages/index.aspx).

DSFA (Department of Social and Family Affairs) (2003), 2002 Statistical Information on Social Welfare Services (www.welfare.ie/EN/Publications/annstats/Pages/index.aspx).

DSFA (2004), Review of the Supplementary Welfare Allowance Scheme: Phase 1 Report (www.welfare.ie/EN/Publications/exp_rev/Pages/index.aspx).

DSFA (2005a), Statement of Strategy 2005-2007, Dublin (www.welfare.ie/EN/Publications/strategy/Pages/index.aspx).

DSFA (2005b), Report of the Working Group on the Review of the Back to Education Allowance (BTEA) Scheme (www.welfare.ie/EN/Publications/exp_rev/Pages/index.aspx).

DSFA (2006a), Government Discussion Paper: Proposals for Supporting Lone Parents, Dublin: DSFA Family Affairs Unit (www.welfare.ie/EN/Publications/exp_rev/Pages/index.aspx).

DSFA (2006b), Review of the Supplementary Welfare Allowance Scheme: Phase II Report (www.welfare.ie/EN/Publications/exp_rev/Pages/index.aspx).

DSFA (2007a), Annual Report 2006 (www.welfare.ie/EN/Policy/Pages/policyandlegislation.aspx).

DSFA (2007b), Annual Output Statement 2007, Dublin (www.welfare.ie/EN/Policy/Pages/policyandlegislation.aspx).

DSFA (2007c), Statistical Information on Social Welfare Services 2006 (www.welfare.ie/EN/Publications/annstats/Pages/index.aspx).

DSFA (2008a), Annual Report 2007, Dublin (www.welfare.ie/EN/Policy/Pages/policyandlegislation.aspx).

DSFA (2008b), Statement of Strategy 2008 - 2010 (www.welfare.ie/EN/Publications/strategy/Pages/index.aspx).

DSW (Department of Social Welfare) (1996), Inter-Departmental Report On The Development Of An Integrated Social Services System (www.welfare.ie/EN/Policy/CorporatePublications/StrategicPlansAndReports/Pages/isss.aspx). 
DWP (2008), "Quarterly Statistical Summary, May 2008" (www.dwp.gov.uk/asd/statistical_summaries.asp).

EAPN (European Anti-Poverty Network) (2007), “Developing Positive Activation”, Briefing Paper (www.eapn.ie/documents/48_Developing\%20Positive\%20Activation.pdf).

Eardley, T., J. Bradshaw, J. Ditch, I. Gough and P. Whiteford (1996), Social assistance in OECD countries: Volume II: Country Reports, Research Report No. 47, UK Department of Social Security, HMSO, London and OECD, Paris.

Eurostat (2006), Labour Market Policy Database Methodology, Revision of June 2006, Luxembourg (http://epp.eurostat.ec.europa.eu/cache/ITY_OFFPUB/KS-BF-06-003/EN/KS-BF-06-003-EN.PDF).

Eurostat (2007), Labour Market Policy: 2007 edition, Luxembourg: Office for Official Publications of the European Communities.

Eurostat Qualitative Reports for years 2001, 2004 and 2006 are available at http://circa.europa.eu/Public/irc/dsis/labour/library.

Eustace and Clarke (2006), Local Development Social Inclusion Programme: Assessing the Impact of the Services for the Unemployed Measure

(www.pobal.ie/media/Publications/LDSIP/ImpactreportonServicesfortheUnemployed06.pdf).

FaCSIA (2007), Annual Report 2006-2007

(www.facsia.gov.au/internet/facsinternet.nsf/aboutfacs/annualreports.htm).

FÁS (2001), Follow Up Survey of FÁS Participants 2001 (www.fas.ie - Miscellaneous Publications).

FÁS (2004a), "Continuing Vocational Education and Training in Ireland", Research and Planning Department (www.fas.ie/en/pubdocs/ContinuingVocationalEducationTraining2004.pdf).

FÁS (2004b), "The vocational education and training system in Ireland", Cedefop Panorama series; No. 83, Luxembourg.

FÁS (2005), Building on our Vision: FÁS Statement of Strategy 2006-2009.

FÁS (2006a), Annual Report 2005, Dublin (www.fas.ie - Annual Reports).

FÁS (2006b), The Irish Labour Market Review 2006: a FÁS review of Irish labour market trends and policies (www.fas.ie - Skills \& labour market reports).

FÁS (2006c), Guidelines for the Operation and Administration of Local Employment Services Networks, Local Employment Services Network unit, Dublin.

FÁS (2007a), Annual Report 2006, Dublin (www.fas.ie - Annual Reports).

FÁS (2007b), “National Contact Centre Employer Customer Survey”, January-June 2007, September.

FÁS (2007c), "Employment Services Market Share 2006”, July.

FÁS (2007d), “Survey of Employers’ Usage of FÁS Services - 2007”, July. 
FÁS (2007e), “2006 Employment Services Customer Satisfaction Survey”, March.

FÁS (2007f), "Follow Up Survey of FÁS Participants 2006/7”.

FÁS (2008), "Overview Paper on the Individual Learner Plan for Community Employment Participants.”, background official paper for the EES Peer Review Vocational training for people at the margin of the labour market, Ireland, 8-9 May (www.mutual-learning-employment.net/peerreviews/).

Faughnan, H. (2008), “Activation and Integrated Approaches to Lone Parent Needs: the role of DSFA in activation strategies" (www.pobal.ie/media/HelenFaughnanDSFA25Sept2008.ppt).

Fine-Davis, M., Craven, F., McCarthy, M., Holzworth, A. and O’Sullivan, M. (2007), “An Evaluation of the FÁS Initiative for Parents in Receipt of the One Parent Family Payment", October.

Fitzpatrick Associates (2003), "Review of the National Employment Service: Final Report", report submitted to the Department of Enterprise, Trade and Employment, mimeo.

Forfás (2005), "Data Analysis of In-Employment Education and Training in Ireland", Expert Group on Future Skills Needs (www.forfas.ie/publication/search.jsp? yr=2005).

Forfás (2007), “Tomorrow's Skills: Towards a National Skills Strategy", $5^{\text {th }}$ Report of the Expert Group on Future Skills Needs (www.forfas.ie/publication/search.jsp?yr=2007).

Government of Ireland (1999), National Development Plan 2000-2006, Dublin, The Stationery Office (www.ndp.ie).

Government of Ireland (2007), National Development Plan 2007-2013: Transforming Ireland, Dublin, The Stationery Office (www.ndp.ie).

Gray, D. (2003), "National versus Regional Financing and Management of Unemployment and Related Benefits", OECD Social, Economic and Migration Working Paper No. 14 (www.oecd.org/els/workingpapers).

Grubb, D. (2007a), "Labour market policies at different benefit replacement rates", paper presented at the Thematic Review Seminar of the European Employment Strategy, 28 March (www.mutual-learningemployment.net/thematicreviews/).

Grubb, D. (2007b), « Audit du Service Public de l'Emploi au Luxembourg », OECD Social, Employment and Migration Working Papers No. 59 (www.oecd.org/els/workingpapers).

Grubb, D. and A. Puymoyen (2008), "Long Time-series for Public Expenditure on Labour Market Programmes", OECD Social Economic and Migration Working Paper No. 73 (www.oecd.org/els/workingpapers).

Hasselpflug, S. (2005), “Availability criteria in 25 countries", Ministry of Finance Working Paper No. 12/2005 (http://uk.fm.dk/Publications/Working\%20Papers.aspx).

Indecon (2005a), "Review of Active Labour Market programmes", Indecon International Economic Consultants (www.entemp.ie/labour/services/review.htm).

Indecon (2005b), "Review of National Employment Action Plan Preventive Strategy: Draft Final Report", Indecon International Economic Consultants (www.entemp.ie/labour/services/neapstrategy.htm). 
INOU (Irish National Organisation of the Unemployed) (2007), "Working for Work, Exploring welfare, work, education and training options for unemployed people", $14^{\text {th }}$ Edition, Dublin.

JobCentre Plus (2008), "Incapacity Benefit: Help if You're Too Ill or Disabled to Work" (www.jobcentreplus.gov.uk).

Joint Committee on Human Rights (2007), "The Treatment of Asylum Seekers: Tenth Report of Session" 2006-07, Volume I (www.publications.parliament.uk/pa/jt200607/jtselect/jtrights/81/81i.pdf).

Kelly, P. (2001), The Irish Social Partnership System, paper presented at the Partnership in the Modern Public Service Conference, Waikato University, June (www.psa.org.nz/library/psa/General/index.asp).

Lippoldt, D. and M. Brodsky (2004), "Public Provision of Employment Services in Selected OECD Countries: the Job Brokerage Function", in D. Balducchi, R. Eberts and C. O'Leary (eds.) Labor Exchange Policy in the United States, Kalamazoo: W.E. Upjohn Institute, pp. 211-248.

Manning, A. (2005), "You Can't Always Get What You Want: The Impact of the UK Jobseeker's Allowance", CEP Discussion Paper No. 697 (http://cep.lse.ac.uk).

McVicar, D. (2008), "Job Search Monitoring Intensity, Unemployment Exit and Job Entry: Quasiexperimental Evidence from the UK", Labour Economics, Vol. 15, pp. 1451-1468.

Michalopoulos, C. (2004), What Works Best for Whom: Effects of Welfare and Work Policies by Subgroup, Administration for Children and Families, Department of Health and Human Services, Washington (www.acf.hhs.gov/programs/opre/welfare_employ/what_wksbest/reports/whatw_best/ whatw_best_toc.html).

Moffitt, R. (2002), “The Temporary Assistance for Needy Families Program”, NBER Working Paper No. 8749 (www.nber.org).

Moseley, M., T. Cherrett and M. Cawley (2001), "Local partnerships for rural development: Ireland's experience in context”, Irish Geography 32 (2001), pp. 176-193 (www.ucd.ie/gsi/pdf/342/partner.pdf).

Mosley, H., H. Schütz and N. Breyer (2001), "Management by Objectives in European Public Employment Services", WZB Discussion Paper FS I 01-203, Social Science Research Center, Berlin (www.wzberlin.de/ars/ab/abstracts/i01-203.en.htm).

MSD (Ministry of Social Development) (2007), The Statistical Report for the Year Ending June 2006 (www.msd.govt.nz/work-areas/social-research/statistical-report.html).

National Development Programme (NDP) "Report of the Working Group on the Review of the Back to Education Allowance (BTEA) Scheme" Dublin: The Stationary Office - see DSFA (2005b).

NDA (National Disability Authority) (2004), "Towards Best Practice in the Provision of Further Education, Employment and Training Services for People with Disabilities in Ireland", (www.nda.ie - Employment \& Training - Towards Best Practice).

NESF (National Economic and Social Forum) (2006), Creating a More Inclusive Labour Market, NESF Report 33, Dublin: NESF (www.nesf.ie/publications.asp). 
NWCI (National Women's Council of Ireland) (2006), "Submission to Department of Social and Family Affairs on the Government Discussion Paper: Proposals for Supporting Lone Parents" (www.nwci.ie/publications/submissions).

Northside Partnership (2007a), Review of Northside Partnership LES Performance 2006 (www.northsidepartnership.ie/content/view/119/192/).

Northside Partnership (2007b), Power Point presentation for OECD Review Team, November.

O'Callaghan, P. (2003), “Ireland: Linking Public Services and the Local Community”, in OECD, Managing Decentralisation. A New Role for Labour Market Policy, pp. 313-24, Paris.

O'Connell, P.J and F. McGinnity (1997) Working Schemes? Active Labour Market Policy in Ireland, Ashgate.

O'Connell, P. (2002), "Employability: Trends in Employment and Unemployment; The Impact of Activation Measures; Unemployment Transitions" in DETE (2002), Impact Evaluation of the European Employment Strategy in Ireland (www.entemp.ie/publications/labour/2004/eesimpactevaluation.pdf).

O'Donnell, R. and C. O'Reardon (2000), “Social Partnership in Ireland's Economic Transformation", in G. Fajertag and P. Pochet (eds.), Social Pacts in Europe - New Dynamics, ETUI, Brussels, pp. 237-56.

O’Donnell, E. (2008), "Initiatives by the social partners for improving the labour market access of disadvantaged groups", paper presented at the Peer Review of Initiatives by the social partners for improving the labour market access of disadvantaged groups, 24-25 April (www.peer-review-socialinclusion.eu).

OECD (1993), The Public Employment Service in Japan, Norway, Spain and the United Kingdom, OECD, Paris.

OECD (1996), Ireland: Local Partnerships and Social Innovation, prepared by Professor Charles Sabel and the LEED Programme, OECD, Paris.

OECD (1998a), The Public Employment Service: Denmark, Finland, Italy, OECD, Paris.

OECD (1998b), The Public Employment Service: Greece, Ireland, Portugal, OECD, Paris.

OECD (2000), Literacy in the Information Age: Final Report of the International Adult Literacy Survey, OECD, Paris.

OECD (2001a), Labour Market Policies and the Public Employment Service: Proceedings of the Prague Conference, OECD, Paris.

OECD (2001b), Innovations in Labour Market Policies: the Australian Way, OECD, Paris.

OECD (2001c), Local Partnerships for Better Governance, OECD, Paris.

OECD (2003a), "Benefits and Employment, Friend or Foe? Interactions Between Passive and Active Social Programmes", Chapter 4 in Employment Outlook, OECD, Paris (www.oecd.org/els/employment/outlook). 
OECD (2003b), Babies and Bosses: Reconciling Work and Family Life: Volume 2, Austria, Ireland and Japan, OECD, Paris.

OECD (2005), "Labour Market Programmes and Activation Strategies: Evaluating the Impacts", Chapter 4 in Employment Outlook, OECD, Paris.

OECD (2006a), Economic Survey of Ireland, OECD, Paris.

OECD (2006b), "forumpartnerships2006" (www.oecd.org/cfe/leed/forum/partnerships - activities of the Forum).

OECD (2007a), "Activating the Unemployed: What Countries Do", Chapter 5 in Employment Outlook, OECD, Paris.

OECD (2007b), International Migration Outlook, OECD, Paris.

OECD (2007c), Babies and Bosses: Reconciling Work and Family Life: A Synthesis of Findings for OECD Countries, OECD, Paris.

OECD (2007d), Benefits and Wages 2007: OECD Indicators, OECD, Paris.

OECD (2007e), Education at a Glance, OECD, Paris.

OECD (2008a), Employment Outlook, OECD, Paris.

OECD (2008b), Sickness, Disability and Work: Breaking the barriers: Denmark, Finland, Ireland and the Netherlands, Volume 3, OECD, Paris.

Office of the Comptroller and Auditor General (2003), Department of Social and Family Affairs:

Evaluation of Control Activity, Value for Money Report No. 45 (http://audgen.irlgov.ie - Value for Money).

O’Hara, P and M. O'Shaughnessy (2004), “Work Integration Social Enterprises in Ireland”, EMES Working Paper No. 04/03 (www.emes.net/index.php?id=49).

OMCYA (Office of the Minister for Children and Youth Affairs) (2006), "National Childcare Strategy: A Guide for Providers" (www.omc.gov.ie - childcare - what we do).

O’Neill, C. (2007), "Profiling", Irish contribution to the workshop seesion "Innovative experiences: Profiling, targeting, etc: segmenting our customers", UNEDIC European Seminar Paris 29 and 30 November (http://info.assedic.fr/assurance_chomage/index.php - l'international).

ONEM (2008), "Feuille info - travailleurs: L'activation du comportement de recherché d'emploi" (www.rva.fgov.be/home/MenuFR.htm - Activation du comportement de recherche).

OPEN (National network of one-parent self-help groups) (2006), "Government Discussion Paper: Proposals for Supporting Lone Parents" (www.oneparent.ie/policy/149).

O’Shaughnessy, M. (2005), "National Profiles of Work Integration Social Enterprises: Ireland”, EMES Working Paper 02/05 (www.emes.net). 
OSI (Office for Social Inclusion) (2003), National Action Plan against Poverty and Social Exclusion 2003-2005, Dublin, The Stationery Office (www.socialinclusion.ie/publications.html).

OSI (2007), National Action Plan for Social Inclusion 2007-2016, Dublin, The Stationery Office.

Özenen, C. (2006), "The Effects of Structural Funds on Ireland's Development and Lessons for Turkey", State Planning Organization, General Directorate of Economic Sectors and Coordination, Department of Infrastructure and Services (http://ekutup.dpt.gov.tr/ab/ozenencg/irlanda.pdf).

Pentony, S. (2005), "Local Development Strategies and their Evaluation in Ireland: Lessons from the Local Development Social Inclusion Programme", Presentation at the LEED Seminar on Evaluating Local Development Strategies, Bratislava (www.oecd.org/document/2/0,3343,en_2649_34459_36195650_1_1_1_1,00.html).

Pobal (2006a), Annual Report and Accounts 2005 (www.pobal.ie/Publications/Pages/publications.aspx).

Pobal (2006b), "Working Together Working for Change: The Achievements of the Local Development Social Inclusion Programme 2000-2006" (www.pobal.ie - Local Development Social Inclusion Publications).

Pobal (2007), Annual Report and Accounts 2006 (www.pobal.ie/Publications/Pages/publications.aspx).

Pobal (2008), Annual Report and Accounts 2007 (www.pobal.ie/Publications/Pages/publications.aspx).

ProjectAtlas (2004 - estimated date), "Definitions and concepts of employment strategies"

(www.projectatlas.org/publications/definitionsandconcepts.pdf).

Pronzato, C. and M. Mogstad (2008), "Are Lone Mothers Responsive o Policy Changes? The Effects of a Norwegian Workfare Reform on Earnings, Education and Poverty" (www.child-centre.it - working papers).

Ronayne, T. (1996), “Activating and Re-integrating the Long-term Unemployed”, Paper presented to MISEP National Correspondents Meeting Dublin Castle, $3^{\text {rd }}$ October (www.wrc.ie/publications/activiat.pdf).

Ronayne, T. and J. Burrows (2003), "Evaluation of the Social Economy programme", WRC Social and Economic Consultants.

SWAO (2007), Social Welfare Appeals Office Annual Report 2006, Dublin, May.

Teague, P. (2006), "Social Partnership and Local Development in Ireland: The Limits to Deliberation", British Journal of Industrial Relations, 44:3, September, pp. 421-443.

Teague, P. (2007), "Developing the Social Economy in Ireland?", International Journal of Urban and Regional Research, Vol. 31.1, March, pp. 91-108.

TMA (Tom Martin \& Associates) (2001), "Sheltered Employment: A Review of the Literature" (www.tma.ie/Publications/review_2001.pdf).

Turok, I. (2001), "Innovation in Local Governance: The Irish Partnership Model”, in OECD, Local Partnerships for Better Governance, Paris, pp. 131-74. 
Unicef (2007), Child Poverty in Perspective: An overview of child well-being in rich countries, Innocenti Research Centre Report Card 7 (www.unicef-irc.org/publications/pdf/rc7_eng.pdf).

Walsh, B. (2003), "How 'Live' is the Live Register' and other puzzles in the measurement of unemployment”, UCD Working Paper No. 3/07 (www.ucd.ieleconomics/research.htm).

Watts, D. (2008), "Supporting Economic Participation by People with Disabilities", presentation to OECD seminar on Sickness, Disability and Work: Breaking the Barriers, Dublin 26-27 June (www.oecd.org/dataoecd/56/57/40996968.pdf).

WRC (WRC Economic and Social Consultants) (2006a), Evaluation of the Midlands Project: Final Report ( www.fas.ie - Disability Publications \& Newsletters).

WRC (2006b), "Employment Support Services: Measure 15 of the EHRDOP Implemented by the Department of Social and Family Affairs", Wider Equality Measure Study (www.equality.ieEquality Studies Unit).

Youthreach national coordinators (2000), "YOUTHREACH 2000 - A Consultative process" (www.youthreach.ie/aatopmenu/Library/YR2K/y2000.html). 


\section{OECD SOCIAL, EMPLOYMENT AND MIGRATION WORKING PAPERS}

Most recent releases are:

No. 74 MAIN FEATURES OF THE PUBLIC EMPLOYMENT SERVICE IN THE CZECH REPUBLIC Daniela Kaluzna (2008)

No. 73 LONG TIME-SERIES FOR PUBLIC EXPENDITURE ON LABOUR MARKET PROGRAMMES David Grubb and Agnès Puymoyen (2008)

No. 72 MAIN FEATURES OF THE PUBLIC EMPLOYMENT SERVICE IN THE SLOVAK REPUBLIC Daniela Kaluzna (2008)

No. 71 SOCIO-ECONOMIC DIFFERENCES IN MORTALITY Edward Whitehouse and Asghar Zaidi (2008)

No. 70 INVESTMENT RISK AND PENSIONS: MEASURING UNCERTAINTY IN RETURNS Anna d'Addio, Jose Seisdedod and Edward Whitehouse (forthcoming)

No. 69 FILLING THE PENSION GAP: COVERAGE AND VALUE OF VOLUNTARY RETIREMENT SAVINGS Antolin, P. and Edward Whitehouse (2009)

No. 68 THE IMPACT OF FOREIGN DIRECT INVESTMENT ON WAGES AND WORKING CONDITIONS Elena Arnal and Alex Hijzen (2008)

No. 67 THE DYNAMICS OF SOCIAL ASSISTANCE RECEIPT: MEASUREMENT AND MODELLING ISSUES, WITH AN APPLICATION TO BRITAIN

Lorenzo Cappellari and Stephen P. Jenkins

No. 66 REFORMING RETIREMENT-INCOME SYSTEMS: LESSONS FROM THE RECENT EXPERIENCES OF OECD COUNTRIES

John P. Martin and Edward Whitehouse (2008)

No. 65 THE JOINT DISTRIBUTION OF HOUSEHOLD INCOME AND WEALTH: EVIDENCE FROM THE LUXEMBOURG WEALTH STUDY

Markus Jantti, Eva Sierminska and Tim Smeeding (2008)

No. 64 A REVIEW OF STUDIES ON THE DISTRIBUTIONAL IMPACT OF CONSUMPTION TAXES IN OECD COUNTRIES

Neil Warren (2008)

No. 63 GLOBALISATION AND LABOUR MARKETS: POLICY ISUES ARISING FROM THE EMERGENCE OF CHINA AND INDIA

David T. Coe (2007)

No. 62 MIGRANT WOMEN INTO WORK - WHAT IS WORKING?

Alexandra Heron (2008) Forthcoming

No. 61 ADDRESSING LABOUR MARKET DUALITY IN KOREA

David Grubb, Jae-Kap Lee and Peter Tergeist (2007)

No. 60 LIFE-EXPECTANCY RISK AND PENSIONS: WHO BEARS THE BURDEN?

Edward Whitehouse (2007)

No. 59 AUDIT DU SERVICE PUBLIC DE L'EMPLOI AU LUXEMBOURG

David Grubb (2007)

No. 58 TRENDS IN INTERNATIONAL MIGRATION FLOWS AND STOCKS, 1975-2005

B. Lindsay Lowell (2007)

Other series of working papers available from the OECD include: OECD HEALTH WORKING PAPERS 
DELSA/ELSA/WD/SEM(2009)01

\section{RECENT RELATED OECD PUBLICATIONS:}

GROWING UNEQUAL? Income Distribution and Poverty in OECD Countries (2008)

SICKNESS, DISABILITY AND WORK: BREAKING THE BARRIERS (VOL. 3) - DENMARK, FINLAND, IRELAND AND THE NETHERLANDS (2008)

JOBS FOR YOUTH: JAPAN (2008)

JOBS FOR YOUTH: CANADA (2008)

JOBS FOR YOUTH: NETHERLANDS (2008)

JOBS FOR YOUTH: NEW ZEALAND (2008)

JOBS FOR YOUTH: NORWAY (2008)

JOBS FOR YOUTH: UNITED KINGDOM (2008)

A PROFILE OF IMMIGRANT POPULATIONS IN THE $21^{\text {ST }}$ CENTURY (2008)

OECD EMPLOYMENT OUTLOOK (2008)

INTERNATIONAL MIGRATION OUTLOOK - 2008 Edition

OECD REVIEWS OF LABOUR MARKET AND SOCIAL POLICIES IN SERBIA (2008)

JOBS FOR IMMIGRANTS (VOL. 2): Labour Market Integration in Belgium, France, The Netherlands and Portugal (2008)

MODERNISING SOCIAL POLICY FOR THE NEW LIFE COURSE (2007)

BABIES AND BOSSES - Reconciling Work and Family Life: A Synthesis of Findings for OECD Countries (2007)

BENEFITS AND WAGES - OECD Indicators (2007)

FACING THE FUTURE: KOREA'S FAMILY, PENSION AND HEALTH POLICY CHALLENGES (2007)

PENSIONS AT A GLANCE: Public policies across OECD countries (2007)

JOBS FOR YOUTH: KOREA (2007)

JOBS FOR YOUTH: BELGIUM (2007)

JOBS FOR YOUTH: SPAIN (2007)

JOBS FOR YOUTH: SLOVAK REPUBLIC (2007)

SICKNESS, DISABILITY AND WORK: BREAKING THE BARRIERS (VOL. 2) - AUSTRALIA, LUXEMBOURG, SPAIN AND THE UNITED KINGDOM (2007)

WOMEN AND MEN IN OECD COUNTRIES (2006)

SOCIETY AT A GLANCE: OECD Social Indicators (2006)

PENSIONS PANORAMA: RETIREMENT INCOME SYSTEMS IN 53 COUNTRIES (joint publication with the World Bank) (2006)

For a full list, consult the OECD On-Line Bookstore at www.oecd.org 